\title{
HÁBITATS Y GRUPOS FUNCIONALES ALIMENTARIOS DE LOS MACROINVERTEBRADOS BENTÓNICOS EN LA COSTA BONAERENSE DEL RÍO DE LA PLATA: RELACIÓN CON LA CONTAMINACIÓN.
}

\section{Lic. Eugenia Soledad Ambrosio}

Trabajo de Tesis para optar al Título de Doctor en Ciencias Naturales

Director de Tesis: Dr. Alberto Rodrigues Capítulo

Año: 2014
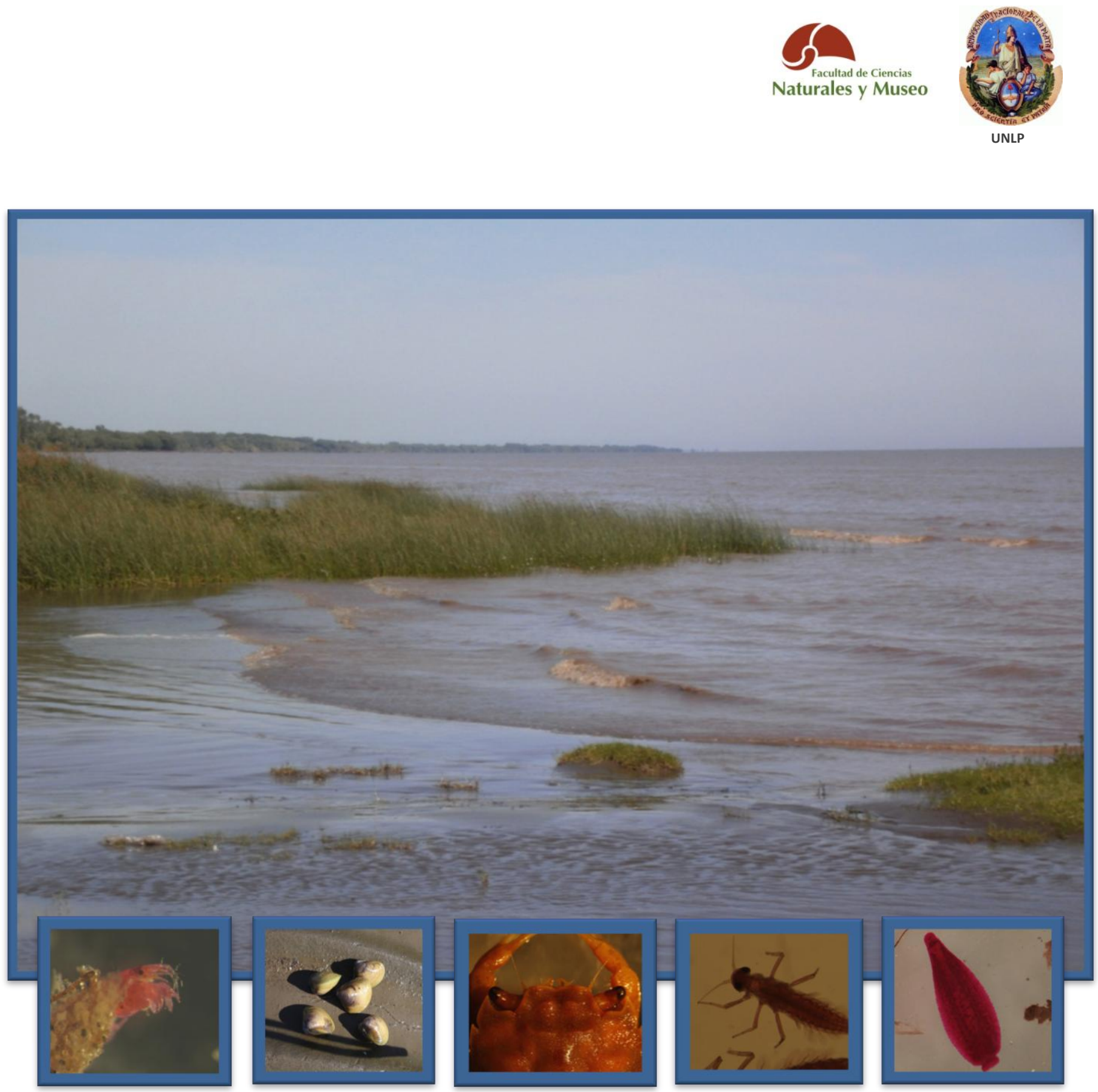


\section{HÁBITATS Y GRUPOS FUNCIONALES ALIMENTARIOS DE LOS MACROINVERTEBRADOS BENTÓNICOS EN LA COSTA BONAERENSE DEL RÍO DE LA PLATA: RELACIÓN CON LA CONTAMINACIÓN.}

\section{Lic. Eugenia Soledad Ambrosio}

Trabajo de Tesis para optar al Título de Doctor en Ciencias Naturales (FCNyM-UNLP) Director de Tesis: Dr. Alberto Rodrigues Capítulo Año: 2014 


\section{INDICE GENERAL}

\section{AGRADECIMIENTOS}

\section{RESUMEN}

\section{ABSTRACT}

\section{INTRODUCCIÓN}

Importancia de los estuarios............................................................... 2

Los invertebrados en los sistemas lóticos................................................ 4

Los macroinvertebrados y el hábitat físico........................................... 6

Los invertebrados y los grupos funcionales alimentarios..................... 8

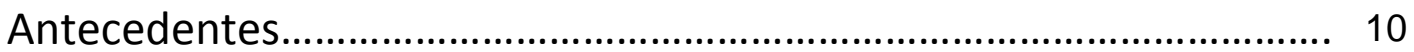

Marco conceptual............................................................................. 12

Hipótesis planteadas.......................................................................... 14

Objetivo general.......................................................................... 14

Objetivos particulares...................................................................... 15

\section{ÁREA DE ESTUDIO}

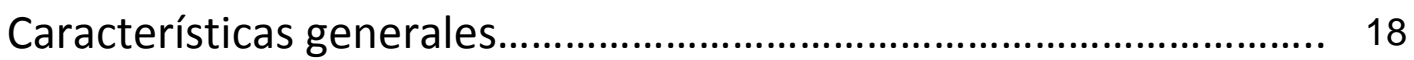

Caracterización de los sitios de muestreo............................................ 21

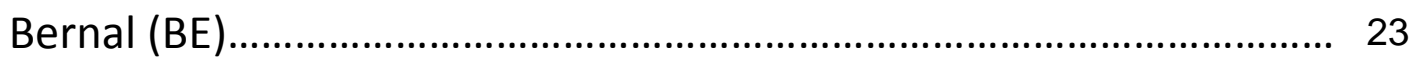

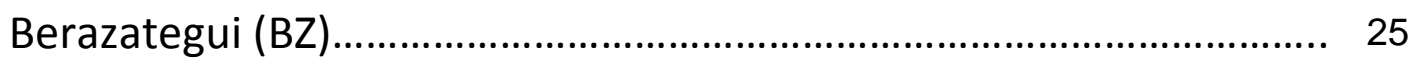

Punta Lara (PL) ........................................................................ 27

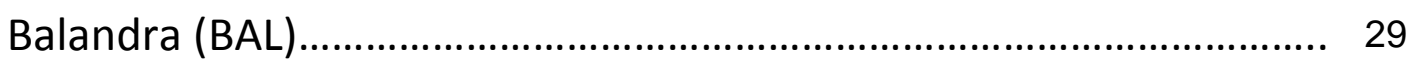




\section{MATERIALES Y MÉTODOS}

Muestreo

Análisis de la granulometría y la materia orgánica............................... 33

Método de estimación de MOPG y MOPF............................................ 34

Parámetros físico-químicos del agua...................................................... 34

Grupos funcionales alimentarios (GFA) ........................................... 35

Análisis de los contenidos digestivos................................................... 35

Análisis estequiométrico e isótopos estables....................................... 40

Sensibilidad de organismos.............................................................. 41

Cálculo de parámetros e índices.............................................................. 42

Índices Bióticos.................................................................................. 43

Modos de vida................................................................................. 44

Análisis estadístico de datos.............................................................. 45

\section{RESULTADOS}

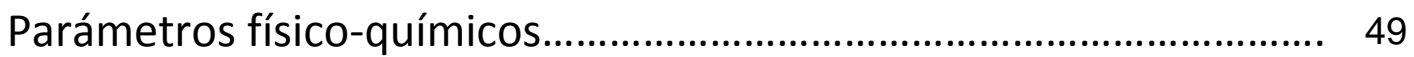

Análisis de la Materia Orgánica............................................................ 56

Análisis de la Granulometría.............................................................. 58

Invertebrados bentónicos, listas de taxa............................................... 60

Riqueza de taxa, diversidad y equitabilidad....................................... 63

Principales grupos taxonómicos............................................................. 65

Sensibilidad de los organismos........................................................... 70

Grupos funcionales alimentarios (GFA) .............................................. 72

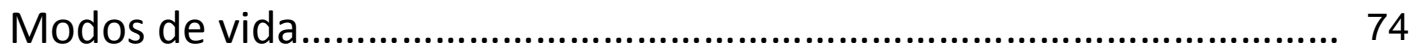

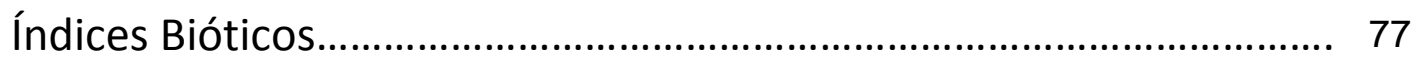

Análisis directo de gradientes........................................................... 78

Sitios de muestreo y hábitats funcionales, confección de fichas........ 80

Determinación de hábitats funcionales................................................. 85 
Composición estequiométrica y análisis de isótopos.

\section{DISCUSIÓN}

\section{CONCLUSIONES}

Conclusiones y consideraciones finales.

Perspectivas futuras.

\section{BIBLIOGRAFÍA}

ANEXO 


\section{AGRADECIMIENTOS}

Agradezco profundamente a mi director de tesis, el Dr. Alberto Rodrigues Capítulo, por haberme brindado su apoyo durante mi carrera como Bióloga, guiándome en cada paso para poder lograr esta meta tan anhelada.

Muchas gracias a mis compañeros del Laboratorio de Bentos del Instituto de Limnología "Dr. Raúl A. Ringuelet" (ILPLA) por brindarme su amistad, por compartir tantos momentos alegres, y por sostenerme en los momentos más difíciles: Dr. Alberto Rodrigues Capítulo, Dra. Analía Paggi, Dra. Sabrina Lavarías, Lic. Fernando Spaccesi, Dra. Laura Armendáriz (gracias totales por la colaboración en la identificación de los oligoquetos), Dra. Agustina Cortelezzi, Lic. Ana Clara Ferreira, Lic. Estefanía Paz, Lic. Vanesa López Van Oosterom, y en especial GRACIAS a la Dra. Carolina Ocon que me ayudó tanto!, brindándome su experiencia, su tiempo y su apoyo incondicional en forma totalmente desinteresada.

A mis colegas del Laboratorio de Plancton y Biofilms, gracias por escucharme y ayudarme siempre con tan buena predisposición: Dra. Nora Gómez, a quien estaré eternamente agradecida por tantos consejos y por responder todas mis preguntas (que fueron y seguirán siendo muchas!), gracias a la Dra. Delia Bauer y al Dr. Joaquín Cochero por su invaluable colaboración con los análisis estadísticos e informáticos, Dras. Magdalena Licursi y Victoria Sierra, Lic. María Belén Sathic, gracias por sus sonrisas y por todo lo vivido en su compañía.

Agradezco también al laboratorio de Química del ILPLA, especialmente a Jorge Donadelli por el análisis de las muestras de agua colectadas en cada muestreo para la determinación de nutrientes y demandas de oxígeno. Gracias a los bibliotecarios del ILPLA Mónica Ringuelet y Ricardo Albino. A Mónica Caviglia gracias por tanta ayuda para las benditas traducciones! 
A todos los miembros de la Cátedra Introducción a la Taxonomía (FCNyM-UNLP), gracias por sus consejos, su gran compañerismo y por enseñarme día a día el camino para perfeccionar mi labor docente.

Agradezco profundamente a los miembros del Jurado Dres. Alicia Poi, Pablo Collins y Diego Giberto, por la lectura crítica del presente manuscrito, por todas sus sugerencias y comentarios, y por todo lo que me han enseñado en esta última etapa.

Gracias a mi familia: a mis viejitos, que me bancaron toda la Carrera (y me siguen bancando, ahora moralmente por suerte para ellos!), a mi hermana que tanto quiero, a mi abuelo Cholo por ser un ejemplo a seguir, por lucharla día a día "a pesar de los achaques"... gracias a todos ellos por prenderme tantas velitas!!!

GRACIAS a Cris por brindarme tanto amor, por transitar juntos este camino, por disfrutar los buenos momentos y afrontar los más difíciles y por darme el regalo más hermoso de nuestras vidas!!!... gracias por tenerme tanta paciencia y aguantar tantas horas de trabajo nocturno para la finalización de este manuscrito. Gracias a Isma, Cami y a mis suegros, por abrirme las puertas de su casa y brindarme tanto cariño durante todos estos años. A mi suegra Margarita, esté donde esté... la voy a extrañar mucho!!!

A Josefa, Lola, Catalina, Mateo, Berni y Chiqui... gracias por tantas risas robadas en el día a día, y por ser "mis más fieles compañeros de ruta".

Finalmente, al resto de mis seres queridos y amados... 


\section{RESUMEN}

La calidad ecológica de los ecosistemas está determinada por la interacción de dos ejes principales: la calidad del hábitat, estimada a partir del análisis de los hábitats funcionales y la calidad del agua, estimada a partir del grado de contaminación (características físico-químicas). Esta interacción determina la calidad biótica del sistema, de manera que la estructura y función de los ensambles de macroinvertebrados varían según la intensidad de cada uno de los factores que intervienen.

El objetivo general de este trabajo de Tesis ha sido evaluar la importancia de los hábitats funcionales que proporciona el sector costero bonaerense del Río de la Plata para el establecimiento y persistencia de las poblaciones de macroinvertebrados bentónicos. Para este fin se utilizaron descriptores estructurales y funcionales del complejo bentónico, y se consideraron ambientes sometidos a diversos tipos de disturbio antropogénico. Se ha pretendido así, contribuir al estudio de la integridad biótica, para el diagnóstico y monitoreo de la calidad del agua y del hábitat del sector mencionado.

Este estudio fue realizado en el sector intermareal de agua dulce del Río de la Plata. Se seleccionaron cuatro sitios de muestreo distribuidos a lo largo de $70 \mathrm{~km}$ de costa aproximadamente. Bernal (BE), ubicado en una zona altamente urbanizada, con intensa actividad industrial y descargas de efluentes domiciliarios. Berazategui (BZ) se localiza en una zona suburbana, con actividad industrial moderada, y recibe los desechos de la cloaca máxima de Berazategui que abastece a más de 12 millones de habitantes. Punta Lara $(\mathrm{PL})$ se localiza en una zona predominantemente rural, donde se practican principalmente la ganadería extensiva y actividades recreativas, pero puede verse afectada por agua de "mala calidad" proveniente de zonas aledañas. Balandra (BAL) se ubica en una zona rural, con baja influencia antropogénica y un elevado grado de naturalidad costera. En cada sitio se consideraron dos hábitats funcionales potenciales: "sedimento libre de vegetación" y "sedimento asociado al junco Schoenoplectus californicus", los cuales fueron visitados en distintas estaciones del año, y en situación de marea baja.

En cada fecha de muestreo se extrajeron en ambos hábitats muestras bentónicas destinadas al análisis de los macroinvertebrados (por triplicado). Asimismo, se 
extrajeron muestras de sedimento para el análisis de la granulometría y de la materia orgánica (MO total, MOPG y MOPF). El sustrato fue clasificado como grava (> $500 \mu \mathrm{m}$ ), arena $(62,5-500 \mu \mathrm{m})$, limo $(3,9-62,5 \mu \mathrm{m})$ y arcilla $(<3.9 \mu \mathrm{m})$. Se midieron in situ diversos parámetros físico-químicos del agua $(\mathrm{pH}$, conductividad, turbidez, oxígeno disuelto y temperatura), y se tomaron por triplicado muestras de agua destinadas al análisis del contenido de nutrientes $\left(\mathrm{NH}_{4}{ }^{+}, \mathrm{NO}_{2}{ }^{-}, \mathrm{NO}_{3}{ }^{-}\right.$y $\left.\mathrm{PO}_{4}{ }^{-3}\right)$ y demandas de oxígeno ( $\mathrm{DBO}_{5}$ y $\left.\mathrm{DQO}\right)$.

Los invertebrados fueron identificados con el máximo nivel de resolución posible y clasificados según distintos aspectos (sensibilidad/tolerancia, modo de vida), utilizando para ello bibliografía específica. Se calcularon parámetros estructurales de la biota (riqueza de taxa, diversidad de Shannon-Wiener y equitabilidad). Para la asignación de grupos funcionales alimentarios (GFAs), se analizó la primera porción del tubo digestivo de los macroinvertebrados más representativos en los sitios de estudio: Hyalella curvispina y Corbicula fluminea. Los ítems consumidos fueron clasificados en detrito, restos vegetales/algas filamentosas, diatomeas, restos animales, euglenofitas/protozoos y material mineral. Ambas especies fueron ubicadas en el GFA correspondiente, según el ítem dominante (> 60\%). A partir de los datos de los contenidos digestivos se analizaron las estrategias alimentarias de las especies referidas (Amundsen et al., 1996). Para complementar el estudio de los contenidos digestivos se analizó el contenido de C, N, P e isótopos estables $\left(\delta^{13} \mathrm{C}\right.$ y $\left.\delta^{15} \mathrm{~N}\right)$. Los invertebrados bentónicos cuyos contenidos digestivos no fueron analizados, se asignaron a GFAs de acuerdo a clasificaciones previamente establecidas (fragmentadores, colectores-recolectores, colectoresfiltradores, raspadores y predadores).

Para explorar los principales gradientes ambientales dentro del área estudiada se realizó un Análisis de Componentes Principales (PCA). Con la finalidad de conocer si existieron diferencias significativas en diferentes descriptores bióticos y abióticos se llevaron a cabo ANOVAs y MANOVAs, y en todos los casos en que se hallaron diferencias se realizaron tests a posteriori. Para establecer las relaciones entre los sitios, las principales variables abióticas y la composición de macroinvertebrados, se llevó a cabo un Análisis de Redundancia (RDA). La significación de los ejes obtenidos se evaluó mediante la Prueba de Monte Carlo. 
El análisis de los datos físico-químicos evidenció que los sitios PL y BAL se asociaron con altos valores de turbidez y mejores condiciones generales en la calidad del agua; mientras que los sitios $B E$ y $B Z$ se asociaron con alto contenido de materia orgánica, elevada conductividad, nutrientes y demandas de oxígeno. La comparación entre hábitats evidenció un predominio de la MOPG en el sedimento de las zonas vegetadas, mientras que en el sedimento libre de vegetación la MOPF fue dominante. De acuerdo al análisis granulométrico, el sedimento fue principalmente arenoso.

Se identificaron 43 taxa de macroinvertebrados en el sedimento libre de vegetación y 91 taxa en el sedimento asociado a ella. A nivel de mesohábitat, la riqueza, diversidad y equitabilidad mostraron diferencias significativas, correspondiendo los mayores valores al sedimento de las zonas vegetadas. Los nematodes presentaron las mayores densidades en el sedimento libre de vegetación. Los oligoquetos Tubificinae alcanzaron mayores abundancias en BE y BZ, y en el sedimento asociado a la vegetación. Los moluscos y crustáceos fueron más abundantes en PL y BAL, especialmente en el sedimento de las zonas vegetadas. Los organismos tolerantes y muy tolerantes dominaron en todo el sector estudiado, mientras que los sensibles sólo se registraron en los sitios poco perturbados. En relación a la diversidad funcional, los colectoresrecolectores fueron dominantes; sin embargo, en las zonas vegetadas de los sitios menos perturbados éstos fueron reemplazados por los colectores-filtradores. En relación a los modos de vida, los organismos apoyados predominaron en el sedimento libre de vegetación, mientras que en el sedimento asociado a la misma predominaron las formas aferradas (PL y $B A L)$.

En relación a la interacción hábitat-biota, los dos primeros ejes del ordenamiento (RDA) permitieron definir las principales variables para la distribución y el establecimiento de los macroinvertebrados en el área estudiada. Los sitios altamente impactados se asociaron a elevados valores de MOPF, conductividad y $\mathrm{DBO}_{5}$ y altas densidades de oligoquetos, hirudíneos, tardígrados, nematodes y quironómidos. Los sitios poco impactados se asociaron con altos valores de turbidez y mayores densidades de organismos considerados "sensibles" (tricópteros, efemerópteros, hidrozoos y cumáceos). 
El análisis de los contenidos digestivos, reveló que el detrito fue el componente más abundante en la dieta de Corbicula fluminea y Hyalella curvispina, mientras que las diatomeas correspondieron al segundo ítem alimentario más consumido por ambas especies. Los diagramas de Amundsen permitieron concluir que la estrategia alimentaria utilizada por ambas correspondería a la categoría generalista. Finalmente, el análisis de la composición estequiométrica evidenció que las proporciones $\mathrm{C}: \mathrm{N}$ y $\mathrm{N}: \mathrm{P}$ fueron similares en todos los sitios de estudio para ambas especies, pero las proporciones C:P fueron superiores en los sitios más impactados para $H$. curvispina, y en los sitios menos perturbados en el caso de $C$. fluminea.

Los resultados obtenidos en el presente estudio han permitido aceptar las hipótesis propuestas. Las características del hábitat y del agua determinarían los ensambles de macroinvertebrados en el sector costero de agua dulce del Río de la Plata. En este sentido, el análisis comparativo de los grupos funcionales alimentarios evidenció una respuesta de los organismos al efecto del impacto antropogénico, con reemplazo de formas filtradoras por consumidores de detrito en ambientes altamente poluídos. Esto sugeriría una simplificación de las tramas tróficas, favoreciendo la vía detrítica y una estrategia alimentaria de tipo generalista. Por otra parte, se destaca la importancia de algunos descriptores (número de taxa, diversidad, equitabilidad, GFAs, modos de vida, proporción de organismos sensibles, predominancia de determinados grupos taxonómicos, características físico-químicas). Estos descriptores estructurales y funcionales podrían incluirse entre los más confiables para contribuir a la evaluación de la calidad ecológica y la integridad biótica del área estudiada. Finalmente, el estudio de los contenidos digestivos reafirmó ser herramienta útil para la asignación de los macroinvertebrados a su GFA correspondiente. Sin embargo, se destaca la importancia de utilizar en forma complementaria otros métodos, tales como el estudio del comportamiento alimentario y el análisis de la composición isotópica y estequiométrica de los invertebrados y las potenciales fuentes de recurso disponibles en el ambiente. Los resultados de este estudio enfatizan la necesidad de dilucidar las interacciones que ocurren en la comunidad bentónica, con el fin de establecer la complejidad de las tramas tróficas en el sector costero de agua dulce del estuario del Río de la Plata. 


\section{ABSTRACT}

Ecological quality of ecosystems is determined by the interaction of two main axes: habitat quality, estimated from functional habitats, and water quality, estimated from physico-chemical variables. This interaction determines the biotic quality of the system, so that the structure and function of macroinvertebrates assemblages vary with the intensity of each of the factors involved.

The general aim of this Thesis was to evaluate the importance of functional habitats that provide the coastal sector of the Río de la Plata estuary for the establishment and persistence of benthical macroinvertebrates populations. For this goal, structural and functional descriptors of macroinvertebrates assemblages were used, and environments with different kinds of anthropogenic disturbance were analyzed. We hope thus contribute to the study of biotic integrity, for the diagnosis and monitoring of both water and habitat quality for the sector mentioned.

This study was conducted on the freshwater tidal zone of Río de la Plata estuary. Four sampling sites were selected, distributed along approximately $70 \mathrm{~km}$ of coastline. Bernal (BE) is located within a highly urban area, characterized by an intense industrial and effluent discharges. Berazategui (BZ) is located in a suburban area with moderate anthropogenic and industrial impact, and receives sewage effluent from more than 12 million inhabitants. Punta Lara $(\mathrm{PL})$ is located in a mainly rural area, exposed to recreational and fishing activities. Balandra (BAL) is located in a rural area, exposed to small-scale recreational fishing, and characterized by a high degree of coastal naturalness. Two potential functional habitats were considered for study: "sediment free of vegetation" and "sediment within stands of bullrush Schoenoplectus californicus", which were visited at low tide in different seasons.

To analyze the macroinvertebrates assemblages, three replicates of benthic samples were taken at each sampling opportunity in both habitats. Sediment samples were taken for analysis of grain size and organic matter content (total OM, COPM, FOPM). The substrate was classified according to the following categories: gravel (>500 $\mu \mathrm{m})$, sand (62.5 to $500 \mu \mathrm{m})$, silt (3.9 to $62.5 \mu \mathrm{m})$ and clay $(<3.9 \mu \mathrm{m})$. Physico-chemical variables of water $(\mathrm{pH}$, conductivity, turbidity, dissolved oxygen and temperature) were 
measured in situ, and water samples were taken by triplicate for analysis of the nutrient contents (NH4+, NO2-, NO3-y PO4-3) and oxygen demands (BOD5 and COD).

Macroinvertebrates were identified at maximum taxonomic level of possible resolution, and classified according to several features (sensitive/tolerant, mode of existence) using available literature. Structural parameters were calculated for the biota (taxa richness, Shannon-Wiener diversity and evenness).

The following taxa were selected for gut contents analysis: Hyalella curvispina and Corbicula fluminea. The items consumed were classified as follow: detritus, vegetal remains/ filamentous algae, diatoms, euglenophytes/protozoa, animal remains, and mineral material. The selected species were assigned to their functional feeding group according to the dominant item consumed (> 60\%). The feeding strategies were analyzed (Amundsen et al., 1996). Benthic invertebrates, whose gut contents were not analyzed, were assigned to functional feeding groups (FFGs) according to previously classifications established (shredders, gathering collectors, filtering collectors, scrapers and predators). In addition, analyzes of $\mathrm{C}, \mathrm{N}, \mathrm{P}$ content and stable isotopes $\left(\delta^{13} \mathrm{C}\right.$ and $\delta^{15} \mathrm{~N}$ ) were carried out to establish the diet in terms of assimilation of nutrients.

In order to explore the main environmental gradients within the study area, a principal-components analysis (PCA) was carried out. For the interpretation of the most relevant variables, the axis defined by PCA was followed by a varimax-normalized rotation. To determine the differences between biotic and abiotic descriptors ANOVAs and MANOVAs were performed. The a posteriori Student-Newman-Keuls test was applied when statistically significant differences were found.

In order to explore the relationships between sampling sites, environmental variables and benthic invertebrates, a Redundance Analysis (RDA) was carried out. The significance of all canonical axes was evaluated through the Monte Carlo test.

The analysis based on physical and chemical data evinced that sites PL y BAL were associated with high levels of turbidity and better conditions of water quality. In the other hand, BZ y BE were associated with higher organic matter content and levels of conductivity, nutrient concentrations and oxygen demands.

Regarding the physical habitat, significant differences were registered in several parameters studied. The major organic matter content corresponded to highly impacted 
sites. At mesohabitat level, the percentage of COPM was significantly higher in sediments within bulrush stands, whereas the percentage of FOPM was higher in sediment free of vegetation. According to grain size analysis, the sediment was mainly sandy.

A total of 43 taxa were identified in sediments free of vegetation, whereas 91 taxa in sediment within bulrush stands. At mesohabitat level, the taxa richness, diversity and equitability showed statistically significant differences, corresponding the major values to vegetated zones. Nematoda showed higher abundances in sediments free of vegetation. Oligochaeta Tubificinae showed major abundances at sites BE and BZ, in sediments of vegetated zones. Mollusca and Crustacea were more abundant in the most slightly impacted sites, especially in sediment within bulrush stands. Tolerant and very tolerant taxa dominated at all sites and habitats studied. The organisms classified as sensitive were only found at less disturbed sites ( $P L$ and $B A L)$. Finally, with respect to functional diversity, the gathering-collectors were dominant, whereas in sediment within bulrush stands these deposit feeders were replaced by filtering-collectors at those undisturbed sites. Similarly, in sediments free of vegetation were more abundant the sprawlers, while in vegetated zones at undisturbed sites, the clingers were the most dominant group.

Interaction between habitat and biota evaluated through the first two axes of the RDA, allowed to define the main variables for the distribution and establishment of the macroinvertebrates in the studied area. The highly impacted sites were associated with higher levels of FOPM, BOD 5 , conductivity, and major abundances of Nematoda, Oligochaeta, Hirudinea, Tardigrada and Chironomidae. The undisturbed sites were associated with higher values of turbidity and major sensitive organism abundances (Ephemeroptera, Trichoptera, Hidrozoa and Cumacea).

Analyses of gut contents revealed that detritus was the most abundant component in the diet of Corbicula fluminea and Hyalella curvispina, with diatoms taking the second place. Amundsen diagrams supported the generalist feeding strategy for both species studied. Finally, the stoichiometric composition analysis evinced that stoichiometric ratios $\mathrm{C}: \mathrm{N}$ and $\mathrm{N}: \mathrm{P}$ for the selected species were similar at sampling sites. 
The stoichiometric ratio C:P was higher at most impacted sites in the case of $\mathrm{H}$. curvispina, while in the case of C. fluminea it was higher at undisturbed sites.

The results of the present study allowed us to accept the proposed hypotheses. The distribution and establishment of macroinvertebrate assemblages in the freshwater coastal sector of the Río de la Plata estuary would be determined by the effect of both habitat and water features. In that sense, the comparative analysis of functional feeding groups evinced the response of the invertebrates to the anthropogenic pollution. The filter feeders were replaced by deposit feeders in environments highly polluted. Based on the above, it could be expected a simplification of food webs with favored detritic pathways and predominance of generalist organisms. Finally, the analysis of gut contents reaffirmed its usefulness as a tool to classify the macroinvertebrates into their corresponding functional feeding group. However, it highlights the importance of using complementary methods, such as the study of feeding behavior and analysis of isotopic and stoichiometric composition for invertebrates and resources available in the environment. The results of this study emphasize the need to elucidate the interactions that occur in the benthic community, in order to establish the complexity of food webs in the freshwater coastal sector of the Río de la Plata estuary. 


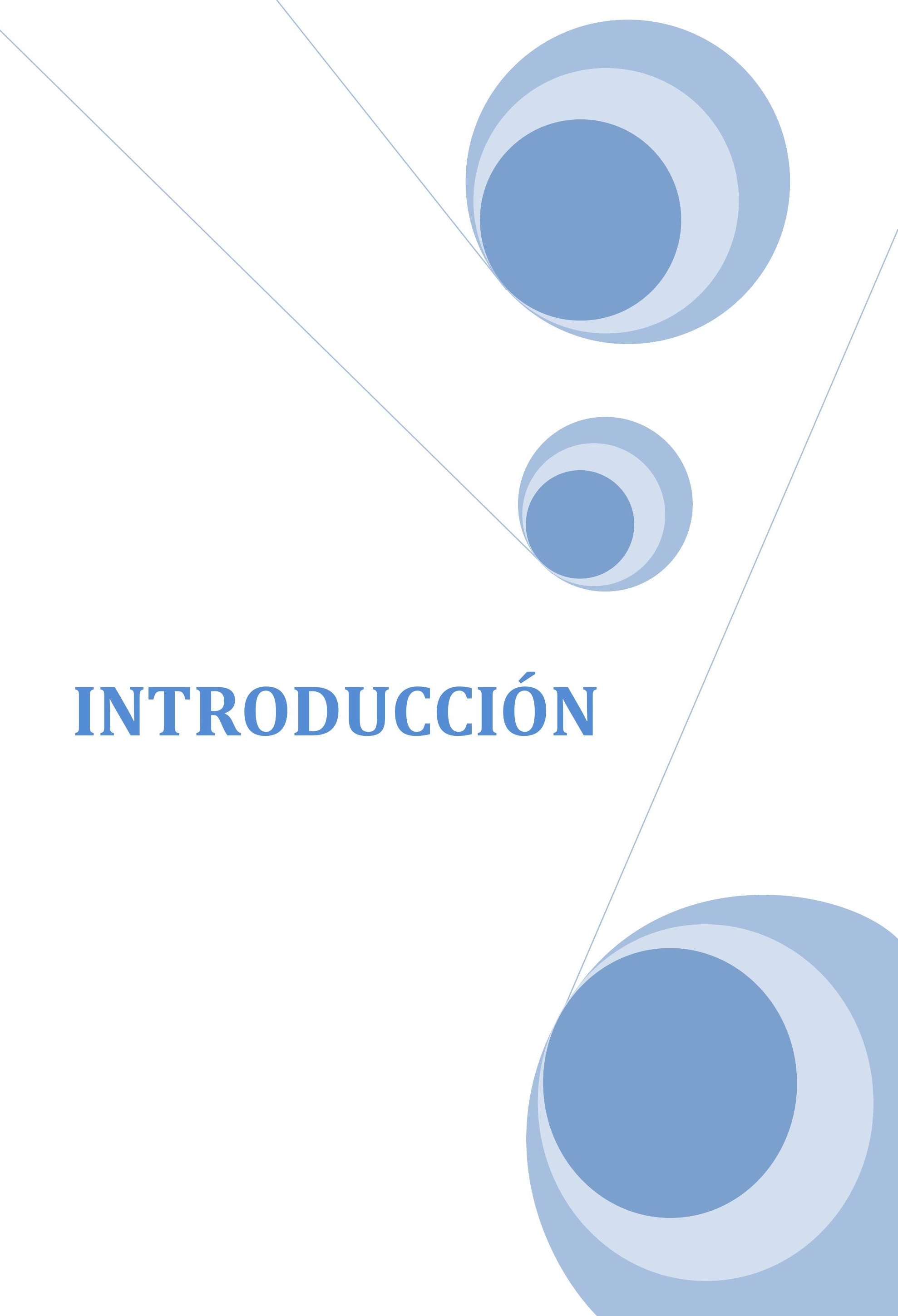


Los estuarios son considerados como zonas de transición donde se produce la interacción entre agua (dulce y salada), tierra y atmósfera, de modo que abarcan una amplia variedad de ambientes/hábitats que se encuentran en continuo cambio (USEPA, 2006). Pritchard (1967) ha dado una de las definiciones de estuario más ampliamente citadas en la literatura científica, definiéndolo como "un cuerpo de agua costero semicerrado que presenta una libre conexión con el mar abierto y en donde el agua de mar contenida está moderadamente diluida por el agua dulce de la cuenca". Sin embargo, ese proceso involucra una serie de fenómenos físicos, químicos y biológicos, que deben ser tomados en cuenta al definir un sistema estuarino. Uno de los atributos más característicos de la mayoría de las zonas costeras es la acción de la marea, de hecho la mezcla de agua dulce y agua salada implica la ocurrencia de dicho proceso. En un estuario, los cambios en la concentración salina se producen diariamente debido al régimen de mareas y a las características de la desembocadura del río en el mar. En este sentido, Fairbridge (1980) dio una definición de estuario más comprensible, según la cual, "un estuario es un entrante del mar que se introduce en un valle fluvial río arriba hasta el límite donde se dejan sentir las mareas", es decir, que mantiene una libre conexión con el mar abierto, evidenciando una fuerte mezcla entre agua dulce y salada, y sujeto diariamente a la acción de la marea y los constantes cambios en la descarga fluvial. De esta manera, se produce un balance continuo entre el movimiento de agua salada hacia aguas arriba y el flujo de agua dulce hacia aguas abajo en el estuario. Esto genera un tiempo de retención prolongado, de modo que los contaminantes presentes en el agua y en los sedimentos permanecen en él por un largo periodo de tiempo, incrementando su potencial efecto sobre la biota. De acuerdo con Boschi (1988), no parece razonable caracterizar como estuario a toda la zona de un río que recibe influencia de las mareas, y por esta razón una definición aceptable e 
inspirada en la propuesta por Ringuelet (1962), podría ser la siguiente: "un cuerpo de agua permanente o temporalmente abierto, con intercambio entre el curso fluvial y el mar, poiquilohalino y favorable para la vida de organismos eurihalinos y anfibióticos".

La importancia de los estuarios no sólo se debe a su valor estético y recreativo, sino también a su rol como zonas críticas para la supervivencia de muchas especies de peces, aves, mamíferos e invertebrados marinos que dependen del ambiente estuarino como fuente de alimento, para su desarrollo y reproducción (Day et al., 1989; USEPA, 2006). Además de su función en el transporte y transformación de nutrientes, sedimentos y contaminantes, los estuarios son importantes sitios de conservación y productividad (primaria y secundaria), proveyendo bienes y servicios fundamentales en términos de vínculos tróficos en el ecosistema y biodiversidad (Gómez et al., 2012). Por otra parte, desde un punto de vista ecológico, al actuar como interfaz entre la tierra y el mar, presentan ciertas características fisicoquímicas y las comunidades biológicas que habitan en ellos presentan una estructura y función particulares (Nedwell \& Raffaelli, 1999).

Los ecosistemas estuarinos se encuentran expuestos a diversos factores de "stress" de origen antropogénico, entre los que se destacan desechos domiciliarios y cloacales, sustancias tóxicas productos de la actividad agrícola e industrial (Amiard-Triquet \& Dauvin, 2009). La mayor problemática se debe al incremento de las actividades humanas en las cuencas fluviales, lo que ha causado grandes deterioros en la calidad del agua, acompañado por un incremento en la carga de nutrientes, materia orgánica y sedimentos hacia ríos y estuarios, con la consiguiente pérdida de hábitats productivos y recursos, y una disminución general en las condiciones ecológicas y económicas de la zona costera (Adams, 2005). 
En Argentina, el Río de la Plata se destaca por su majestuosidad e importancia socio-económica, razón por la cual ha sido estudiado como una ruta navegable y como proveedor de agua para las actividades humanas. Este estuario es el receptor del agua aportada por la extensa cuenca del Plata, y en sus costas se asienta el mayor conglomerado humano de la Argentina, generando una fuerte presión antropogénica que produce distintas problemáticas ambientales que ponen en riesgo la biota y representan una amenaza para la salud humana, como el enriquecimiento con materia orgánica y nutrientes, la contaminación con productos de desecho de la actividad urbana e industrial, entre otras. Más aún, el desarrollo progresivo de construcciones en la línea de costa, dragados, alteración del régimen hidrológico de humedales costeros, entre otros, ha alterado la morfología de las costas e interferido con los procesos naturales de la dinámica costera, atentando a la integridad del hábitat físico (FREPLATA, 2005). En este sentido, se trata de una zona donde convergen actividades extractivas (principalmente captación de agua para su potabilización), recreativas, portuarias, vertidos industriales y domiciliarios, entre otras. Por otro lado, en la zona se ubican reservas naturales y áreas protegidas de suma importancia en la conservación de la biodiversidad para el área rioplatense (Gómez \& Rodrigues Capítulo, 2000). En definitiva, el deterioro en la calidad del agua y la destrucción de los hábitats en una buena parte de la costa bonaerense no hace más que remarcar la relación inversa entre la vertiginosa explotación del ecosistema en cuestión y la información fragmentaria sobre la biota y su dinámica.

\section{Los invertebrados en los sistemas lóticos:}

Los ambientes lóticos en general están compuestos por una gran variedad de organismos que se estructuran en comunidades bióticas definidas principalmente por características climáticas, geomorfológicas e hidráulicas. En 
estos sistemas, una parte considerable de la biodiversidad es aportada por los invertebrados, entre los que se destacan los macroinvertebrados bentónicos.

En las zonas costeras de los grandes sistemas lóticos, la fracción de macroinvertebrados bentónicos, representa una biomasa importante y constituye un recurso alimentario fuertemente explotado por peces (Hynes, 1976; Bechara, 1993) y otros vertebrados. En este sentido, el papel de los macroinvertebrados, en la estructura y función de los sistemas lóticos, es convertir los compuestos reducidos de carbono en acumulación temporaria en sus propios tejidos y en $\mathrm{CO}_{2}$ (Cummins, 1973), participando de manera importante en la degradación de la materia orgánica y el ciclo de nutrientes. Así, los macroinvertebrados bentónicos pueden ser vistos como intermediarios de la trama trófica actuando como nexo entre la base de esa trama (productores primarios y detrito orgánico) y los compartimentos superiores (consumidores secundarios), dependiendo de la cuenca en términos de movimientos de materia orgánica (Albariño, 1998).

Aún más, es reconocido que los macroinvertebrados bentónicos son capaces de reflejar las diferentes perturbaciones antropogénicas a través de cambios en la estructura o función de sus asociaciones. Dado que estos organismos proporcionan la base fundamental de la red alimentaria, su presencia resulta fundamental en el funcionamiento de muchos de los procesos ecológicos, como la degradación de material orgánico y el transporte de energía en las tramas tróficas (Allan, 1995; Wallace \& Webster, 1996; Covich et al., 1999).

Por otra parte, diversos estudios han demostrado que la estructura de las poblaciones de macroinvertebrados se ve potencialmente afectada por la heterogeneidad de su ambiente circundante (Borchardt, 1993; Armitage, 1995; Petts \& Calow, 1996). Los resultados de dichas investigaciones describen relaciones claras entre la estructura de la comunidad de macroinvertebrados 
en función de la heterogeneidad ambiental y el cambio de los grupos faunísticos en respuesta a la manipulación del flujo en sistemas lóticos montañosos donde el concepto de Río Continuo (Cummins, 1975; Vannote et al., 1980) es aplicable.

Para los ambientes de llanura sudamericanos, los estudios tendientes a evaluar estas respuestas biológicas son aún escasos (Cortelezzi, 2010).

\section{Los macroinvertebrados y el hábitat físico:}

La "calidad ecológica" se refiere a la estructura y función de la comunidad biológica, los factores naturales de tipo físico, geográfico y climático sumado a condiciones físicas y químicas del agua (incluidas las resultantes de la actividad humana y la estética de los ecosistemas) (Prat et al., 1996). Dado que el creciente impacto producto de las actividades humanas sobre los sistemas lóticos ha generado cambios en la geomorfología de la costa y en los hábitats que sostienen las comunidades bióticas, se plantea la necesidad de estudiar la importancia de los hábitats sobre la calidad ecológica de esos sistemas. La diversidad de hábitats es uno de los indicadores más empleados para establecer la salud de los ríos, dado que se correlaciona con la diversidad biológica. Una reducción de la heterogeneidad ambiental puede reducir la diversidad de especies y la abundancia de las poblaciones. De acuerdo a ello, una forma de medir el efecto de diferentes impactos antropogénicos puede ser a partir del estudio de las comunidades biológicas o del hábitat físico que éstos emplean para su desarrollo, reproducción, refugio, entre otros.

En las últimas décadas, desde el ámbito científico y de gestión, el interés por ampliar los conocimientos sobre los hábitats acuáticos ha ido incrementándose, debido a la necesidad de contar con información para el manejo y la restauración de esos hábitats. Jowet (1977) ha sugerido que el 
término "hábitat" describe el entorno físico de plantas y animales, y así el hábitat acuático puede ser definido como el conjunto de características físicas, químicas y biológicas locales que proporcionan un entorno a la biota (Gómez \& Cochero, 2013). De acuerdo con diversos autores, el hábitat se ve afectado por las características propias del cuerpo de agua y la topografía circundante (Aadland, 1993), y la cantidad y calidad de hábitats disponibles afectan la estructura y composición de las comunidades biológicas locales (Callow \& Petts, 1994; Graham et al., 2000; Bortone, 2005; Borja et al., 2009). Por este motivo, la valoración ambiental de las riberas (en términos de diversidad, riqueza, condición sanitaria, etc.) es necesaria para conocer el estado ecológico de los cursos de agua. En Argentina, los antecedentes sobre la evaluación de las zonas ribereñas son incipientes (Miserendino \& Masi, 2010; Kutschker et al., 2009; Troitiñio et al., 2010) y en particular, para los ecosistemas estuarinos del país sólo puede citarse el trabajo de Gómez \& Cochero (2013) para el Río de la Plata.

El concepto de "hábitats funcionales" (Harper et al., 1995) surgió en relación al estudio del hábitat y el ensamble de invertebrados bentónicos, quedando definidos como "los componentes estructurales del sustrato y la vegetación objetivamente identificados como diferentes por las asociaciones de invertebrados que sostienen". Diversos estudios han aplicado este concepto en la conservación, manejo y rehabilitación de ríos (Harper et al., 1998; Harper \& Everard, 1998; Kemp et al., 1999; Buffagni et al., 2000; Newson \& Newson, 2000; Storey \& Lynas, 2007), demostrando que la presencia y frecuencia de hábitats funcionales reflejan los procesos geomorfológicos dominantes en el cauce y en consecuencia, son sensibles al impacto humano, de manera que la conservación de los mismos preserva la diversidad biológica (Tickner et al., 2000; Rabeni et al., 2002). Así, el término hábitats funcionales reconoce la importancia que la presencia o ausencia de los mismos podría tener para los 
procesos que ocurren en los ríos, la salud ecológica y diversidad de la biota (Buffagni et al., 2000).

Como se mencionó anteriormente, la alteración de los ríos por influencia antrópica afecta directa o indirectamente a las comunidades bióticas, siendo los impactos en este sentido ecológicamente negativos. Entre las principales consecuencias se encuentran la pérdida de heterogeneidad del sustrato, disminución de hábitats funcionales y pérdida de refugios.

Si bien la identificación de los hábitats en el ambiente acuático es una herramienta valiosa en estudios de monitoreo, existe confusión dentro de la literatura ecológica con respecto al reconocimiento y definición de diferentes ambientes dentro de los ríos (Wadeson, 1994).

\section{Los invertebrados y los grupos funcionales alimentarios:}

Debido a la estrecha relación que existe entre las condiciones del hábitat y los rasgos biológicos de las especies que lo habitan (Townsend \& Hildrew, 1994), estos últimos pueden ser utilizados para predecir cambios en las comunidades de invertebrados en gradientes ambientales (naturales o antrópicos) (Statzner et. al., 2005). De esta forma, la clasificación de la comunidad en estrategias tróficas puede considerarse un rasgo biológico, que brinda información de tipo funcional y se relaciona con funciones ecológicas, (tipo de alimentación, etc.), permitiendo establecer hipótesis simples que puedan predecir cambios en las comunidades debido a cambios en el ambiente (Rodrigues Capítulo et al., 2009). Puntualmente, las estrategias alimentarias reflejan la adaptación de las especies a las condiciones ambientales y son una medida para comparar comunidades de composición taxonómica diferente (Statzner et al., 2001). Así, la clasificación funcional de los macroinvertebrados acuáticos basada en sus hábitos alimentarios facilita la comprensión de los procesos ecológicos que ocurren en los ecosistemas lóticos 
dado que permite analizar las relaciones tróficas en esos sistemas (Palmer et al., 1993; Vannote et al., 1980). Merritt et al. (2008) caracterizaron la estructura del macrozoobentos basándose en el mecanismo de obtención del alimento y en el tipo y tamaño del material ingerido, definiendo 6 categorías tróficas o grupos funcionales alimentarios (GFA): depredadores, fragmentadores, colectores-recolectores, colectores-filtradores, raspadores y herbívoros/detritívoros. En Sudamérica se han realizado estudios referentes a la ubicación de los invertebrados acuáticos dentro de grupos funcionales alimentarios: en los Ríos Paraná y Negro (Bonetto \& Wais, 1995), algunos sistemas lóticos pampeanos bonaerenses (Tangorra, 2004; López van Oosterom et al., 2013), sistemas andino-patagónicos (Díaz Villanueva \& Albariño, 1999; Miserendino, 2001) y otros arroyos neotropicales (Tomanova et al., 2006). En el Río de la Plata, los estudios referidos a los grupos funcionales alimentarios son aún muy escasos (Rodrigues Capítulo et al., 2006) y están basados en clasificaciones establecidas para América del Norte (Merritt \& Cummins, 1996; Heino, 2005).

Otro enfoque que ha permitido profundizar el conocimiento respecto de las estrategias tróficas es la Teoría Ecológica de la Estequiometría, que estudia el balance de energía y elementos químicos (tales como C, N y P) en las interacciones ecológicas que ocurren en las comunidades bentónicas fluviales, analizando los organismos en función de su composición elemental (Sterner \& Elser, 2002). Las relaciones C:N y C:P proveen información sobre las conexiones tróficas en el ecosistema, y determinan la capacidad de la comunidad bentónica de absorber uno u otro nutriente del medio (Muñoz et al., 2009). De esta manera, la determinación de la estequiometría de la comunidad permite relacionar posibles desequilibrios entre estos elementos y los procesos que tienen lugar en el ecosistema, como la utilización y el reciclaje de la materia orgánica (Frost et al., 2002; Cross et al., 2005). En Argentina, existe un gran 
vacío en esta temática, y sólo pueden citarse algunos trabajos realizados para sistemas acuáticos andino-norpatagónicos (Modenutti et al., 2010), arroyos del área pampeana (Ocon et al., 2013) y el sector marino del Río de la Plata (Botto et al., 2011).

\section{Antecedentes:}

Trabajos realizados previamente en el Río de la Plata

Los macroinvertebrados bentónicos han sido utilizados de manera creciente para monitorear cambios físicos y químicos en la calidad del agua producidos por las actividades humanas (Resh et al., 1995; Wright et al., 1995; Barbour et al., 1999; Gómez \& Rodrigues Capítulo, 2001), empleando descriptores estructurales y funcionales del complejo bentónico, y adaptando índices bióticos basados en la sensibilidad y tolerancia de los organismos. Los estudios previos sobre la fauna bentónica del Río de la Plata se han referido principalmente a los moluscos costeros (entre ellos se destacan los trabajos de Ituarte, 1981, 1985; Darrigran \& Maroñas, 1989; Darrigran, 1992 a y b; Pastorino et al., 1993; Scarabino, 1999). En 1993, el equipo de trabajo del laboratorio de Bentos del Instituto de Limnología "Dr. Raúl A. Ringuelet" ha sido incorporado al proyecto de monitoreo de la Franja Costera Sur (definida como el sector costero argentino comprendido entre el Río Luján y el Cabo San Antonio, por la Comisión Administradora del Río de la Plata). Desde entonces se han venido desarrollando estudios biológicos sobre la composición faunística y aspectos ecológicos del bentos del río (Rodrigues Capítulo et al., 1997, 1998 y 2003; César et al., 2000; Gómez \& Rodrigues Capítulo, 2001; Cortelezzi et al., 2002, 2007; Giberto et al., 2004, 2007; Ocon et al., 2008, Armendáriz et al., 2011; Spaccesi \& Rodrigues Capítulo, 2012), distribución del fitoplancton y diatomeas bentónicas (Gómez \& Bauer, 1997, 1998 y 2000; Gómez \& Licursi, 2001; Gómez et al., 2009, Licursi et al., 2010) y diversos 
parámetros relacionados con la calidad de sus aguas (AA, AGOSBA, ILPLA, SHIN, 1997; Bazán \& Arraga, 1993). Asimismo, pueden citarse investigaciones orientadas al estudio de los macroinvertebrados como indicadores de la calidad de sus aguas (Gómez \& Rodrigues Capítulo, 2001; Paggi et al., 2006) y el desarrollo de índices para la evaluación de la calidad del hábitat (Gómez \& Cochero, 2013) e integridad biótica (Gómez et al., 2012) empleando distintos indicadores ambientales.

Como se mencionara anteriormente, la mayoría de los estudios sobre el hábitat realizados hasta el momento son referidos a sistemas lóticos montañosos, especialmente del hemisferio norte. Con una aceptación creciente, el concepto de hábitat funcional ha sido utilizado para detectar con claridad los efectos del impacto humano sobre los ecosistemas acuáticos y su fauna, así como también para establecer programas rentables de monitoreo para mejorar la gestión de los ríos (Buffagni et al., 2000) y maximizar la heterogeneidad de hábitats y la biodiversidad en proyectos de rehabilitación (Kemp et al., 2000).

En el caso de los sistemas lóticos de nuestro país, existen diversos estudios sobre las respuestas biológicas a los cambios ambientales producidos por el impacto de las actividades humanas, referidos principalmente al fitoplancton, diatomeas bentónicas y grupos zoobentónicos particulares. A partir de la necesidad de incorporar el efecto de la calidad del hábitat en la evaluación de la calidad ecológica en los grandes sistemas lóticos, surge esta propuesta que incluye el análisis de algunas respuestas (estructurales y funcionales) de los macroinvertebrados bentónicos a las modificaciones de la costa generadas por distintos tipo de impacto antropogénico. 


\section{Marco conceptual:}

El estudio de descriptores estructurales y funcionales del complejo bentónico en la zona costera del Río de la Plata contribuye a la evaluación de la calidad del agua y la integridad biótica del mismo. En este sentido, resulta necesario abordar diversos aspectos (factores bióticos y del ambiente) que permitan una visión holística del sistema, determinando la respuesta de los organismos sensibles y tolerantes característicos del área de estudio en ambientes sometidos a distinto tipo de disturbio (Fig. 1).

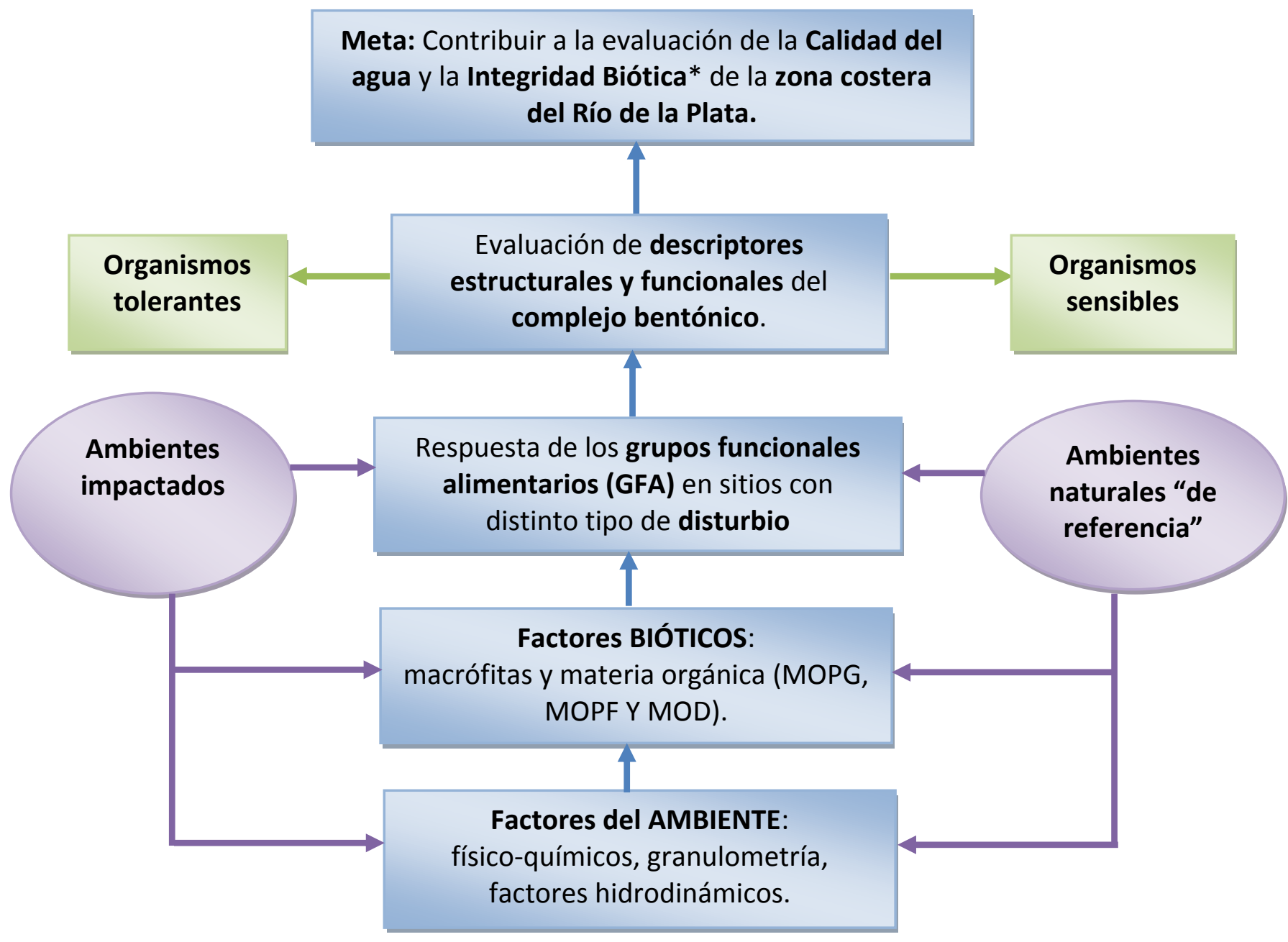

* Integridad Biótica: capacidad de sustentar y mantener una comunidad de organismos balanceada, integrada y adaptada, cuya composición específica, diversidad y organización funcional sea comparable con la comunidad propia de un hábitat natural de la región (Karr \& Dudley, 1981).

Figura 1. Diagrama que resume el marco conceptual en el que se ha enmarcado el presente estudio. 
La calidad ecológica de los ecosistemas está determinada por la interacción de dos ejes principales:

- la calidad del hábitat, estimada a partir del análisis de los hábitats funcionales y de las características morfológicas del cauce,

- la calidad del agua, estimada a partir del grado de contaminación (características físico-químicas).

Esta interacción determina la calidad biótica del sistema, de manera que la estructura y función de las asociaciones de macroinvertebrados varían según la intensidad de cada uno de los factores que intervienen (Fig. 2).

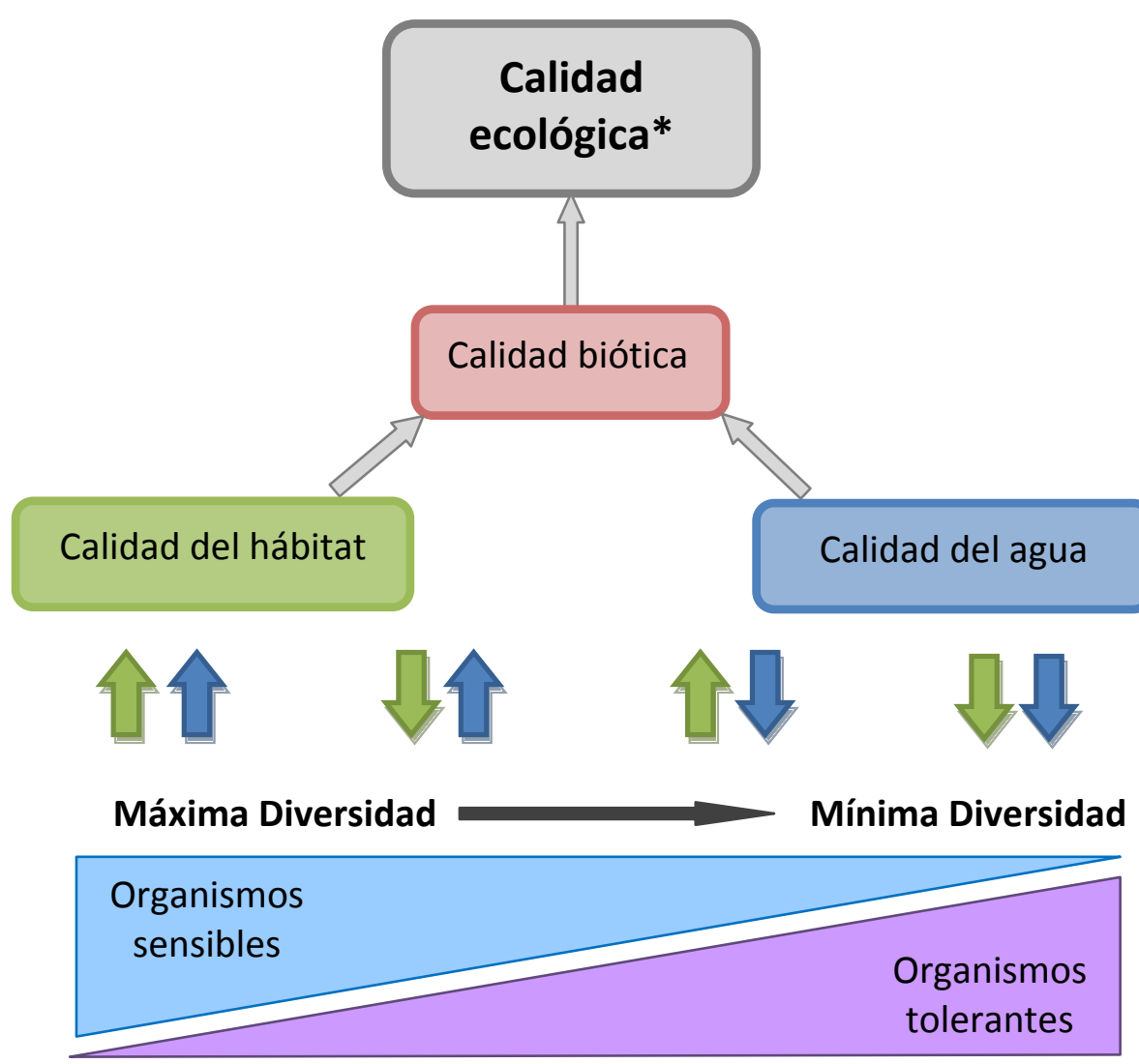

Figura 2. Esquema conceptual de los diferentes elementos que determinan la calidad ecológica de los ecosistemas. Las flechas representan situaciones de "buena calidad" (flechas hacia arriba) y "mala calidad" (flechas hacia abajo) del hábitat y del agua. 


\section{Hipótesis planteadas:}

A- "La presencia de hábitats funcionales de buena calidad disponibles en la costa del Río de la Plata favorece el establecimiento de macroinvertebrados bentónicos en los sedimentos"

Predicciones a observar en el campo:

Menor diversidad y densidad de macroinvertebrados bentónicos asociados al sedimento y a la vegetación ribereña en ambientes impactados por la actividad humana.

B- "La presencia de vegetación costera genera la acumulación de sedimentos finos y materia orgánica en las riberas, favoreciendo el desarrollo de organismos detritívoros"

Predicciones a observar en el campo:

Mayor densidad de organismos detritívoros en los sedimentos asociados a la vegetación.

Mayor densidad de organismos filtradores que detritivoros y carnivoros en los sedimentos libres de vegetación.

C- "La contaminación de origen orgánico e inorgánico genera mayor acumulación de materia orgánica y nutrientes en detrimento de la calidad del hábitat, favoreciendo la dominancia de organismos detritívoros en desmedro de los filtradores y carnívoros" Predicciones a observar en el campo:

Densidades más altas de detritívoros en ambientes con altos porcentajes de materia orgánica producto de la contaminación.

\section{Objetivo General:}

El objetivo general es evaluar la importancia de los hábitats funcionales que proporciona el sector costero bonaerense del Río de la Plata en el establecimiento y persistencia de las poblaciones de macroinvertebrados bentónicos y el mantenimiento de la calidad ecológica de los grandes sistemas lóticos. Para este fin se utilizaron descriptores estructurales y funcionales del complejo bentónico y se consideraron ambientes sometidos a diversos tipos de 
disturbio antropogénico, (desde zonas con intensa actividad portuaria, urbana e industrial hasta zonas con elevado grado de naturalidad costera). Se pretende así contribuir al estudio de la integridad biótica, para el diagnóstico y monitoreo de la calidad del agua y del hábitat de la zona costera del Río de la Plata. El producto final será un aporte al mapeo de la calidad ecológica del mismo, lo que contribuye al objetivo general del Proyecto: "Medidas de integridad biótica para la costa del Río de la Plata (Argentina)", PICT 32077, dentro del cual el plan de tesis ha sido incluido. Asimismo, se espera que los resultados obtenidos puedan utilizarse en el futuro como una herramienta complementaria que contribuya a la evaluación de la calidad ecológica de los ecosistemas lóticos de llanura y a complementar el mapa de sensibilidad ecológica desarrollado por Boltovskoy et al. (2008).

\section{Objetivos particulares planteados:}

- Evaluar la calidad de los hábitats funcionales presentes en la costa bonaerense del Río de la Plata y su importancia en el diagnóstico de la calidad del agua/ecológica.

- Comparar el efecto de los diversos usos de la costa sobre la calidad de los hábitats funcionales determinados y evaluar la importancia de cada uno de ellos sobre las poblaciones de macroinvertebrados.

- Determinar características estructurales del complejo zoobentónico (riqueza, densidad, diversidad, equitabilidad, etc.) para la posterior comparación de las poblaciones expuestas a diferentes tipos de disturbio antropogénico.

- Analizar los cambios físico-químicos (conductividad, turbidez, oxígeno disuelto, nutrientes, demandas de oxígeno) en sitios sometidos a distinto tipo de impacto antropogénico.

- Conocer las dietas de los grupos predominantes de macroinvertebrados en sitios con diferente tipo de disturbio antropogénico, para comparar la 
información de los grupos funcionales alimentarios en sitios de referencia y aquellos sometidos a diverso grado de contaminación.

- Conocer las relaciones estequiométricas (C:N, C:P y N:P) de aquellos macroinvertebrados más representativos en los sitios de muestreo estudiados. 


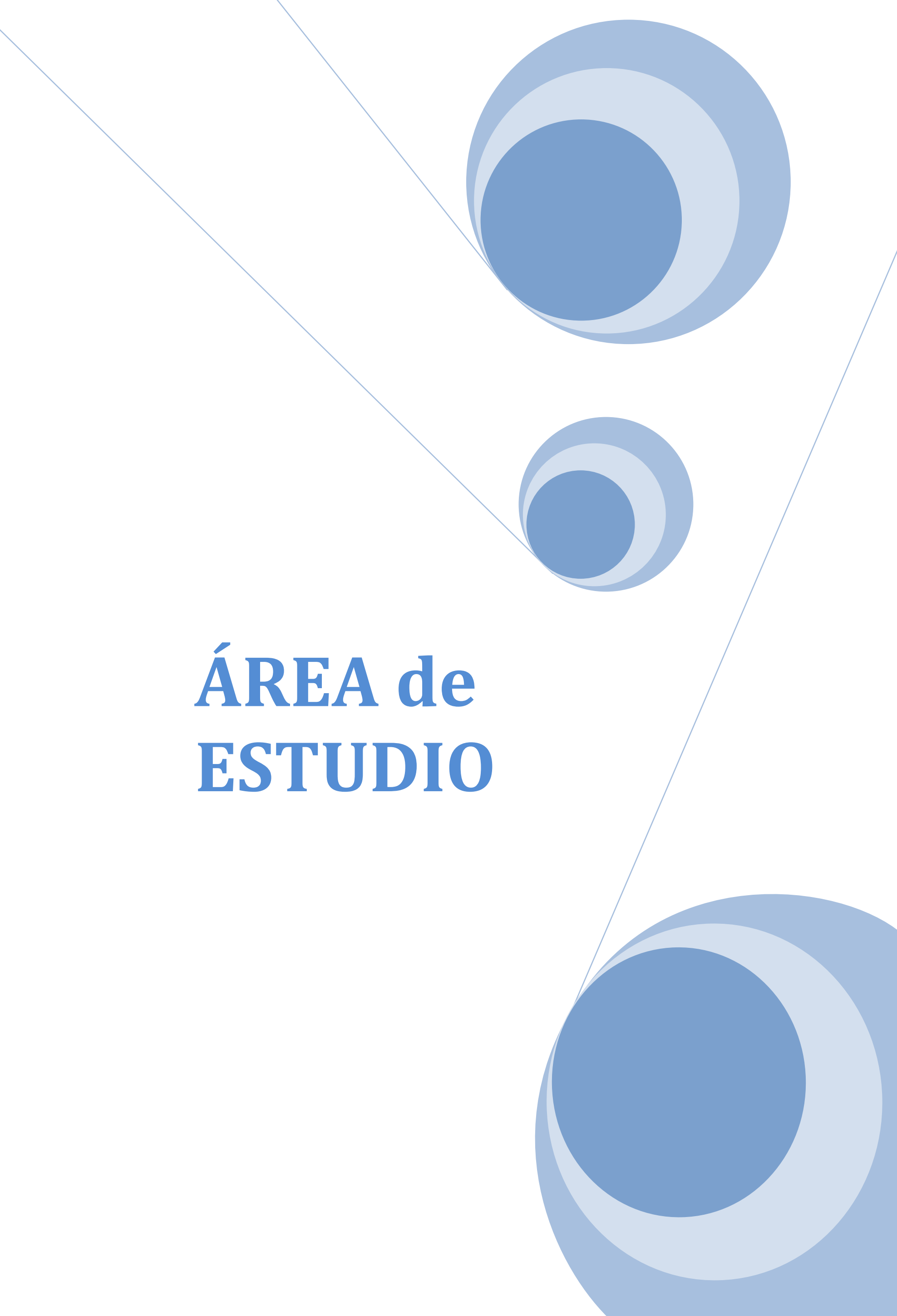


El Río de la Plata es uno de los ambientes estuarinos más importantes de Sudamérica, y primero en términos de importancia socioeconómica (alberga una población humana de 15 millones de habitantes), representando una de las principales rutas de navegación y un vasto recurso de agua potable. Se caracteriza por ser un estuario de llanura, somero y micromareal, con una pequeña amplitud de marea $(\sim 1 \mathrm{~m})$, que puede ser superada por los fenómenos meteorológicos conocidos como sudestadas. Recibe agua dulce de la segunda cuenca más grande de Sudamérica (Cuenca del Plata con un área de 3,2 millones de $\mathrm{Km}^{2}$, abarcando territorios dentro de Argentina, Bolivia, Brasil, Paraguay y Uruguay). Este estuario presenta $320 \mathrm{~km}$ de largo y cubre un área de $35.000 \mathrm{~km}^{2}$. La descarga de agua dulce (media anual: $22.000 \mathrm{~m}^{3} \mathrm{~s}^{-1}$ ) de los Ríos Paraná y Uruguay (sus mayores tributarios) dentro del estuario, muestra una estacionalidad mínima, con una máxima media de $26.000 \mathrm{~m}^{3} \mathrm{~s}^{-1}$ en invierno, y una mínima media de $19.000 \mathrm{~m}^{3} \mathrm{~s}^{-1}$ en verano (Guerrero et al., 1997). La baja transparencia del agua debido al elevado contenido de sólidos en suspensión que arrastran sus tributarios, puede limitar la productividad primaria independientemente del alto aporte de nutrientes de la cuenca y de la disponibilidad del oxígeno (Pizarro \& Orlando, 1984; Acha et al., 2008).

La dinámica del estuario está controlada principalmente por las mareas, las olas impulsadas por el viento y la escorrentía continental, pero se ve modificada por la topografía y las fuerzas de Coriolis. El rango de amplitud de marea varía entre 30 a $100 \mathrm{~cm}$, y el ciclo de cambios de marea completa su pasaje a través de todo el estuario en un período de 12 horas aproximadamente, es decir, dos mareas altas y dos mareas bajas por día, lo que genera fenómenos hidráulicos complejos (Balay, 1961; Lanfredi et al., 1979).

A lo largo de toda la costa, la vegetación muestra una sucesión espacial de juncos, matorrales y bosques higrófilos, constituyendo una zona 
transicional entre el ecosistema acuático y el terrestre. La vegetación acuática está dominada por el junco Schoenoplectus californicus (Meyer) Soják, que forma "parches" que son empleados como zonas de refugio y alimentación por varias especies de vertebrados e invertebrados (Gómez \& Rodrigues Capítulo, 2000). Esta distribución puede verse interrumpida o fragmentada como consecuencia de las intervenciones antropogénicas, al punto de ser eliminadas diversas especies de la vegetación nativa (Lahitte et al., 2004).

Los sedimentos superficiales de la zona intermareal consisten principalmente de arena fina y muy fina $(62,5-250 \mu \mathrm{m})$, pero en sitios con mayor contenido de materia orgánica como consecuencia del impacto antropogénico a lo largo de la costa, predominan las fracciones de limo y arcilla (Gómez et al., 2009; Armendáriz et al., 2011).

De acuerdo con sus características dinámicas y geomorfológicas, se divide en dos zonas: una zona interna, de agua dulce con conductividades menores a $5000 \mu \mathrm{S} \mathrm{cm}^{-1}$, una superficie de $13.000 \mathrm{~km}^{2}$ aproximadamente y profundidades entre 1 y $5 \mathrm{~m}$, donde la marea es la única influencia oceánica (Urien, 1972), y una zona externa, con características mixohalinas de aproximadamente $22.000 \mathrm{~km}^{2}$, y profundidades entre 5 y $25 \mathrm{~m}$. La isohalina de 0,5 unidades prácticas de salinidad constituye el límite entre ambas zonas (FREPLATA, 2005), formando un "frente de máxima turbidez" (Bazán \& Arraga, 1993).

El sector de agua dulce abarca aproximadamente $180 \mathrm{~km}$ de costa argentina, y constituye la principal fuente de agua potable para las ciudades adyacentes. A lo largo de la costa argentina, presenta un elevado grado de urbanización e industrialización, generando la entrada masiva de contaminantes que representan una amenaza para la biota acuática y la salud humana. Entre dichos contaminantes se pueden mencionar nutrientes, materia orgánica, metales pesados, pesticidas organoclorados, bifenilos 
policlorinados, hidrocarburos, sólidos en suspensión y agentes patógenos (AA, AGOSBA, ILPLA, SHIN, 1997; Bilos et al., 1998; Colombo et al., 2005, 2006; Ocon et al., 2008). Asimismo, construcciones a lo largo de la línea costera sumado a los dragados y otras modificaciones del régimen hidrológico de los humedales costeros, han alterado la morfología de la costa interfiriendo con los procesos naturales de su dinámica, afectando la integridad del hábitat físico (FREPLATA, 2005; Gómez et al., 2009; Armendáriz et al., 2011). Diversos estudios han demostrado que el enriquecimiento con materia orgánica y la eutrofización, junto con la destrucción del hábitat son los principales aspectos que afectan la costa rioplatense (Mianzan et al., 2001; FREPLATA, 2005). No obstante, en esta área también se encuentran reservas naturales y áreas protegidas, que constituyen importantes centros para la conservación de la biodiversidad (Gómez \& Rodrigues Capítulo, 2000).

Quizás debido a su posición intermedia entre el campo de la investigación limnológica y marina, el sector de agua dulce de los estuarios ha recibido, en general, poca atención en los estudios ecológicos (Schuchardt \& Schirmer, 1991; Gómez et al., 2004; Cortelezzi et al., 2007). De hecho, aunque las zonas de agua dulce típicamente constituyen una pequeña proporción de la superficie total del sistema estuarino, algunos estudios han sugerido que juegan un rol fundamental en la energía y la biogeoquímica del ecosistema (Lampman et al., 1999; Lionard et al., 2008).

El presente estudio fue realizado en la costa bonaerense del Río de la Plata, dentro del sector conocido como "Franja Costera Sur", entre las coordenadas $34^{\circ} 41^{\prime} 30^{\prime \prime} \mathrm{S}, 58^{\circ} 15^{\prime} 14^{\prime \prime} \mathrm{O}$ y $34^{\circ} 55^{\prime} 44^{\prime \prime} \mathrm{S}, 57^{\circ} 42^{\prime} 56^{\prime \prime} \mathrm{O}$. A partir de la información brindada por muestreos previos realizados en diversos puntos a lo largo del mencionado sector, se establecieron para el presente estudio cuatro sitios de muestreo distribuidos a lo largo de $70 \mathrm{~km}$ de costa aproximadamente (Fig. 3), ubicados en el sector intermareal de agua dulce del estuario. 


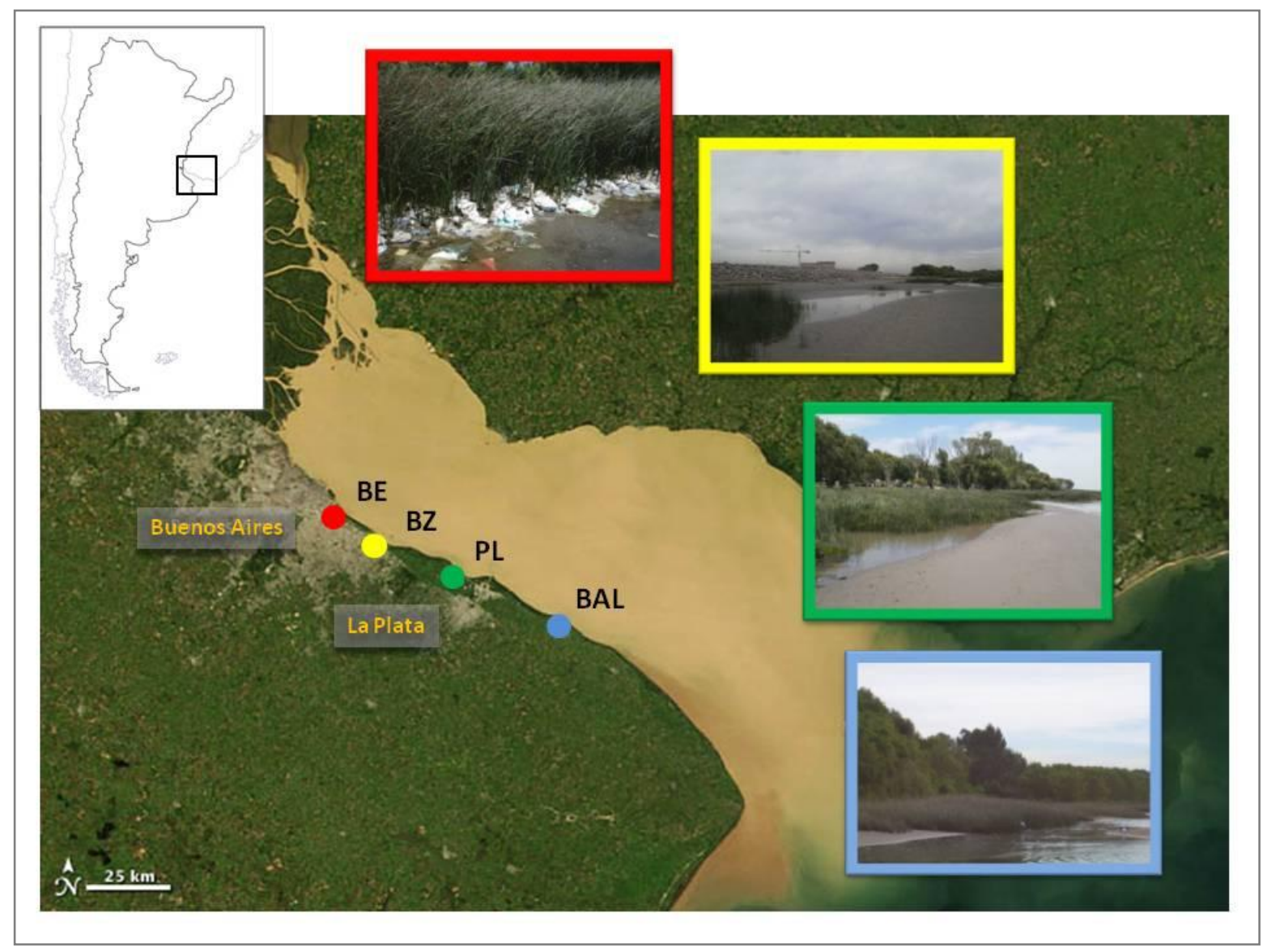

Figura 3. Área de estudio donde se ubican los sitios de muestreo seleccionados para la presente investigación. BE: Bernal, BZ: Berazategui, PL: Punta Lara, BAL: Balandra.

\section{Caracterización de los sitios de muestreo:}

La localización de los sitios de muestreo, así como las barreras físicas (escolleras, terraplenes, etc.) introducidas por el hombre y los porcentajes de usos del suelo (urbano, suburbano y rural) predominantes se resumen en la Tabla 1. Asimismo, a modo introductorio, se detallan los principales aspectos de cada uno de los sitios analizados (Tabla 2). 
Tabla 1. Sitios de muestreo: localización, porcentajes de usos del suelo y barreras físicas.

\begin{tabular}{|c|c|c|c|c|c|c|}
\hline \multirow{2}{*}{ Sitio } & \multirow{2}{*}{ Acrónimo } & \multirow{2}{*}{ Coordenadas } & \multicolumn{3}{|c|}{$\%$ de Usos del suelo* } & \multirow{2}{*}{$\begin{array}{l}\text { Barreras } \\
\text { Físicas* }\end{array}$} \\
\hline & & & Urbano & Suburbano & Rural & \\
\hline Bernal & BE & $\begin{array}{l}34^{\circ} 41^{\prime} 30^{\prime \prime} \mathrm{S} \\
58^{\circ} 15^{\prime} 14^{\prime \prime O}\end{array}$ & 60,8 & 38,7 & 0,5 & $\begin{array}{l}\text { Estructuras } \\
\text { temporarias }\end{array}$ \\
\hline Berazategui & BZ & $\begin{array}{l}34^{\circ} 44^{\prime} 38^{\prime \prime} \mathrm{S} \\
58^{\circ} 10^{\prime} 42^{\prime \prime O}\end{array}$ & 39,3 & 60,7 & 0 & $\begin{array}{c}\text { Estructuras } \\
\text { temporarias y } \\
\text { rellenos }\end{array}$ \\
\hline Punta Lara & PL & $\begin{array}{l}34^{\circ} 49^{\prime} 29^{\prime \prime} \mathrm{S} \\
57^{\circ} 57^{\prime} 35^{\prime \prime O}\end{array}$ & 19,0 & 11,6 & 69,4 & $\begin{array}{l}\text { Estructuras } \\
\text { temporarias }\end{array}$ \\
\hline Balandra & BAL & $\begin{array}{l}34^{\circ} 55^{\prime} 44^{\prime \prime} \mathrm{S} \\
57^{\circ} 42^{\prime} 56^{\prime \prime} \mathrm{O}\end{array}$ & 0 & 0 & 100 & $\begin{array}{l}\text { Estructuras } \\
\text { temporarias }\end{array}$ \\
\hline
\end{tabular}

* tomado de Gómez \& Cochero (2013)

Tabla 2. Aspectos más relevantes de los sitios de muestreo seleccionados para su estudio.

\begin{tabular}{||l|c|c|c|c||}
\hline & Bernal & Berazategui & Punta Lara & Balandra* $^{*}$ \\
\hline $\begin{array}{l}\text { Principal/es uso/s de la } \\
\text { costa }\end{array}$ & $\begin{array}{c}\text { Descarga de desechos } \\
\text { domiciliarios e } \\
\text { industriales }\end{array}$ & $\begin{array}{c}\text { Descarga de } \\
\text { efluentes } \\
\text { cloacales }\end{array}$ & $\begin{array}{c}\text { Recreativo y } \\
\text { Pesquero }\end{array}$ & $\begin{array}{c}\text { Recreativo y } \\
\text { Pesquero (a "baja } \\
\text { escala") }\end{array}$ \\
\hline $\begin{array}{l}\text { Grado de naturalidad } \\
\text { costera }\end{array}$ & Bajo & Bajo & Moderado & Alto \\
\hline $\begin{array}{l}\text { Grado de } \\
\text { contaminación (según } \\
\text { Indices Bióticos) }\end{array}$ & Fuerte a débil & Moderada a débil & Débil a escasa & Escasa a nula \\
\hline Presencia de Juncal & $\mathrm{Si}$ & $\mathrm{Si}$ & $\mathrm{Si}$ & $\mathrm{Si}$ \\
\hline $\begin{array}{l}\text { Facilidad de acceso al } \\
\text { punto de muestreo }\end{array}$ & $\mathrm{Si}$ & $\mathrm{Si}$ & $\mathrm{Si}$ & $\mathrm{Si}$ \\
\hline
\end{tabular}

* Considerado como sitio "de referencia" para esta investigación debido al mayor grado de naturalidad costera que presenta y la baja influencia antropogénica a la que se encuentra sometido. 


\section{Bernal (BE)}

Este sitio de muestreo se ubica a una distancia de $20-25 \mathrm{~km}$ aproximadamente de la ciudad de Buenos Aires, y se encuentra dentro de una zona urbana, con actividad industrial intensa y diversificada (Fig. 4). La costa rioplatense presenta un elevado grado de influencia humana, expuesta directamente al impacto de la ciudad de Buenos Aires, desarrollo de actividades portuarias y de navegación, y descargas de efluentes domésticos e industriales. Asimismo, la presencia de gran cantidad de basura forma parte del paisaje cotidiano. Diversos estudios (Lammel et al., 1997; FREPLATA, 2005; INA, 2011) han demostrado que en este sector del estuario, los niveles de metales pesados (principalmente cromo y plomo) registrados en el agua y en el sedimento superan los límites de exposición permitidos, alcanzando en algunas ocasiones el orden del miligramo. Estos aspectos han repercutido negativamente sobre la calidad del agua y del hábitat. De acuerdo a los resultados obtenidos por Gómez \& Cochero (2013), este sitio corresponde a un ambiente con "mala" calidad del hábitat. Esto está evidenciado por una marcada modificación de la sucesión espacial de la vegetación ribereña, moderada a alta ocurrencia de residuos, presencia de indicadores de déficit de oxígeno disuelto y conectividad entre el ecosistema acuático y terrestre claramente disminuida.

De acuerdo con Gómez et al. (2012) este sitio presenta un estatus biológico "malo", caracterizado por una polución fuerte, con concentraciones de nutrientes muy elevadas que contribuyen al crecimiento algal y al desarrollo de floraciones de cianobacterias potencialmente tóxicas. 


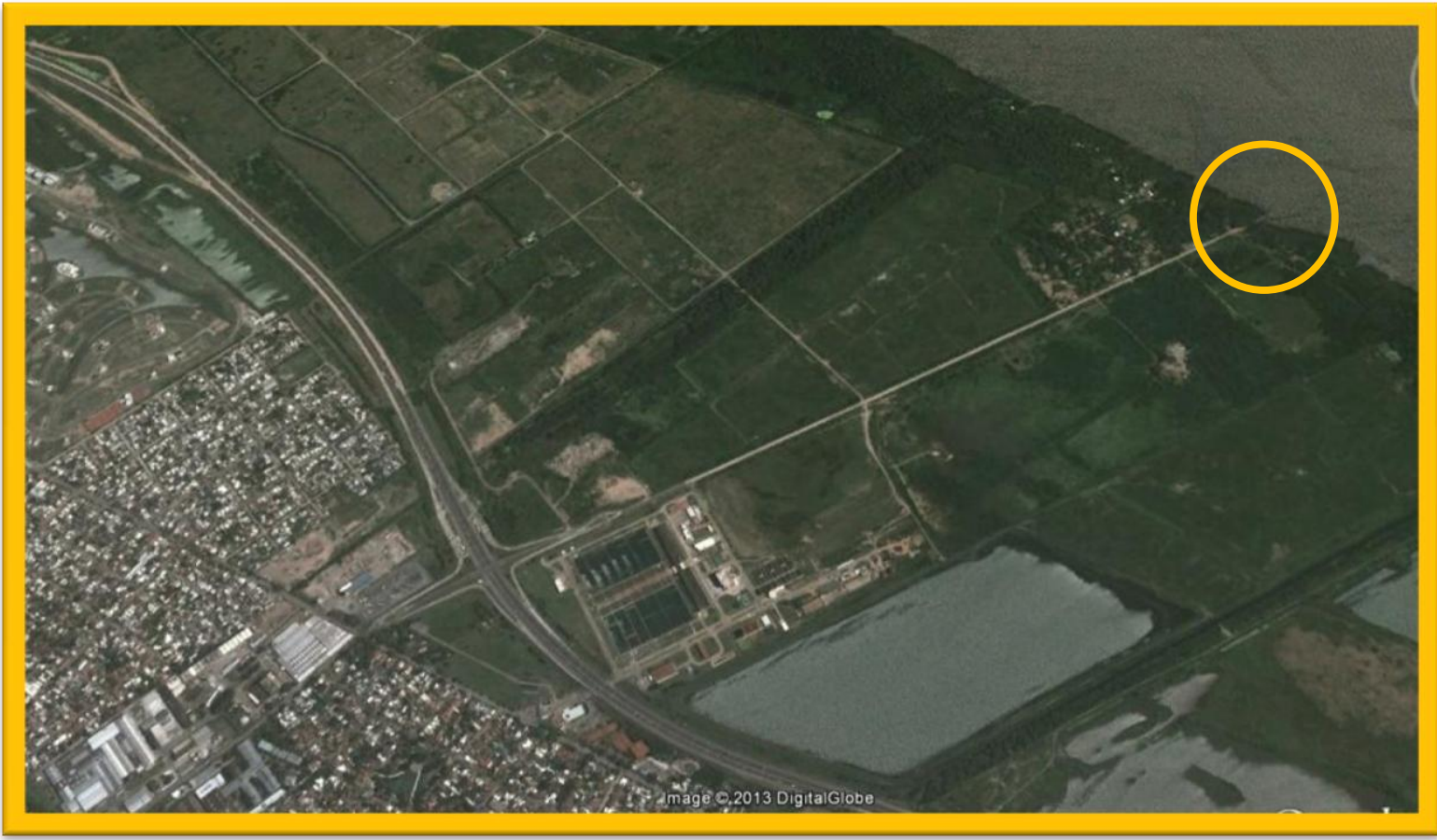

Figura 4. Imagen satelital de Bernal, indicando la ubicación del sitio de muestreo correspondiente. 


\section{Berazategui (BZ)}

Este sitio se localiza en una zona suburbana, con influencia de origen antrópico y actividad industrial moderadas (Fig. 5). Sus costas reciben los desechos de la cloaca máxima de Berazategui, que abastece a más de 12 millones de habitantes de la ciudad de Buenos Aires (Mianzan et al., 2001; Acha et al., 2003) y descarga más de 3 millones $\mathrm{m}^{3}$ día ${ }^{-1}$ de efluentes urbanos e industriales sin ningún tipo de tratamiento. La presencia de basura en la costa forma parte del paisaje cotidiano. Por otra parte, su ribera se halla modificada por rellenos y estructuras construidas a lo largo de la línea de costa (escolleras), interrumpiendo la sucesión espacial de la vegetación. En este sector del estuario se han registrado niveles relativamente elevados de metales pesados (principalmente plomo) en el agua y en el sedimento, que en algunas ocasiones han superado los niveles guía para agua de consumo, alcanzando incluso el orden del miligramo (Lammel et al., 1997; FREPLATA, 2005; INA, 2011). De acuerdo a los resultados obtenidos por Gómez \& Cochero (2013), este sitio presenta una "moderada" calidad del hábitat, evidenciando una modificación en la sucesión espacial de la vegetación ribereña, presencia de residuos en moderada cantidad, ausencia de indicadores de déficit de oxígeno disuelto, y conectividad aceptable entre el ecosistema acuático y terrestre.

De acuerdo con Gómez et al. (2012) este sitio presenta un status de calidad biológica "moderada", caracterizado por presentar concentraciones de nutrientes moderadas que pueden eventualmente favorecer el desarrollo de floraciones algales potencialmente tóxicas. 


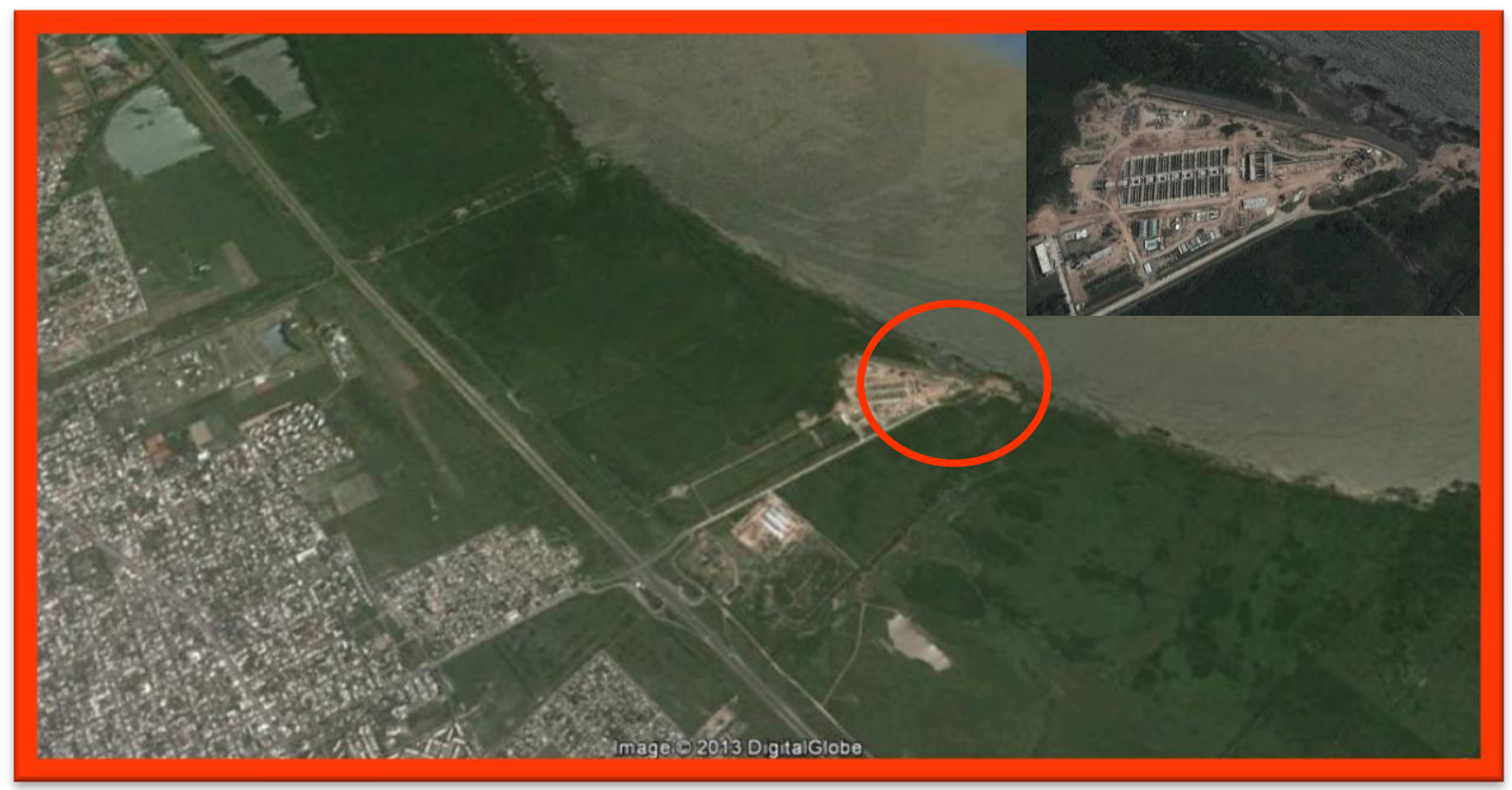

Figura 5. Imagen satelital de Berazategui, indicando la ubicación del sitio de muestreo correspondiente. 


\section{Punta Lara (PL)}

Este sitio se localiza a $5 \mathrm{~km}$ aproximadamente al sur de la reserva natural "Selva Marginal de Punta Lara", en una zona predominantemente rural, donde se practican principalmente ganadería extensiva y actividades recreativas y pesqueras (Fig. 6). Sus costas han sido levemente modificadas por la introducción de infraestructuras, la mayoría de las cuales son temporarias, con fines recreativos. Los niveles de metales pesados registrados en el sedimento son inferiores a los valores estándar de calidad del agua destinada a la conservación y desarrollo de la vida acuática (Lammel et al., 1997; FREPLATA, 2005; INA, 2011). De acuerdo a los resultados obtenidos por Gómez \& Cochero (2013), este sitio presenta una "buena" calidad del hábitat, de manera que la sucesión espacial de los tipos de vegetación ribereña se halla levemente modificada y la ocurrencia de residuos es baja. Asimismo, no se observan indicadores de déficit de oxígeno disuelto, y presenta buena conectividad entre el ecosistema acuático y terrestre. Sin embargo, puede verse afectada por agua de "mala calidad" proveniente de zonas aledañas.

De acuerdo con Gómez et al. (2012) este sitio presenta un estatus biológico "bueno", caracterizado por presentar escasa polución, y un bajo riesgo de desarrollo de floraciones algales potencialmente tóxicas. 


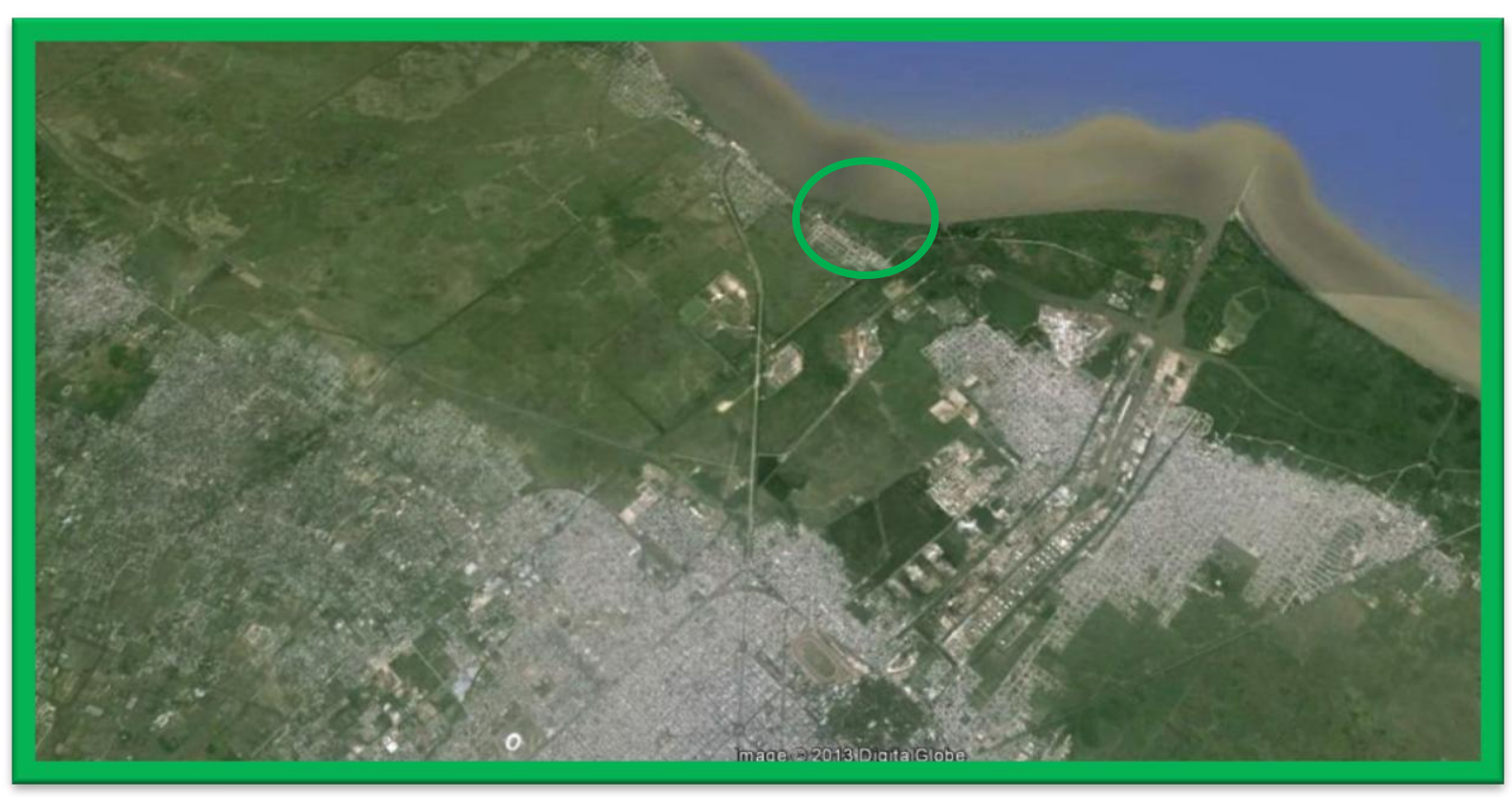

Figura 6. Imagen satelital de Punta Lara, indicando la ubicación del sitio de muestreo correspondiente. 


\section{Balandra (BAL)}

Este sitio se encuentra en una zona rural, con escasa influencia antropogénica y un elevado grado de naturalidad costera, expuesto a actividades recreativas y pesqueras a baja escala (Fig. 7). Sus costas han sido levemente modificadas por la escasa construcción de estructuras temporarias con fines recreativos. De acuerdo a los resultados obtenidos por Gómez \& Cochero (2013), este sitio presenta una "muy buena" calidad del hábitat, sin alteraciones en la sucesión espacial de la vegetación ribereña, ausencia o muy baja ocurrencia de residuos, ausencia de indicadores de déficit de oxígeno disuelto, y muy buena conectividad entre el ecosistema acuático y terrestre.

De acuerdo con Gómez et al. (2012) este sitio presenta un estatus biológico "muy bueno", caracterizado por bajas concentraciones de nutrientes y materia orgánica, y un escaso crecimiento algal.

Debido a todas las características mencionadas, en la presente investigación es considerado como sitio "de referencia".

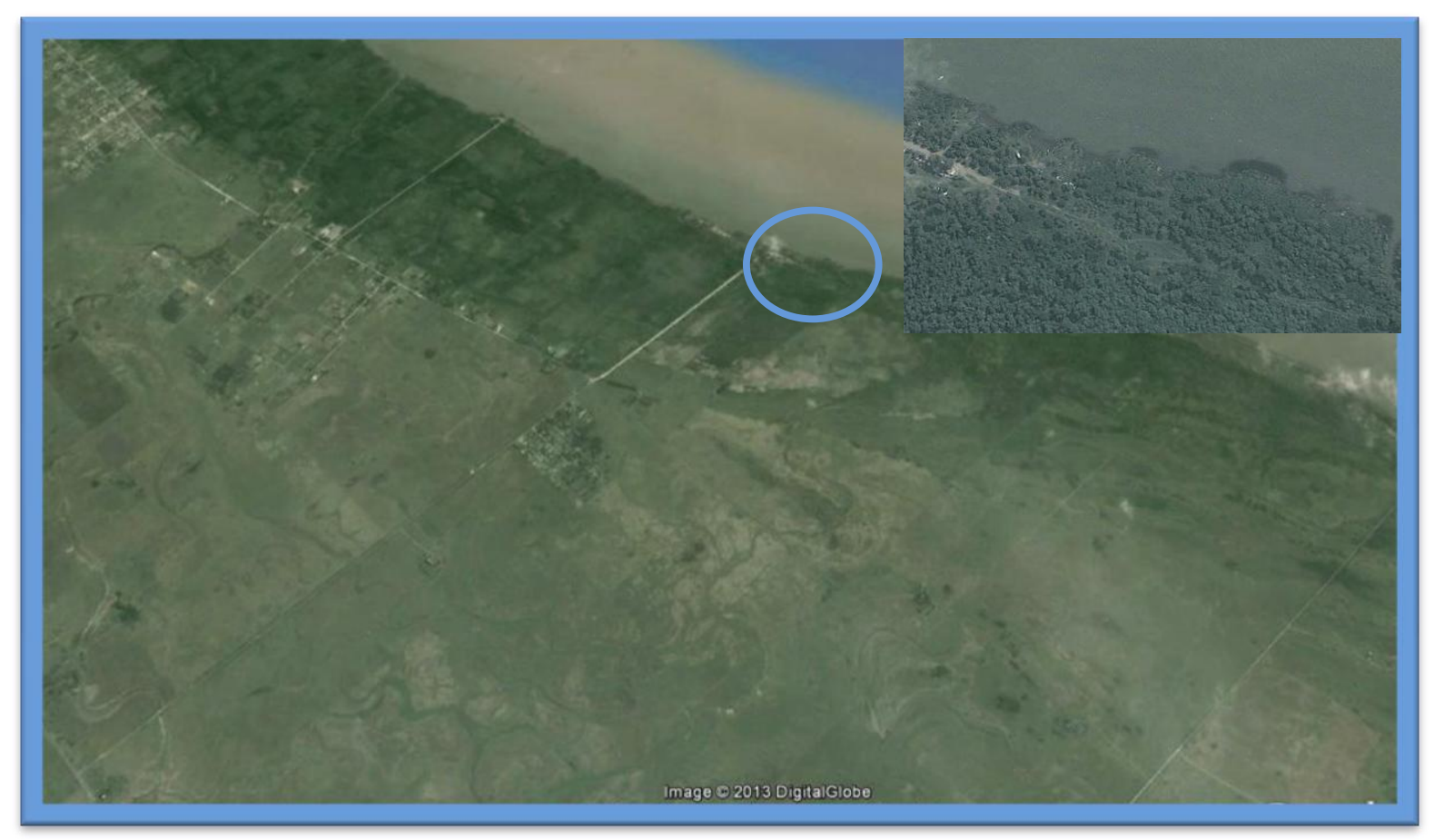

Figura 7. Imagen satelital de Balandra, indicando la ubicación del sitio de muestreo correspondiente. 


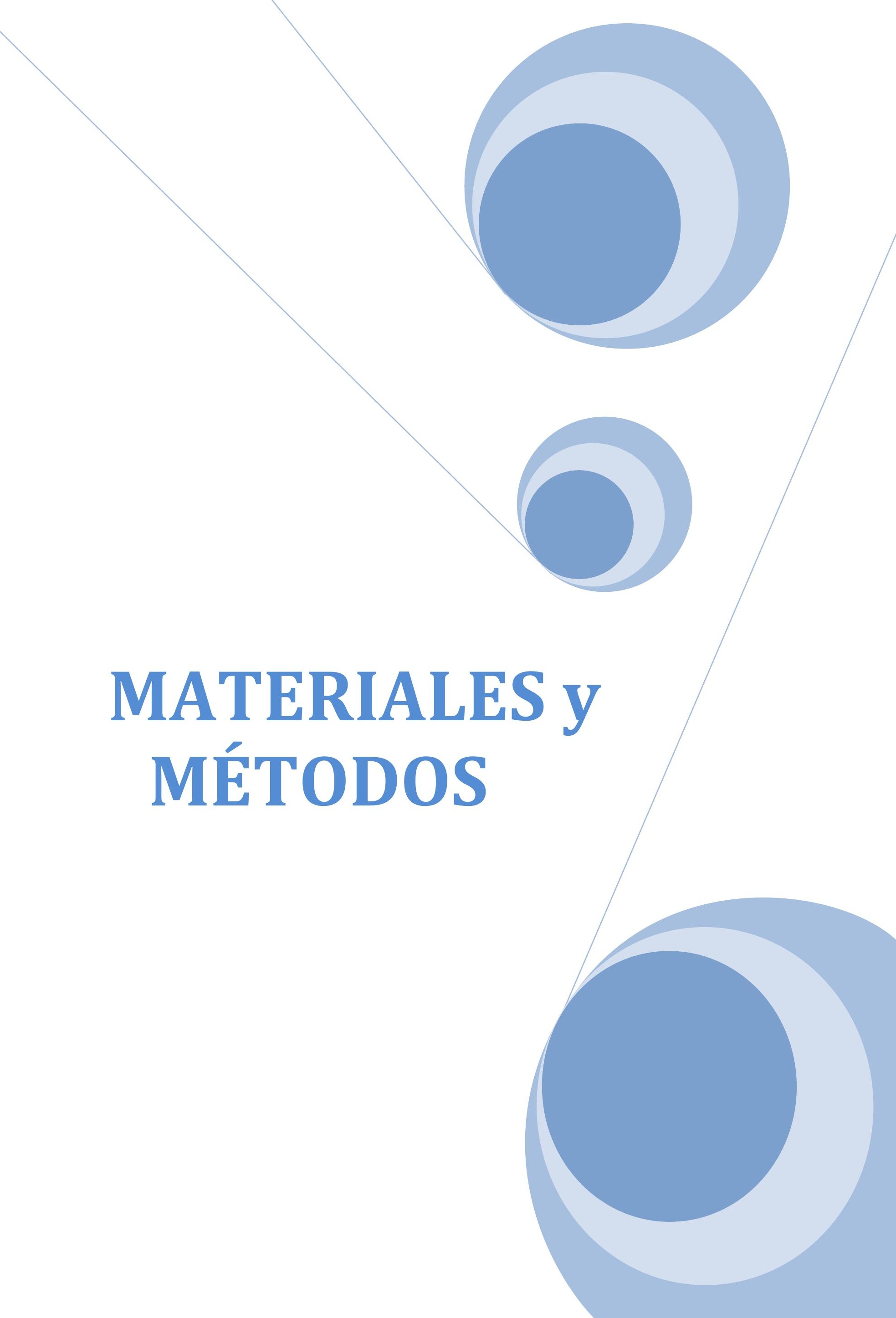




\section{Toma de muestras en el campo:}

Los sitios de muestreo seleccionados fueron georreferenciados y visitados entre noviembre de 2009 y diciembre de 2011, en distintas estaciones del año. Durante el período de estudio se realizaron 5 muestreos extensivos: dos en primavera y uno correspondiente a cada una de las restantes estaciones del año (verano, otoño e invierno), cada uno de los cuales fue llevado a cabo en situación de marea baja, para asegurar la toma de muestras correspondientes al sector intermareal.

En cada sitio se consideraron dos potenciales hábitats funcionales: el "sedimento libre de vegetación" y el "sedimento asociado al junco $S$. californicus", y se consignaron en planillas de campo datos relevantes, tales como la presencia en la ribera de basura, plásticos, estructuras, entre otras.

\section{Muestras biológicas:}

En cada oportunidad se extrajeron por triplicado muestras de sedimento libre de vegetación, empleando para tal fin una draga Ekman (Rodrigues Capítulo et al., 2001), considerando cada unidad muestral (u.m.) de $100 \mathrm{~cm}^{2}$ de superficie. Asimismo, se extrajeron muestras de sedimento asociado al junco $S$. californicus, donde cada u.m. fue tomada con un cuadrado de plexiglás de 50 $\mathrm{cm} \times 50 \mathrm{~cm}$ para extraer con tamices de $500 \mu \mathrm{m}$ los invertebrados asociados a la vegetación costera, como cangrejos, ancílidos, entre otros (Rodrigues Capítulo et al., 2001; Cortelezzi et al., 2007).

El material extraído en cada caso fue fijado in situ con formaldehído al $5 \%(v / v)$ (Barbour et al., 1999) y almacenado en frascos de plástico de 1 litro rotulados debidamente para su posterior procesamiento.

En el laboratorio, las muestras bentónicas fueron lavadas con agua corriente sobre un tamiz de $500 \mu \mathrm{m}$ de apertura de malla (Hauer \& Resh, 2006), con el fin de separar los macroinvertebrados para su análisis. El material 
biológico recolectado fue teñido con Eritrosina B, para facilitar la posterior identificación, separación y recuento de los organismos bajo microscopio estereoscópico (Olympus SZ). En el caso de muestras con elevada cantidad de materia orgánica (MO) y alta densidad de organismos se obtuvieron alícuotas representativas con un fraccionador tipo Folsom (25 ó 50\% según la muestra). El resto de las muestras fueron observadas al 100\% para la separación de organismos.

Para la identificación de los invertebrados, se utilizaron claves correspondientes a cada grupo taxonómico, alcanzando la máxima resolución posible (Ringuelet, 1985; Brinkhurst \& Marchese, 1991; Gullo \& Darrigran, 1991; Lopretto \& Tell, 1995; Fernández \& Domínguez, 2001, y la serie de publicaciones sobre macroinvertebrados perteneciente a Fauna de Agua Dulce de la República Argentina, entre otros). Con el fin de lograr una identificación taxonómica más precisa, se utilizaron técnicas microscópicas específicas para algunos de los grupos considerados. Los especímenes fueron fotografiados utilizando una cámara Olympus E-330 acoplada al microscopio estereoscópico. El material identificado se preservó en alcohol 70\% (v/v) (Barbour et al., 1999). 


\section{Muestras de sedimento para el análisis de la granulometría y la materia orgánica:}

Las muestras de sedimento destinadas al estudio de la granulometría fueron extraídas por triplicado. Se siguió la metodología propuesta por Folk (1974), según la cual el sustrato se clasifica en: grava (>500 $\mu \mathrm{m})$, arena $(62,5-$ $500 \mu \mathrm{m})$, limo $(3,9-62,5 \mu \mathrm{m})$ y arcilla $(<3,9 \mu \mathrm{m})$. Para determinar la proporción de cada tipo de grano se pesaron 20 gramos de sedimento húmedo que se dispusieron en un recipiente donde se agregaron $30 \mathrm{ml}$ de solución dispersante (hexametafosfato de sodio, $1 \mathrm{~g}^{-1}$ ), durante 12-20 horas de agitación periódica. La separación entre el material grueso (arena y grava) y el material fino (limos y arcillas) se realizó mediante el tamizado húmedo con la solución de dispersante descripta. El tamizado se efectuó sobre un embudo de diámetro adecuado, utilizando un tamiz de $500 \mu \mathrm{m}$ de apertura de malla para separar la grava y un tamiz de $62,5 \mu \mathrm{m}$ de apertura de malla para separar la arena. Los sedimentos finos arrastrados por la solución de dispersante se colectaron en una probeta de vidrio graduada. El volumen de solución empleado fue de 1 litro en todos los casos. Para la separación de los sedimentos finos (limo y arcilla) se aplicó el Principio de Stokes ("la velocidad de sedimentación de una partícula es proporcional al cuadrado de su diámetro") mediante el "método de la pipeta", según el cual la probeta que contenía el material fino se agitó vigorosamente hasta homogeneizar la mezcla, extrayéndose a los 20 segundos de finalizada la agitación $20 \mathrm{ml}$ de mezcla, a una profundidad de $20 \mathrm{~cm}$ desde la superficie. Posteriormente, se dejó sedimentar la mezcla durante 2 horas aproximadamente, y se realizó una segunda extracción de $20 \mathrm{ml}$ de mezcla, a una profundidad de $10 \mathrm{~cm}$ desde la superficie. Cada fracción fue colocada en estufa a $60^{\circ} \mathrm{C}$ durante 48 horas hasta alcanzar un peso constante, y posteriormente pesada utilizando una balanza analítica de alta precisión. 


\section{Método de estimación de MOPG y MOPF:}

Para evaluar la cantidad de materia orgánica particulada gruesa (MOPG) y materia orgánica particulada fina (MOPF), las muestras de sedimento extraídas por triplicado para tal fin fueron procesadas de manera que los fragmentos orgánicos fueron separados mediante tamices de 500 y $60 \mu \mathrm{m}$, quedando entonces una fracción de 60-500 $\mu \mathrm{m}$ (correspondiente a la MOPF) y otra mayor de $500 \mu \mathrm{m}$ (correspondiente a la MOPG). Ambas fracciones fueron secadas en estufa a $60^{\circ} \mathrm{C}$, durante 48 horas, hasta obtener un peso constante y posteriormente colocadas en mufla a $500^{\circ} \mathrm{C}$ durante 4 horas. Ambas fracciones fueron pesadas utilizando una balanza analítica de alta precisión.

\section{Parámetros físico-químicos del agua:}

Con el fin de conocer posibles diferencias entre los mesohábitats estudiados, se midieron in situ diversas variables físico-químicas del agua: $\mathrm{pH}$, conductividad, turbidez, oxígeno disuelto y temperatura. Para ello se utilizó un sensor multiparamétrico HORIBA U-10. Los datos fueron registrados por triplicado y consignados debidamente en planillas de campo.

\section{Muestras de agua:}

Para el análisis del contenido de nutrientes y demandas de oxígeno, en cada oportunidad muestreada se colectaron por triplicado muestras de agua en botellas plásticas de $250 \mathrm{ml}$ para el análisis de nutrientes de nitrógeno (amonio: $\mathrm{NH}_{4}{ }^{+}$, nitrito: $\mathrm{NO}_{2}{ }^{-}$, y nitrato: $\mathrm{NO}_{3}{ }^{-}$) y fósforo $\left(\mathrm{PO}_{4}{ }^{-3}\right)$, y de $500 \mathrm{ml}$ para el análisis de las demandas bioquímica y química del oxígeno $\left(\mathrm{DBO}_{5}\right.$ y $\mathrm{DQO}$, respectivamente) (APHA, 1998). Estas muestras fueron transportadas refrigeradas y en oscuridad hasta el laboratorio, donde se procesaron en forma inmediata. Para eliminar los sólidos en suspensión en las muestras destinadas al análisis de nutrientes, se utilizaron filtros de fibra de vidrio (Whatman GF/C) 
previamente muflados y pesados. La determinación de las concentraciones de fosfato, nitrato y amonio se realizó a través del método colorimétrico (Mackereth et al., 1978). Previo a la medición colorimétrica, el nitrato fue reducido a nitrito. $\mathrm{La} \mathrm{DBO}_{5}$ fue determinada luego de 5 días de incubación a $20^{\circ} \mathrm{C}$, mientras que la DQO fue determinada por oxidación con dicromato de potasio en medio ácido (APHA, 1998).

\section{Grupos funcionales alimentarios (GFA):}

Para la asignación de grupos funcionales alimentarios, se escogieron los grupos de macroinvertebrados más representativos (según su biomasa y/o densidad) presentes en los sitios de muestreo estudiados. Se seleccionaron así dos taxa diferentes: crustáceos (anfípodos: Hyalella curvispina) y moluscos (bivalvos: Corbicula fluminea). La metodología adoptada consistió en el análisis de la primera porción del tubo digestivo (análisis de la dieta). Para tal fin, en cada fecha de muestreo se colectaron en forma complementaria individuos de los taxa seleccionados utilizando tamices de $500 \mu \mathrm{m}$.

\section{Metodología para el análisis del contenido del tubo digestivo:}

Los ejemplares colectados fueron refrigerados (para evitar la regurgitación) y transportados hasta el laboratorio, donde se procedió a su fijación mediante formaldehido 5\% (v/v) (Muñoz et al., 2009; López van Oosterom et al., 2013; Ocon et al., 2013).

Hyalella curvispina: se separó un mínimo de 10 ejemplares adultos (machos y hembras), para cada uno de los cuales se midió el largo total bajo microscopio estereoscópico empleando un ocular micrométrico (Fig. 8a).

Corbicula fluminea: se separó un mínimo de 10 ejemplares, para cada uno de los cuales se midió la altura máxima de la valva, empleando un calibre digital (Fig. 8b). 


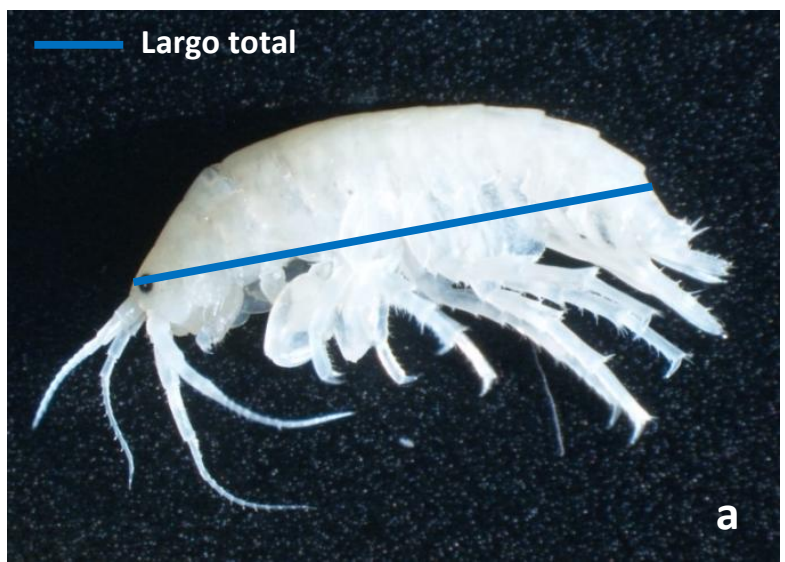

Altura máxima

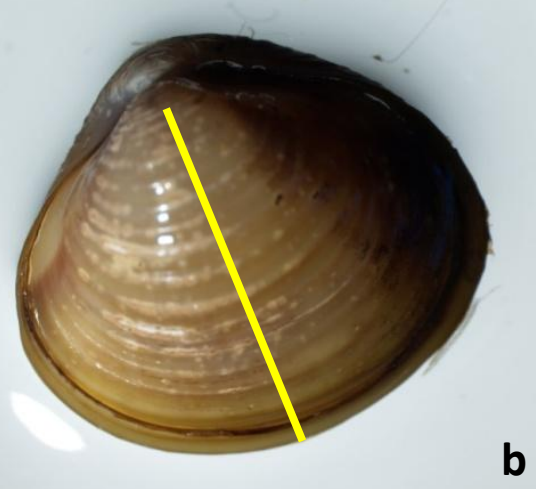

Figura 8. Medidas corporales tomadas en cada ejemplar de a: Hyalella curvispina, b: Corbicula fluminea.

El tracto digestivo de cada individuo fue extraído mediante su disección bajo microscopio estereoscópico, procurando que el contenido recogido pertenezca a la zona más próxima a la boca (Closs \& Lake, 1994; Jaarsma et al., 1998). Para facilitar la identificación del material ingerido, el contenido del tubo digestivo de cada individuo fue centrifugado, para separarlo del resto del material, y teñido con colorante Rosa de Bengala durante 24 horas. El material teñido fue examinado bajo microscopio óptico, seleccionándose aleatoriamente un número representativo de campos (15 campos) (López van Oosterom et al., 2013; Ocon et al., 2013) utilizando aumentos entre 100X y 400X. En cada campo se calculó el área cubierta por cada ítem alimentario, mediante fotografías con cámara digital Olympus acoplada al microscopio óptico (una fotografía por campo). Los ítems consumidos fueron clasificados en detrito (materia orgánica no identificable), restos vegetales/algas filamentosas, diatomeas, euglenofitas/protozoos, restos animales y material mineral (Fig. 9). El tamaño de las partículas consumidas fue estimado usando el software Image-Pro Plus 6.0 que permite estimar el área cubierta por cada ítem en cada fotografía. La cuantificación de cada ítem ingerido se expresó como la frecuencia relativa respecto del total del contenido digestivo analizado 
(Winterbourn et al., 1984; Jaarsma et al., 1998; Díaz Villanueva \& Albariño, 1999).
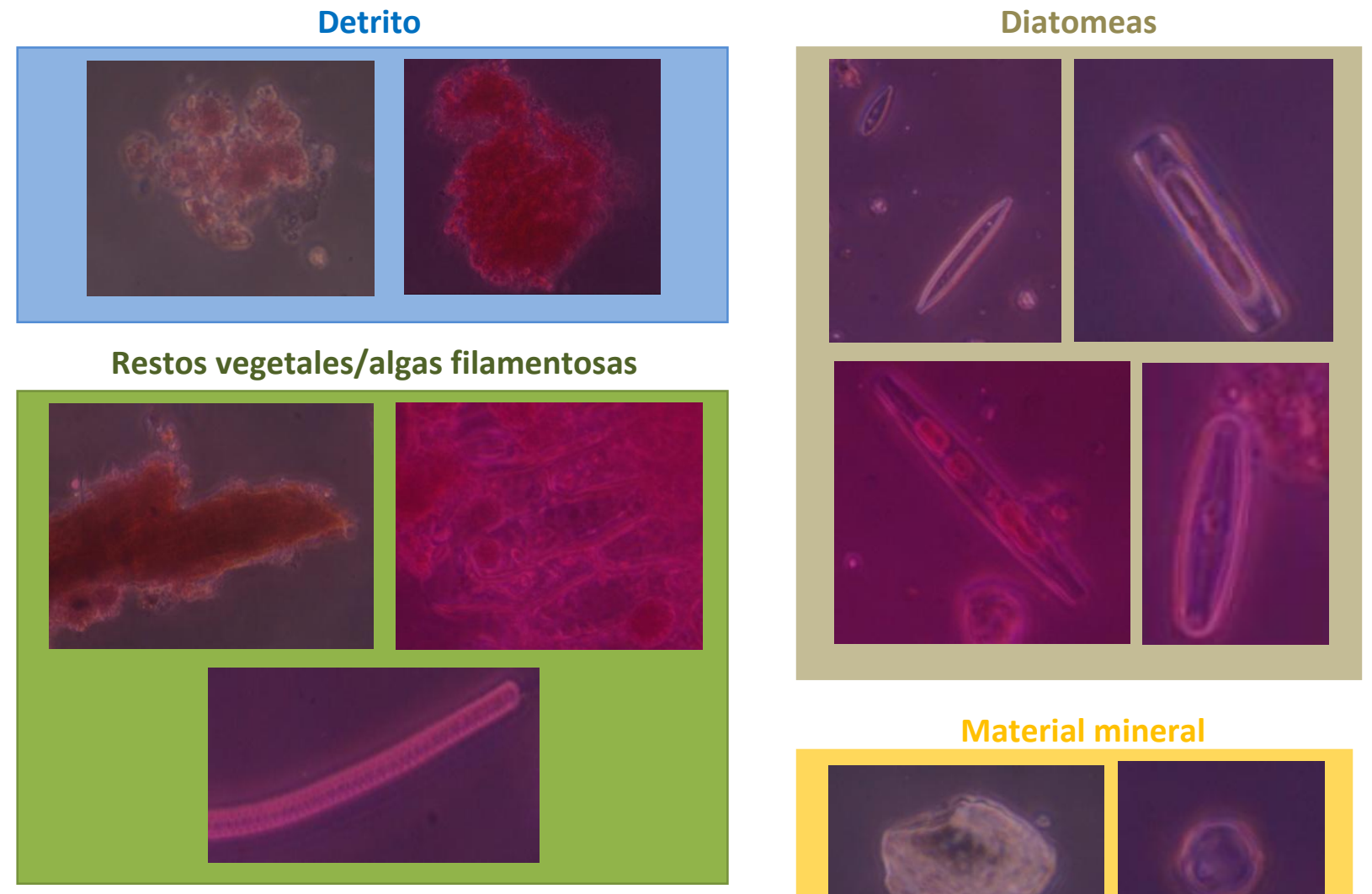

\section{Material mineral}
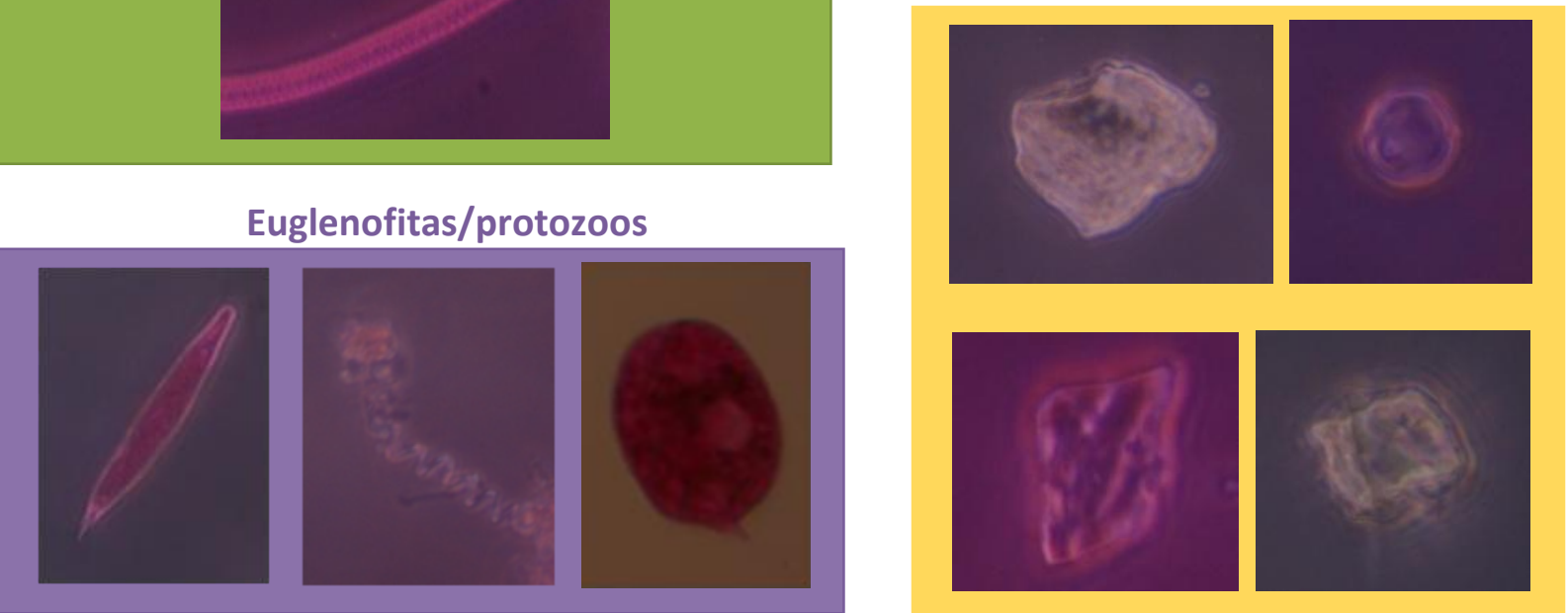

Restos animales

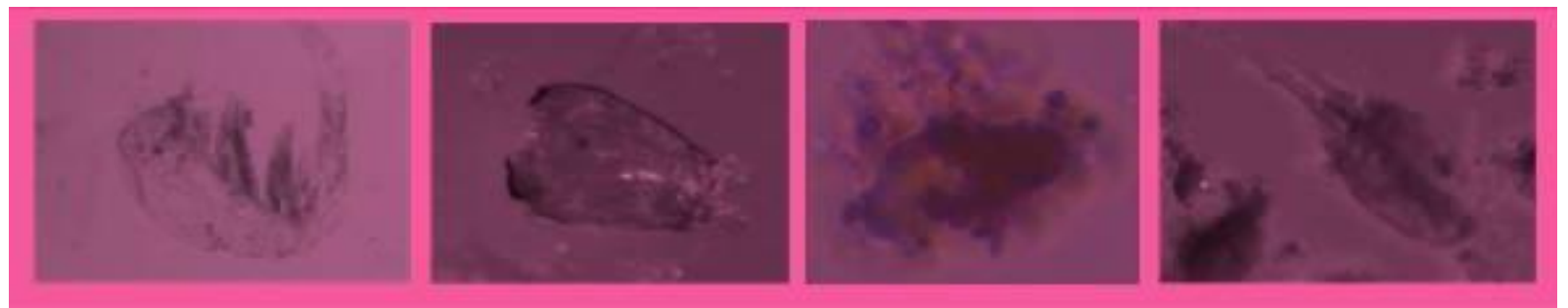

Figura 9. Fotografías de los ítems alimentarios definidos en el análisis de los contenidos digestivos. Las imágenes fueron tomadas con aumento de $400 \mathrm{X}$ y ampliadas para su visualización. 
Finalmente, se procedió a la clasificación de las especies analizadas en el grupo funcional alimentario correspondiente, según el ítem alimentario dominante (> 60\% del contenido digestivo), y se compararon los resultados obtenidos con las clasificaciones preexistentes.

Los invertebrados bentónicos cuyos contenidos digestivos no fueron analizados en la presente investigación, fueron asignados a grupos funcionales alimentarios (GFAs), de acuerdo a clasificaciones previamente establecidas por Merritt et al. (2008), Bonetto \& Wais (1995), Heino (2005), Cummins et al. (2005) y Tangorra (2004). En este sentido, se definieron las siguientes categorías: (1) fragmentadores (individuos masticadores de tejidos vegetales y materia orgánica particulada gruesa: MOPG $>1 \mathrm{~mm}$, la cual convierten en materia orgánica particulada fina: MOPF <1 mm); (2) colectores-recolectores (organismos consumidores de MOPF del sedimento correspondiente a pequeñas partículas de detrito); (3) colectores-filtradores (organismos consumidores de MOPF obtenida por filtración de pequeñas partículas suspendidas); (4) raspadores (invertebrados con adaptaciones para pastoreo de superficies minerales y orgánicas, tales como materia orgánica muerta, algas, y bacterias); (5) depredadores (organismos que capturan presas vivas e ingieren animales completos o partes de ellos) (ANEXO, Tabla A). El porcentaje de cada categoría fue calculado a partir de la abundancia de cada grupo (ind $\mathrm{m}^{-}$ $\left.{ }^{2}\right)$.

\section{Análisis de los datos de los contenidos digestivos}

A partir de los datos de los contenidos digestivos de las especies seleccionadas, se analizaron las estrategias alimentarias de las mismas mediante el método gráfico de Costello, modificado por Amundsen et al. (1996). Este método permite obtener información sobre la estrategia alimentaria de una especie mediante la representación gráfica de la 
abundancia de un determinado ítem alimentario ( $\mathrm{Pi}$ ) en función de la frecuencia de ocurrencia del mismo.

La abundancia, en porcentaje, de cada ítem alimentario (Pi) fue calculada según la siguiente ecuación:

$$
\mathrm{P}_{\mathrm{i}}=\frac{\sum \mathrm{S}_{\mathrm{i}}}{\sum \mathrm{St}_{\mathrm{i}}} \times 100
$$

donde:

$\sum \mathrm{S}_{\mathrm{i}}$ : contenido de un ítem alimentario i dentro de todos los tubos digestivos. $\sum \mathrm{St}_{\mathrm{i}}$ :contenido total de los tubos digestivos donde el ítem i fue encontrado.

La frecuencia de ocurrencia $\left(\mathrm{FO}_{\mathrm{i}}\right)$ fue obtenida a partir de la siguiente ecuación:

$$
F O i=\frac{N i}{N} \times 100
$$

donde:

$\mathrm{N}_{\mathrm{i}}$ : número de individuos donde se encontró el ítem alimentario i.

$\mathrm{N}$ : número total de individuos con contenido estomacal. 
Análisis estequiométrico $(\mathrm{C}, \mathrm{N}, \mathrm{P})$ e isótopos estables $\delta^{13} \mathrm{C}$ y $\delta^{15} \mathrm{~N}$ :

Para complementar la información brindada por el estudio de los contenidos digestivos y establecer la dieta (en términos de asimilación de nutrientes), se analizó el contenido de $\mathrm{C}, \mathrm{N}, \mathrm{P}$ e isótopos estables $\left(\delta^{13} \mathrm{C}\right.$ y $\left.\delta^{15} \mathrm{~N}\right)$ de los macroinvertebrados predominantes en cada sitio de muestreo. La metodología empleada consistió en la colección en campo de los individuos seleccionados (en número dependiente de su biomasa: al menos 10 para anfípodos y 5 para moluscos), los cuales fueron transportados refrigerados al laboratorio y mantenidos en recipientes independientes con agua del río filtrada durante 12 a 24 horas, para asegurar la evacuación de los contenidos del tracto digestivo. Posteriormente, los ejemplares fueron secados en estufa a 60 ㄷ C durante 48 horas hasta alcanzar un peso constante, y triturados para obtener una fracción homogénea (Muñoz et. al., 2009). Cabe destacar que en el caso de los bivalvos, las valvas fueron extraídas previamente, y sólo se analizaron los tejidos blandos.

El material seco y molido fue pesado utilizando una balanza analítica Ohaus $(0,0001 \mathrm{mg})$, y colocado en viales previamente a la implementación de técnicas analíticas.

Determinación del contenido de $C, N$ e isótopos estables $\left(\delta^{13} \mathrm{C}\right.$ y $\left.\delta^{15} N\right)$ :

Para la determinación del contenido de $\mathrm{C}, \mathrm{N}$ e isótopos estables $\left(\delta^{13} \mathrm{C}\right.$ y $\left.\delta^{15} \mathrm{~N}\right)$, se pesaron entre 3-4 miligramos de material seco y molido, el cual fue posteriormente analizado mediante un analizador elemental acoplado a un espectrofotómetro de masa. Las determinaciones fueron llevadas a cabo por el Centro de Aplicaciones de Tecnología Nuclear en Agricultura Sostenible (CATNAS) - Montevideo, Uruguay.

La composición isotópica fue cuantificada a través del uso de materiales de referencia estándar internacionales (Pee Dee Belemnita para carbono y $\mathrm{N}_{2}$ 
atmosférico para nitrógeno). Las relaciones ${ }^{13} \mathrm{C} /{ }^{12} \mathrm{C}$ y ${ }^{15} \mathrm{~N} /{ }^{14} \mathrm{~N}$ fueron expresadas como las diferencias relativas en partes por mil entre la muestra y el estándar convencional.

\section{Análisis de P:}

La cantidad de $\mathrm{P}$ total fue determinada mediante colorimetría (APHA, 1998) a partir de un peso conocido de muestra (7-10 miligramos), que fue digerido con una solución básica (Grasshoff et al., 1983). Estas determinaciones fueron llevadas a cabo por personal técnico del Laboratorio de Química del Instituto de Limnología "Dr. Raúl A. Ringuelet".

A partir de los resultados obtenidos se realizó el cálculo de las relaciones estequiométricas C:N, C:P y N:P molares. Los resultados obtenidos del análisis de isótopos estables $\left(\delta^{13} \mathrm{C}\right.$ y $\left.\delta^{15} \mathrm{~N}\right)$ fueron comparados entre sitios perturbados y sitios poco impactados para analizar posibles diferencias debidas a la calidad del agua.

\section{Organismos sensibles y tolerantes:}

Con el fin de evaluar la predominancia de organismos sensibles, tolerantes y muy tolerantes en los sitios analizados, se realizó una estimación de la proporción en que fueron registrados los tres grupos. Para establecer la categoría correspondiente a cada taxa se consideraron los valores de sensibilidad ecológica $\left(V_{x}\right)$ propuestos por Rodrigues Capítulo (1999) y se utilizó bibliografía específica (Barbour et al., 1999; Hilsenhoff, 1987; Bode et al., 1997, 2002; Ocon \& Rodrigues Capítulo, 2004; Ocon et al., 2008) (ANEXO, Tabla B). 


\section{Cálculo de parámetros e índices:}

- Riqueza de taxa (S; Margalef, 1955):

Debido a que los diversos organismos encontrados en el área estudiada han sido identificados hasta niveles taxonómicos diferentes (alcanzando en algunos casos la categoría de especie), el índice de riqueza se consideró en el presente estudio como "riqueza de taxa", definida como el número total de taxa registrados en un determinado ambiente.

- Diversidad de Shannon-Wiener ( $H^{\prime}$; Shannon \& Weaver, 1949):

Este índice se estimó de acuerdo con la siguiente fórmula:

$$
\mathrm{H}^{\prime}=-\sum_{\mathrm{i}=1}^{\mathrm{S}} p_{\mathrm{i}} \ln p_{\mathrm{i}}
$$

donde $\mathrm{S}$ es el número de taxa (riqueza de taxa) y $p_{\mathrm{i}}$ es la proporción de individuos del taxón i respecto del total de individuos (abundancia relativa del taxón i).

- Equitabilidad (J'; Pielou, 1975):

Este índice se calculó según la siguiente fórmula:

$$
\mathrm{J}^{\prime}=\mathrm{H}^{\prime} / \log _{2} \mathrm{~S}
$$

siendo $\mathrm{S}$ la riqueza de taxa y $\mathrm{H}^{\prime}$ la diversidad de Shannon-Wiener. 


\section{Índices Bióticos:}

Para evaluar la calidad ecológica de los sitios estudiados se aplicó el IMRP (Indice de Macroinvertebrados de Ríos Pampeanos) (Rodrigues Capítulo et al., 1997; Rodrigues Capítulo, 1999), el cual está basado en la sumatoria de los valores de sensibilidad ecológica $\left(V_{x}\right)$ mencionados anteriormente (ANEXO, Tabla C). Este índice varía de 0 a infinito, correspondiendo los valores más bajos a ambientes altamente perturbados (Tabla 3). Debido a que el índice se calcula en función de la presencia de los taxa, se integraron los datos de ambos hábitats con el fin de establecer el estado general de cada uno de los sitios de muestreo estudiados.

$$
\operatorname{IMRP}=\sum_{\mathrm{x}=1}^{\mathrm{n}} \mathrm{V}_{\mathrm{x}}
$$

Tabla 3. Índice de Macroinvertebrados de Ríos Pampeanos (IMRP): Rango de valores y definición de cada categoría. Los colores indican el código establecido para la representación gráfica.

\begin{tabular}{cl}
\hline IMRP & Definición \\
\hline $0-1$ & Contaminación muy fuerte \\
$1,1-2,5$ & Contaminación fuerte \\
$2,6-3,9$ & Contaminación moderada \\
$4-7,9$ & Contaminación débil \\
$8-12$ & Contaminación escasa \\
$>12,1$ & Contaminación muy leve a nula \\
\hline
\end{tabular}




\section{Modos de vida:}

Para la determinación de los modos de vida de los invertebrados analizados se utilizó bibliografía específica (Merritt \& Cummins, 1996; Heino, 2005), a partir de los cuales los taxa fueron clasificados en las siguientes categorías: aferrados, trepadores, minadores, apoyados, planctónicos, patinadores, nadadores subacuáticos y nadadores (ANEXO, Tabla A). La definición de cada categoría se resume en la Tabla 4.

Tabla 4. Modos de vida: categorías, definiciones y ejemplos.

\begin{tabular}{|c|c|c|}
\hline Modos de vida* & Definición & Ejemplos \\
\hline Aferrados & $\begin{array}{l}\text { Poseen adaptaciones comportamentales o } \\
\text { morfológicas para aferrarse a superficies. }\end{array}$ & ancílidos, hirudíneos \\
\hline Trepadores & $\begin{array}{l}\text { Viven sobre hidrófitas o restos moviéndose } \\
\text { verticalmente sobre la superficie vertical del tallo. }\end{array}$ & $\begin{array}{l}\text { gasterópodos (Pomacea, } \\
\text { planórbidos, Physa) }\end{array}$ \\
\hline Minadores & $\begin{array}{l}\text { Habitan sobre sedimento fino y pueden construir } \\
\text { madrigueras y tubos. }\end{array}$ & $\begin{array}{l}\text { quironómidos, bivalvos, } \\
\text { oligoquetos tubificinos, dípteros }\end{array}$ \\
\hline Apoyados & $\begin{array}{l}\text { Habitan la superficie de hojas flotantes de } \\
\text { hidrófitas o sedimentos finos. }\end{array}$ & $\begin{array}{l}\text { oligoquetos naidinos, } \\
\text { planarias, colémbolos }\end{array}$ \\
\hline Planctónicos & Viven en la columna de agua. & culícidos \\
\hline Patinadores & $\begin{array}{l}\text { Viven sobre la superficie del agua en las márgenes } \\
\text { del río. }\end{array}$ & $\begin{array}{l}\text { colémbolos smintúridos, } \\
\text { arácnidos }\end{array}$ \\
\hline $\begin{array}{l}\text { Nadadores } \\
\text { subacuáticos }\end{array}$ & $\begin{array}{l}\text { Nadan remando con patas posteriores adaptadas, } \\
\text { asociados a ambientes de baja corriente. }\end{array}$ & coríxidos \\
\hline Nadadores & $\begin{array}{l}\text { Adaptados para períodos cortos de natación } \\
\text { entre los objetos del bentos. }\end{array}$ & anfípodos \\
\hline
\end{tabular}

*Tomado de Merritt \& Cummins (1996), modificado por Heino (2005). 


\section{Análisis estadístico:}

Con la finalidad de explorar los principales gradientes ambientales dentro del área estudiada se realizó un Análisis de Componentes Principales (PCA), el cual permitió un ordenamiento de los sitios de estudio en función de sus características ambientales. Para asegurar que todas las variables utilizadas tuvieran el mismo peso en el análisis (Pla, 1986), los datos ambientales fueron previamente estandarizados $[Z=(X-\mu) / \sigma]$. Este análisis fue realizado con el programa STATISTICA for Windows (6.0 Stat Soft, Inc., 2001). Los componentes principales (PCs) con eigenvalores > 1 fueron retenidos. Con el fin de revelar aquellas variables que correlacionaron fuertemente con los ejes definidos del PCA, se llevó a cabo una rotación "varimax" normalizada de los mismos (Singh et al., 2004). El nuevo grupo de variables extraídas a través de la rotación se definen como varifactores (VFs). De acuerdo con Liu et al. (2003), los "factor loadings" fueron clasificados de acuerdo a sus valores absolutos como: "fuerte" $(>0,75)$, "moderado" $(0,75-0,5)$ y “débil" $(0,5-0,3)$.

Con el fin de conocer si las variables ambientales presentaron diferencias significativas temporales, espaciales y entre hábitats se utilizó el Análisis Multivariado de la Varianza (MANOVA). Para analizar los factores "tiempo" y "hábitat" se realizó un MANOVA factorial de dos vías, utilizando como datos de entrada los valores medidos por triplicado en los cuatro sitios de muestreo en cada campaña y en cada hábitat. Para analizar el factor "sitio", se realizó un MANOVA de una vía, considerando en este caso todos los valores medidos en cada sitio de muestreo durante el período estudiado. Estos análisis fueron realizados mediante el programa STATISTICA for Windows (6.0 Stat Soft, Inc., 2001), aplicando en cada caso el test de Wilks ( $p<0,05)$. Debido a que el MANOVA es un método paramétrico que asume que los datos tienen homogeneidad de varianzas y tienden a una distribución normal, aquellos datos que no siguieron una distribución normal fueron previamente 
transformados usando " $\log _{10}(X+1)$ ". En todos los casos en que se hallaron diferencias significativas se aplicó el test a posteriori Newman-Keuls (Underwood, 2007).

Con la finalidad de conocer si existieron diferencias significativas temporales, espaciales y entre hábitats en el porcentaje de materia orgánica

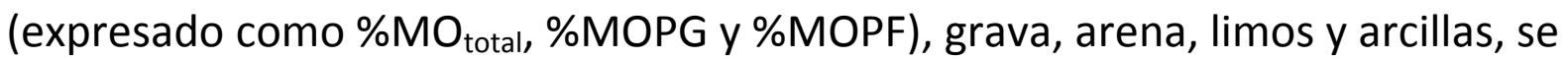
Ilevó a cabo un Análisis de la Varianza (ANOVA de tres vías, $p<0,05$ ), y se realizó un test a posteriori (test de Student-Newman-Keuls, $p<0,05$ ) para evaluar las diferencias encontradas. Estos análisis fueron realizados con el programa SigmaStat 3.5.

Con el fin de evaluar la interacción hábitat-biota y detectar diferencias temporales, espaciales y entre hábitats para los índices riqueza, diversidad y equitabilidad mencionados, se realizaron ANOVAs de tres vías y se aplicaron los correspondientes tests a posteriori. El mismo procedimiento fue utilizado para establecer posibles diferencias de densidad de los principales grupos taxonómicos (Nematoda, Oligochaeta, Mollusca, Crustacea y Diptera). Asimismo, se evaluó la diferencia entre sitios de muestreo a partir del análisis de la sensibilidad de los organismos encontrados, los grupos funcionales alimentarios y los modos de vida predominantes. Se analizaron posibles diferencias temporales y entre los hábitats estudiados.

En todos los casos en que se hallaron diferencias significativas en el Análisis de la Varianza realizado, se aplicó el test a posteriori Student-NewmanKeulds (Underwood, 2007). Para cumplir con los supuestos de normalidad y homosedasticidad, cuando resultara necesario los datos fueron transformados previamente.

En los casos de los análisis estadísticos donde el valor de $p$ obtenido sea $<0,05$, el resultado se expresará como significativo y cuando el valor sea de $p$ $<0,001$ se referirá como altamente significativo. 


\section{Análisis directo de gradientes:}

Con el fin de establecer las relaciones existentes entre los sitios, las principales variables abióticas y la composición de macroinvertebrados, se realizó un primer análisis exploratorio para determinar si la respuesta de los organismos en cada hábitat podía ser interpretada con técnicas de análisis lineal o unimodal. Para ello se llevó a cabo un Análisis de Correspondencia Destendenciado (DCA) a partir de los datos de densidad de la biota. Debido a que la máxima longitud de gradiente en unidades de desviación estándar obtenido en este análisis fue $<2$, se asumió un modelo de respuesta lineal para los taxa y se llevó a cabo un Análisis de Redundancia (RDA) a partir de los datos de abundancias y variables ambientales. Los datos de densidad fueron transformados previamente usando "In( $\mathrm{X}+1)$ ", mientras que las variables ambientales fueron estandarizadas. Aquellas variables abióticas que presentaron un factor de incremento de la varianza $>10$ fueron excluidas de este análisis, dado que de acuerdo a ter Braak \& Smilauer (1999) un valor mayor estaría indicando colinearidad entre las variables. La significación de los ejes extraídos del RDA fue evaluada mediante la Prueba de Monte Carlo (499 permutaciones, modelo reducido, $p<0,05)$. Los dos primeros ejes fueron seleccionados para graficar el ordenamiento de las variables ambientales, junto con los sitios de muestreo y los taxones (triplot). Las variables abióticas se representan como flechas y la longitud de la flecha y su cercanía a los ejes representa un mayor grado de correlación.

Estos análisis se realizaron utilizando el programa CANOCO for Windows versión 4.02 (ter Braak, 1998). 


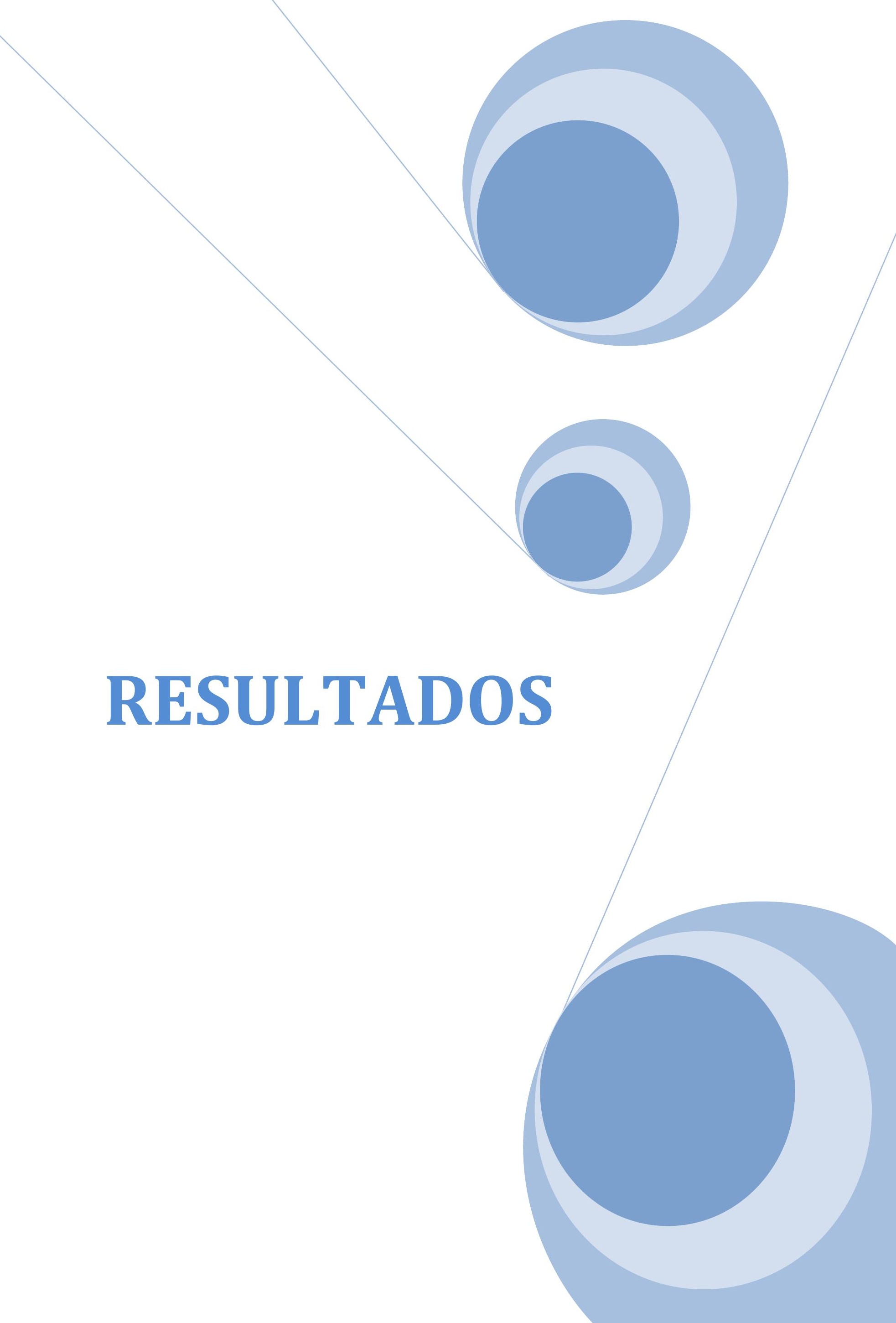




\section{Parámetros físico-químicos}

Un primer análisis exploratorio, realizado a través de un PCA (Análisis de Componentes Principales), permitió un ordenamiento de los sitios de muestreo en función de sus características físico-químicas (Fig. 10). El primer factor explicó el $31,3 \%$ de la varianza total y estuvo correlacionado $(r>0,70)$ con la conductividad y los nutrientes. El segundo factor representó el $23,5 \%$ de la varianza total, y estuvo correlacionado con la DBO y la DQO, y en menor medida con el porcentaje de saturación de oxígeno disuelto $(r:-0,69)$. El tercer factor explicó el $14 \%$ de la varianza total, correlacionado con los valores de $\mathrm{pH}$ ( $\mathrm{r}$ : 0,67). El factor 4 explicó el 9,6\% de la varianza total y se correlacionó con la turbidez $(r>0,80)$. Los restantes PCs no correlacionaron con ninguno de los parámetros.

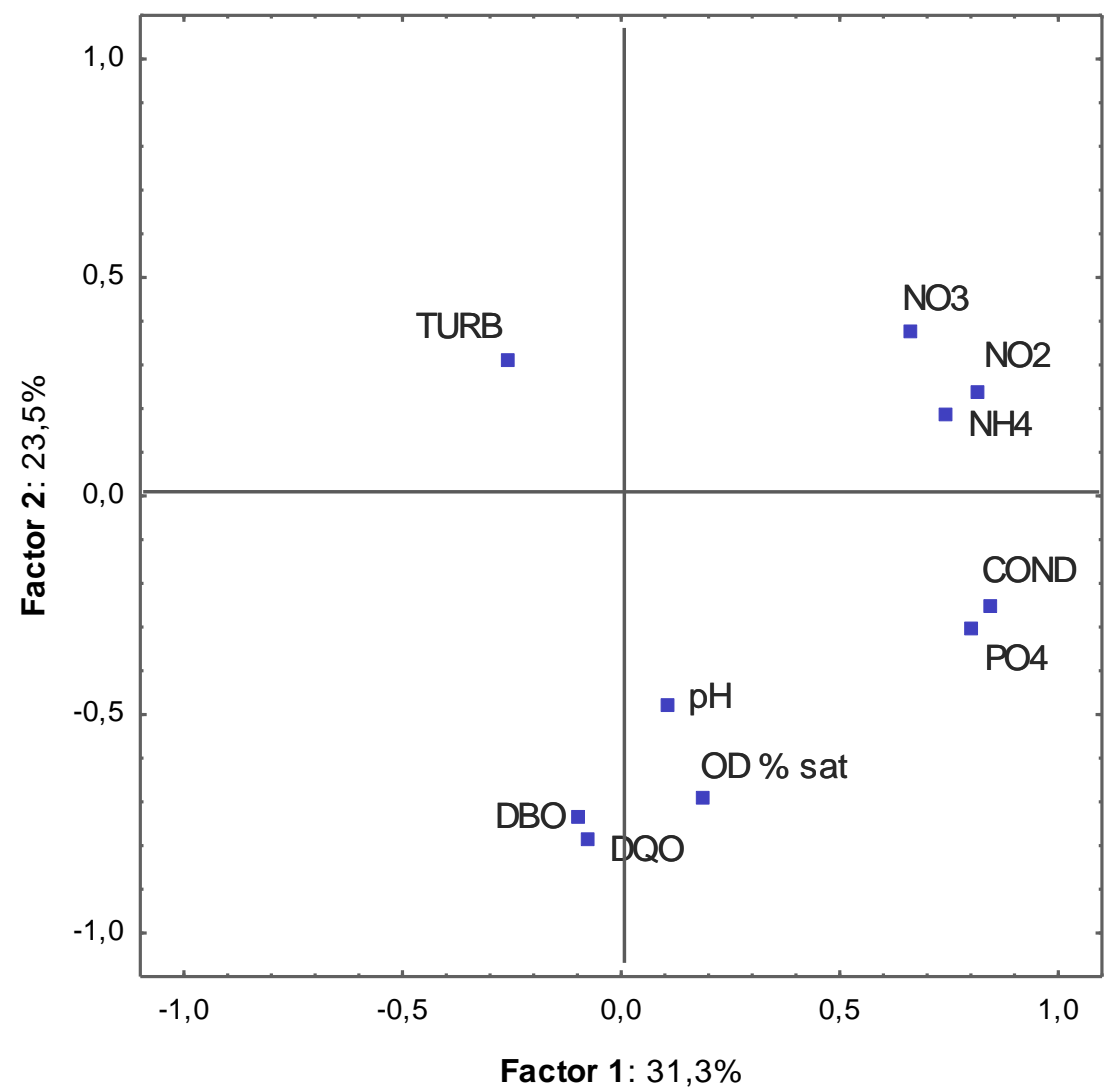

Figura 10. Representación de los dos primeros ejes del Análisis de Componentes Principales (PCA) mostrando el ordenamiento de las variables físico-químicas medidas en los sitios de muestreo durante el período de estudio. 
A partir de la representación de los dos primeros factores del PCA que muestra el ordenamiento de las variables ambientales y la disposición de los sitios de muestreo en base a sus características físico-químicas (Fig. 11), se observa que los sitios PL y BAL (sedimento y vegetación) se asociaron con altos valores de turbidez y mejores condiciones generales en la calidad del agua; mientras que los sitios BZ y BE (sedimento y vegetación) se asociaron con altos niveles de conductividad, nutrientes y demandas de oxígeno.

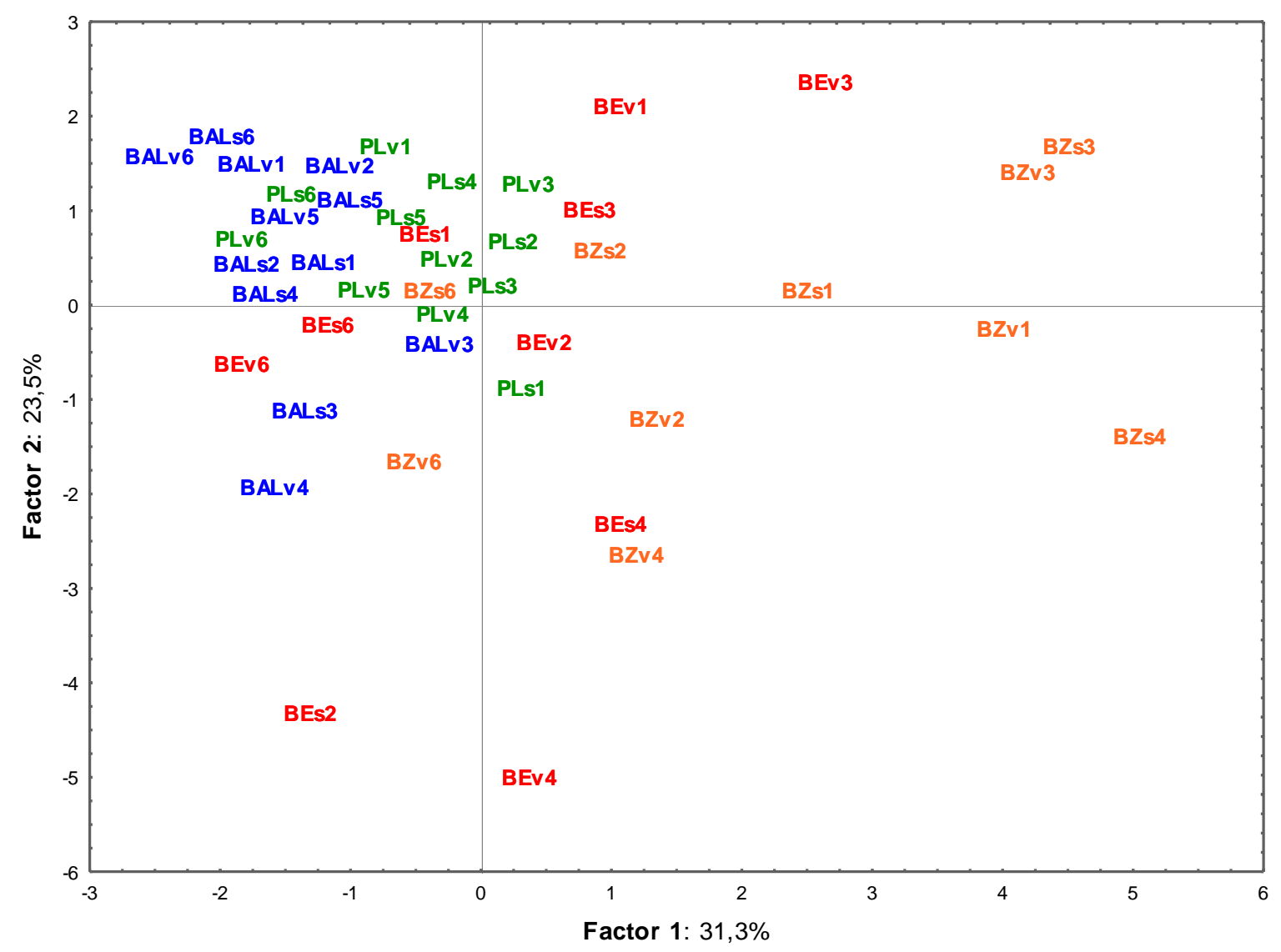

Figura 11. Representación de los dos primeros ejes del Análisis de Componentes Principales mostrando el ordenamiento de los sitios de muestreo en base a las variables físico-químicas medidas en los mismos durante el período estudio. s: "sedimento libre de vegetación"; v: "sedimento asociado a la vegetación". Los números representan fechas de muestreo (1: primavera 2009, 2: otoño 2010, 3: invierno 2010, 4: verano 2010, 5: otoño 2011, 6: primavera 2011). 
A partir de los resultados obtenidos del PCA, los cuatro primeros PCs fueron retenidos (eigenvalue $>1$ ). La rotación normalizada (varimax) de estos ejes produjo un nuevo set de factores (cada uno designado como "Varifactor") que explicaron el $78,4 \%$ de la varianza total. Este análisis permitió identificar aquellos parámetros que contribuyen a las variaciones en la calidad del agua del sistema estudiado (Tabla 5). El VF1, que explicó el 30\% de la varianza total, estuvo fuertemente asociado (factor loading $>0,75$ ) con la conductividad, fosfato, amonio y nitrito, y moderadamente con la concentración de nitrato. El VF2, que explicó el 20,2\% de la varianza total, presentó una fuerte relación con las demandas de oxígeno. El VF3 (17,2\% de la varianza total) presentó una fuerte correlación con los niveles de pH y porcentaje de saturación de OD. EI VF4, que explicó el 11,1\% de la varianza total estuvo fuertemente asociado con los valores de turbidez.

Tabla 5. "Factor loadings" de las variables ambientales en los cuatro primeros ejes rotados (VFs) del PCA. En negrita se indican los valores de correlación "fuerte" y en cursiva los de correlación "moderada".

\begin{tabular}{lcccc}
\hline & VF1 & VF2 & VF3 & VF4 \\
\hline Conductividad & $\mathbf{0 , 8 4 7}$ & 0,104 & 0,281 & 0,046 \\
Turbidez & $-0,075$ & $-0,073$ & $-0,136$ & $-0,949$ \\
pH & $-0,021$ & $-0,044$ & $\mathbf{0 , 8 6 7}$ & 0,023 \\
OD \% saturación & 0,080 & 0,201 & $\mathbf{0 , 8 5 3}$ & 0,136 \\
PO4 & $\mathbf{0 , 8 1 3}$ & 0,196 & 0,251 & 0,045 \\
NO3 & 0,560 & $-0,504$ & $-0,066$ & 0,314 \\
NO2 & $\mathbf{0 , 8 1 2}$ & $-0,241$ & $-0,101$ & 0,074 \\
NH4 & $\mathbf{0 , 7 9 9}$ & $-0,045$ & $-0,235$ & $-0,028$ \\
DBO & 0,029 & $\mathbf{0 , 9 0 2}$ & 0,071 & $-0,088$ \\
DQO & $-0,013$ & $\mathbf{0 , 8 9 2}$ & 0,065 & 0,262 \\
\hline \hline Varianza expl. & $30 \%$ & $20,2 \%$ & $17,2 \%$ & $11,1 \%$ \\
\hline
\end{tabular}

Los valores promedio registrados en cada sitio de muestreo para las variables ambientales analizadas se resumen en las Tablas 6 (hábitat "sedimento libre de vegetación") y 7 (hábitat "sedimento asociado a vegetación"). La 
comparación de los sitios de muestreo mediante Análisis Multivariados de la Varianza (MANOVAs) y tests a posteriori (Student-Newman-Keuls) determinaron diferencias significativas temporales, espaciales y entre hábitats para algunos de los sitios y parámetros físico-químicos estudiados. Los resultados obtenidos mostraron que el efecto "temporal" fue altamente significativo $(p<0,001)$ para todas las variables analizadas; mientras que el factor "hábitat" fue significativo para turbidez, porcentaje de saturación de OD y DBO, y altamente significativo para DQO (Tabla 8). El efecto "espacial" (sitios) fue altamente significativo en la mayoría de las variables analizadas, excepto el pH y la turbidez (Tabla 9).

En términos generales, el pH fluctuó de ligeramente alcalino a muy alcalino en todos los sitios y oportunidades muestreadas, no encontrándose diferencias significativas entre los hábitats estudiados.

La temperatura fue muy similar en todos los sitios de muestreo, encontrándose diferencias significativas temporales (variabilidad debida a los muestreos estacionales a lo largo del año). Por otra parte, se encontraron diferencias significativas entre los hábitats estudiados, registrándose temperaturas superiores en las áreas vegetadas respecto de las zonas libres de vegetación.

La conductividad mostró diferencias significativas espaciales y temporales. Si bien se registraron valores elevados en los sitios más cercanos a la desembocadura del estuario (PL y BAL), los valores más elevados de este parámetro correspondieron a BZ.

La turbidez mostró diferencias significativas temporales y entre hábitats. Los mayores valores de este parámetro se registraron en primavera y verano, y en el agua libre de vegetación. Si bien no se registraron diferencias significativas espaciales, como era de esperarse de acuerdo a la dinámica propia del estuario en todas las ocasiones muestreadas los valores más altos de este parámetro correspondieron a BAL. Este sitio se ubica en la parte más externa del estuario, y 
por lo tanto, más próximo al frente de máxima turbidez cercano al límite entre el sector de agua dulce y la porción marina de este estuario.

El oxígeno disuelto ( $\mathrm{mg} \mathrm{l}^{-1} \mathrm{y}$ expresado como \% de saturación) mostró diferencias significativas temporales, espaciales y entre hábitats. Los valores más elevados registrados para este parámetro correspondieron a los meses más fríos del año, y a las zonas vegetadas. En general, en los sitios poco impactados se registraron los niveles más altos de este parámetro. Sin embargo, en algunas ocasiones también se midieron niveles elevados en los sitios más perturbados, especialmente BZ, coincidiendo en este último caso con la presencia de floraciones algales (observación directa).

Si bien no se encontraron diferencias significativas entre hábitats en relación a los nutrientes, en algunos casos se hallaron diferencias temporales y espaciales, que se detallarán a continuación. Tanto el $\mathrm{PO}_{4}$, como el $\mathrm{NO}_{3}, \mathrm{NO}_{2} \mathrm{y}$ $\mathrm{NH}_{4}$ mostraron diferencias significativas temporales y espaciales. Las mayores concentraciones de dichos parámetros se registraron en los meses más fríos del año, y en los sitios más impactados (BE y BZ). En general, BZ presentó los niveles más altos de aquellos nutrientes, mientras que las concentraciones más bajas correspondieron a BAL.

Tanto la DBO como la DQO mostraron diferencias significativas temporales, registrándose las mayores concentraciones de estos parámetros en los meses más cálidos. Asimismo, se encontraron diferencias significativas espaciales y entre hábitats, donde los valores más elevados de ambos parámetros correspondieron en general a BE y BZ. 
Tabla 8. Valores de $p$ del MANOVA factorial de dos vías realizado teniendo en cuenta los factores "tiempo", "hábitat" y su "interacción".

\begin{tabular}{lccc}
\hline & Tiempo & Hábitat & Tiempo*Hábitat \\
& $p$ & $p$ & $p$ \\
\hline Conductividad & $<0,001$ & 0,105 & 0,882 \\
Turbidez & $<0,001$ & 0,003 & 0,034 \\
pH & 0,011 & 0,408 & 0,044 \\
T $^{\circ}$ & $<0,001$ & 0,009 & 0,996 \\
OD mg/l & 0,004 & 0,090 & 0,769 \\
OD \% saturación & 0,008 & 0,016 & 0,736 \\
PO4 & $<0,001$ & 0,374 & 0,419 \\
NO3 & 0,024 & 0,160 & $<0,001$ \\
NO2 & $<0,001$ & 0,787 & 0,002 \\
NH4 & $<0,001$ & 0,865 & 0,059 \\
DBO & $<0,001$ & 0,014 & 0,125 \\
DQO & $<0,001$ & $<0,001$ & 0,001 \\
\hline
\end{tabular}

Tabla 9. Valores de p del MANOVA de una vía realizado teniendo en cuenta el factor "sitio".

\begin{tabular}{lc}
\hline & Sitio \\
& $p$ \\
\hline Conductividad & $<0,001$ \\
Turbidez & 0,065 \\
pH & 0,060 \\
$T^{\circ}$ & 0,009 \\
OD mg/l & 0,368 \\
OD \% saturación & 0,022 \\
PO4 & $<0,001$ \\
NO3 & $<0,001$ \\
NO2 & $<0,001$ \\
NH4 & $<0,001$ \\
DBO & $<0,001$ \\
DQO & $<0,001$ \\
\hline
\end{tabular}


Tabla 6. Valores promedio de los parámetros físico-químicos registrados en el "sedimento libre de vegetación" en los sitios de muestreo estudiados. Valores mínimo y máximo se indican entre paréntesis.

\begin{tabular}{|c|c|c|c|c|c|c|c|c|c|c|c|c|}
\hline Sitio & $\begin{array}{c}\text { Conductividad } \\
\mu \mathrm{S} \mathrm{cm}-1\end{array}$ & $\begin{array}{l}\text { Turbidez } \\
\text { NTU }\end{array}$ & pH & $\begin{array}{c}\text { Temperatura } \\
{ }^{\circ} \mathrm{C}\end{array}$ & $\begin{array}{c}\text { OD } \\
\mathrm{mg} \mathrm{l-1}\end{array}$ & $\begin{array}{c}\text { OD } \\
\text { \% Saturación }\end{array}$ & $\begin{array}{l}\text { P-PO4 } \\
\text { mg l-1 }\end{array}$ & $\begin{array}{l}\mathrm{N}-\mathrm{NO} 3 \\
\mathrm{mg} \mathrm{l-1}\end{array}$ & $\begin{array}{l}\mathrm{N}-\mathrm{NO} 2 \\
\mathrm{mg} \mathrm{l-1}\end{array}$ & $\begin{array}{l}\mathrm{N}-\mathrm{NH} 4 \\
\mathrm{mg} \mathrm{l-1}\end{array}$ & $\begin{array}{l}\text { DBO } \\
\mathrm{mg} \mathrm{l-1}\end{array}$ & $\begin{array}{l}\text { DQO } \\
\mathrm{mg} \mathrm{l-1}\end{array}$ \\
\hline $\mathrm{BE}$ & $\begin{array}{c}491 \\
(364-651)\end{array}$ & $\begin{array}{c}98 \\
(24-199)\end{array}$ & $\begin{array}{c}8,6 \\
(7,8-9,9)\end{array}$ & $\begin{array}{c}28,7 \\
(21,2-37,7)\end{array}$ & $\begin{array}{c}9,3 \\
(5,8-14)\end{array}$ & $\begin{array}{c}124 \\
(65-210)\end{array}$ & $\begin{array}{c}0,314 \\
(0,02-0,67)\end{array}$ & $\begin{array}{c}0,565 \\
(0,01-1,8)\end{array}$ & $\begin{array}{c}0,054 \\
(0,002-0,1)\end{array}$ & $\begin{array}{c}0,104 \\
(0,02-0,35)\end{array}$ & $\begin{array}{c}44 \\
(15-154)\end{array}$ & $\begin{array}{c}73 \\
(32-181)\end{array}$ \\
\hline BZ & $\begin{array}{c}971 \\
(477-1720)\end{array}$ & $\begin{array}{c}94 \\
(42-180)\end{array}$ & $\begin{array}{c}8,5 \\
(8-9,2)\end{array}$ & $\begin{array}{c}28,9 \\
(21,4-36,8)\end{array}$ & $\begin{array}{c}9,7 \\
(7,6-12,3)\end{array}$ & $\begin{array}{c}127 \\
(87-176)\end{array}$ & $\begin{array}{c}0,744 \\
(0,05-1,33)\end{array}$ & $\begin{array}{c}1,084 \\
(0,12-1,63)\end{array}$ & $\begin{array}{c}0,128 \\
(0,014-0,25)\end{array}$ & $\begin{array}{c}1,033 \\
(0,03-4,05)\end{array}$ & $\begin{array}{c}19 \\
(5-29)\end{array}$ & $\begin{array}{c}46 \\
(29-80)\end{array}$ \\
\hline BAL & $\begin{array}{c}355 \\
(228-607)\end{array}$ & $\begin{array}{c}209 \\
(28-683)\end{array}$ & $\begin{array}{c}8,4 \\
(7,6-9,4)\end{array}$ & $\begin{array}{c}22,2 \\
(9,5-30,2)\end{array}$ & $\begin{array}{c}10,1 \\
(7,5-17,3)\end{array}$ & $\begin{array}{c}113 \\
(89-179)\end{array}$ & $\begin{array}{c}0,118 \\
(0,01-0,25)\end{array}$ & $\begin{array}{c}0,316 \\
(0,03-0,49)\end{array}$ & $\begin{array}{c}0,01 \\
(0,002-0,03)\end{array}$ & $\begin{array}{c}0,18 \\
(0,04-0,63)\end{array}$ & $\begin{array}{c}10 \\
(1-19)\end{array}$ & $\begin{array}{c}42 \\
(24-71)\end{array}$ \\
\hline
\end{tabular}

Tabla 7. Valores promedio de los parámetros físico-químicos registrados en el "sedimento asociado a la vegetación" en los sitios de muestreo estudiados. Valores mínimo y máximo se indican entre paréntesis.

\begin{tabular}{|c|c|c|c|c|c|c|c|c|c|c|c|c|}
\hline Sitio & $\begin{array}{c}\text { Conductividad } \\
\mu \mathrm{S} \mathrm{cm-1}\end{array}$ & $\begin{array}{c}\text { Turbidez } \\
\text { NTU }\end{array}$ & pH & $\begin{array}{l}\text { Temperatura } \\
{ }^{\circ} \mathrm{C}\end{array}$ & $\begin{array}{l}\text { OD } \\
\mathrm{mg} \mathrm{l}-1\end{array}$ & $\begin{array}{c}\text { OD } \\
\text { \% Saturación }\end{array}$ & $\begin{array}{l}\text { P-PO4 } \\
\text { mg l-1 }\end{array}$ & $\begin{array}{l}\mathrm{N}-\mathrm{NO} 3 \\
\mathrm{mg} \mathrm{l-1}\end{array}$ & $\begin{array}{l}\mathrm{N}-\mathrm{NO} 2 \\
\mathrm{mg} \mathrm{l-1}\end{array}$ & $\begin{array}{l}\mathrm{N}-\mathrm{NH} 4 \\
\mathrm{mg} \mathrm{l-1}\end{array}$ & $\begin{array}{l}\text { DBO } \\
\text { mg l-1 }\end{array}$ & $\begin{array}{l}\text { DQO } \\
\text { mg l-1 }\end{array}$ \\
\hline BE & $\begin{array}{c}464 \\
(373-747)\end{array}$ & $\begin{array}{c}90 \\
(28-232)\end{array}$ & $\begin{array}{c}8,7 \\
(8,1-9,8)\end{array}$ & $\begin{array}{c}31,3 \\
(23,8-38,3)\end{array}$ & $\begin{array}{c}9,7 \\
(7,1-13,3)\end{array}$ & $\begin{array}{c}132 \\
(105-199)\end{array}$ & $\begin{array}{c}0,348 \\
(0,03-0,65)\end{array}$ & $\begin{array}{c}0,97 \\
(0,28-1,63)\end{array}$ & $\begin{array}{c}0,111 \\
(0,003-0,31)\end{array}$ & $\begin{array}{c}0,241 \\
(0,003-0,73)\end{array}$ & $\begin{array}{c}14 \\
(5-39)\end{array}$ & $\begin{array}{c}38 \\
(17-95)\end{array}$ \\
\hline BZ & $\begin{array}{c}1554 \\
(636-2935)\end{array}$ & $\begin{array}{c}67 \\
(20-157)\end{array}$ & $\begin{array}{c}8,8 \\
(7,9-9,3)\end{array}$ & $\begin{array}{c}31,7 \\
(24,9-37,4)\end{array}$ & $\begin{array}{c}11,1 \\
(8,5-13,9)\end{array}$ & $\begin{array}{c}153 \\
(119-188)\end{array}$ & $\begin{array}{c}0,447 \\
(0,05-0,8)\end{array}$ & $\begin{array}{c}0,886 \\
(0,35-1,33)\end{array}$ & $\begin{array}{c}0,086 \\
(0,009-0,23)\end{array}$ & $\begin{array}{c}0,707 \\
(0,006-2,32)\end{array}$ & $\begin{array}{c}13 \\
(3-25)\end{array}$ & $\begin{array}{c}38 \\
(18-64)\end{array}$ \\
\hline BAL & $\begin{array}{c}414 \\
(220-680)\end{array}$ & $\begin{array}{c}206 \\
(24-697)\end{array}$ & $\begin{array}{c}8,1 \\
(7,5-9,5)\end{array}$ & $\begin{array}{c}23,3 \\
(11,9-33,1)\end{array}$ & $\begin{array}{c}9,5 \\
(6,5-16,8)\end{array}$ & $\begin{array}{c}109 \\
(80-175)\end{array}$ & $\begin{array}{c}0,116 \\
(0,01-0,23)\end{array}$ & $\begin{array}{c}0,462 \\
(0,23-0,77)\end{array}$ & $\begin{array}{c}0,012 \\
(0,001-0,03)\end{array}$ & $\begin{array}{c}0,119 \\
(0,002-0,34)\end{array}$ & $\begin{array}{c}10 \\
(4-21)\end{array}$ & $\begin{array}{c}24 \\
(11-41)\end{array}$ \\
\hline
\end{tabular}




\section{Análisis de la Materia Orgánica}

Los valores promedio (y desviaciones estándar) del porcentaje de materia orgánica total registrados en los sitios y hábitats estudiados se resumen en la figura 12. El ANOVA de tres vías aplicado a los datos de materia orgánica reveló diferencias significativas entre sitios de muestreo y entre hábitats, no encontrándose diferencias significativas temporales (Tabla 10). Según los resultados obtenidos por el test a posteriori, el "sedimento asociado a la vegetación" se diferenció del "sedimento libre de vegetación" por presentar mayor porcentaje de materia orgánica. Por otra parte, los sitios más impactados se diferenciaron de los restantes por presentar mayores porcentajes de materia orgánica en sus sedimentos, destacándose BE por evidenciar los valores más elevados.

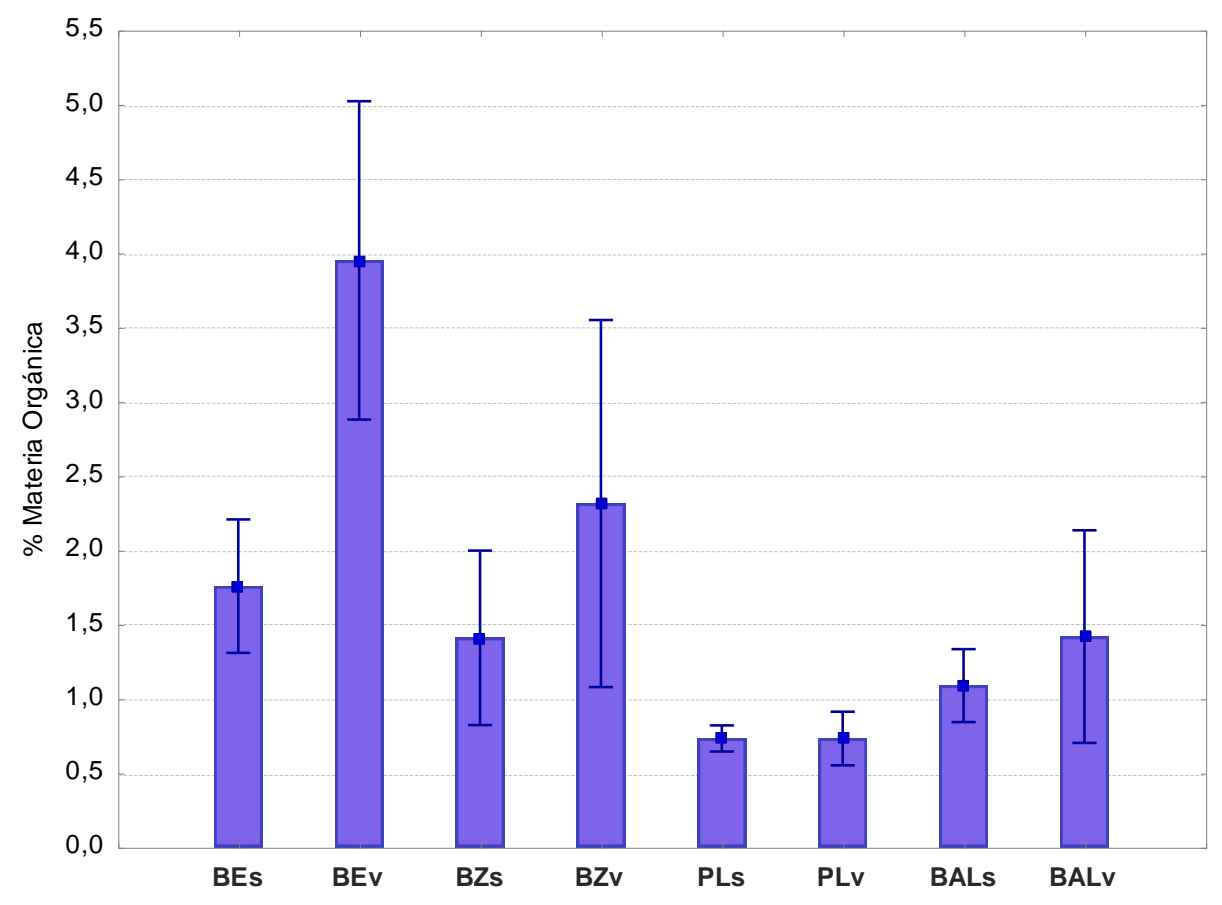

Figura 12. Promedio y desvío estándar del porcentaje de la materia orgánica en los sitios de muestreo analizados. s: "sedimento libre de vegetación"; v: "sedimento asociado a la vegetación". 
En relación al contenido de las fracciones de materia orgánica estudiadas (MOPG y MOPF), el ANOVA de tres vías realizado para analizar los factores "tiempo", "sitio" y "hábitat" no mostró diferencias significativas temporales para ambas fracciones, pero sí se encontraron diferencias significativas entre los sitios y hábitats estudiados (Tabla 10). Los mayores porcentajes promedio de MOPG se registraron en el "sedimento asociado a la vegetación", especialmente en los sitios BZ, PL y BAL, mientras que en el "sedimento libre de vegetación" se registraron los más altos porcentajes promedio de MOPF (Fig. 13).

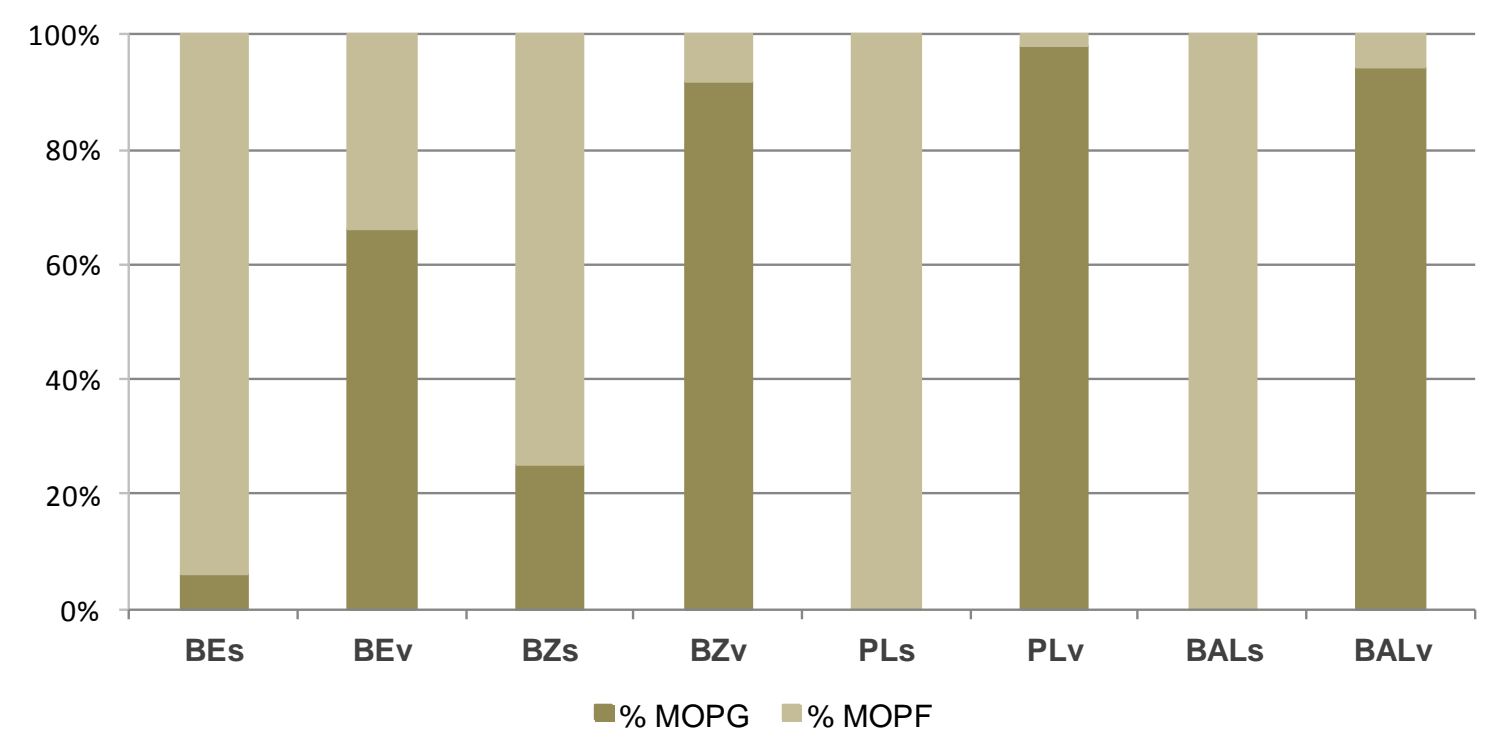

Figura 13. Porcentaje promedio de las fracciones de MO (MOPG y MOPF) en los sitios de muestreo analizados. s: "sedimento libre de vegetación"; v: "sedimento asociado a la vegetación".

Tabla 10. Valores de $p$ del ANOVA de tres vías realizado para el contenido de materia orgánica total (MO) y sus fracciones (MOPG y MOPF).

\begin{tabular}{lccc}
\hline & Tiempo & Sitio & Hábitat \\
& $p$ & $p$ & $p$ \\
\hline \% MO & 0,433 & $<0,001$ & 0,012 \\
\% MOPG & 0,299 & 0,002 & $<0,001$ \\
\% MOPF & 0,436 & $<0,001$ & 0,021 \\
\hline
\end{tabular}




\section{Análisis de la Granulometría}

De acuerdo al análisis granulométrico (Tabla 11) el sedimento fue principalmente arenoso en todos los sitios de muestreo y hábitats analizados. Si bien no se encontraron diferencias significativas temporales en las distintas fracciones de grano, el ANOVA de tres vías realizado reveló diferencias significativas entre sitios y entre hábitats en el porcentaje de grava y arena (Tabla 12). Según demostró el test a posteriori, BE se diferenció de los restantes sitios por tener los porcentajes de grava más elevados y a su vez, los porcentajes de arena más bajos. Por su parte, el "sedimento asociado a la vegetación" se diferenció significativamente de aquél libre de ella por presentar mayor porcentaje de grava y menor porcentaje de arena. Si bien no se encontraron diferencias significativas en el porcentaje de limo y arcilla, cabe resaltar que los valores promedio más elevados correspondieron a BZ, especialmente al "sedimento asociado a la vegetación". 
Tabla 11. Porcentaje promedio y desvío estándar de las fracciones del sedimento estimadas a partir de las muestras colectadas en los sitios de muestreo durante el período de estudio. s: "sedimento libre de vegetación"; v: "sedimento asociado a la vegetación".

\begin{tabular}{ccccc}
\hline Sitio & $\%$ Grava & $\%$ Arena & $\%$ Limo & $\%$ Arcilla \\
\hline BEs & $4,1( \pm 2,9)$ & $95,8(2,8)$ & $0,1( \pm 0,3)$ & 0 \\
BEv & $68,2( \pm 13,9)$ & $31,1( \pm 13,5)$ & $0,7( \pm 0,5)$ & 0 \\
BZs & $0,08( \pm 0,09)$ & $98,3(2,4)$ & $1,03( \pm 1,5)$ & $0,6( \pm 0,8)$ \\
BZv & $8,4( \pm 8,1)$ & $74,1( \pm 41,3)$ & $9,1( \pm 17,3)$ & $8,3( \pm 16)$ \\
PLs & 0 & $99,4(0,8)$ & $0,3( \pm 0,4)$ & $0,3( \pm 0,4)$ \\
PLv & $0,4( \pm 0,5)$ & $99,4( \pm 0,8)$ & 0 & $0,2( \pm 0,3)$ \\
BALs & 0 & $98,7(1,7)$ & $0,6( \pm 1,1)$ & $0,7( \pm 0,8)$ \\
BALv & $2,3( \pm 2,1)$ & $97,1( \pm 2,6)$ & $0,3( \pm 0,4)$ & $0,3( \pm 0,4)$ \\
\hline
\end{tabular}

Tabla 12. Valores de $p$ del ANOVA de tres vías realizado para el estudio de las distintas fracciones del sedimento en el área estudiada.

\begin{tabular}{lccc}
\hline & Tiempo & Sitio & Hábitat \\
& $p$ & $p$ & $p$ \\
\hline \% Grava & 0,783 & $<0,001$ & $<0,001$ \\
\% Arena & 0,46 & 0,006 & 0,003 \\
\% Limo & 0,46 & 0,422 & 0,409 \\
\% Arcilla & 0,465 & 0,429 & 0,418 \\
\hline
\end{tabular}




\section{Macroinvertebrados}

De las muestras bentónicas se identificaron invertebrados pertenecientes a diversos Phyla: Nematoda, Platyhelmintha, Cnidaria, Annelida, Mollusca y Arthropoda. En el "sedimento libre de vegetación" se reconocieron organismos pertenecientes a 43 taxa, mientras que en el "sedimento asociado a la vegetación" se determinaron 91 taxa (Tabla 13).

Tabla 13. Lista de taxones registrados en los sitios y hábitats estudiados. s: "sedimento libre de vegetación"; v: "sedimento asociado a la vegetación".

\begin{tabular}{|c|c|c|c|c|c|c|c|c|}
\hline Taxones & BEs & BZs & PLs & BALs & BEv & $B Z v$ & PLv & BALV \\
\hline NEMATODA & $x$ & $x$ & $x$ & $x$ & $x$ & $x$ & $x$ & $x$ \\
\hline $\begin{array}{l}\text { TARDIGRADA } \\
\text { Dactylobiotus dispar (Murray, 1907) }\end{array}$ & $\mathrm{x}$ & $\mathrm{X}$ & & $\mathrm{x}$ & $\mathrm{X}$ & $\mathrm{x}$ & $\mathrm{X}$ & $\mathrm{X}$ \\
\hline $\begin{array}{l}\text { PLATYHELMINTHA } \\
\text { Girardia anceps (Kenk, 1930) } \\
\text { Temnocephala spp. }\end{array}$ & $\mathrm{x}$ & & & & $\begin{array}{l}X \\
X\end{array}$ & $\mathrm{x}$ & $\begin{array}{l}X \\
X\end{array}$ & $\mathrm{x}$ \\
\hline $\begin{array}{l}\text { HYDROZOA } \\
\text { Cordylophora caspia (Pallas, 1771) } \\
\text { Hydra sp. }\end{array}$ & & & $\mathrm{x}$ & $\mathrm{X}$ & $\mathrm{x}$ & & $\mathrm{X}$ & $\begin{array}{l}X \\
X\end{array}$ \\
\hline $\begin{array}{l}\text { ENTOPROCTA } \\
\text { Urnatella gracilis Leidy, } 1851\end{array}$ & & & & & $\mathrm{x}$ & & & \\
\hline OLIGOCHAETA & & & & & & & & \\
\hline $\begin{array}{l}\text { Naididae Tubificinae } \\
\text { Limnodrilus hoffmeisteri Claparede, } 1862\end{array}$ & $\mathrm{X}$ & $\mathrm{x}$ & $\mathrm{X}$ & & $\mathrm{X}$ & $\mathrm{x}$ & $\mathrm{X}$ & $\mathrm{x}$ \\
\hline Limnodrilus udekemianus Claparede, 1862 & & $x$ & & & & $x$ & $\mathrm{x}$ & $\mathrm{x}$ \\
\hline $\begin{array}{l}\text { Limnodrilus claparedianus Ratzel, } 1868 \\
\text { Aulodrilus pigueti Kowalewski, } 1914\end{array}$ & $\mathrm{X}$ & $\mathrm{X}$ & & & $\mathrm{X}$ & $\begin{array}{l}X \\
X\end{array}$ & & $\mathrm{x}$ \\
\hline Naididae Naidinae & & & & & & & & \\
\hline Nais variabilis Piguet, 1906 & & $\mathrm{x}$ & $\mathrm{x}$ & $\mathrm{x}$ & $\mathrm{x}$ & $\mathrm{x}$ & $\mathrm{x}$ & $\mathrm{x}$ \\
\hline Nais communis Piguet, 1906 & & $\mathrm{x}$ & & & & $\mathrm{X}$ & $\mathrm{X}$ & \\
\hline Nais bretscheri Michaelsen, 1899 & & & & & & $\mathrm{X}$ & $\mathrm{X}$ & \\
\hline Nais pardalis Piguet, 1906 & & & & & $\mathrm{x}$ & $x$ & $\mathrm{x}$ & \\
\hline Stephensoniana trivandrana (Aiyer, 1926) & $x$ & $x$ & & & & $x$ & & \\
\hline Stylaria lacustris Lamarck, 1816 & & & & & & $x$ & $\mathrm{x}$ & \\
\hline Dero (Dero) sawayai Marcus, 1943 & & $x$ & & & & $x$ & $x$ & \\
\hline Dero (Dero) pectinata Aiyer, 1929 & & & & & $\mathrm{X}$ & $\mathrm{X}$ & $\mathrm{X}$ & \\
\hline Dero (Dero) digitata (Müller, 1773) & & & & & & $x$ & $\mathrm{x}$ & \\
\hline Paranais frici Hrabé, 1941 & $x$ & $x$ & & $x$ & $\mathrm{x}$ & $x$ & $\mathrm{x}$ & $x$ \\
\hline Chaetogaster diastrophus (Gruithuisen, 1828) & & $x$ & & $\mathrm{X}$ & $\mathrm{x}$ & $\mathrm{x}$ & $\mathrm{x}$ & $\mathrm{x}$ \\
\hline Chaetogaster diaphanus (Gruithuisen, 1828) & & & & & & $x$ & $x$ & \\
\hline Slavina isochaeta Cernosvitov, 1939 & & & $x$ & & & $x$ & & \\
\hline Slavina appendiculata (d'Udekem, 1855) & & $x$ & & & $x$ & $x$ & $x$ & $x$ \\
\hline Amphichaeta leydigi Tauber, 1879 & & $x$ & & & & & & \\
\hline Allonais paraguayensis (Michaelsen, 1905) & & & & & & & & $x$ \\
\hline
\end{tabular}




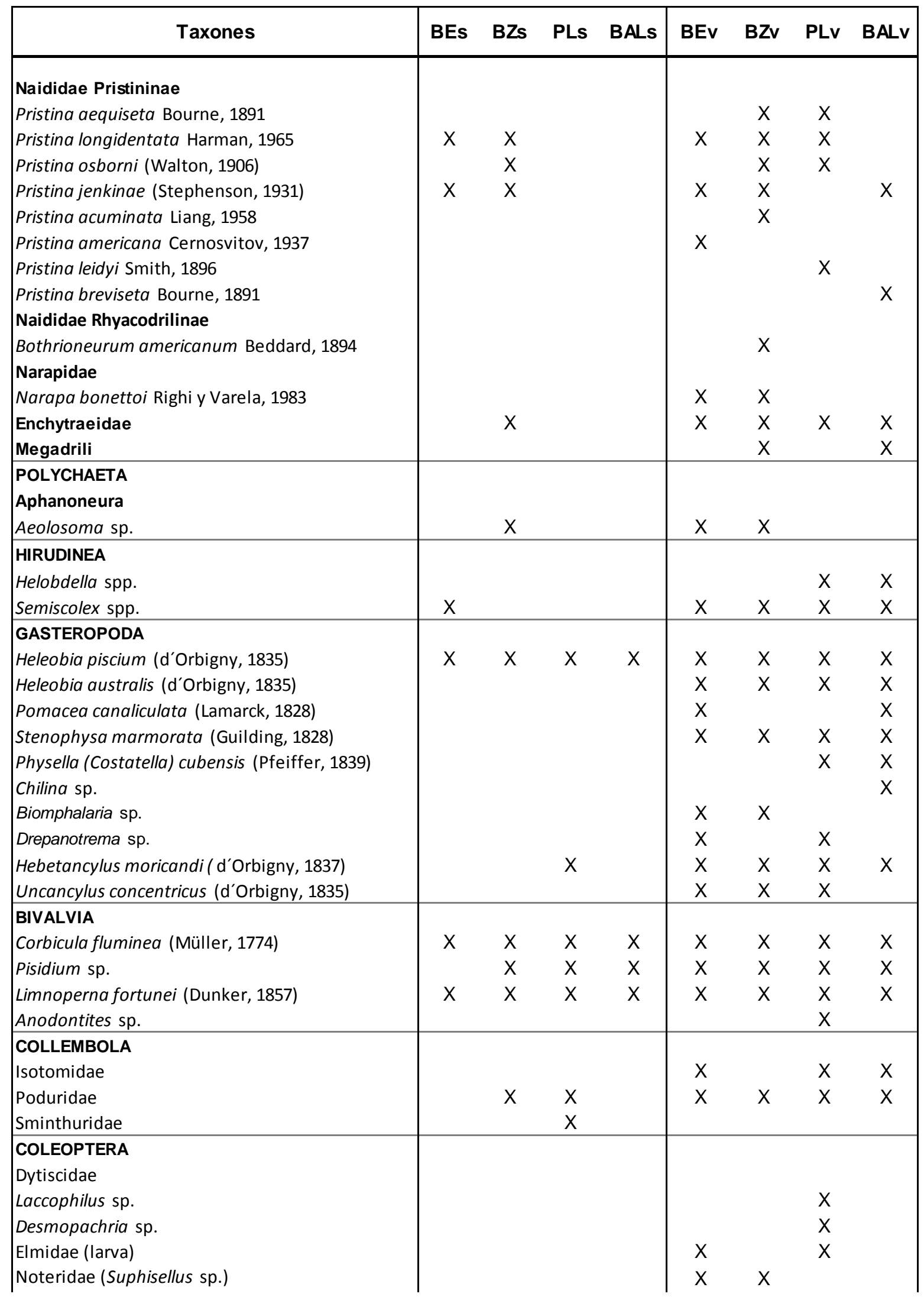




\begin{tabular}{|c|c|c|c|c|c|c|c|c|}
\hline Taxones & BEs & BZs & PLs & BALs & BEv & $B Z v$ & PLv & BALV \\
\hline $\begin{array}{l}\text { ODONATA } \\
\text { Anisoptera } \\
\text { Aeshna bonariensis (Rambur, 1842) } \\
\text { Zygoptera } \\
\text { Coenagrionidae }\end{array}$ & & & & & $\mathrm{X}$ & $X$ & & $X$ \\
\hline $\begin{array}{l}\text { EPHEMEROPTERA } \\
\text { Baetidae (Baetis sp.) } \\
\text { Caenidae (Caenis sp.) }\end{array}$ & & & & & & $\begin{array}{l}X \\
X\end{array}$ & $\begin{array}{l}X \\
X\end{array}$ & $\begin{array}{l}X \\
X\end{array}$ \\
\hline $\begin{array}{l}\text { DIPTERA } \\
\text { Chironomidae (Chironominae spp.) } \\
\text { Ceratopogonidae } \\
\text { Psychodidae } \\
\text { Stratiomyidae } \\
\text { Tipulidae } \\
\text { Ephydridae }\end{array}$ & $X$ & $X$ & $X$ & $X$ & $\begin{array}{l}x \\
x \\
x \\
x\end{array}$ & $\begin{array}{l}X \\
X \\
X \\
X \\
X\end{array}$ & $\begin{array}{l}X \\
X \\
X \\
X \\
X\end{array}$ & $\begin{array}{l}X \\
X\end{array}$ \\
\hline $\begin{array}{l}\text { TRICHOPTERA } \\
\text { Leptoceridae (Nectopsyche sp.) } \\
\text { Hydroptilidae }\end{array}$ & & & & & & & $X$ & $\begin{array}{l}X \\
X\end{array}$ \\
\hline $\begin{array}{l}\text { OSTRACODA } \\
\text { Cyprididae }\end{array}$ & & $X$ & & $X$ & $X$ & $X$ & $X$ & $X$ \\
\hline \begin{tabular}{|l|} 
CLADOCERA \\
Daphnidae \\
Chidoridae \\
Bosminidae \\
Macrothricidae \\
\end{tabular} & $\begin{array}{l}X \\
X \\
X\end{array}$ & $\begin{array}{l}X \\
X \\
X \\
X\end{array}$ & $\begin{array}{l}X \\
X\end{array}$ & $\begin{array}{l}X \\
X \\
X\end{array}$ & $\begin{array}{l}X \\
X \\
X\end{array}$ & $\begin{array}{l}X \\
X \\
X \\
X\end{array}$ & $\begin{array}{l}X \\
X \\
X \\
X\end{array}$ & $\begin{array}{l}X \\
X \\
X \\
X\end{array}$ \\
\hline $\begin{array}{l}\text { COPEPODA } \\
\text { Harpacticoida sp. } \\
\text { Acanthocyclops spp. }\end{array}$ & $\begin{array}{l}X \\
X\end{array}$ & $X$ & $X$ & $X$ & $\begin{array}{l}X \\
X\end{array}$ & $\begin{array}{l}X \\
X\end{array}$ & $\begin{array}{l}X \\
X\end{array}$ & $\begin{array}{l}X \\
X\end{array}$ \\
\hline $\begin{array}{l}\text { AMPHIPODA } \\
\text { Hyalella curvispina Shoemaker, } 1942 \\
\text { Corophium rioplatense Giambiagi, } 1926 \\
\end{array}$ & & & $X$ & & $X$ & $X$ & $\begin{array}{l}X \\
X\end{array}$ & $\begin{array}{l}X \\
X\end{array}$ \\
\hline $\begin{array}{l}\text { TANAIDACEA } \\
\text { Sinelobus stanfordi (Richardson, 1901) }\end{array}$ & & & & & $X$ & $X$ & $X$ & $X$ \\
\hline $\begin{array}{l}\text { CUMACEA } \\
\text { Claudicuma platensis Roccatagliata, } 1981\end{array}$ & & & $X$ & $x$ & & & $X$ & $X$ \\
\hline $\begin{array}{l}\text { ISOPODA } \\
\text { Pseudosphaeroma platense (Giambiagi, 1922) } \\
\text { Heterias (Fritzianira) exul (Müller, 1892) } \\
\text { Basphaeroma rhombobrontale (Giambiagi, 1922) }\end{array}$ & $X$ & & $X$ & $X$ & $\begin{array}{l}X \\
X\end{array}$ & $X$ & $\begin{array}{l}x \\
x\end{array}$ & $\begin{array}{l}X \\
X \\
X\end{array}$ \\
\hline $\begin{array}{l}\text { DECAPODA } \\
\text { Trichodactylus panoplus (von Martens, 1869) } \\
\text { Palaemonetes argentinus (Nobili, 1901) }\end{array}$ & & & & & $X$ & $X$ & $\begin{array}{l}X \\
X\end{array}$ & $\begin{array}{l}X \\
X\end{array}$ \\
\hline $\begin{array}{l}\text { ACARI } \\
\text { Hydrachnidia }\end{array}$ & $X$ & $X$ & $X$ & $X$ & $X$ & $X$ & $X$ & $X$ \\
\hline $\begin{array}{l}\text { HETEROPTERA } \\
\text { Belostoma sp. }\end{array}$ & & & & & $X$ & & & \\
\hline
\end{tabular}


Riqueza de Taxa, diversidad de Shannon-Wiener $\left(H^{\prime}\right)$ y equitabilidad $(J)$

La riqueza de taxa (S) fue similar en todos los sitios de muestreo, aunque se encontraron diferencias temporales altamente significativas, diferenciándose primavera y otoño por presentar mayor número de taxa. Por otra parte, la comparación entre los hábitats estudiados evidenció diferencias altamente significativas, registrándose en el "sedimento asociado a la vegetación" valores más altos para este índice (Fig. 14, Tabla 14). Al considerar la riqueza de taxa a partir del total de organismos registrados en los sitios y hábitats estudiados, se observa que en el sedimento asociado a vegetación los valores fluctuaron entre 55 y 66 correspondiendo a los sitios BE y PL, respectivamente. Por su parte, en el sedimento libre de vegetación, los mayores valores de riqueza total correspondieron al sitio BZ, donde se registraron invertebrados pertenecientes a 31 taxa. Mientras que en los restantes sitios la riqueza total no superó los 21 taxa.

La diversidad de Shannon-Wiener $\left(\mathrm{H}^{\prime}\right)$ y equitabilidad $(\mathrm{J})$ no mostraron diferencias significativas temporales ni entre los sitios de muestreo estudiados, sin embargo se encontraron diferencias altamente significativas entre hábitats, registrándose en el "sedimento asociado a la vegetación" los valores más elevados para ambos índices (Fig. 15 y 16, Tabla 14).

Tabla 14. Valores de $\mathrm{p}$ del ANOVA de tres vías realizado para los índices: riqueza de taxa, diversidad de Shannon-Wiener y equitabilidad.

\begin{tabular}{lccc}
\hline & Tiempo & Sitio & Hábitat \\
& $p$ & $p$ & $p$ \\
\hline Riqueza de Taxa (S) & 0,015 & 0,060 & $<0,001$ \\
Diversidad (H') & 0,167 & 0,951 & $<0,001$ \\
Equitabilidad $(\mathrm{J})$ & 0,120 & 0,706 & $<0,001$ \\
\hline
\end{tabular}




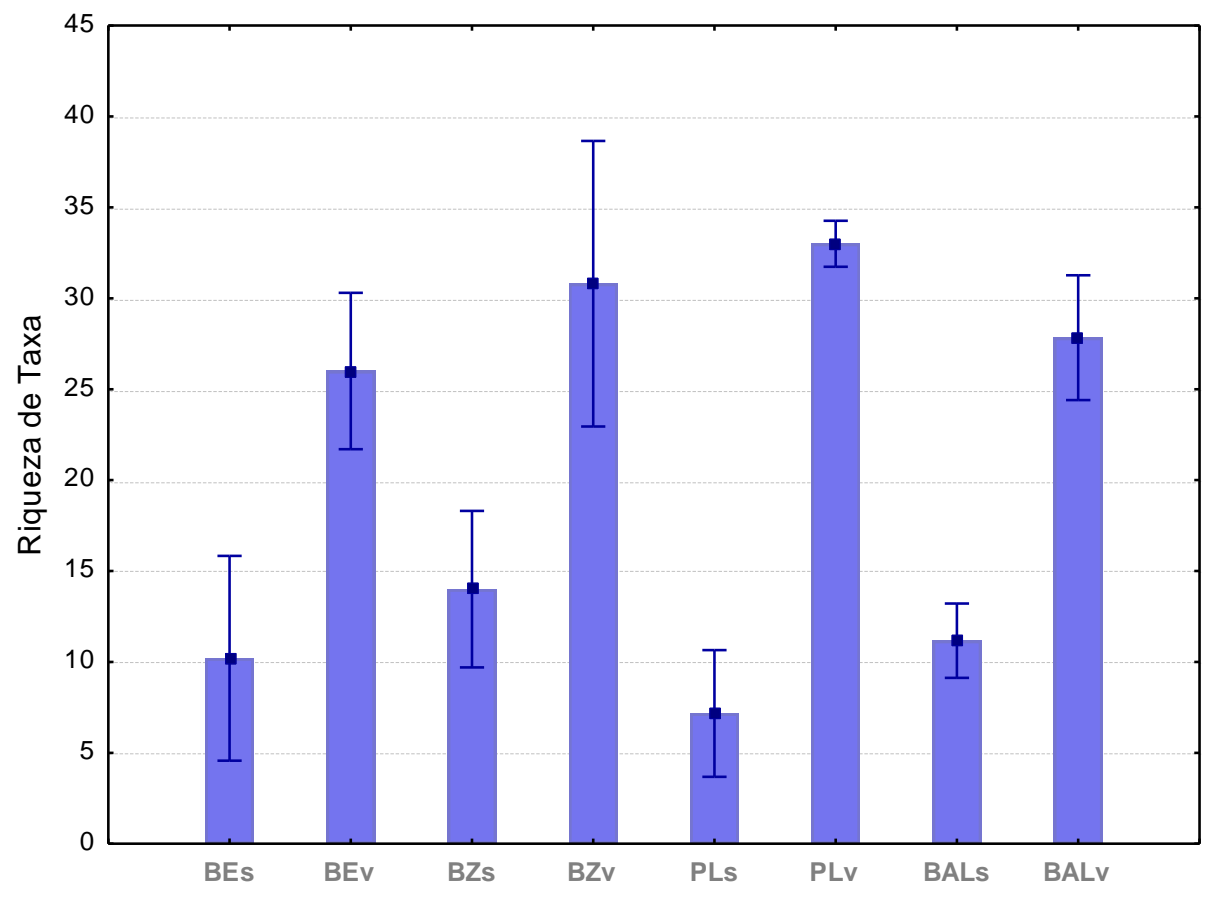

Figura 14. Riqueza de Taxa en los sitios de muestreo y hábitats estudiados. s: "sedimento libre de vegetación"; v: "sedimento asociado a la vegetación".

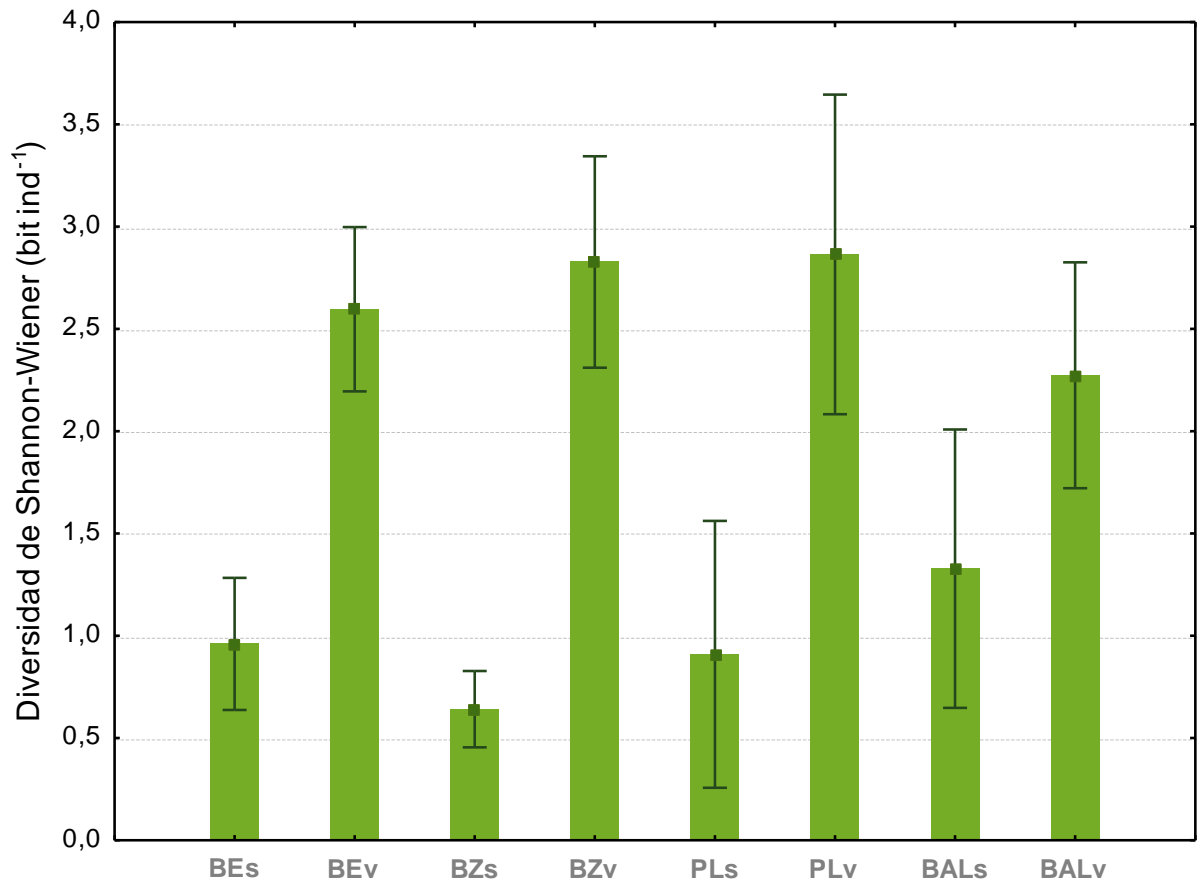

Figura 15. Diversidad de Shannon-Wiener (bit ind ${ }^{-1}$ ) en los sitios de muestreo y hábitats estudiados. s: "sedimento libre de vegetación"; v: "sedimento asociado a la vegetación". 


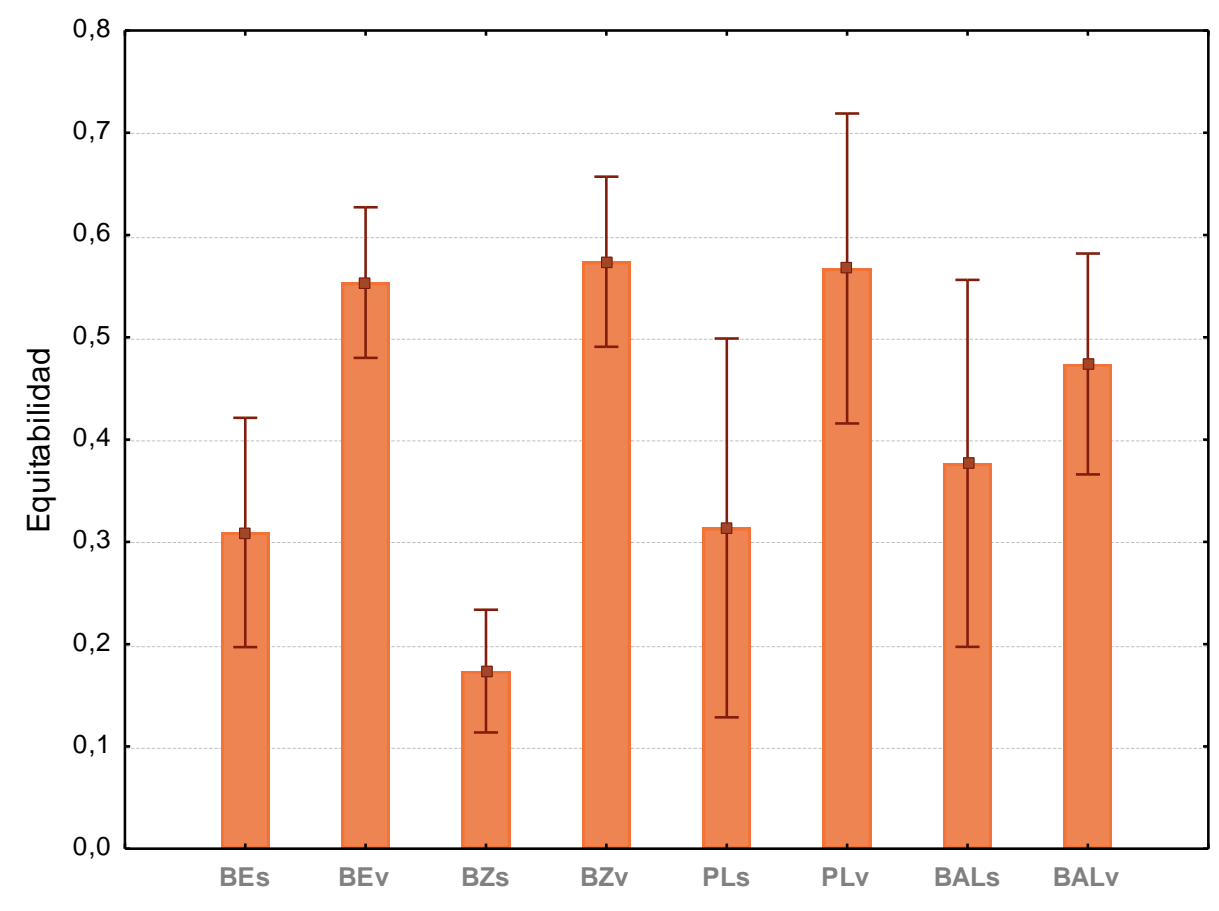

Figura 16. Equitabilidad (J) en los sitios de muestreo y hábitats estudiados. s: "sedimento libre de vegetación"; v: "sedimento asociado a la vegetación".

Grupos taxonómicos principales

En cuanto a los principales grupos taxonómicos analizados, los nematodes mostraron diferencias significativas temporales, registrándose densidades más bajas en los meses más cálidos. Asimismo, este grupo presentó diferencias significativas entre sitios y altamente significativas entre los hábitats estudiados. En este sentido, el test a posteriori reveló que las mayores densidades se registraron en los sitios más impactados (BE y BZ) y en el "sedimento libre de vegetación". Por su parte, los oligoquetos presentaron diferencias significativas entre sitios y hábitats, registrándose las mayores abundancias en BE y BZ, en el "sedimento asociado a la vegetación". Los moluscos y crustáceos mostraron diferencias significativas temporales, registrándose las mayores densidades en los meses más cálidos. Asimismo, 
ambos grupos evidenciaron diferencias altamente significativas entre sitios y hábitats analizados. El test a posteriori reveló que las mayores abundancias de estos invertebrados se registraron en los sitios PL y $B A L$, especialmente en el "sedimento asociado a la vegetación" (Fig. 17, Tabla 15).
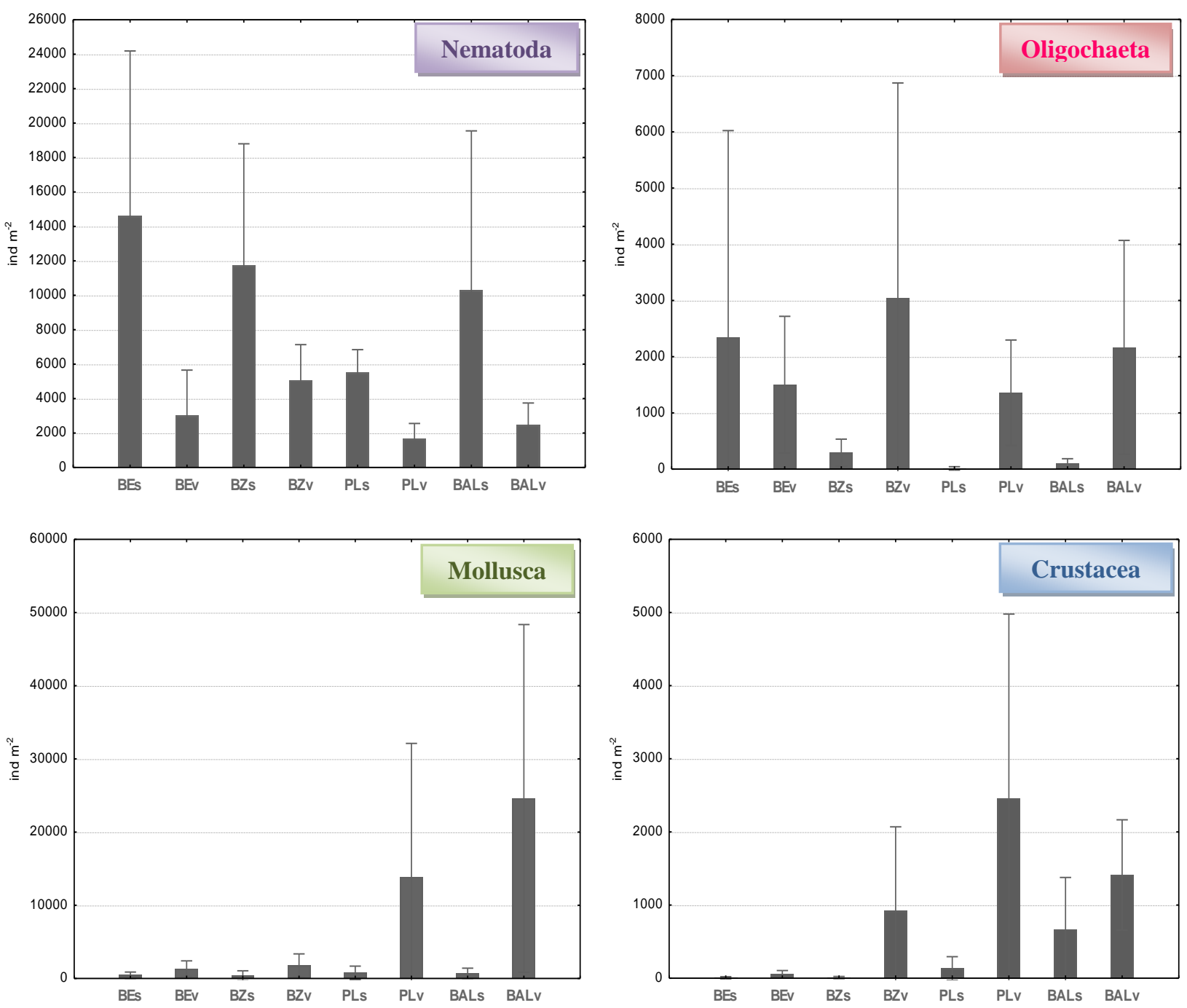

Figura 17. Densidades promedio y desviaciones estándar (ind $\mathrm{m}^{-2}$ ) de los principales grupos taxonómicos registrados en los sitios de muestreo y hábitats analizados durante el período de estudio. s: "sedimento libre de vegetación"; v: "sedimento asociado a la vegetación". 
Tabla 15. Valores de $\mathrm{p}$ del ANOVA de tres vías realizado para los principales grupos taxonómicos teniendo cuenta los factores "tiempo", "sitio" y "hábitat".

\begin{tabular}{lccc}
\hline & Tiempo & Sitio & Hábitat \\
& $p$ & $p$ & $p$ \\
\hline Nematoda & 0,003 & 0,005 & $<0,001$ \\
Oligochaeta & 0,169 & 0,036 & $<0,001$ \\
Mollusca & 0,014 & 0,001 & $<0,001$ \\
Crustacea & 0,002 & $<0,001$ & $<0,001$ \\
Díptera & 0,068 & 0,461 & 0,002 \\
\hline
\end{tabular}

Los dípteros se registraron en todos los sitios de muestreo durante el período de estudio, fundamentalmente representados por miembros de la familia Chironomidae (>95\%). El ANOVA de tres vías realizado evidenció diferencias significativas entre hábitats, correspondiendo las mayores densidades al sedimento asociado a la vegetación (Fig. 18, Tabla 15).

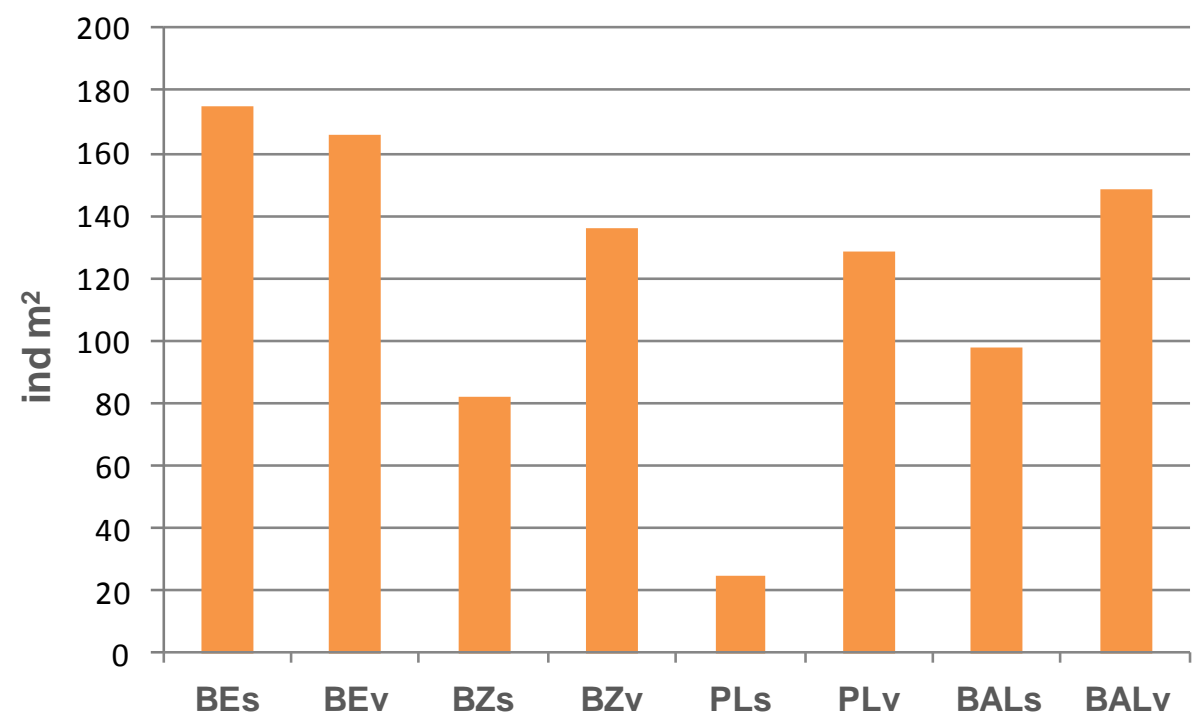

Figura 18. Densidad promedio (ind $\mathrm{m}^{-2}$ ) de dípteros registrados en los sitios y hábitats analizados durante el período de estudio. s: "sedimento libre de vegetación"; v: "sedimento asociado a la vegetación". 
Al analizar las densidades promedio de los distintos taxa de oligoquetos registrados en el área de estudio (Fig. 19), se observa que los oligoquetos Naidinae estuvieron presentes en todos los sitios de muestreo y presentaron las mayores densidades promedio en el sedimento asociado a la vegetación, alcanzando en ocasiones densidades que fluctuaron entre 6000 ind $\mathrm{m}^{-2}$ (BAL) y 10000 ind $\mathrm{m}^{-2}$ (BZ). Los oligoquetos Tubificinae fueron en general abundantes, especialmente predominantes en BE donde superaron en algunos casos los 2300 ind $\mathrm{m}^{-2}$ en ambos hábitats estudiados. A excepción de Bothrioneurum americanum y Narapa bonettoi (cuya frecuencia relativa porcentual fue menor al 5\%), los restantes taxa de oligoquetos mostraron diferencias entre los hábitats estudiados, registrándose las mayores abundancias en el sedimento asociado a la vegetación. En especial, especies de Enchytraeidae y Megadrili no fueron observados en el sedimento libre de vegetación.

Por su parte, el poliqueto Aeolosoma sp. fue registrado en BE y BZ. Esta especie fue capturada en el sedimento asociado a la vegetación con densidades que no superaron en ninguna ocasión los 200 ind $\mathrm{m}^{2}$ y sólo se encontró un ejemplar de este individuo en una muestra de sedimento libre de vegetación colectada en BZ (Fig. 19). 


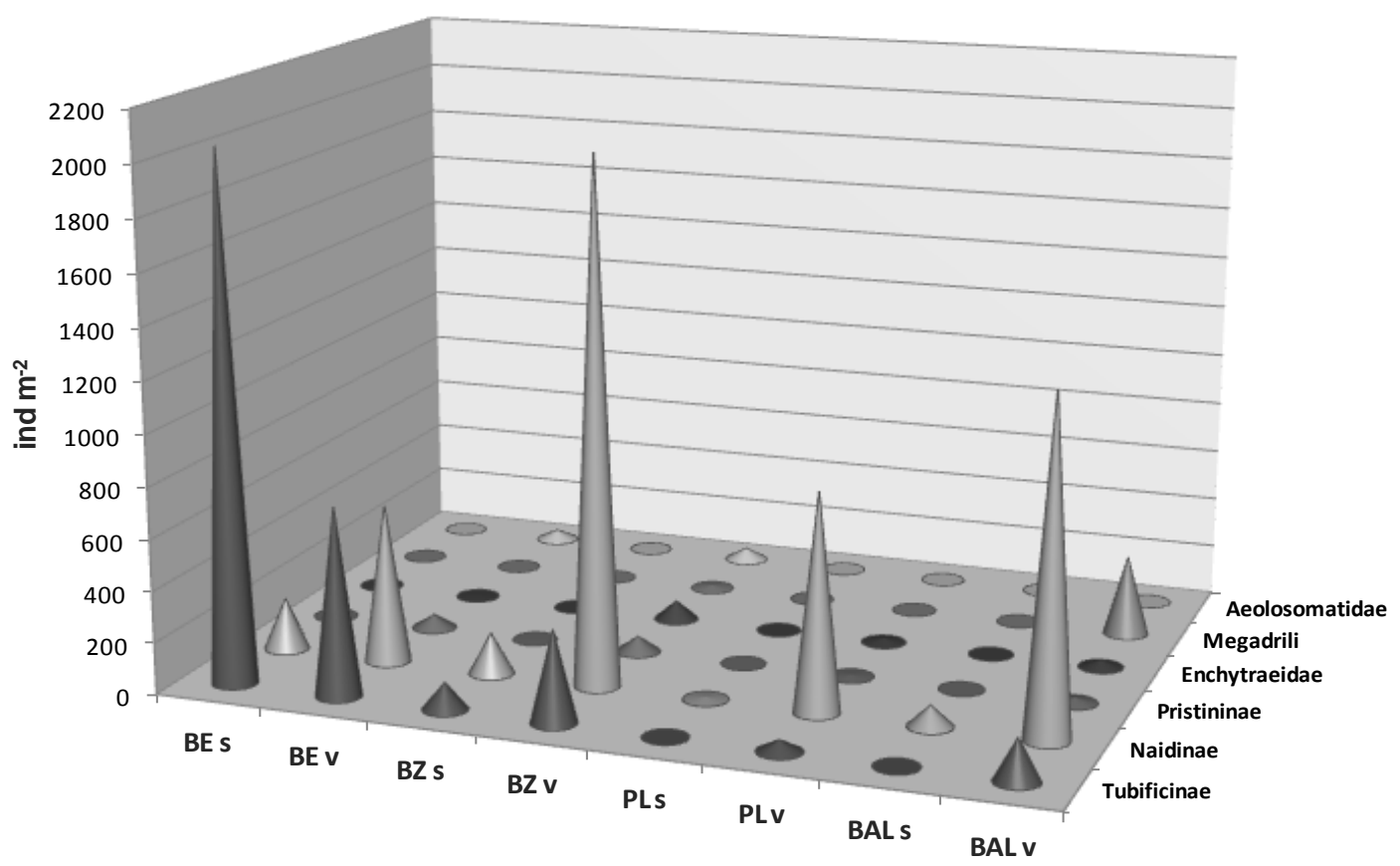

Figura 19. Densidades promedio (ind $\mathrm{m}^{-2}$ ) de los taxa de anélidos registrados en los sitios de muestreo y hábitats analizados durante el período estudiado. s: "sedimento libre de vegetación"; v: "sedimento asociado a la vegetación".

Al comparar los dos grupos principales de moluscos encontrados en el área de estudio se observa que en BE y BZ los gasterópodos en general predominaron sobre los bivalvos, mientras que en PL y BAL los bivalvos fueron los más abundantes (Fig. 20). 


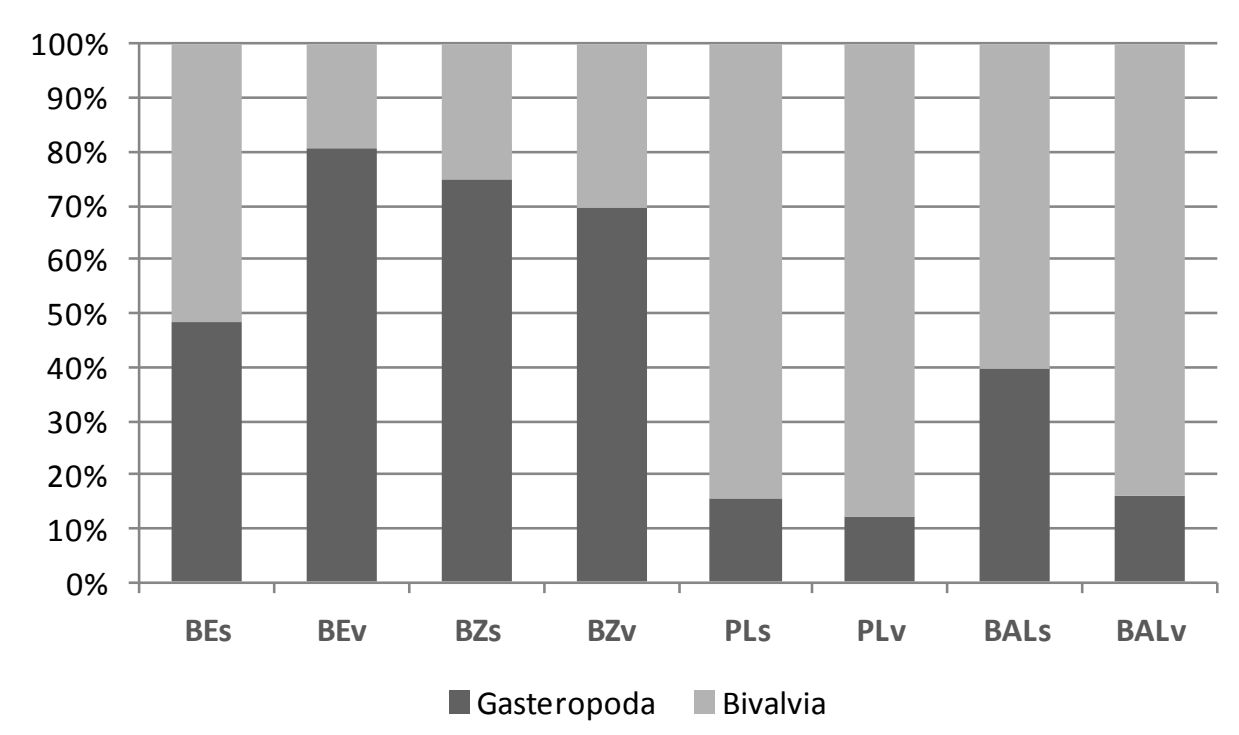

Figura 20. Proporción de moluscos gasterópodos y bivalvos registrados en los sitios y hábitats de estudio durante la presente investigación. s: "sedimento libre de vegetación"; v: "sedimento asociado a la vegetación".

\section{Sensibilidad de los organismos}

- Sedimento asociado a la vegetación:

En los sitios más impactados (BE y BZ) predominaron los organismos "muy tolerantes" con porcentajes que fluctuaron entre $50-95 \%$, mientras que los organismos "tolerantes" se registraron en menor proporción (10-50\%) (Fig. 21). Por su parte, no se encontraron organismos "sensibles" en estos sitios.

En los sitios poco impactados (PL y BAL) las especies "tolerantes" predominaron sobre las restantes, registrándose porcentajes mayores al 50\%. Los organismos "sensibles" se registraron en ambos sitios, principalmente en BAL (con porcentajes que en ocasiones superaron el 25\%), y en menor proporción en PL (<1\%). 


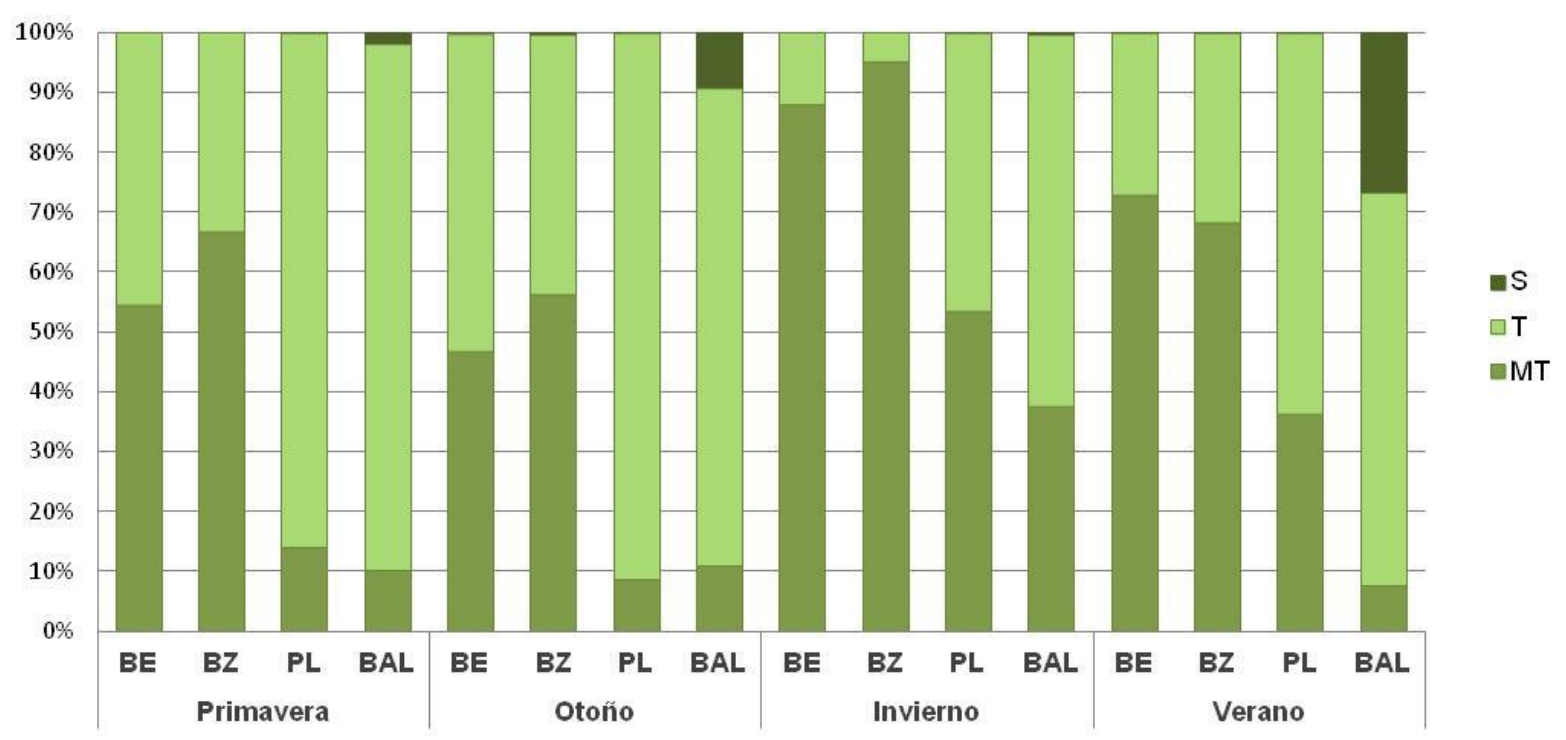

Figura 21. Porcentaje de organismos "sensibles" (S), "tolerantes" (T) y "muy tolerantes" (MT) en el sedimento asociado a vegetación.

- Sedimento libre de vegetación:

En todos los sitios y fechas de muestreo, los organismos "muy tolerantes" predominaron sobre los restantes con valores superiores al $60 \%$. Por su parte, los organismos "tolerantes" presentaron porcentajes mayores en $\mathrm{PL}$ y $\mathrm{BAL}$ respecto de los restantes sitios. Cabe destacar que los organismos "sensibles" sólo se registraron en PL y BAL, con porcentajes que fluctuaron entre $2-10 \%$ (Fig. 22). 


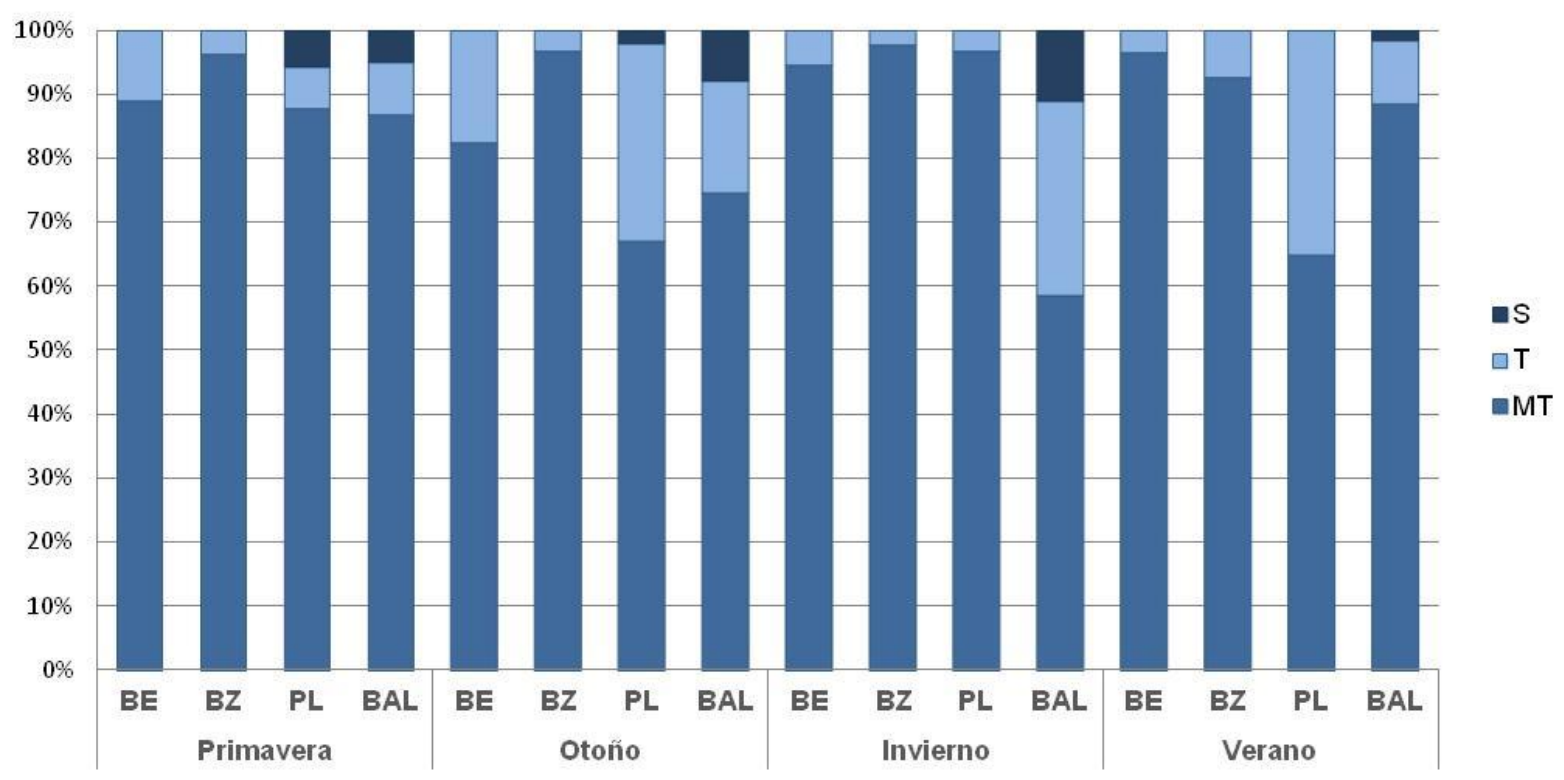

Figura 22. Porcentaje de organismos "sensibles" (S), "tolerantes" (T) y "muy tolerantes" (MT) en el sedimento libre de vegetación.

Una comparación de ambos gráficos muestra que los organismos sensibles sólo se registraron en PL y BAL, correspondiendo a este último los mayores porcentajes tanto en el sedimento libre de vegetación como en el sedimento asociado a ella.

Grupos funcionales alimentarios (GFA)

El grupo funcional alimentario predominante en el sedimento libre de vegetación de todos los sitios de muestreo fue el de los colectoresrecolectores, con valores que superaron el $80 \%$, en $\mathrm{PL}$ y $\mathrm{BAL}$, en segundo lugar podría citarse a los colectores-filtradores, aunque con porcentajes más bajos, que fluctuaron entre $5-12 \%$. Los grupos funcionales alimentarios predominantes en el sedimento asociado a la vegetación fueron los colectoresrecolectores en los sitios más impactados (BE y BZ), con valores que fluctuaron entre $60-75 \%$, mientras que en los sitios con mayor grado de naturalidad 
costera y mejores condiciones en la calidad del agua y del hábitat (PL y BAL) los GFA que predominaron fueron los colectores-filtradores, con porcentajes superiores al $60 \%$ y los colectores-recolectores, con valores que fluctuaron entre 18-25\%. Los restantes GFA (raspadores, fragmentadores y depredadores) presentaron valores similares en todos los sitios de muestreo, con porcentajes inferiores al $15 \%$ en el caso de los raspadores e inferiores al $7 \%$ en el caso de los fragmentadores y depredadores (Fig. 23).

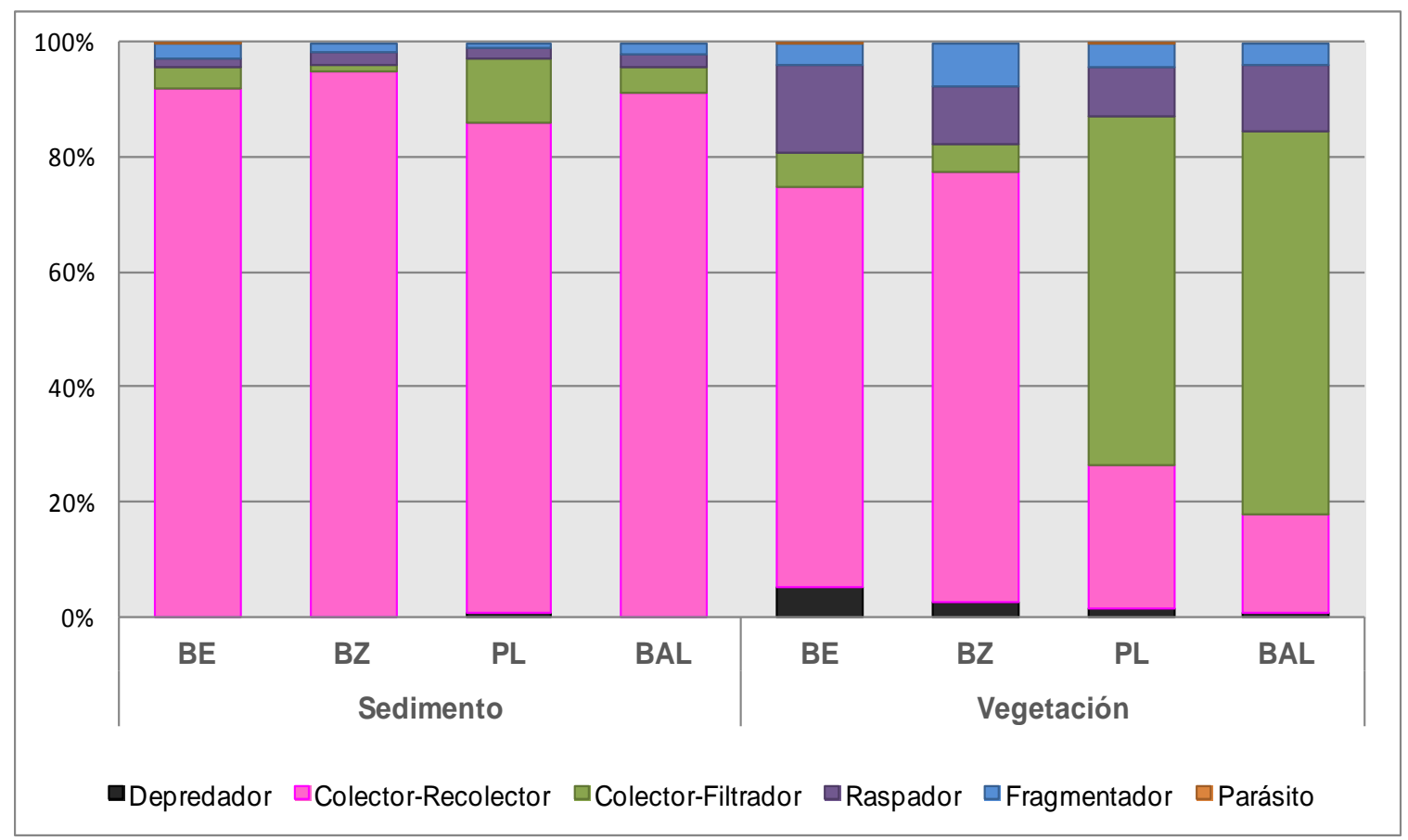

Figura 23. Grupos Funcionales Alimentarios (GFA) presentes en los sitios de muestreo estudiados.

El ANOVA de tres vías realizado (Tabla 16) evidenció diferencias significativas entre los hábitats estudiados para todos los GFA (excepto parásitos que no pudo ser testeado), observándose un predominio de depredadores, colectores-filtradores, raspadores y fragmentadores en el sedimento asociado a vegetación, mientras que los colectores-recolectores 
predominaron en el sedimento libre de vegetación. Asimismo, se encontraron diferencias significativas entre sitios de muestreo para los colectoresfiltradores del nivel "sedimento asociado a vegetación", registrándose los mayores valores en PL y BAL. Los fragmentadores y depredadores, por su parte, presentaron diferencias significativas temporales, registrándose los mayores valores en primavera.

Tabla 16. Valores de $p$ del ANOVA de tres vías realizado para los GFA registrados en el área de estudio.

\begin{tabular}{lccc}
\hline & Tiempo & Sitio & Hábitat \\
& $p$ & $p$ & $p$ \\
\hline Depredador & 0,032 & 0,658 & $<0,001$ \\
Colector-Recolector & 0,303 & 0,147 & 0,016 \\
Colector-Filtrador & 0,07 & 0,031 & 0,008 \\
Raspador & 0,097 & 0,509 & 0,038 \\
Fragmentador & 0,007 & 0,447 & 0,004 \\
\hline
\end{tabular}

Modos de vida

El análisis de los principales modos de vida registrados en los sitios estudiados evidenció un predominio de organismos "apoyados" en BE y BZ (porcentajes mayores al 70\%), mientras que en $\mathrm{PL}$ y $\mathrm{BAL}$, los organismos "minadores" predominaron sobre los restantes (porcentajes superiores al 65\%). Por su parte, los organismos "aferrados", "trepadores" y "nadadores" se registraron en todos los sitios de muestreo con porcentajes inferiores al $10 \%$ (Fig. 24). 


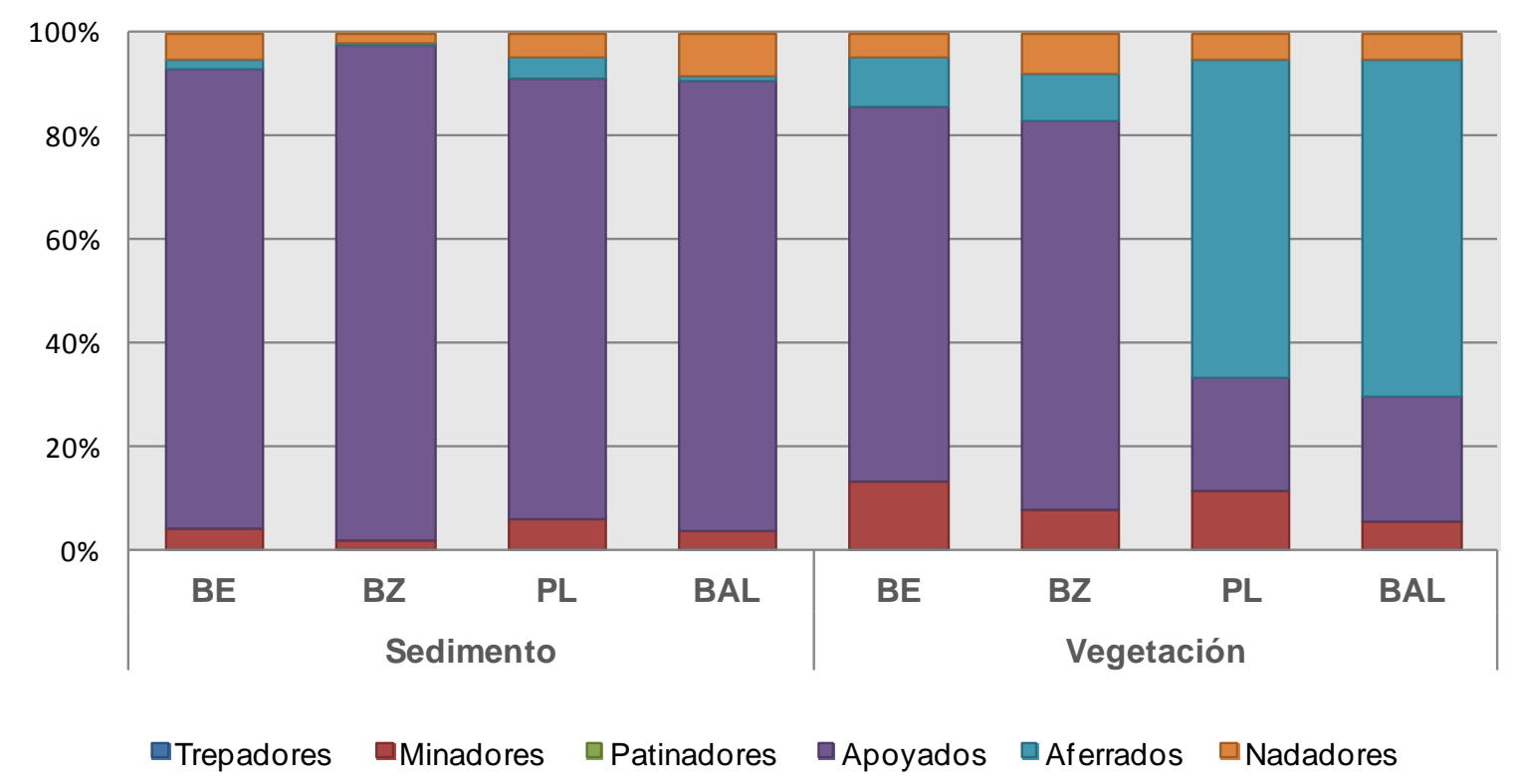

Figura 24. Modos de vida presentes en los sitios de muestreo estudiados.

El ANOVA de tres vías (Tabla 17 ) realizado con los modos de vida no mostró diferencias temporales, espaciales y entre hábitats en las categorías trepador y patinador. Por su parte, se encontraron diferencias significativas entre los hábitats estudiados en los minadores, aferrados y apoyados; los mayores valores correspondieron al sedimento asociado a la vegetación en los dos primeros y al sedimento libre de vegetación en los últimos. Asimismo se encontraron diferencias significativas entre sitios de muestreo en el modo de vida aferrado del nivel "sedimento asociado a vegetación", registrándose los mayores valores en PL y BAL. Los organismos nadadores mostraron diferencias significativas temporales, registrándose los mayores valores en primavera y verano. 
Tabla 17. Valores de $\mathrm{p}$ del ANOVA de tres vías realizado para los modos de vida de los macroinvertebrados registrados en el área de estudio.

\begin{tabular}{lccc}
\hline & Tiempo & Sitio & Hábitat \\
& $p$ & $p$ & $p$ \\
\hline Trepador & 0,257 & 0,201 & 0,079 \\
Minador & 0,156 & 0,418 & 0,007 \\
Patinador & 0,445 & 0,426 & 0,337 \\
Apoyado & 0,316 & 0,162 & 0,047 \\
Aferrado & 0,084 & 0,04 & 0,005 \\
Nadador & 0,001 & 0,076 & 0,123 \\
\hline
\end{tabular}




\section{Índices Bióticos}

De acuerdo a los valores de IMRP calculados para cada sitio, BE y BZ evidenciaron contaminación "débil a escasa", fluctuando los valores de este índice entre 5,7-8,3 y 5,5-7 respectivamente. PL y $\mathrm{BAL}$, por su parte, correspondieron a sitios con contaminación "escasa a muy leve/nula", dado que los valores de este índice fluctuaron entre 8,9-14,8 y 10,2-12,9 respectivamente. A partir de la totalidad de los valores calculados para cada sitio durante el período de estudio, se estimó el grado de representatividad de cada categoría del IMRP, representada como frecuencia relativa porcentual (Fig. 25).

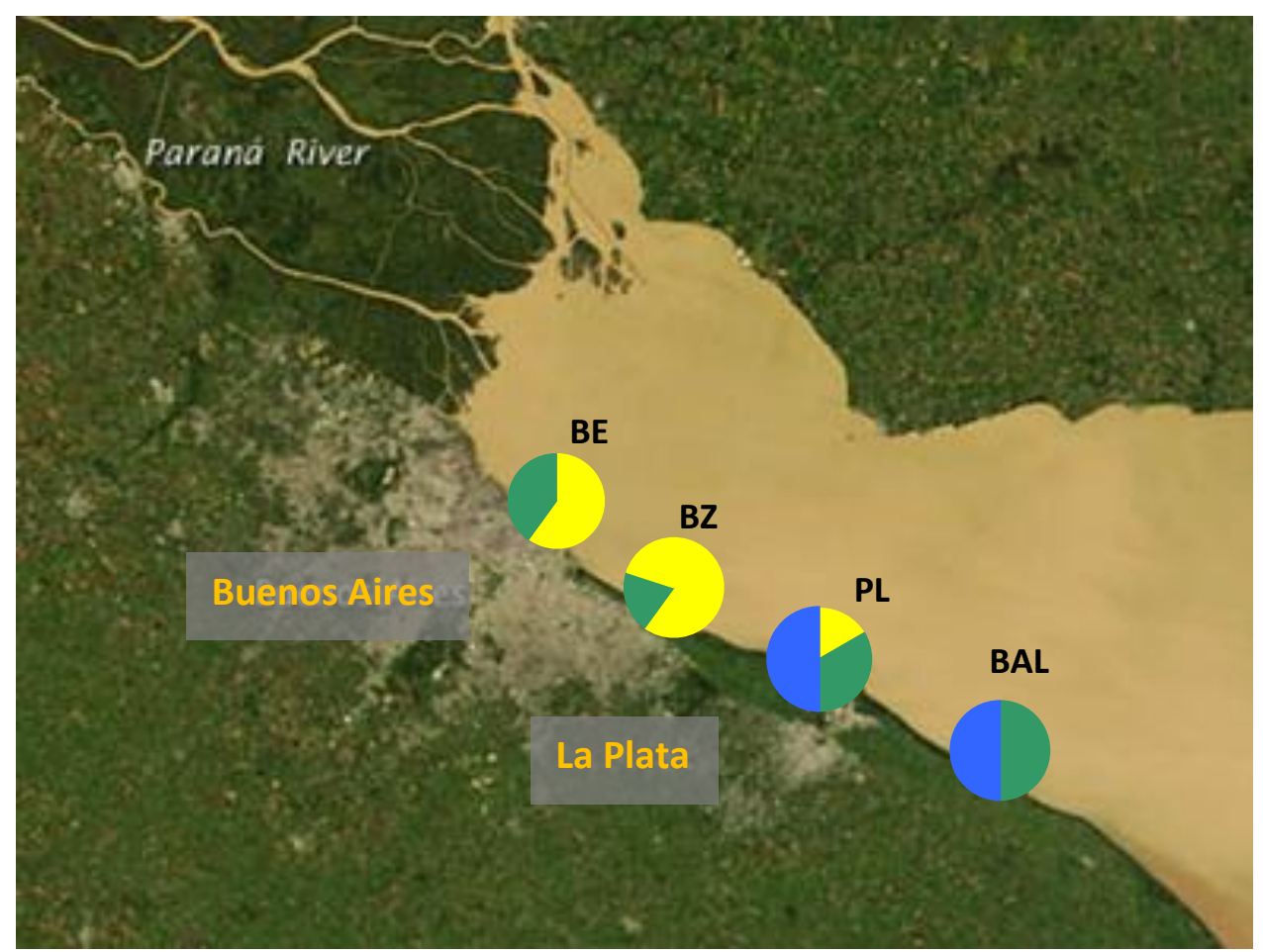

Figura 25. Grado de representatividad de cada categoría establecida para el IMRP en los sitios de muestreo durante el período de estudio. Amarillo: "contaminación débil"; Verde: "contaminación escasa"; Azul: "contaminación muy leve/nula. 


\section{Análisis directo de gradientes}

Los dos primeros ejes del ordenamiento (RDA) explicaron el $74,4 \%$ de la varianza total acumulada y permitieron definir las principales variables en la distribución y establecimiento de los macroinvertebrados en el área estudiada (Fig. 26). El primer eje representó el 48,9\% de la varianza total y correlacionó positivamente con el \%MOPG ( $r: 0,97)$. Los sitios asociados con esta condición fueron BZv, PLv y BALv. El segundo eje representó el 25,5\% de la varianza total y correlacionó fuertemente con el \%MOPF ( $r: 0,72)$, la DBO $(r: 0,69)$ y la conductividad ( $r$ : 0,48). Los sitios BEs, BEv, BZs y BZv estuvieron asociados con esta condición, registrándose fundamentalmente organismos considerados "tolerantes" y "muy tolerantes", entre los que se destacan fundamentalmente oligoquetos tubificinos, naidinos, pristininos, hirudíneos, tardígrados, nematodes, chironómidos. Asimismo, el segundo eje correlacionó negativamente con la turbidez $(r:-0,58)$, siendo PLs, PLv, BALs y BALv los sitios que se hallaron asociados con esta sección negativa y donde se registraron organismos de diversos taxa, especialmente aquellos considerados "sensibles", tales como tricópteros, efemerópteros, hidrozoos y cumáceos. En términos generales podría resumirse que los macroinvertebrados se distribuyeron en función de las características propias de los hábitats estudiados y del gradiente de deterioro ambiental encontrado en el sector estudiado. El Test de Monte Carlo mostró un valor de $p=0,024$ para el primer eje y un valor de $p=0,018$ para todos los ejes (Tabla 18). 


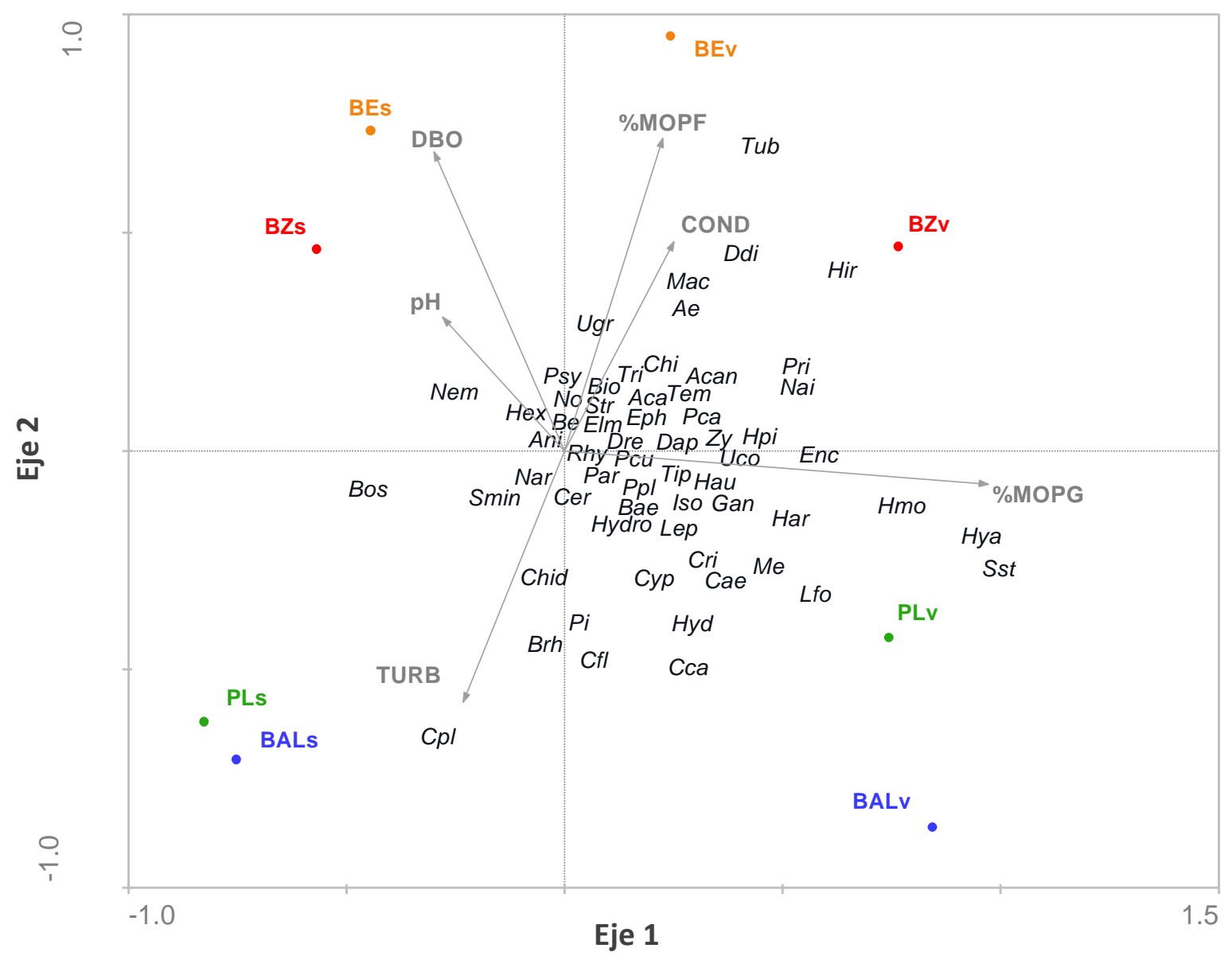

Figura 26. Ordenamiento de los sitios de muestreo, variables ambientales y taxones registrados en el área de estudio en relación a los dos primeros ejes del Análisis de Redundancia (RDA). (Los acrónimos de los taxa se indican en la sección ANEXO, Tabla C).

Tabla 18. Resumen de los resultados obtenidos para los cuatro primeros ejes del RDA y Test de significación de los ejes canónicos mediante la Prueba de Monte Carlo.

\begin{tabular}{|c|c|c|c|c|c|}
\hline \multicolumn{6}{|l|}{$* * * *$ Resumen $* * * *$} \\
\hline & 1 & 2 & 3 & 4 & Varianza total \\
\hline Autovalores: & 0,467 & 0,243 & 0,095 & 0,070 & 1.000 \\
\hline Correlaciones especies-ambiente: & 1,000 & 0,999 & 0,948 & 0,990 & \\
\hline $\begin{array}{l}\text { Porcentaje de la varianza acumulada } \\
\text { para datos de especies: }\end{array}$ & 46,7 & 71,0 & 80,4 & 87,4 & \\
\hline para la relación especies-ambiente: & 48,9 & 74,4 & 84,3 & 91,6 & \\
\hline \multicolumn{6}{|l|}{$* * * *$ Resumen Test de Monte Carlo**** } \\
\hline \multirow{3}{*}{\multicolumn{2}{|c|}{ Test de significación para el primer eje canónico: }} & \multicolumn{3}{|c|}{ Autovalor $=0,467$} & \\
\hline & & & F-ratio & $=0,876$ & \\
\hline & & & P-value & $=0,0240$ & \\
\hline \multirow{3}{*}{\multicolumn{2}{|c|}{ Test de significación para todos los ejes canónicos: }} & & Trace & $=0,954$ & \\
\hline & & & F-ratio & $=3,475$ & \\
\hline & & & $\mathrm{P}$-value & $=0,0180$ & \\
\hline
\end{tabular}


Caracterización de los sitios de muestreo y hábitats funcionales a partir de la confección de fichas

Los datos colectados para cada sitio de muestreo y hábitat estudiados son presentados en diferentes fichas, junto con las características principales de la fauna bentónica que en ellos habita, resumiendo así las principales características del hábitat físico y la biota en cada sitio de muestreo analizado.

Cabe aclarar que los valores presentados para los parámetros físicoquímicos y las variables biológicas son valores promedio estimados a partir de todas las muestras obtenidas en cada sitio y hábitat durante el período de estudio. 


\section{BERNAL}

\section{Uso del suelo predominante: URBANO}

\section{Barreras físicas: Estructuras temporarias}

Sedimento libre de vegetación:

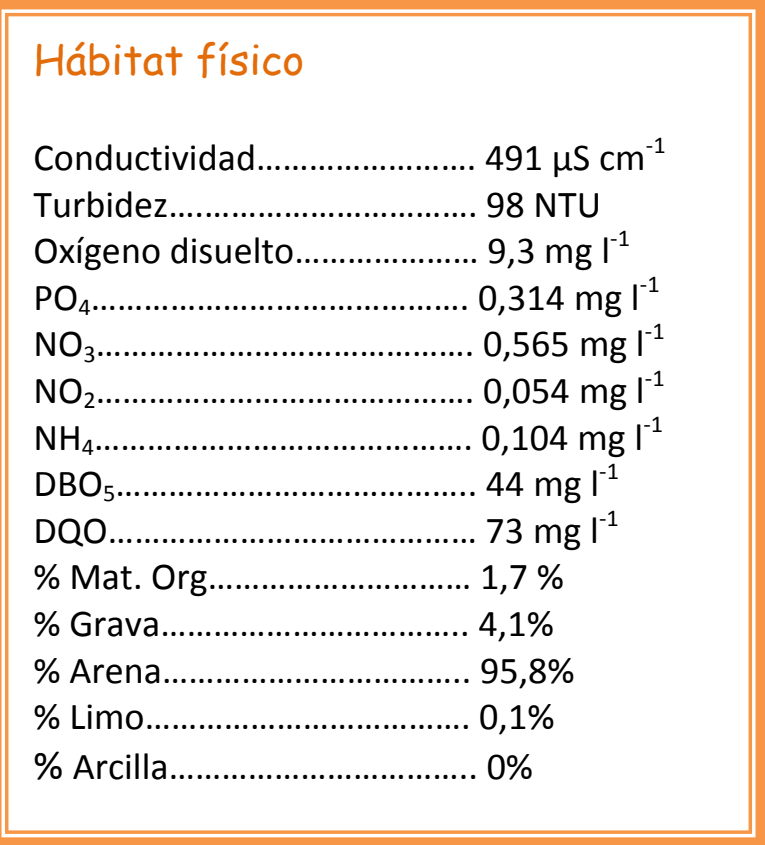

\section{Sedimento asociado a la vegetación:}

\begin{tabular}{|c|}
\hline Hábitat físico \\
\hline Conductividad.......................... $464 \mu \mathrm{S} \mathrm{cm}^{-1}$ \\
\hline Turbidez....................................... NTU \\
\hline Oxígeno disuelto....................... 8,7 $\mathrm{mg} \mathrm{l}^{-1}$ \\
\hline 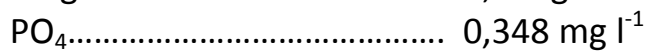 \\
\hline 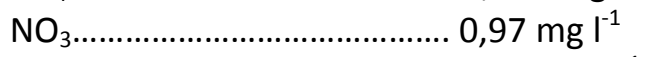 \\
\hline 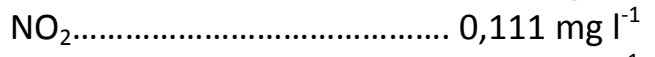 \\
\hline $\mathrm{NH}_{4} \ldots \ldots \ldots \ldots \ldots \ldots \ldots \ldots . . .0,241 \mathrm{mg} \mathrm{l}^{-1}$ \\
\hline 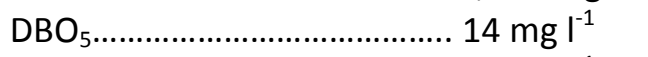 \\
\hline DQO. \\
\hline \% Mat. Org............................. 3,9\% \\
\hline \% Grava.................................. 68,2\% \\
\hline \% Arena................................... \\
\hline \% Limo.................................. 0,7\% \\
\hline \% Arcilla.................................. 0\% \\
\hline
\end{tabular}

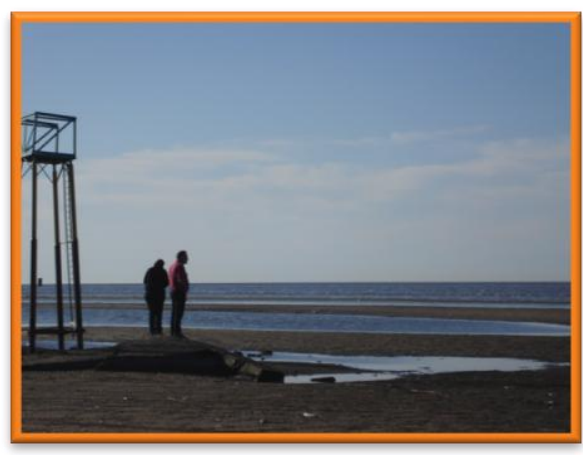

\section{Descriptores estructurales de la biota}

Riqueza de taxa. 10

Diversidad de Shannon 0,96 bit ind $^{-1}$ Equitabilidad 0,31

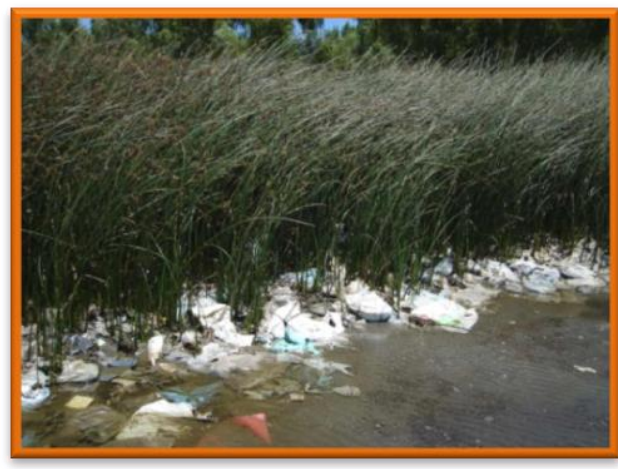

\section{Descriptores estructurales de la biota}

Riqueza de taxa 26

Diversidad de Shannon 2,6 bit ind $^{-1}$ Equitabilidad. 0,55 


\section{BERAZATEGUI}

Uso del suelo predominante: SUBURBANO

Barreras físicas: Estructuras temporarias y rellenos

Sedimento libre de vegetación:

\begin{tabular}{|c|}
\hline Hábitat físico \\
\hline Conductividad....................... $971 \mu \mathrm{S} \mathrm{cm}^{-1}$ \\
\hline Turbidez.................................. 94 NTU \\
\hline Oxígeno disuelto....................... 9,7 $\mathrm{mg} \mathrm{l}^{-1}$ \\
\hline 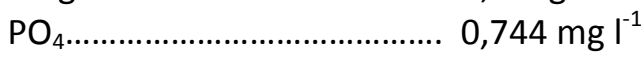 \\
\hline 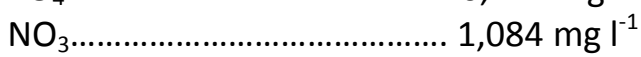 \\
\hline 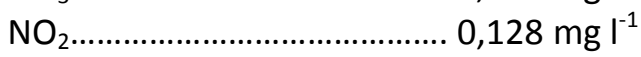 \\
\hline 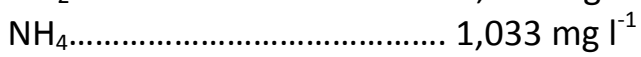 \\
\hline 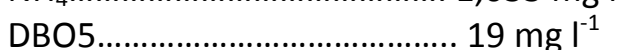 \\
\hline DQO......................................... \\
\hline \% Mat. Org............................... 1,9\% \\
\hline 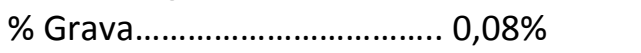 \\
\hline \% Arena............................... 98,3\% \\
\hline 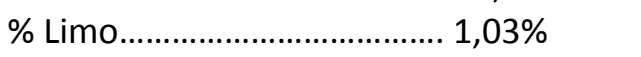 \\
\hline 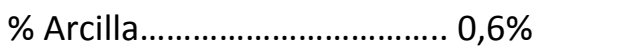 \\
\hline
\end{tabular}

\section{Sedimento asociado a la vegetación:}

\begin{tabular}{|c|}
\hline Hábitat físico \\
\hline Conductividad......................... $1554 \mu \mathrm{S} \mathrm{cm}^{-1}$ \\
\hline Turbidez................................67 NTU \\
\hline Oxígeno disuelto...................... 11,1 $\mathrm{mg} \mathrm{l}^{-1}$ \\
\hline PO4 \\
\hline 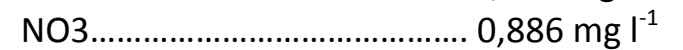 \\
\hline 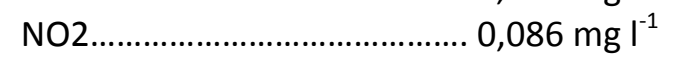 \\
\hline 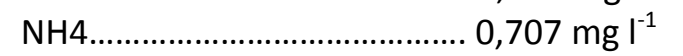 \\
\hline DBO5 \\
\hline DQO............................................... \\
\hline \% Mat. Org............................... 2,3\% \\
\hline \% Grava...................................... 8, \\
\hline \% Arena..................................1\% \\
\hline \% Limo........................................ \\
\hline \% Arcilla....................................... \\
\hline
\end{tabular}

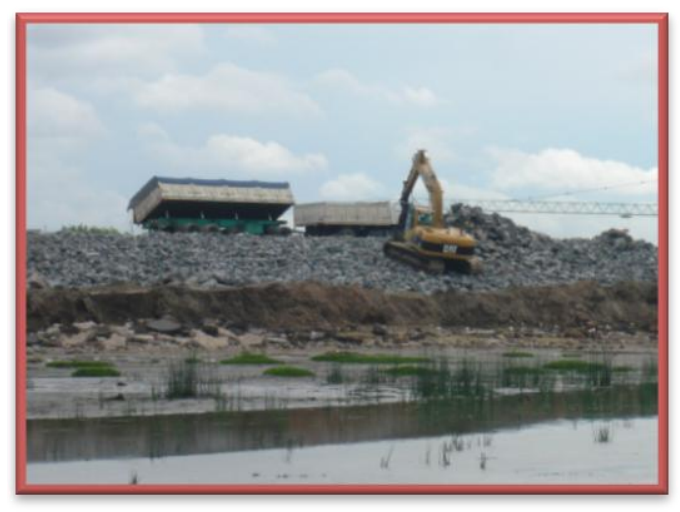

Descriptores estructurales de la biota

Riqueza de taxa. 14

Diversidad de Shannon. 0,64 bit ind $^{-1}$

Equitabilidad 0,17
Descriptores estructurales de la biota

Riqueza de taxa. 31

Diversidad de Shannon 2,83 bit ind $^{-1}$ Equitabilidad 0,57 


\section{PUNTA LARA}

Uso del suelo predominante: RURAL

Barreras físicas: Estructuras temporarias

\begin{tabular}{|c|}
\hline Hábitat físico \\
\hline Conductividad......................... $461 \mu \mathrm{S} \mathrm{cm}^{-1}$ \\
\hline Turbidez........................................ 93 NTU \\
\hline Oxígeno disuelto...................... 9,6 $\mathrm{mg} \mathrm{l}^{-1}$ \\
\hline 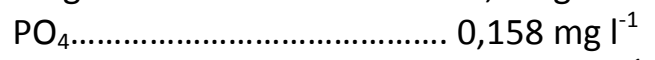 \\
\hline 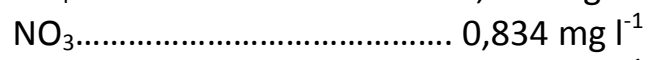 \\
\hline 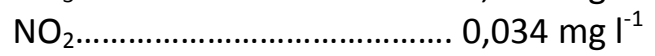 \\
\hline 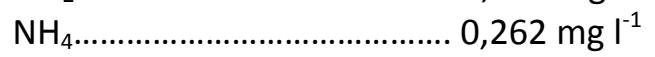 \\
\hline 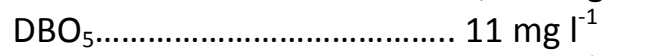 \\
\hline DQO \\
\hline$\%$ Mat. Org.............................. \\
\hline \% Grava.................................. 0\% \\
\hline \% Arena.................................. 99,4\% \\
\hline 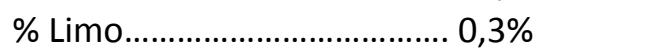 \\
\hline \% Arcilla...................................... \\
\hline
\end{tabular}

\section{Sedimento asociado a la vegetación:}

\begin{tabular}{|c|}
\hline Hábitat físico \\
\hline Conductividad.......................... $446 \mu \mathrm{S} \mathrm{cm}^{-1}$ \\
\hline Turbidez.......................................... NT \\
\hline Oxígeno disuelto..................... 9,6 $\mathrm{mg} \mathrm{l}^{-1}$ \\
\hline PO4 \\
\hline NO3 \\
\hline 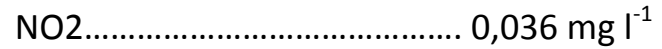 \\
\hline 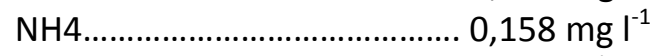 \\
\hline DBO5 \\
\hline DQO................................... $\mathrm{mg} \mathrm{l}^{-1}$ \\
\hline$\%$ Mat. Org.............................. 0,7\% \\
\hline \% Grava................................. 0,4\% \\
\hline \% Arena.....................................4\% \\
\hline \% Limo.................................. $0 \%$ \\
\hline$\%$ Arcilla................................. \\
\hline
\end{tabular}

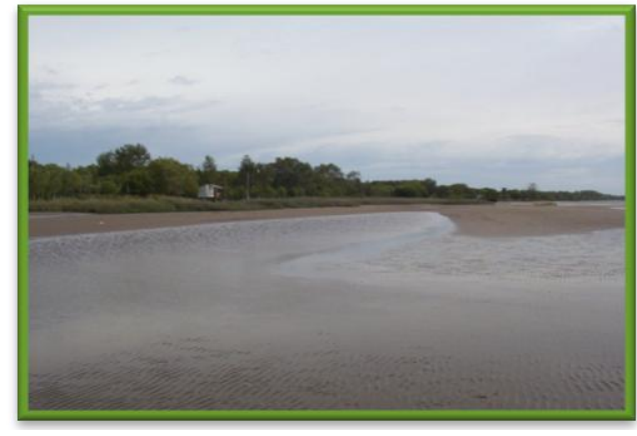

Descriptores estructurales de la biota

Riqueza de taxa.............................. 7

Diversidad de Shannon.................. 0,91 bit ind $^{-1}$

Equitabilidad................................. 0,31

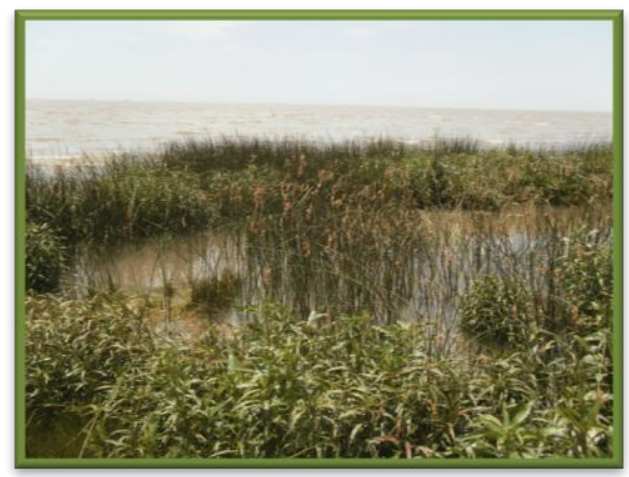

Descriptores estructurales de la biota

Riqueza de taxa............................... 33

Diversidad de Shannon.................. 2,86 bit ind $^{-1}$

Equitabilidad.................................... 0,57 


\section{BALANDRA}

Uso del suelo predominante: RURAL

Barreras físicas: Estructuras temporarias

\begin{tabular}{|c|}
\hline Hábitat físico \\
\hline Conductividad......................... $355 \mu \mathrm{S} \mathrm{cm}^{-1}$ \\
\hline Turbidez................................... 209 NTU \\
\hline Oxígeno disuelto.......................10,1 $\mathrm{mg} \mathrm{l}^{-1}$ \\
\hline PO4................................. \\
\hline NO3 \\
\hline 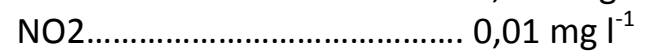 \\
\hline $\mathrm{NH} 4 \ldots \ldots \ldots \ldots \ldots \ldots \ldots \ldots \ldots . . .0,18 \mathrm{mg} \mathrm{l}^{-1}$ \\
\hline DBO5 \\
\hline DQO \\
\hline \% Mat. Org............................ 0,9\% \\
\hline \% Grava.................................. 0\% \\
\hline \% Arena................................. 98,7\% \\
\hline \% Limo \\
\hline \% Arcilla \\
\hline
\end{tabular}

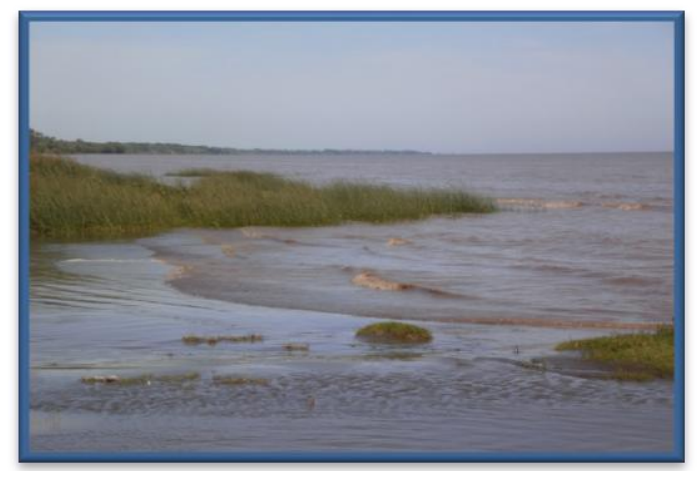

Descriptores estructurales de la biota

Riqueza de taxa. 11

Diversidad de Shannon

Equitabilidad.
1,33 bit ind $^{-1}$ 0,38

\section{Sedimento asociado a la vegetación:}

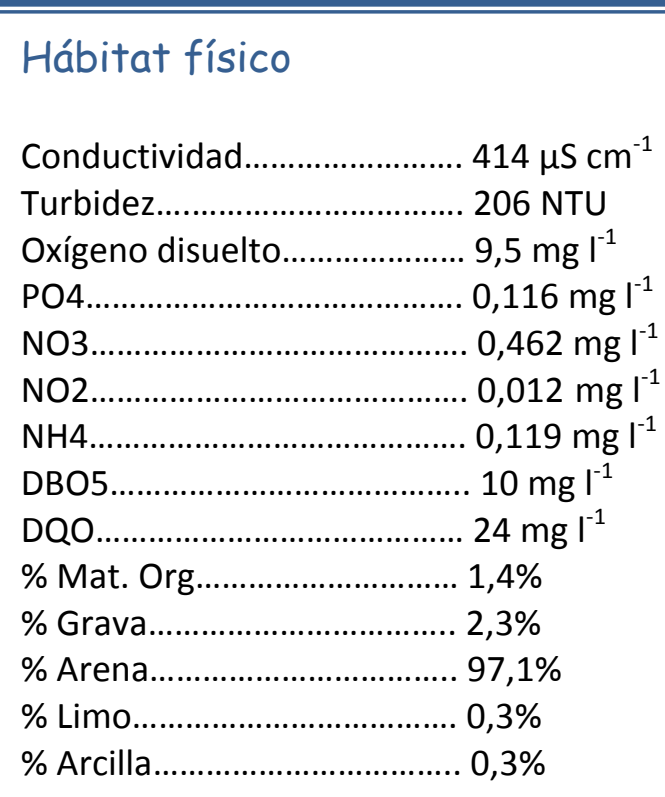

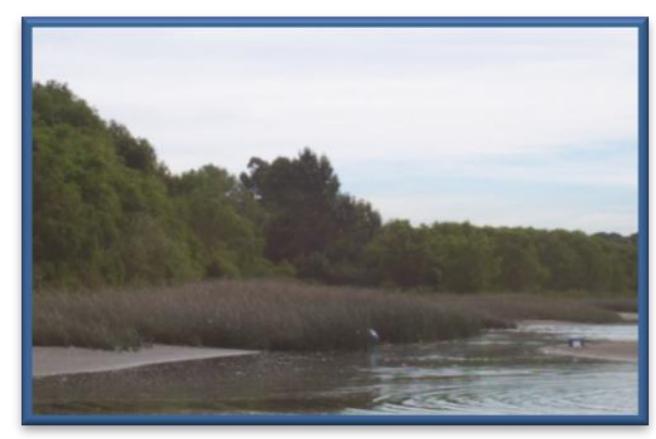

Descriptores estructurales de la biota

Riqueza de taxa. 28

Diversidad de Shannon

Equitabilidad.
2,27 bit ind $^{-1}$ 0,47 
Determinación de hábitats funcionales (mesohábitats) en cada sitio de muestreo

En la etapa inicial de la presente investigación, la observación directa del sector costero realizada en los sitios de muestreo seleccionados para su estudio permitió establecer hábitats funcionales potenciales que podrían congregar ensambles de invertebrados particulares. Se diferenciaron en campo dos tipos de hábitats distinguibles: el "sedimento libre de vegetación" y el "sedimento asociado a la vegetación". Cabe resaltar aquí que a lo largo de todo el sector costero estudiado, la vegetación estuvo representada por el junco Schoenoplectus californicus. A partir de los resultados obtenidos, las diferencias existentes en sus características físico-químicas, granulometría, materia orgánica y asociaciones de macroinvertebrados presentes, han permitido definirlos como los hábitats funcionales principales que ofrece el sector costero del Río de la Plata como opciones de asentamiento de los invertebrados acuáticos, donde los mismos se asientan, resguardan, alimentan y reproducen (Fig. 27).

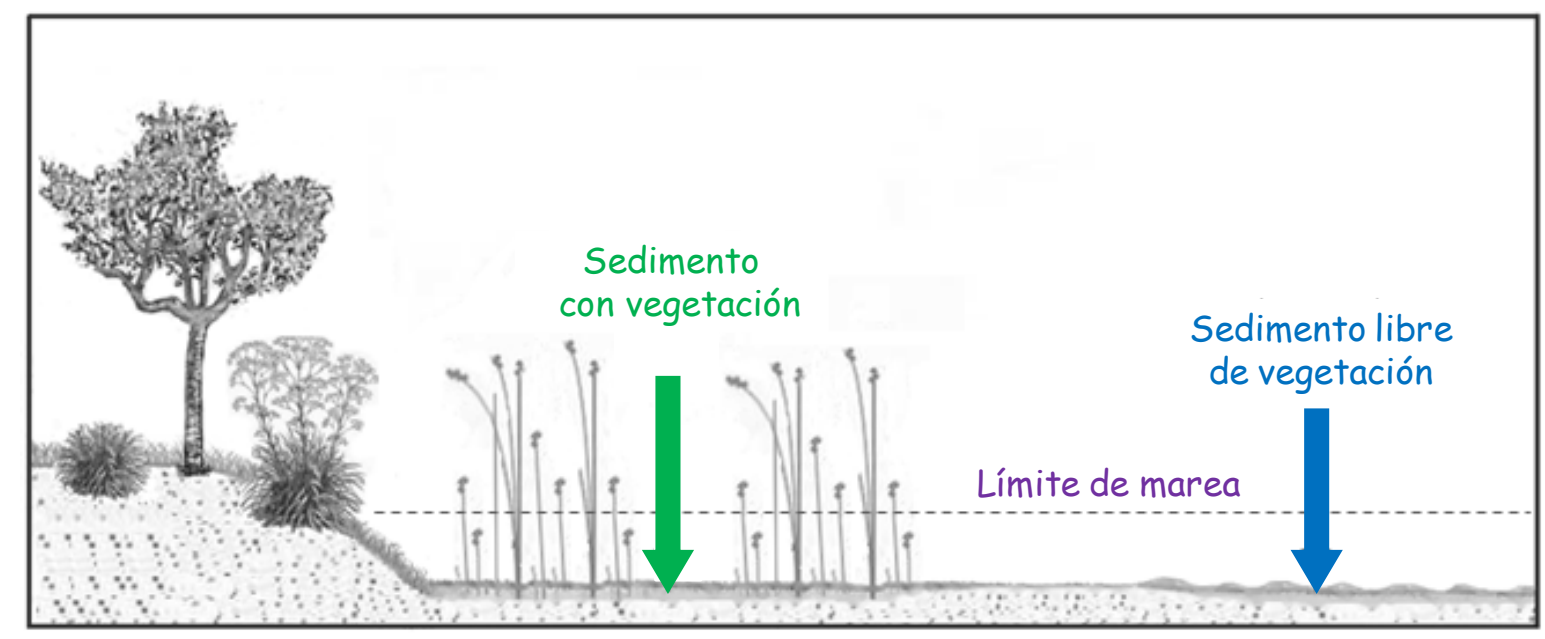

Figura 27. Resumen de los hábitats funcionales principales que ofrece el sector costero del Río de la Plata. 


\section{Análisis de la dieta: Corbicula fluminea y Hyalella curvispina}

Los resultados obtenidos a partir del análisis de la dieta revelaron que el detrito fue el componente más abundante encontrado en los contenidos digestivos de ambas especies analizadas, observándose un aumento significativo de dicho ítem alimentario en los sitios más impactados. En el caso de $C$. fluminea, el detrito representó entre el $50-70 \%$ de la dieta en los sitios poco impactados ( $P L$ y $B A L)$, mientras que en los sitios con alto grado de disturbio (BE y BZ), el porcentaje fue mayor (70-85\% de la dieta). El segundo ítem alimentario consumido por este molusco correspondió a las diatomeas, cuyo porcentaje varió desde un $25 \%$ en los sitios poco impactados hasta un $10 \%$ en aquellos con alto grado de disturbio. Asimismo, se encontraron euglenofitas y protozoos, aunque en porcentaje menor ( $5 \%)$. No se encontraron restos de animales en los contenidos digestivos de los ejemplares analizados (Fig. 28). 

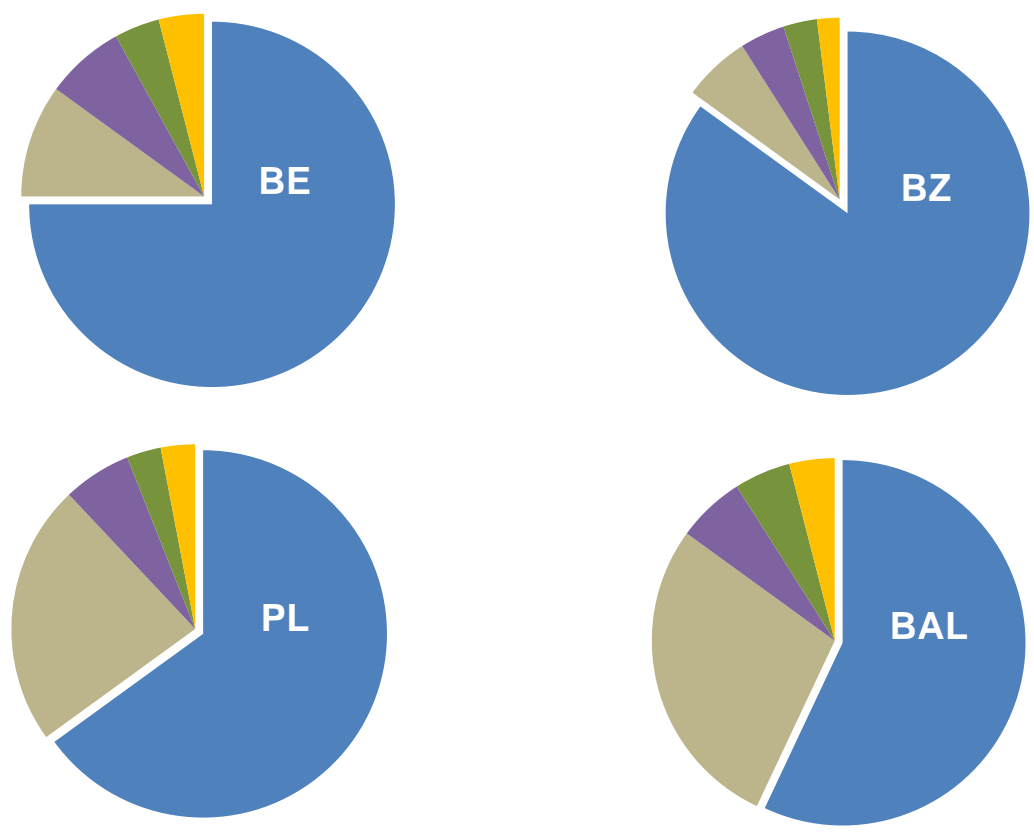

$$
\begin{aligned}
& \text { Detrito } \\
& \text { Euglenofitas/Protozoos } \\
& \text { Material mineral }
\end{aligned}
$$

Figura 28. Porcentaje promedio de los ítems alimentarios encontrados en los contenidos digestivos de Corbicula fluminea.

Los resultados obtenidos en las diferentes tallas de este molusco no revelaron diferencias significativas en los ítems consumidos, dado que el detrito representó más del $50 \%$ en todos los casos, correspondiendo los mayores valores en general a BE y BZ (Fig. 29). 

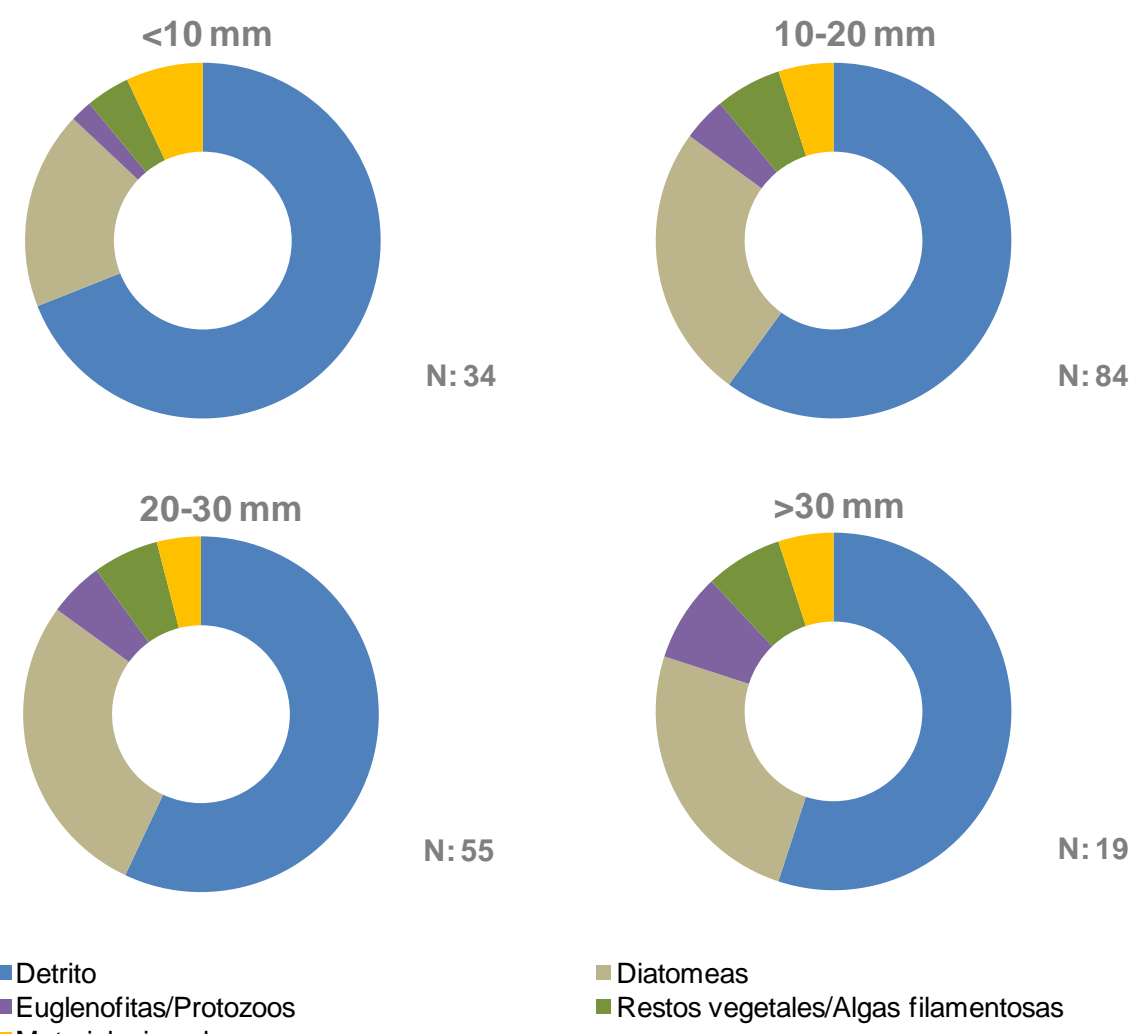

Detrito
Euglenofitas/Protozoos

Material mineral

- Restos vegetales/Algas filamentosas

Figura 29. Porcentaje promedio de los ítems alimentarios encontrados en los contenidos digestivos de las diferentes tallas de Corbicula fluminea.

En el caso de $H$. curvispina, como se mencionara anteriormente, el detrito fue uno de los ítems alimentarios más consumidos; sin embargo, los porcentajes correspondientes fueron menores que en el caso de $C$. fluminea, fluctuando desde $35 \%$ en los sitios poco impactados hasta $55 \%$ en aquellos sitios sometidos a alto grado de disturbio. El segundo ítem alimentario consumido por este crustáceo correspondió a las diatomeas (15-30\%). Las euglenofitas y protozoos ocuparon el tercer lugar (10-15\%), mientras que los restos animales y vegetales fueron encontrados en porcentajes que no superaron el $5 \%$ (Fig. 30). 


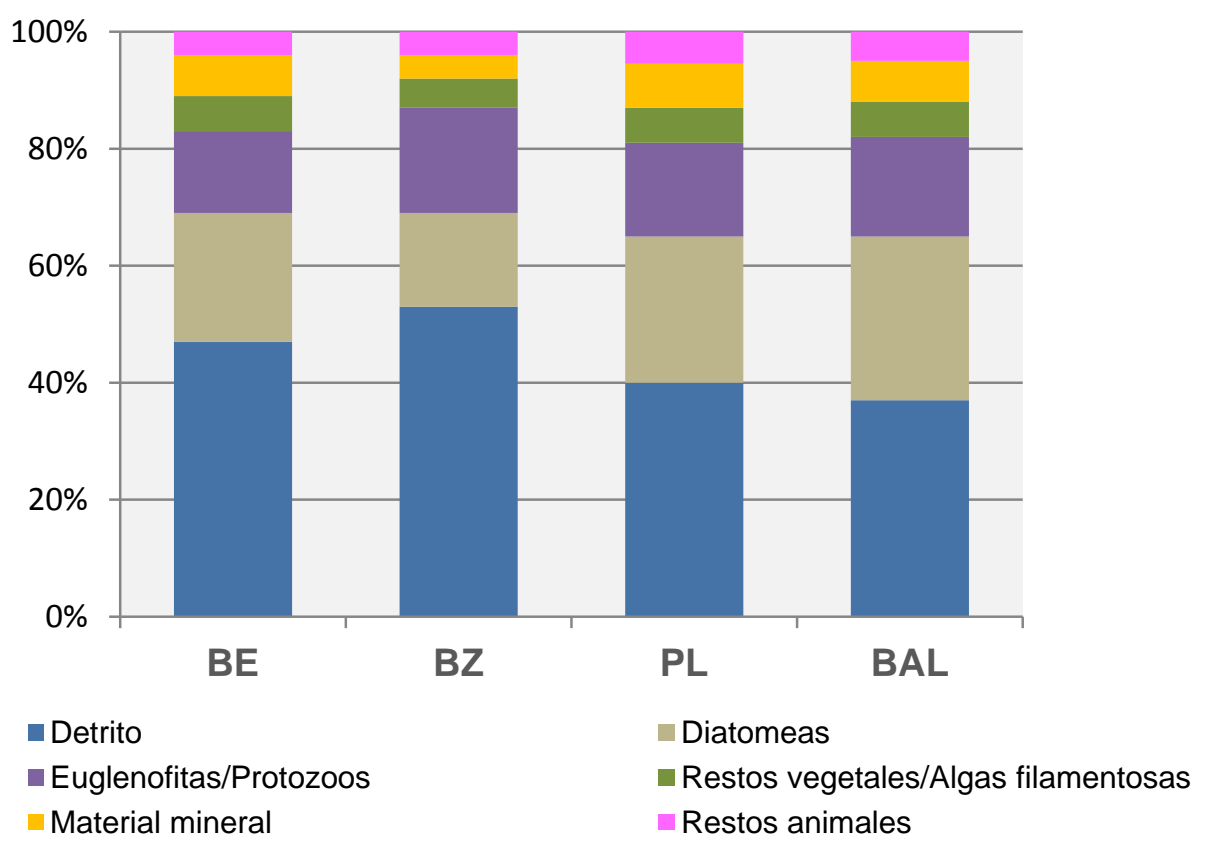

Figura 30. Porcentaje promedio de los ítems alimentarios encontrados en los contenidos digestivos de Hyalella curvispina.

Los resultados obtenidos del análisis comparativo entre machos y hembras de este crustáceo no mostraron diferencias significativas entre ambos sexos, registrándose porcentajes similares en cada ítem alimentario en todos los sitios y oportunidades muestreadas (Fig. 31). En ambos casos, los ítems alimentarios más consumidos fueron el detrito, que representó más del $40 \%$ de su dieta, las diatomeas, con porcentajes que en ocasiones superaron el $25 \%$, y las euglenofitas y protozoos, con porcentajes fluctuantes entre $10-15 \%$, registrándose en general los mayores valores de este ítem en los machos. 


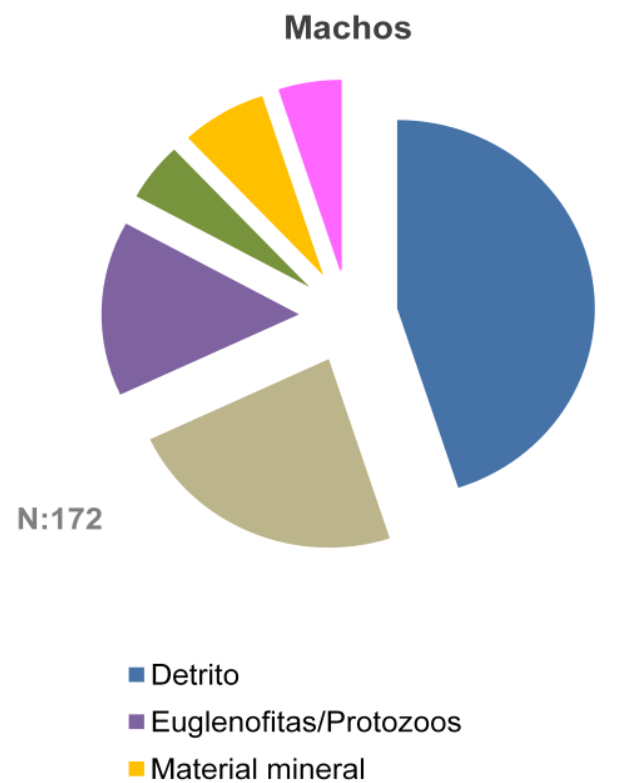

Material mineral

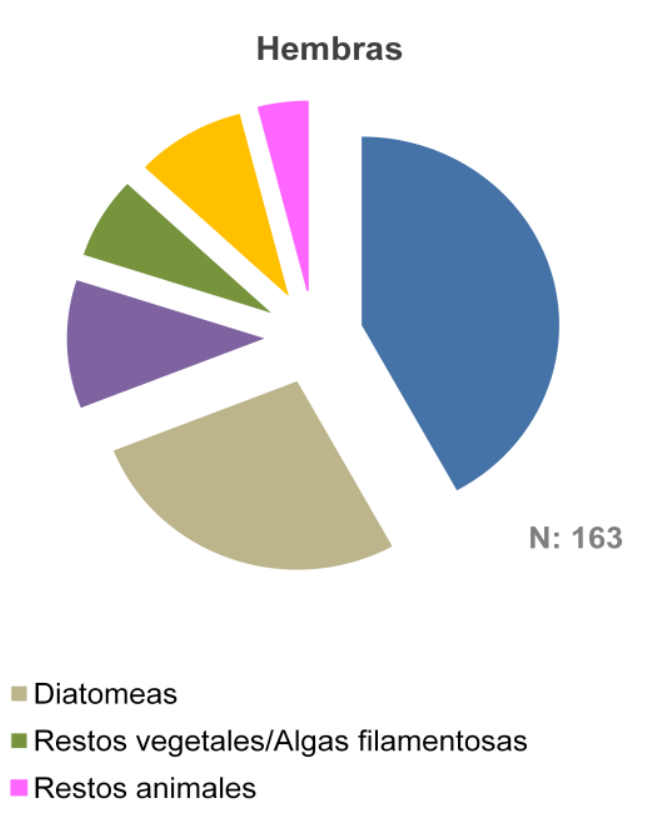

Figura 31. Porcentaje promedio de los ítems alimentarios encontrados en los contenidos digestivos de machos y hembras de Hyalella curvispina.

Al analizar los diagramas de Amundsen realizados para C. fluminea (Fig. 32a) y $H$. curvispina (Fig. 32b) puede observarse que la estrategia alimentaria de utilizada por ambas especies correspondería a la categoría generalista, dado que se alimentan fundamentalmente de detrito. Las frecuencias de ocurrencia de detrito, diatomeas y material mineral fueron elevadas en ambas especies, constituyéndose el detrito como el componente más representativo de la dieta (>50\%). Las diatomeas correspondieron al segundo ítem más consumido por ambas especies. Si bien se encontraron restos animales y vegetales en los contenidos del tracto digestivo de las mismas, las abundancias y frecuencias de estos ítems fueron bajas. 


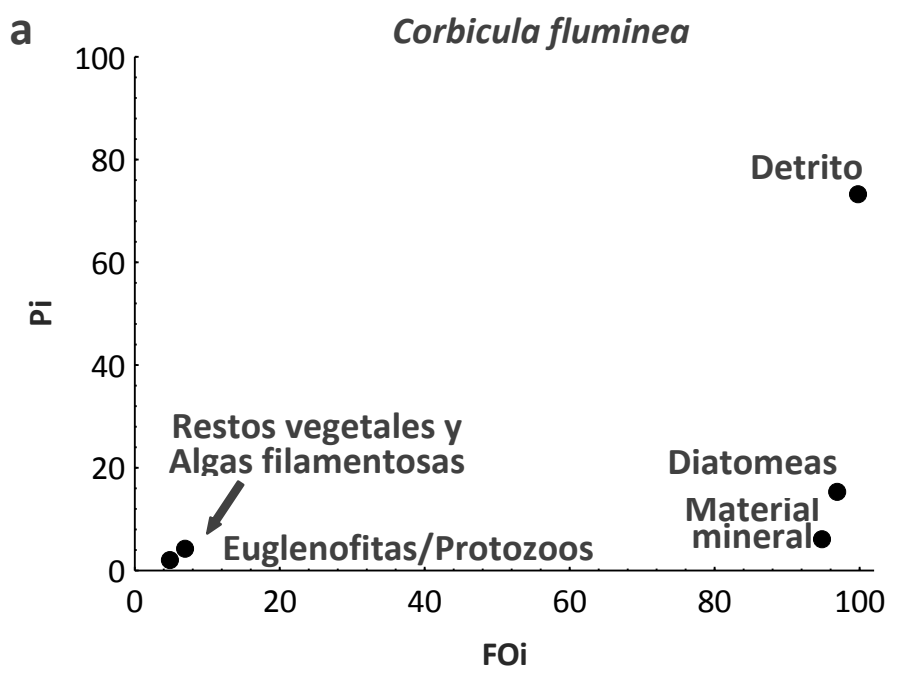

b

Hyalella curvispina

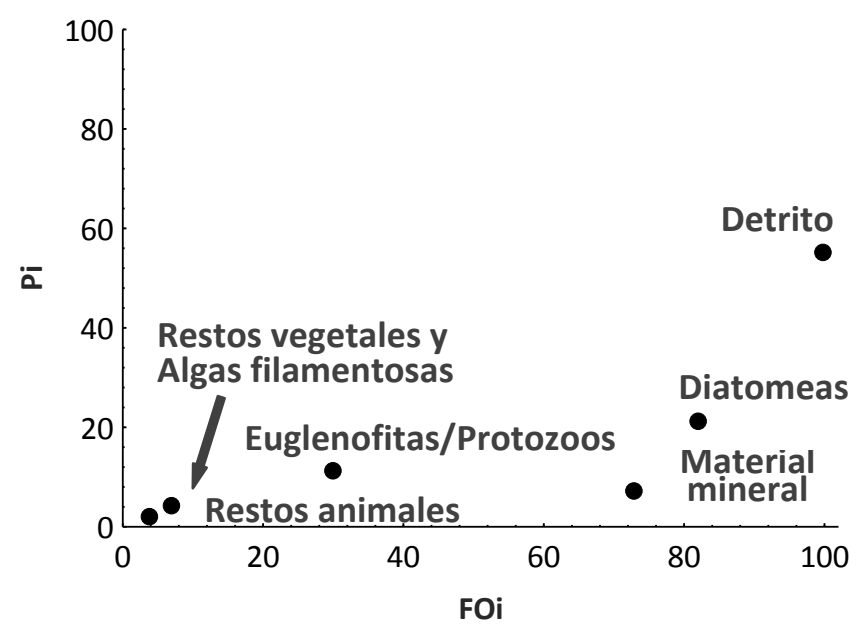

Figura 32. Diagramas de Amundsen para a: Corbicula fluminea, b: Hyalella curvisvina durante el período de estudio. Pi: abundancia, en porcentaje, de un determinado ítem alimentario; FOi: frecuencia de ocurrencia. 
Composición estequiométrica y análisis de isótopos estables:

El análisis de la composición estequiométrica de los macroinvertebrados más representativos $H$. curvispina y $C$. fluminea mostró que, en términos generales, los valores promedio del contenido de $\mathrm{C}$ de las especies mencionadas fueron mayores en los sitios poco impactados $\left(38,2 \mathrm{mg} \mathrm{g}^{-1}\right.$ en $\mathrm{H}$. curvispina y $49,7 \mathrm{mg} \mathrm{g}^{-1}$ en C. fluminea). Por otra parte, los valores promedio del contenido de $\mathrm{N}$ y $\mathrm{P}$ fueron mayores en los ejemplares de $H$. curvispina colectados en los sitios considerados poco impactados $\left(8,4\right.$ y $12,5 \mathrm{mg} \mathrm{g}^{-1}$, respectivamente), mientras que estos valores fueron mayores en los ejemplares de $C$. fluminea capturados en los sitios más contaminados (9,5 y $7,76 \mathrm{mg} \mathrm{g}^{-1}$, respectivamente). Las relaciones estequiométricas (molares) calculadas para ambas especies en el área de estudio se resumen en la Tabla 19. Si bien no se encontraron diferencias significativas, puede observarse que en $H$. curvispina las proporciones $\mathrm{C}: \mathrm{N}$ y N:P fueron similares en todos los sitios de estudio. Las relaciones C:P fueron mayores en los sitios más impactados. Asimismo, para $C$. fluminea las proporciones $\mathrm{C}: \mathrm{N}$ y $\mathrm{N}: \mathrm{P}$ fueron similares en todos los sitios de muestreo, mientras que en general las relaciones C:P en esta especie fueron superiores en los sitios menos perturbados, especialmente en BAL. 
Tabla 19. Promedio y desvío estándar de las relaciones estequiométricas (molares) para Hyalella curvispina y Corbicula fluminea en los sitios de muestreo estudiados.

\begin{tabular}{|c|c|c|c|c|c|c|}
\hline & \multicolumn{2}{|c|}{ C:N } & \multicolumn{2}{|c|}{ C:P } & \multicolumn{2}{|c|}{$\mathbf{N}: P$} \\
\hline & Promedio & DS & Promedio & DS & Promedio & DS \\
\hline \multicolumn{7}{|c|}{ Hyalella curvispina } \\
\hline BE & 4,046 & 0,146 & 20,504 & 6,821 & 5,032 & 1,541 \\
\hline BZ & 4,001 & 0,175 & 19,538 & 9,931 & 4,836 & 2,295 \\
\hline PL & 3,962 & 0,069 & 12,185 & 0,112 & 3,076 & 0,025 \\
\hline BAL & 3,994 & 0,243 & 12,090 & 0,441 & 3,056 & 0,010 \\
\hline \multicolumn{7}{|c|}{ Corbicula fluminea } \\
\hline BE & 4,313 & 0,676 & 25,673 & 1,475 & 6,022 & 0,723 \\
\hline BZ & 4,424 & 0,254 & 24,198 & 5,166 & 5,487 & 1,273 \\
\hline PL & 5,035 & 0,619 & 26,346 & 3,404 & 5,233 & 0,284 \\
\hline BAL & 4,974 & 0,893 & 32,576 & 10,321 & 6,459 & 1,259 \\
\hline
\end{tabular}

En relación a la composición isotópica $\left(\delta^{13} \mathrm{C}\right.$ y $\left.\delta^{15} \mathrm{~N}\right)$ en las especies analizadas (Tabla 20), si bien no se encontraron diferencias significativas entre los sitios de estudio, puede observarse que en promedio las señales isotópicas de nitrógeno fluctuaron entre $10,2 \%$ (BZ) y $14,1 \%$ (PL) en $H$. curvispina, mientras que para $C$. fluminea lo hicieron entre $11,05 \%$ (BZ) y $15,37 \%$ (PL). Por su parte, los valores promedio correspondientes a las señales isotópicas de carbono oscilaron entre $-23,05 \%$ (BZ) y $-24,88 \%$ (PL) en $H$. curvispina, y entre $-24,1 \%$ oo $(B E)$ y $-25,75 \%(P L)$. 
Tabla 20. Promedio y desvío estándar de los isótopos estables $\left(\delta^{13} \mathrm{C}\right.$ y $\left.\delta^{15} \mathrm{~N}\right)$ para Hyalella curvispina y Corbicula fluminea en los sitios de muestreo estudiados.

\begin{tabular}{llllll}
\hline & \multicolumn{2}{c}{$\boldsymbol{\delta}^{\mathbf{1 3}} \mathbf{C}$} & & \multicolumn{2}{c}{$\boldsymbol{\delta}^{\mathbf{1 5}} \mathbf{N}$} \\
\cline { 2 - 3 } \cline { 5 - 6 } & Promedio & DS & & Promedio & DS \\
\hline Hyalella curvispina & & & & & \\
BE & $-23,746$ & 0,205 & & 11,615 & 1,591 \\
BZ & $-23,048$ & 0,782 & & 10,216 & 3,569 \\
PL & $-24,880$ & 1,025 & & 14,137 & 1,735 \\
BAL & $-24,667$ & 0,992 & & 10,604 & 0,895 \\
Corbicula fluminea & & & & & \\
BE & $-24,099$ & 1,269 & & 13,891 & 1,589 \\
BZ & $-24,827$ & 1,487 & & 11,404 & 0,390 \\
PL & $-25,754$ & 0,889 & & 15,376 & 0,998 \\
BAL & $-25,716$ & 1,235 & & 11,048 & 0,937 \\
\hline
\end{tabular}

En la Tabla D de la sección ANEXO se incluyen valores para la composición estequiométrica e isótopos estables de otras especies de macroinvertebrados (Palaemonetes argentinus, Heleobia piscium, Trichodactylus panoplus) registradas en el área de estudio pero que no fueron incluidos en este análisis por no presentar datos para todos los sitios y/o fechas de muestreo, lo cual no permitió un análisis comparativo. 


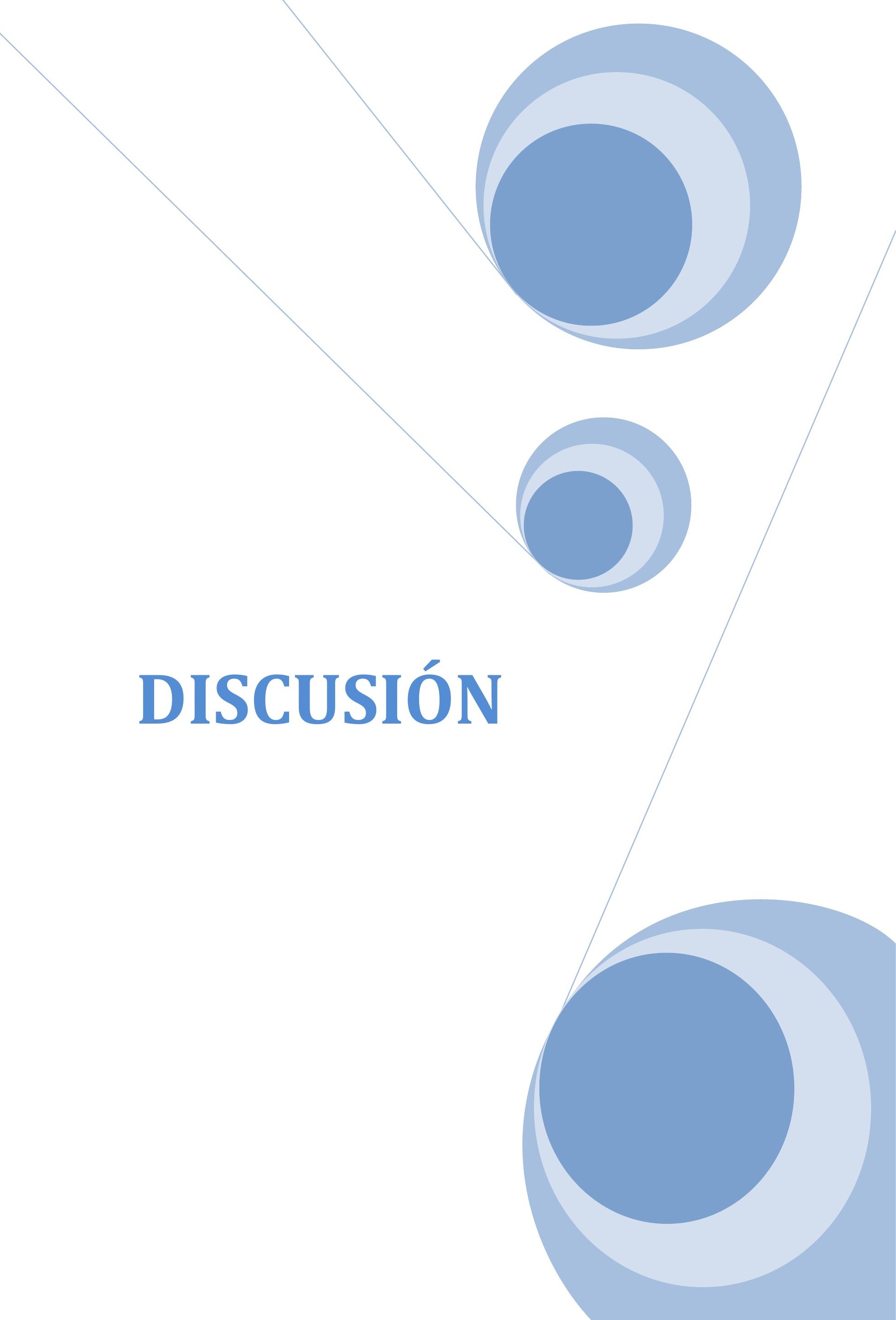


Durante el presente trabajo de Tesis se evaluó la calidad de los hábitats en varios sitios sometidos a diverso grado de impacto antropogénico, ubicados a lo largo del sector costero de agua dulce del Río de la Plata. Para ello se consideraron dos distintos enfoques principales: 1) diferenciación de los sitios de muestreo y sus hábitats funcionales según los parámetros físico-químicos y la biota presente en cada uno de ellos, y 2) evaluación de las estrategias alimentarias de las especies de macroinvertebrados más representativas (Hyalella curvispina y Corbicula fluminea) en estos sitios. La relación entre estos aspectos se espera contribuyan a la aproximación del conocimiento del estado ecológico de los sectores considerados.

\section{Hábitat}

El análisis de los datos físico-químicos ha permitido diferenciar aquellos sitios asociados a mejores condiciones en la calidad del agua (que se reflejaron en una mayor oxigenación y menores concentraciones de nutrientes y materia orgánica), de aquellos sitios más perturbados, asociados a altos niveles de nutrientes, conductividad y demandas de oxígeno. Por su parte, los resultados del análisis multivariado sugieren que la mayoría de las variaciones observadas en el área de estudio se deben principalmente a la polución de origen antropogénico, y en menor medida a la dinámica propia del estuario. Los resultados obtenidos en la presente investigación coinciden en términos generales con lo mencionado por diversos autores para el área costera rioplatense (Armendáriz et al., 2011; Gómez et al., 2012). Más aún, diversos estudios han demostrado que en los sitios con mala calidad del agua, ya sea debido a la escorrentía urbana o a los vertidos industriales, los niveles de metales pesados generalmente han superado los límites estándares para la 
protección de la vida acuática e incluso el límite de exposición permisible (Lammel et al., 1997; FREPLATA, 2005; INA, 2011).

En relación al estudio de los mesohábitats, de acuerdo con diversos autores el tipo de flujo de agua es un factor que debería ser considerado en la identificación de los mismos (Buffagni et al., 2000; Storey \& Lynas, 2007; Príncipe, 2008) debido a que influye sobre la distribución de los organismos. En el caso del Río de la Plata, el efecto de las ondas de marea que lo recorren diariamente origina fenómenos hidráulicos complejos (Balay, 1961; Lanfredi et al., 1979). Según Kemp et al. (1999), existen diferentes procesos que determinan el número y frecuencia de hábitats posibles en un sistema dado. Sin embargo, de los mesohábitats potenciales (distinguidos en base a sus características físicas), sólo aquellos que presenten diferencias significativas en los ensambles de macroinvertebrados pueden ser determinados como hábitats funcionales (Storey \& Lynas, 2007). En el presente estudio, se definieron en principio dos mesohábitats potenciales por observación a simple vista en la zona intermareal del Río de la Plata: "sedimento libre de vegetación" y "sedimento asociado a la vegetación". Debe recordarse que este último caso se refiere al sedimento encontrado entre los "parches" del junco $S$. californicus, el cual se establece como la vegetación riparia dominante en todo el sector costero estudiado, cuando no la única. Los resultados obtenidos en este estudio mostraron diferencias claras entre estos dos compartimentos no sólo debido a sus características físicas, sino también a los ensambles de macroinvertebrados que éstos albergan, estableciéndose entonces como las principales opciones de asentamiento y desarrollo de los invertebrados acuáticos en este tipo de sistema. De acuerdo con varios estudios, los sustratos duros colonizados por Limnoperna fortunei, así como los conglomerados 
formados por gran cantidad de estos individuos asociados mediante sus bisos, proporcionan nuevos refugios con recursos alimentarios para el complejo bentónico (Darrigran et al., 1998; Boltovskoy et al., 2006; Sardiña et al., 2008; Spaccesi \& Rodrigues Capítulo, 2012). Así, podría decirse que estos asentamientos actúan como hábitats capaces de ser colonizados por asociaciones de organismos bentónicos dado que brindan un ambiente propicio para el establecimiento y supervivencia de los mismos. Sin embargo, debido a que dichos microambientes ocupan un margen muy estrecho y discontinuo bajo el agua (Spaccesi \& Rodrigues Capítulo, op cit.), el estudio comparativo de los mismos en diversas situaciones de stress a lo largo del sector intermareal puede verse dificultado. Finalmente, tomando la idea de Buffagni et al. (2000), conociendo la importancia ecológica de los hábitats será posible mantener hábitats funcionales específicos con el fin de proteger especies raras o en peligro de extinción, protegiendo la morfología natural de las riberas.

En relación con el contenido de materia orgánica del sedimento (MO), las principales diferencias encontradas correspondieron a los hábitats estudiados dado que, como era de esperarse, en el sedimento libre de vegetación predominó la fracción fina (MOPF), mientras que en el sedimento vinculado a la vegetación predominó la fracción gruesa (MOPG). Por su parte, la comparación entre los sitios estudiados evidenció que los mayores porcentajes de MO total correspondieron a aquellos sitios sometidos a un alto grado de impacto ambiental, donde el principal aporte es de origen antropogénico. Asimismo, el análisis granulométrico permitió establecer que el sedimento fue principalmente arenoso en todos los sitios y hábitats estudiados. Cabe destacar el sitio con mayor grado de impacto urbano e 
industrial (BE) se diferenció significativamente de los restantes por presentar los mayores porcentajes de grava. Por su parte, el sitio con mayor grado de impacto producto de los desechos domiciliarios y cloacales (BZ) se diferenció de los restantes por presentar los mayores porcentajes de limo y arcilla en el sedimento asociado a la vegetación. Estos resultados coinciden con los obtenidos por Rodrigues Capítulo et al. (2009), Gómez et al. (2009, 2012), Armendáriz et al. (2011) para el sector estudiado, quienes mencionan al área como una de las más afectadas de la costa rioplatense, desde el punto de vista de los efluentes y descargas.

\section{Macroinvertebrados}

En relación con la biota, se identificaron un total de 91 taxa en el sedimento asociado a la vegetación y 43 taxa en el sedimento libre de ella. A partir del estudio comparativo se observó que los descriptores estructurales de la biota (riqueza taxonómica, diversidad de Shannon-Wiener y equitabilidad) mostraron diferencias significativas entre los mesohábitats estudiados, registrándose valores superiores para todos ellos en el sedimento de las zonas vegetadas. Estos índices no reflejaron diferencias significativas entre los sitios más afectados por el impacto humano y aquellos con mayor grado de naturalidad costera. En este sentido, Rosenberg \& Resh (1996) criticaron la aseveración de que un valor alto de diversidad indica una comunidad balanceada y estable. Esto podría deberse a que la mayoría de las medidas de diversidad se calculan en función de la riqueza de especies y/o la distribución de la abundancia de las mismas, sin tomar en cuenta el tipo de organismos presentes y la capacidad de los mismos de adaptarse a los cambios de las condiciones del ambiente (Segnini, 2003; Ocon \& Rodrigues Capítulo, 2004). 
En cuanto a los principales grupos taxonómicos registrados, los nematodes y oligoquetos estuvieron presentes en todos los sitios de estudio, correspondiendo las mayores abundancias a aquellos altamente impactados por descargas urbanas. Entre los oligoquetos, los Tubificinae dominaron en los sitios más disturbados, mientras que los Naidinae predominaron en el sedimento de las zonas vegetadas de Berazategui (BZ) y de los sitios menos impactados (PL y BAL). De acuerdo con Rodrigues Capítulo et al. (1998) y Cortelezzi et al. (2007), los nematodes y oligoquetos son los más frecuentes y abundantes organismos bentónicos en los sustratos blandos del estuario, y principalmente en las zonas con alto contenido de $\mathrm{MO}$ en los sedimentos. Por su parte, aunque estuvieron presentes en todos los sitios de estudio, los moluscos y crustáceos se registraron en altas densidades en los sitios PL y BAL. El análisis comparativo de los grupos principales de moluscos, reveló una predominancia (en porcentaje) de gasterópodos en los sitios más impactados, correspondiendo a elevadas densidades de Heleobia piscium y Hebetancylus moricandi. Por el contrario, los bivalvos fueron más abundantes en los restantes sitios, destacándose numéricamente Limnoperna fortunei y Corbicula fluminea. Estos resultados coinciden en ciertos aspectos con lo registrado por diversos autores en estudios previos del sector intermareal. Entre ellos, Darrigran \& Damborenea (2005) reportaron altas densidades de los bivalvos mencionados a lo largo de todo el sector de agua dulce del estuario. Asimismo, Cortelezzi et al. (2007) registraron elevadas densidades de gasterópodos en sitios con altas concentraciones de nutrientes y demandas de oxígeno. Los dípteros, representados fundamentalmente por miembros de la familia Chironomidae, fueron registrados en todos los sitios de muestreo durante el período de estudio. Otros grupos, como los odonatos y los efemerópteros 
estuvieron poco representados numéricamente. En particular para estos últimos, la baja frecuencia podría deberse a que requieren de condiciones ambientales estables para su desarrollo, por lo que no son capaces de mantener poblaciones en ríos frecuentemente disturbados (van der Geest et al., 2002). Otra explicación podría relacionarse al efecto de las ondas de marea que recorren diariamente el estuario, razón por la cual los mencionados grupos sólo podrían habitar áreas más protegidas del embate de las mismas.

En relación a la sensibilidad de los organismos, aquellos grupos faunísticos considerados "tolerantes" y "muy tolerantes" (Rodrigues Capítulo et al., 2001) predominaron en todos los sitios y hábitats estudiados, especialmente en aquéllos más perturbados, afectados por la contaminación orgánica e industrial. Los organismos clasificados como "sensibles" sólo se registraron en los sitios poco impactados y con mayor grado de naturalidad costera. Estos resultados coinciden en cierto grado con lo mencionado por Ocon et al. (2008), quienes reportaron que en los sitios altamente poluídos, afectados por un derrame de petróleo, predominaron las especies tolerantes, mientras que los grupos sensibles sólo se registraron en sectores muy alejados del área afectada. Es importante remarcar que la clasificación seguida en el presente estudio fue basada en la propuesta por Rodrigues Capítulo et al. (2001), la cual coincide en algunos casos con las categorías establecidas por otros autores. En este sentido, C. fluminea es considerada una especie tolerante, coincidiendo con lo reportado por Darrigran (1993), quien mencionó que este bivalvo es capaz de tolerar ciertas concentraciones de contaminantes orgánicos, e incluso Cataldo (2001) reportó su capacidad de bioacumular metales pesados en los tejidos blandos. Más aún, Darrigran \& Lagreca (2005) establecieron que los moluscos en general están asociados en mayor o menor 
medida a las categorías de facultativos. Estos mismos autores determinaron que los mesogasterópodos (Heleobia sp. y Pomacea sp.), los uniónidos (sin representantes en este estudio) y con frecuencia los esféridos (como Pisidium sp.) presentan baja resistencia ante los contaminantes orgánicos. Mientras que los gasterópodos basomatóforos (Uncancylus sp., Biomphalaria sp., Physa sp.) presentan mayor tolerancia a este tipo de contaminación. Por su parte, Fernández \& Schnack (1977) categorizaron a H. piscium y Pisidium sterkianum como especies sensibles. En este estudio, ambas fueron consideradas tolerantes de acuerdo a los valores de sensibilidad propuestos por Rodrigues Capítulo (1999) y Gómez \& Rodrigues Capítulo (2001) para ríos pampeanos. Los efemerópteros (Baetidae y Caenidae) registrados en la presente investigación han sido considerados en la categoría de tolerantes. Esto coincide con lo expuesto por Domínguez et al. (1994) quienes propusieron su capacidad de tolerar bajos a moderados disturbios ambientales. Por último, los grupos de odonatos registrados en este estudio han sido clasificados por Mandaville (2002) como sensibles (en el caso de la familia Aeshnidae) y tolerantes a muy tolerantes (en el caso de la familia Coenagrionidae). En el presente estudio, se reconoce una sensibilidad moderada en las larvas de Aeshna bonariensis, y la categoría de tolerantes en la familia Coenagrionidae (sin embargo, debe tenerse en cuenta el nivel de resolución taxonómica alcanzado en este grupo).

En relación a la diversidad reflejada por los diferentes grupos funcionales alimentarios (GFA), los organismos colectores-recolectores (nematodes, oligoquetos, entre otros) dominaron en el sedimento libre de vegetación de todos los sitios de muestreo. Al comparar con el sedimento de las zonas vegetadas se observa que si bien en los sitios más impactados predominaron 
los colectores-recolectores, en los sitios con mayor grado de naturalidad costera y mejores condiciones de calidad estos organismos se vieron reemplazados por los colectores-filtradores. Es importante aclarar en este punto que dentro del grupo Nematoda existe una gran variedad de especies que utilizan diferentes recursos tróficos (Traunspurger, 2000). De acuerdo con Zilli et al. (2008), los nematodes se incluyen dentro del grupo funcional depredador. Sin embargo, no se cuenta con información detallada sobre los tipos de alimentación de los nematodos en los ambientes lóticos y resulta dificultoso una determinación taxonómica más precisa. Por este motivo, de acuerdo con la clasificación seguida en la presente investigación, la cual ha sido basada en publicaciones recientes (Ocon et al., 2013), se ubicó a este grupo dentro de los colectores-recolectores, lo que incrementó en gran medida la proporción de los mismos como grupo alimentario. Coincidiendo en ciertos aspectos con lo registrado en la presente investigación, diversos estudios han demostrado que en arroyos afectados por la contaminación orgánica e inorgánica, con alto grado de impacto antropogénico, los colectoresrecolectores estuvieron ampliamente representados (Miserendino, 2009; Cortelezzi, 2010). Más aún, de acuerdo con Palmer et al. (1993) los detritos finos son utilizados como una importante fuente de alimento por los macroinvertebrados, lo que indica la importancia de la actividad de los colectores-recolectores en los ecosistemas lóticos sudamericanos, donde este recurso abunda. Sin embargo, cuando las condiciones del medio cambian, el predominio de los GFA puede verse modificado. En este sentido, Ocon et al. (2013) registraron un reemplazo de las formas filtradoras por los consumidores de detrito (MOPG y MOPF) en respuesta a incrementos significativos en las concentraciones de nutrientes del medio. Asimismo, Tomanova et al. (2006) 
proponen que las estrategias alimentarias que implican una mayor movilidad en la búsqueda de alimento (depredadores, raspadores) no se verían favorecidas en ambientes inestables o frecuentemente perturbados, como es el caso de la zona costera del Río de la Plata. Por tal motivo, los organismos capaces de sobrevivir en este tipo de ambientes podrían adaptarse a estrategias de tipo colector-recolector de acuerdo con lo propuesto por Lamouroux et al. (2004). Por otra parte, en los sistemas perturbados, la oferta y persistencia de un determinado tipo de alimento puede ser variable, por lo que la capacidad de explotar los recursos puede cambiar potencialmente favoreciendo el desarrollo de los organismos generalistas y manteniendo la estabilidad de la población frente a las fluctuaciones naturales. Asimismo, la baja presencia de depredadores (Chaetogaster spp., Helobdella spp., Semiscolex spp. y odonatos) podría explicarse debido a otros factores, tales como baja tolerancia de los mismos a la contaminación y/o la falta o mala calidad del sedimento donde resguardarse.

A escala de hábitat, los resultados obtenidos en esta investigación evidenciaron diferencias significativas en el sedimento de las zonas vegetadas, entre sitios altamente impactados, con predominio de colectores-recolectores, y aquellos sitios con mayor grado de naturalidad costera, donde predominaron los colectores-filtradores. Por su parte, en el sedimento libre de vegetación, no se encontraron diferencias significativas, dado que en todos los casos el grupo dominante fue el de los colectores-recolectores. En términos generales, las variables más importantes que explicaron la distribución de los taxa (y sus correspondientes GFA) fueron: por un lado la MOPG, con porcentajes superiores en el sedimento de las zonas vegetadas, y por otro lado la MOPF, la conductividad y las demandas de oxígeno, que permitieron separar los sitios 
altamente impactados de aquellos sitios con bajo grado de disturbio. En este sentido, la mayor abundancia de los fragmentadores en los sedimentos de las zonas vegetadas podría vincularse a que dichos hábitats retienen más cantidad de MOPG, como se observa en los resultados arrojados por el RDA. Estudios similares fueron realizados en arroyos serranos (Príncipe et al., 2010) y de Ilanura (Zilli et al., 2008), quienes estudiaron el ensamble de los invertebrados bentónicos y sus GFAs, analizando la distribución de los mismos en diferentes hábitats y las variables ambientales que explicaron esa distribución a escala de mesohábitat. Estos autores encontraron que los colectores-recolectores fueron dominantes en la mayoría de los hábitats estudiados, corroborando la importancia de este grupo funcional y del detrito fino como el recurso alimentario principal en estos ecosistemas lóticos. Asimismo, Zilli et al. (2008) encontraron diferencias entre mesohábitats en la composición del ensamble de macroinvertebrados y GFA; mientras que Príncipe et al. (2010) sugirieron que la cantidad y tipo (calidad) de materia orgánica retenida en cada hábitat explicaría el patrón espacio-temporal de distribución de los GFA, lo cual también estaría relacionado con las características propias de las especies, como su fenología y forma de vida. Otros estudios realizados a nivel de hábitat encontraron resultados similares a los referidos (Callisto et al., 2001; Velásquez \& Miserendino, 2003 a y b; Fenoglio et al., 2004; Subramanian \& Sivaramakrishnan, 2005), sugiriendo que uno de los factores más importantes en la distribución de los GFA fue la materia orgánica y el tipo de sustrato.

Sin embargo, debido a la falta de información exacta sobre las categorías alimentarias a las que pertenecen algunos taxa sudamericanos, la mayoría de los estudios neotropicales realizados para la determinación de los grupos funcionales alimentarios se han basado en las clasificaciones establecidas para 
el hemisferio norte (Merritt \& Cummins, 1996; Heino, 2005; Merritt et al., 2008). Según Tomanova et al. (2006) esto puede producir diferencias significativas en la clasificación de los GFA debido a que: 1) la mayoría de los macroinvertebrados son capaces de ocupar al menos dos niveles tróficos, evidenciando un comportamiento alimentario bastante flexible, razón por la cual su agrupación en un único GFA puede ser idealista, y 2) algunos taxa sudamericanos no pueden alimentarse como la mayoría de sus congéneres que habitan en la zona templada, y por tanto no deben ser colocados en el mismo GFA. Además, la composición de la dieta puede variar en función de la disponibilidad de los recursos alimentarios (Palmer et al., 1993; Díaz Villanueva \& Albariño, 1999), y de los mecanismos utilizados por los taxa del hemisferio sur en la obtención de dichos recursos (Covich, 1988). En consecuencia, la estructura resultante de las comunidades neotropicales basada en los GFA establecidos para el hemisferio norte, donde cada taxa es asignado a una sola categoría trófica (Poi de Neiff, 1990; Callisto et al., 2001; Buss et al., 2002; Miserendino \& Pizzolón, 2004; Cortelezzi et al., 2010) así como la de este estudio, puede resultar sesgada.

En relación a los modos de vida, los organismos apoyados (nematodes, bivalvos) dominaron en el sedimento libre de vegetación de todos los sitios de muestreo. Sin embargo, se encontraron diferencias en el sedimento de las zonas vegetadas, dado que en los sitios menos perturbados predominaron las formas aferradas (tales como los gasterópodos). Esto coincide con lo propuesto por Frady (2005), según el cual los apoyados bentónicos habitan la superficie de los sedimentos finos, o en determinados casos las acumulaciones de materia orgánica. Asimismo, según este mismo autor, algunos macroinvertebrados minadores habitan en los sedimentos finos mientras que 
otros se refugian en las acumulaciones de materia orgánica. Esto coincide con lo encontrado en algunos sitios del presente estudio, donde se combinaron ambos aspectos: sedimentos finos y moderada acumulación de materia orgánica, favoreciendo la aparición de estas formas. Sin embargo, ninguno de los grupos mencionados se estableció como dominante. De acuerdo con los resultados obtenidos, podría decirse que la mayor diversidad de modos de vida registrada, en general, en los sitios menos perturbados estaría sugiriendo que los macroinvertebrados responden favorablemente a la calidad y disponibilidad de hábitats en el río.

Respecto al estatus de calidad ecológica estimado en los sitios estudiados mediante el cálculo del IMRP, los puntajes obtenidos sugirieron una contaminación débil a escasa en los sitios más impactados (BE y BZ) y escasa a muy leve/nula en los sitios menos perturbados y con mayor grado de naturalidad costera (PL y BAL). Sin embargo, al analizar estos resultados deben tenerse en cuenta dos aspectos fundamentales. El primero, en relación a la aplicabilidad del índice en el sector estudiado, dado que este índice ha sido elaborado con el fin de establecer la calidad del agua de la cuenca MatanzaRiachuelo (Rodrigues Capítulo et al., 1997) y está adaptado de los índices desarrollados por Armitage et al. (1983) y Alba Tercedor \& Sánchez Ortega (1988). El segundo, podría deberse a una diferencia de "escala" en los valores de sensibilidad ecológica asignados para los taxa en el río o estuario en relación a los valores asignados para los taxa característicos de arroyos.

\section{Análisis de la dieta: Corbicula fluminea y Hyalella curvispina}

En Argentina, son varios los trabajos que han abarcado el estudio de los contenidos digestivos y la composición estequiométrica e isotópica con el fin 
de establecer los GFA y las relaciones tróficas de los invertebrados de agua dulce. Albariño (1998) estudió la alimentación de plecópteros en la zona austral andina de Argentina, en tanto que Miserendino (2001) estudió la alimentación de algunos invertebrados en ríos de la Patagonia austral. Sin embargo, para el área pampeana estos estudios son aún incipientes y se han llevado a cabo en arroyos de llanura con elevada concentración de nutrientes (López Van Oosterom et al., 2013; Ocon et al., 2013).

En relación al análisis de los contenidos digestivos de $C$. fluminea y $\mathrm{H}$. curvispina, los resultados mostraron una predominancia del detrito en la dieta de ambas especies, alcanzando el $85 \%$ en el primer caso y el $55 \%$ en el segundo, registrándose los mayores porcentajes en los sitios sometidos a alto grado de disturbio. En ambos casos, las diatomeas se establecieron como el segundo ítem alimentario más consumido. Las euglenofitas y protozoos, si bien se encontraron en los contenidos digestivos de ambas especies, en el caso de C. fluminea los porcentajes fueron menores al 5\%, mientras que en $H$. curvispina este porcentaje fue mayor (10-15\%). Por su parte, los restos vegetales se encontraron en porcentajes muy bajos, y en el caso de los restos animales no se registraron en los digestivos de los ejemplares analizados de $C$. fluminea.

En términos generales, los resultados mencionados anteriormente eran esperables, dado que de acuerdo con diversos estudios (Tomanova et al., 2006; Motta \& Uieda, 2004; Henriques Oliveira et al., 2003) los detritos son abundantes en los ecosistemas de agua dulce de Sudamérica. De esta manera, la ocurrencia de este recurso en el digestivo se debe principalmente a su elevada disponibilidad en el hábitat. Asimismo, varios estudios han establecido que el detrito es una fuente de nutrición clave en las redes tróficas (Cummins 
et al., 1966; Hildrew et al., 1985; Closs \& Lake, 1994; Acuña et al., 2005; Ocon et al., 2013). Más aún, Shieh et al. (2002) afirmaron que, con excepción de los depredadores, todos los taxa de invertebrados consumen una mayor cantidad de detrito en relación a cualquier otro tipo de alimento. Así, este recurso alimentario abundante sería muy ventajoso en ambientes nutricionalmente inestables. Por otra parte, resulta evidente que, en función de la disponibilidad de recursos alimentarios, la composición de la dieta puede variar estacionalmente y entre hábitats (Palmer et al., 1993; Díaz Villanueva \& Albariño, 1999; Albariño, 2001). En este sentido, los resultados obtenidos en la presente investigación, no mostraron diferencias significativas temporales para la dieta de las especies cuyos contenidos digestivos fueron analizados, y esto podría relacionarse a una disponibilidad de recursos alimentarios constante a lo largo del año. En resumen, a partir del análisis de los contenidos digestivos, podría decirse que $C$. fluminea y $H$. curvispina son especies generalistas, que se alimentan principalmente de materia orgánica (detrito), correspondiendo la estrategia alimentaria utilizada a la categoría "colector-recolector". Asimismo, el registro ocasional de restos animales en los contenidos digestivos de $H$. curvispina podría vincularse al tipo de estrategia alimentaria utilizada.

En el caso particular de $C$. fluminea, las tallas de los ejemplares cuyos contenidos fueron analizados coinciden con los reportados en ejemplares adultos en diversos estudios (Boltovskoy et al., 1995; Cataldo, 2001; McMahon, 2000). Los resultados encontrados en este estudio en relación a la dieta de este molusco coinciden con lo reportado en un arroyo de llanura pampeana por Ocon et al. (2013). Estos autores registraron un consumo predominante de detrito (MOPG principalmente) en la dieta de dicho molusco, seguido por el consumo de diatomeas. Asimismo, aunque en baja proporción, 
hallaron evidencias de consumo de materia animal. Por su parte, Boltovskoy et al. (1995) reportaron para C. fluminea una dieta rica en fitoplancton de gran tamaño. Esta podría ser atribuida a una alimentación por filtración, asociada con otro tipo de estrategia alimentaria en situaciones de escasez de alimento: alimentación de depósito. Esta capacidad de alimentarse de componentes que habitan la columna de agua y los sedimentos del fondo, ha sido sugerida previamente por Way et al. (1990) y más recientemente por Wittman et al. (2008). Más aún, Aldridge \& McMahon (1978) mencionaron que una alimentación filtradora no cubre los requerimientos energéticos de este molusco, reforzando la suposición de que el detrito es una fuente significativa para la nutrición del mismo, especialmente en situaciones donde el alimento escasea. Por otra parte, de acuerdo con Boltovskoy et al. (1995), el cambio en la dieta de $C$. fluminea en respuesta a la escasez total de alimento evidenció la ausencia de selectividad alimentaria. En el caso del Río de la Plata, como se mencionara anteriormente, la alta turbidez genera una baja transparencia del agua y el desarrollo del fitoplancton puede verse limitado. Por esta razón, este bivalvo se vería forzado a emplear el detrito como recurso alimentario principal, y esto se comprobaría con las elevadas cantidades de este ítem halladas en los estómagos analizados. En este sentido, Motta \& Uieda (2004) proponen que la flexibilidad en el modo de alimentación facilita la adaptación de los organismos acuáticos a los cambios en la disponibilidad de alimento en un ambiente dado. Consecuentemente, Albariño \& Díaz Villanueva (2006) indicaron que una estrategia generalista permitiría una mejor adaptación a los cambios impredecibles en las condiciones ambientales cuando recursos específicos pueden no estar disponibles. 
En el caso particular de $H$. curvispina, debe mencionarse que esta especie ha sido considerada en distintos GFAs según diferentes autores. De acuerdo con Cummins et al. (2005), Zilli et al. (2008) y Príncipe et al. (2010), esta especie debería ser incluida en el grupo fragmentador, mientras que Wantzen \& Wagner (2006) han sugerido que es una especie depredadora y Poi de Neiff et al. (2006) indican que pertenece al grupo colector-recolector. En este sentido, coincidiendo con Motta \& Uieda (2004), es común encontrar diferentes asignaciones de los invertebrados a GFA porque los estudios basados en el análisis de los contenidos digestivos son aún escasos, y el tipo de alimentación puede cambiar durante el ciclo de vida de un organismo. Como se refiriera anteriormente, de acuerdo con el análisis de la dieta realizado en la presente investigación, $H$. curvispina debería ser incluida en el grupo funcional colector-recolector.

En relación al análisis de la composición estequiométrica, se encontraron diferencias (no significativas) en las proporciones molares $\mathrm{C}: \mathrm{N}, \mathrm{C}: \mathrm{P}$ y N:P de los taxa estudiados ( $H$. curvispina y $C$. fluminea). Frost et al. (2003) reportaron diferencias similares en distintos grupos de invertebrados litorales. Estos autores encontraron que la proporción C:P, por ejemplo, fue mucho más baja en anfípodos que en otros grupos de macroinvertebrados y sugirieron que las diferencias en la composición elemental entre taxa indicarían que algunos consumidores bentónicos son más susceptibles que otros al efecto de un alimento pobre en nutrientes. En este sentido, debe tenerse en cuenta que, de acuerdo con Finlay \& Kendall (2007) existen cinco fuentes principales de MO (viva o muerta) que están disponibles en un ambiente acuático, y entre éstas incluyen dos fuentes alóctonas (detritos procedentes de plantas terrestres y 
suelos), dos fuentes autóctonas (macrófitas y algas acuáticas), y bacterias y hongos acuáticos heterotróficos.

Respecto a la composición isotópica, puede observarse que, en términos generales, los valores de $\delta^{15} \mathrm{~N}$ fueron superiores a $9 \%$ en ambas especies $\mathrm{y}$ comúnmente más altos que los datos reportados por otros autores en regiones neotropicales (Molina et al., 2011). De acuerdo con López Van Oosterom et al. (2013), estos valores más elevados indicarían una dieta omnívora en los macroinvertebrados analizados. Por otra parte, se ha mencionado que valores isotópicos más elevados podrían asociarse con ambientes poluídos, mientras que valores bajos de estos isótopos se vincularían a condiciones más prístinas, con mejor calidad del agua (Newsome et al., 2007). En el caso particular del Río de la Plata, Botto et al. (2011) realizaron un análisis de isótopos estables para explorar la importancia relativa de las diferentes fuentes de producción primaria en las tramas tróficas del sector salino del estuario. Sus resultados evidenciaron que el fitoplancton y el detrito fueron los principales recursos que contribuyeron a la trama trófica de dicho sector, actuando como importantes fuentes de energía en este ambiente.

\section{Hábitat-Biota}

En resumen, la interacción hábitat-biota reveló diferencias significativas entre los grandes compartimentos considerados originalmente como potenciales hábitats funcionales. Estas diferencias fueron evidentes en algunos grupos taxonómicos y descriptores estructurales de riqueza de taxa, diversidad y equitabilidad. Las mayores densidades de nematodes y oligoquetos se registraron en general en el sedimento libre de vegetación, mientras en el sedimento de las zonas vegetadas los moluscos y crustáceos predominaron 
sobre los restantes taxa. Por su parte, todos los descriptores estructurales evidenciaron valores superiores en el sedimento de las zonas vegetadas. En particular, los mayores valores de riqueza de taxa se registraron en los sitios con mejor calidad ecológica, correspondiendo a Punta Lara y Balandra (PL y BAL). Esto podría asociarse, a su vez, con una mejor calidad de los hábitats en estos sitios. Coincidentemente, Buffagni et al. (2000), reportaron que las macrófitas se establecieron como los hábitats funcionales con mayores valores de riqueza de taxa, heterogeneidad y densidad por muestra. Asimismo, Gregg \& Rose (1985) sugirieron que las macrófitas actúan como refugios contra el stress hidráulico por presentar grandes superficies de asentamiento de algas y fauna acuática.

En cuanto a la presencia de los grupos taxonómicos en los diferentes hábitats, los nematodes y oligoquetos (Tubificinae y Naidinae) mostraron preferencias por el hábitat sedimento libre de vegetación, mientras que los crustáceos y moluscos presentaron una preferencia por el sedimento de las zonas vegetadas. Por otra parte, al comparar los grupos principales de moluscos, los bivalvos mostraron preferencia por el sedimento libre de vegetación, mientras que los gasterópodos, se vincularon preferentemente al sedimento de las zonas vegetadas, especialmente en aquellos sitios poco impactados. Sin embargo, la proporción de cada grupo en los hábitats mencionados puede variar según las características físico-químicas del agua y la calidad del hábitat. Por esta razón, cuando el sedimento libre de vegetación presenta algún tipo de disturbio que afecta la presencia de los organismos, éstos deben migrar hacia las zonas vegetadas, o bien, se encuentran en distinta proporción (menor abundancia). La falta de diferencias entre sitios de muestreo en el sedimento libre de vegetación podría deberse a que el sustrato 
predominante y característico de este tipo de ambientes, como es la arena, no evidenció diferencias significativas entre los mismos.

En relación a la sensibilidad de los taxa, los escasos organismos sensibles registrados se ubicaron principalmente en las zonas vegetadas y especialmente en los sitios con mejor calidad ecológica. En términos generales, los organismos tolerantes estuvieron presentes en todos los sitios, hábitats y fechas de muestreo en proporciones variables. Finalmente, los organismos muy tolerantes predominaron en las zonas vegetadas de los sitios más afectados antropogénicamente. En el sedimento libre de vegetación no se observaron variaciones dado que este último grupo fue el que dominó en todos los casos.

Por todo lo antedicho, podrían diferenciarse aquellos sitios con mejor calidad ecológica caracterizados por poseer mayores valores de oxígeno disuelto y especies sensibles presentes, predominando los colectoresfiltradores pero bastante bien representados los colectores-recolectores y raspadores; mientras que en aquellos con mayor proporción de materia orgánica y altas concentraciones de nutrientes y demandas de oxígeno, predominaron ampliamente las formas colectoras-recolectoras y los organismos sensibles estuvieron ausentes.

Los resultados de este estudio muestran la importancia de los indicadores funcionales como descriptores para detectar el efecto negativo de las perturbaciones de origen antropogénico dadas principalmente por la modificación y el deterioro del hábitat físico. Según Dyer et al. (2002), el hábitat es la primer variable ecológica moduladora del funcionamiento de los ríos, en tanto que la calidad del agua es el segundo factor más influyente. Sin embargo, según estos mismos autores, una integridad biótica excelente sólo es 
posible cuando tanto el hábitat como la química del agua no son limitantes sino que están optimizadas. Se plantea así la necesidad de integrar ambas áreas, estableciendo los vínculos directos entre la calidad del hábitat y la calidad del agua. 


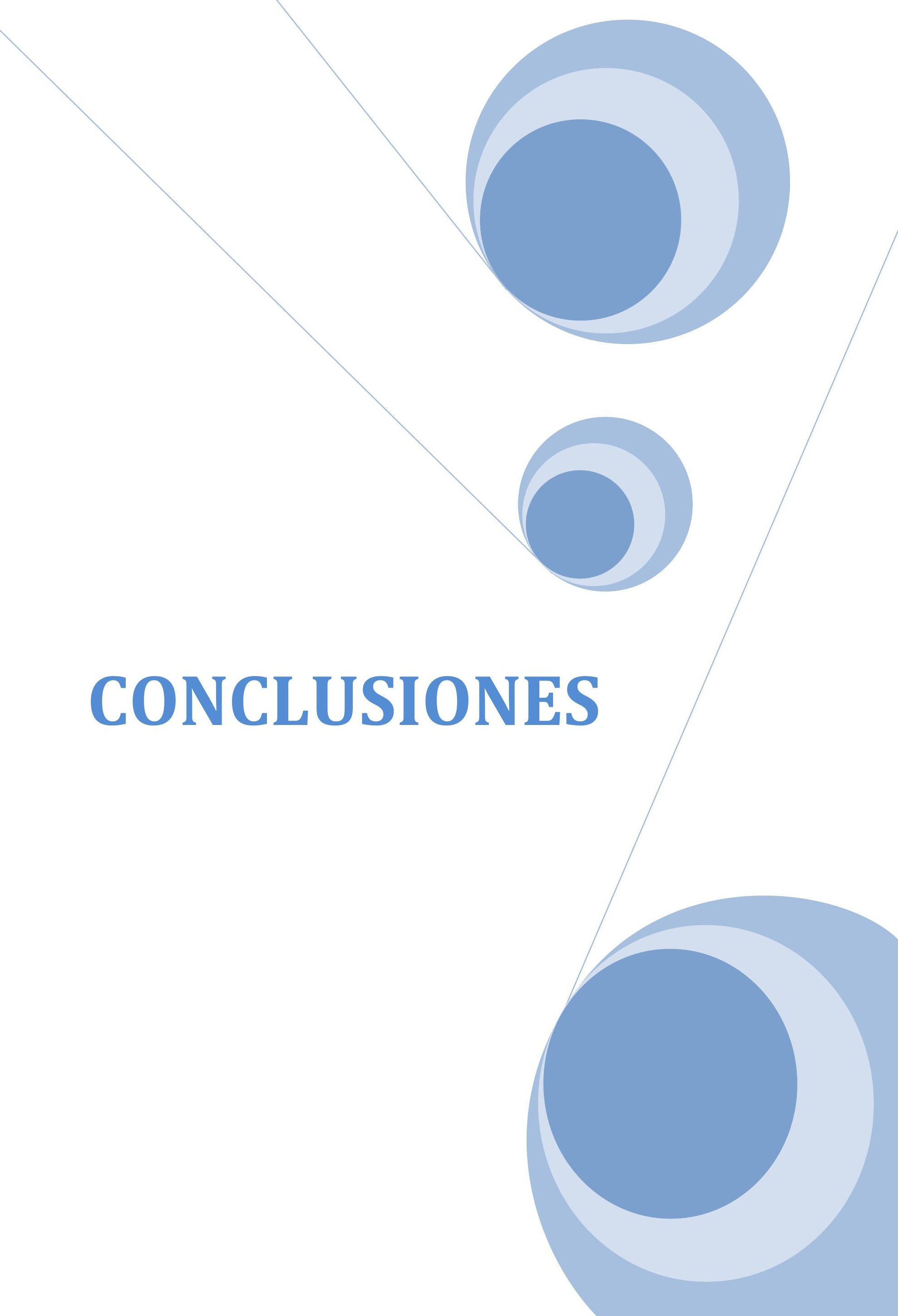




\section{Conclusiones - Consideraciones finales}

Los resultados obtenidos en el presente estudio han permitido aceptar las hipótesis propuestas. Las características del hábitat y del agua de los sitios estudiados en el sector costero de agua dulce del Río de la Plata son aspectos que determinan los ensambles de macroinvertebrados. En este sentido, el análisis comparativo de los grupos funcionales alimentarios evidenció una respuesta de los organismos a los efectos del impacto antropogénico en el sector estudiado. En ambientes altamente poluídos, los colectores-filtradores fueron reemplazados por las formas asociadas típicamente al consumo de detrito, como es el caso de los colectores-recolectores, lo cual podría traducirse en una simplificación de las tramas tróficas, favoreciendo la vía detritívora y una estrategia alimentaria generalista.

El análisis comparativo de los hábitats estudiados evidenció diferencias claras entre los compartimentos no sólo debido a sus características físicas, sino también a los ensambles de macroinvertebrados que éstos albergan. De esta manera, el sedimento libre de vegetación y el sedimento asociado a la misma (incluyendo los organismos que viven adosados sobre la vegetación) se establecen como las principales opciones de asentamiento y desarrollo para los invertebrados acuáticos en este tipo de sistema.

Se destaca la importancia de algunos descriptores estructurales y funcionales analizados en el presente trabajo de Tesis. En este sentido, la calidad del hábitat estimada a partir de las características físico-químicas, y la calidad biótica a través del número de taxa, diversidad, grupos funcionales alimentarios y modos de vida, proporción de organismos sensibles y predominancia de los grupos taxonómicos principales podrían incluirse entre 
los descriptores más confiables para contribuir a la evaluación de la calidad ecológica y la integridad biótica del área estudiada.

El estudio de los contenidos digestivos reafirmó ser una herramienta muy útil en la asignación de los macroinvertebrados a su grupo funcional alimentario real correspondiente. Sin embargo, se destaca la importancia de utilizar en forma complementaria otros métodos, tales como el estudio del comportamiento alimentario y el análisis de la composición isotópica y estequiométrica de los invertebrados y las probables fuentes de recurso disponibles en el ambiente. De esta manera podrán establecerse las interacciones existentes, asignando los organismos a un determinado nivel trófico, y dilucidando en última instancia las relaciones tróficas dentro de la comunidad.

\section{Perspectivas futuras}

Los resultados alcanzados en este estudio revelaron la necesidad de incrementar el conocimiento de algunos descriptores, tales como grupos funcionales alimentarios y modos de vida para los sistemas costeros de los ambientes lóticos de llanura, en general, y ambientes estuariales, en particular.

Por otra parte, resulta fundamental fortalecer los estudios para continuar con el establecimiento de óptimos y tolerancias de las especies de invertebrados a las variables ambientales que condicionan su desarrollo en estos ecosistemas. Esto permitirá dar validez a los índices bióticos utilizados para conocer el estatus ecológico del sector intermareal rioplatense de una manera más confiable.

Asimismo, se plantea la necesidad de responder ciertos interrogantes para el sector costero de agua dulce del Río de la Plata, tales como las posibles 
consecuencias ecológicas de las diferencias en las proporciones de C:N:P halladas entre los consumidores bentónicos, y su relación con la calidad del agua y del ambiente. Más aún, se desconocen las interacciones y el grado de complejidad o simplicidad de las tramas tróficas en el sector mencionado. En este sentido, será fundamental el análisis conjunto de la dieta y la composición isotópica de los organismos y sus potenciales recursos.

Finalmente, la generación de índices ecológicos que incluyan la valoración del los hábitats funcionales presentes en el sector intermareal es un desafío pendiente para futuros estudios. 


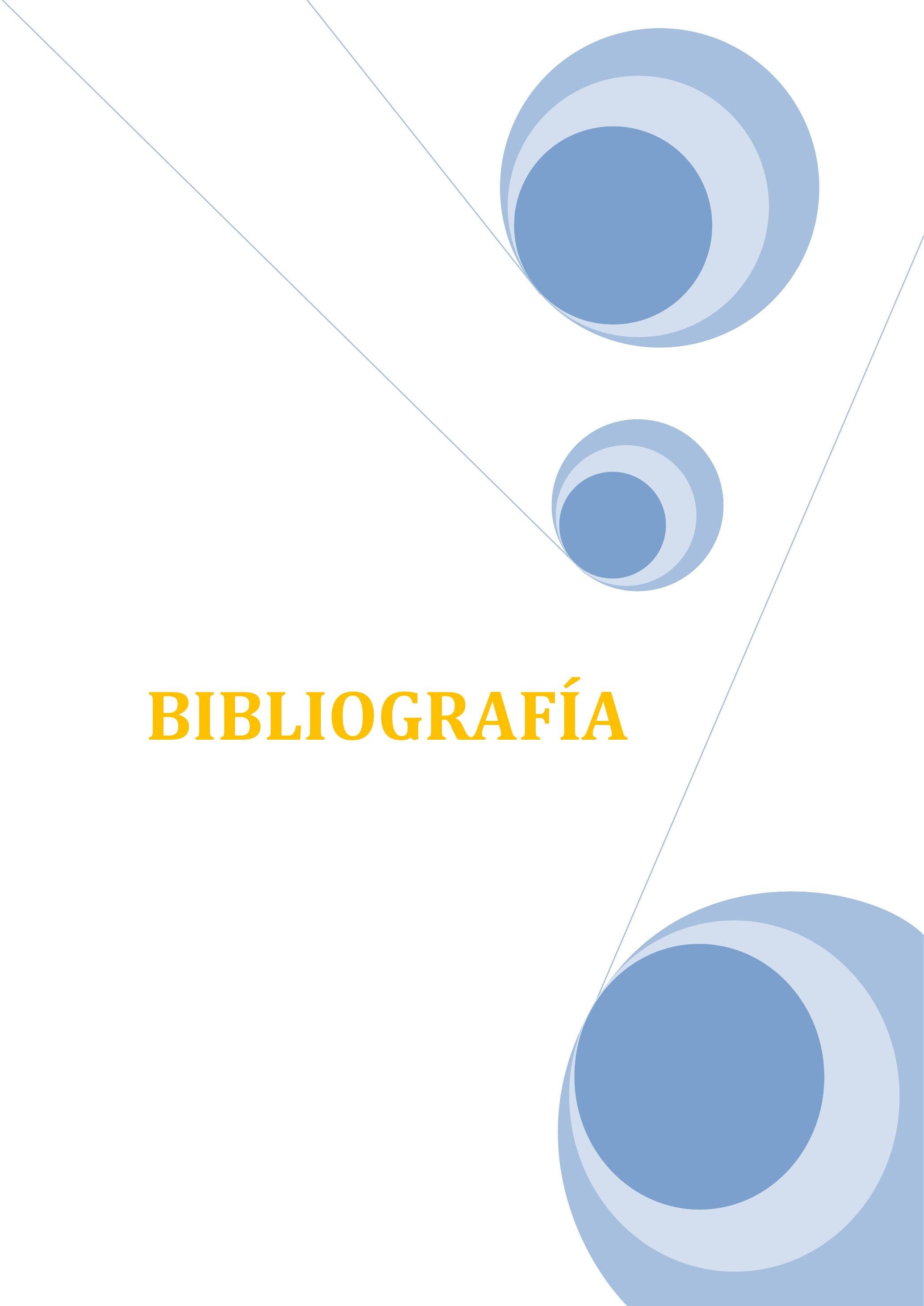


AA, AGOSBA, ILPLA, SHIN. 1997. Calidad de las aguas. Franja Costera Sur del Río de la Plata (San Fernando-Magdalena). Buenos Aires, 157 pp.

AADLAND, L.P. 1993. Stream habitat types: their fish assemblages and relationships to flow. North American Journal of Fisheries Management, 13: 790806.

ACHA, E.M., MIANZAN, H.W., GUERRERO, R., CARRETO, J., GIBERTO, D., MONTOYA, N., \& M. CARIGNAN. 2008. An overview of physical and ecological processes in the Río de la Plata Estuary. Continental Shelf Research, 28: 15791588.

ACHA, E.M., MIANZAN, H.W., IRIBARNE, O., GAGLIARDINI, A., LASTA, C. \& P. DALEO. 2003. The role of the Río de la Plata bottom salinity front in accumulating debris. Marine Pollution Bulletin, 46: 197-202.

ACUÑA, V., MUÑóz, I., GIORGI, A., OMELLA, M., SABATER, F. \& S. SABATER. 2005. Drought and posdrought recovery cyces in an intermittent Mediterranean stream: Structural and Functional aspects. Journal of the North American Benthological Society, 24: 919-933.

ADAMS, S.M. 2005. Using multiple response bioindicators to assess the health of estuarine ecosystems: An operational framework. In: "Estuarine indicators", Bortone S.A. (ed), Washington: CRC.

ALBARIÑO, R.J. 1998. Dinámica del procesamiento de la materia orgánica particulada gruesa por el macrozoobentos en arroyos andinos. Trabajo de Tesis Doctoral. Universidad Nacional del Comahue. Centro Regional Universitario Bariloche.

ALBARIÑO, R.J. 2001. The food habits and mouthpart morphology of a South Andes population of Klapopteryx kuscheli (Plecoptera: Austroperlidae). Aquatic Insects, 23: 171-181.

ALBARIÑO, R.J. \& V. DÍAZ VILLANUEVA. 2006. Feeding ecology of two plecopterans in low order Andean-Patagonian streams. International Review of Hydrobiology, 91: $122-135$. 
ALBA-TERCEDOR, J. \& A. SÁNCHEZ ORTEGA. 1988. Un método rápido y simple para evaluar la calidad de las aguas corrientes basado en el de Helawell (1978). Limnetica, 4: 51-56.

ALDRIDGE, D.W. \& R.F. MCMAHON. 1978. Growth, fecundity, and bioenergetics in a natural population of the freshwater clam, Corbicula fluminea Philippi, from north central Texas. Journal of Molluscan Studies, 44: 49-70.

ALLAN, J.D. 1995. Stream Ecology. Structure and Function of Running Waters. Chapman \& Hall, London, 338 pp.

AMIARD-TRIQUET, C. \& J.C. DAUVIN. 2009. Introduction to Estuaries. In: "Environmental Assessment of Estuarine Ecosystems: A Case Study", AmiardTriquet C. \& P.S. Rainbow (eds), Boca Raton: CRC.

AMUNDSEN, P.A., GABLER, H.M. \& F.J. STALDVIK. 1996. A new approach to graphical analysis of feeding strategy from stomach contents data - modification of the Costello (1990) method. Journal of Fish Biology, 48(4): 607-614.

ARMENDÁRIZ, L.C., RODRIGUES CAPÍTULO, A. \& E.S. AMBROSIO. 2011. Relationships between the spatial distribution of oligochaetes (Annelida, Clitellata) and the environmental variables in a temperate estuary system of South America (Río de la Plata, Argentina). New Zealand Journal of Marine and Freshwater Research, 45: 263- 279.

ARMITAGE, P. 1995. Faunal community change in response to flow manipulation. In: "The ecological basis for river management", Wiley Publ., D.M Harper \& A.J.D. Ferguson (eds).

ARMITAGE, P., MOSS, D., WRIGHT, J. \& M. FURSE. 1983. The performance of a new biological water quality score system based on macroinvertebrates over a wide range of unpolluted running water sites. Water research, 17: 333-347.

BALAY, M.A. 1961. El Río de la Plata entre la atmósfera y el mar. Servicio de Hidrografía Naval, 621: 1-153.

BARBOUR M.T., GERRITSEN, J., SNYDER, B.D. \& J.B. STRIBLING. 1999. Rapid Bioassessment Protocols for Use in Streams and Wadeable Rivers: Periphyton, Benthic Macroinvertebrates and Fish, Second Edition. EPA, Washington, D.C. 
BAZAN J.M. \& E. ARRAGA. 1993. El Río de la Plata. ¿Un sistema fluvio-marítimo frágil? Acercamiento a una definición de la calidad de sus aguas (p: 71-82). En: "Conferencias de Limnología", Boltovskoy, A. \& H.L. López (eds), Instituto de Limnología "Dr. Raúl A. Ringuelet”, La Plata.

BECHARA, J.A. 1993. El papel de los peces en la estructura de las comunidades bentónicas de ecosistemas lóticos (p: 143-158). En: "Conferencias de Limnología", Boltovskoy, A. \& H.L. López (eds.), Instituto de Limnología "Dr. Raúl A. Ringuelet", La Plata.

BILOS, C., COLOMBO, J.C. \& M.J. RODRIGUEZ PRESA. 1998. Trace metals in suspended particles, sediments and Asiatic clams (Corbicula fluminea) of the Río de la Plata Estuary, Argentina. Environmental Pollution, 99: 1-11.

BODE, R.W., NOVAK, M.A. \& L.E. ABELE. 1997. Biological Stream Testing. NYS Department of Environmental Conservation, Albany, NY. 14 pp.

BODE, R.W., NOVAK, M.A. \& L.E. ABELE. 2002. Quality Assurance Work Plan for Biological Stream Monitoring in New York State. NYS Department of Environmental Conservation, Albany, NY. 122 pp.

BOLTOVSKOY, D., CORREA, N., CATALDO, D. \& F. SYLVESTER. 2006. Dispersion and ecological impact of the invasive fresh-water bivalve Limnoperna fortunei in the Río de la Plata watershed and beyond. Biological Invasions, 8: 947-963.

BOLTOVSKOY, D., INSTITUTO ARGENTINO DEL PETRÓLEO (IAP), INSTITUTO NACIONAL DE INVESTIGACIÓN Y DESARROLLO PESQUERO (INIDEP) Y SERVICIO DE HIDROGRAFía NAVAL (SHN). 2008. Atlas de Sensibilidad Ambiental de la Costa y el Mar Argentino.

BOLTOVSKOY, D., IZAGUIRRE, I. \& N. CORREA. 1995. Feeding selectivity of Corbicula fluminea (Bivalvia) on natural phytoplankton. Hydrobiologia, 312: 171182.

BONETTO, A.A. \& I.R. WAIS. 1995. Southern South American streams and rivers (p: 257-293.). In: "Ecosystems of the World: Rivers and Stream Ecosystems", Cushing, C.E., Cummins, K.W. \& G.W. Minshall (eds), Elsevier, Amsterdam, The Netherlands. 
BORCHARDT, D. 1993. Effects of flow and refugia on drift loss of benthic macroinvertebrates: implications for habitat restoration in lowland streams. Freshwater Biology, 29: 221-227.

BORJA A., BALD, J., FRANCO, J., LARRETA, J., MUXICA, I., REVILLA, M., RODRÍGUEZ, J.G., SOLAUN, O., URIARTE, A. \& V. VALENCIA. 2009. Using multiple ecosystem components, in assessing ecological status in Spanish (Basque Country) Atlantic marine waters. Marine Pollution Bulletin, 59: 54-64.

BORTONE, S.A. 2005. Estuarine indicators. CRC Press, Boca Raton, Florida. 507pp.

BOSCHI, E. 1988. El ecosistema estuarial del Río de la Plata (Argentina y Uruguay). Anales del Instituto de Ciencias del Mar y Limnología, UNAM, 15(2): 159-182.

BOTTO, F., GAITÁN, E., MIANZAN, H., ACHA, H., GIBERTO, D., SCHIARITI, A. \& O. IRIBARNE. 2011. Origin of resources and trophic pathways in a large SW Atlantic estuary: An evaluation using stable isotopes. Estuarine, Coastal and Shelf Science, 92: 70-77.

BRINKHURST, R.O. \& M.R. MARCHESE. 1991. Guía para la identificación de oligoquetos acuáticos continentales de Sud y Centro América. Revista de la Asociación de Ciencias Naturales del Litoral. Climax, №6, 2da. Ed., 207 pp.

BUFFAGNI A., CROSA G., HARPER, D.M. \& J. KEMP. 2000. Using macroinvertebrate species assemblages to identify river channel habitat units: an application of the functional habitats concept to a large, unpolluted Italian river (River Ticino, Northen Italy). Hydrobiologia, 435: 213-225.

BUSS, D.F., BAPTISTA, D.F., SILVEIRA, M.P., NESSIMIAN, J.L. \& L.F.M. DORVILLE. 2002. Influence of water chemistry end environmental degradation on macroinvertebrate assemblages in a river basin in south-east Brazil. Hydrobiologia, 481: 125-136.

CALlISTO, M., MORENO, C. \& F. BARBOSA. 2001. Habitat diversity and benthic functional feeding groups at Cerra do Cipó, Southeast Brazil. Revista Brasileira de Biología, 61: 259-266. 
CALLOW, P. \& G.E. PETTS (eds). 1994. The rivers handbook. Vol.2. Blackwell Scientific, Oxford.

CATALDO, D.H. 2001. Dinámica poblacional y potencial bioindicador de contaminación acuática del molusco bivalvo Corbicula fluminea en el Delta del Río Paraná. Tesis Doctoral. Universidad de Buenos Aires. FCEYN. 178 pp.

CESAR, I., OCON, C., PAGGI, A., RODRIGUES CAPITULO, A., SPACCESI, F., TANGORRA, M. \& M. TASSARA. 2000. Diversidad de invertebrados bentónicos del Río de la Plata. En: "Biodiversidad en la Franja Costera Sur del Río de la Plata: fitoplancton, zoobentos; peces de la zona portuaria de la ciudad de Buenos Aires". Biología Acuática, 19: 27-63.

CLOSS, G.P. \& P.S. LAKE. 1994. Spatial and temporal variation in the structure of an intermittent-stream food web. Ecological Monographs, 64(1): 1-21.

COLOMBO, J.C., CAPELLETTI, N., LASCI, J., MIGOYA, M.C., SPERANZA, E. \& C.N. SKORUPKA. 2005. Sources, vertical fluxes and accumulation of aliphatic hydrocarbons in coastal sediments of the Rio de la Plata Estuary, Argentina. Environmental Science \& Technology, 39: 8227- 8234.

COLOMBO, J.C., CAPELLETTI, N., LASCI, J., MIGOYA, M.C., SPERANZA, E. \& C.N. SKORUPKA. 2006. Sources, vertical fluxes and accumulation of aromatic hydrocarbons in coastal sediments of the Rio de la Plata Estuary, Argentina. Environmental Science \& Technology, 40: 734-740.

CORTELEZZI, A. 2010. Hábitats funcionales y macroinvertebrados en cauces modificados de arroyos de llanura: impacto sobre la calidad ecológica. Tesis Doctoral. Fac. Cs. Naturales y Museo. UNLP. 154 pp.

CORTELEZZI, A., RODRIGUES CAPÍTULO, A., BOCCARDI, L. \& R. AROCENA. 2007. Benthic assemblages of a temperate estuarine system in South America: Transition from a freshwater to an estuarine zone. Journal of Marine Systems, 68: 569-580.

CORTELEZZI, A., RODRIGUES CAPÍTULO, A., BOCCARDI, L., TANGORRA, M., BALLAVIO, R. \& R. AROCENA. 2002. Distribución de los invertebrados bentónicos en el Río de la Plata. Proyecto FREPLATA. Argentina-Uruguay. Segundas Jornadas sobre Ecología y Manejo de Ecosistemas Acuáticos Pampeanos. 
COVICH, A.P. 1988. Geographical and historical comparisons of neotropical streams: biotic diversity and detrital processing in highly variable habitats. Journal of the North American Benthological Society, 7: 361-386.

COVICH, A.P., PALMER, M.A. \& T.A. CROWL. 1999. The role of benthic invertebrates species in freshwater ecosystems. BioScience, 49: 119-127.

CROSS, W.F., BENSTEAD, J.P., FROST, P.C \& S.A. THOMAS. 2005. Ecological stoichiometry in freshwater benthic systems: recent progress and perspectives. Freshwater Biology, 50: 1895-1912.

CUMMINS, K.W. 1973. Trophic relations of aquatic insects. Annual Review of Entomology, 18: 183-206.

CUMMINS, K. W. 1975. The ecology of running waters; theory and practice ( $p$ : 227-293). In: "Proceeding of the Sandusky River Basin Symposium, International Joint Commission, Great Lakes Pollution", Baker, D.B., Jackson, W.B. \& B.L. Prater (eds), Environmental Protection Agency.

CUMMINS, K.W., COFFMAN, W. \& P. ROFF. 1966. Trophic relationships in a small woodland stream. Verhandlungen des Internationalen Verein Limnologie, 16: 627-638.

CUMMINS, K.W., MERRITT, R.W. \& P.C.N. ANDRADE. 2005. The use of invertebrate functional groups to characterize ecosystem attributes in selected streams and rivers in south Brazil. Studies on Neotropical Fauna and Environment, 40(1): 69-89.

DARRIGRAN, G.A. 1992 a. Nuevos datos acerca de la distribución de dos especies del género Corbicula (Bivalvia, Sphaeriacea) en el área del Río de la Plata, República Argentina. Notas del Museo de La Plata, 21(210): 143-148.

DARRIGRAN, G.A. 1992 b. Variación temporal y espacial de la distribución de las especies de Corbicula Megerle, 1811 (Bivalvia, Corbiculidae), en el estuario del Río de la Plata, República Argentina. Neotropica, 38 (99): 59-63.

DARRIGRAN, G.A. 1993. Los moluscos del Río de la Plata como indicadores de Contaminación Ambiental (p: 309-313). En: "Elementos de Política Ambiental", Goin, F. \& R. Goñi (eds.), Cámara de Diputados de la Provincia de Buenos Aires. 
DARRIGRAN, G.A. \& C. DAMBORENEA. 2005. La almeja de agua dulce Corbicula fluminea (Müller, 1774) (p: 133-177). En: "INVASORES: Invertebrados exóticos en el Río de la Plata y región marina aledaña", P.E. Penchaszadeh (Coord.), Eudeba (Editorial Universitaria de Buenos Aires).

DARRIGRAN, G.A. \& M. LAGRECA. 2005. Moluscos litorales del estuario del Río de la Plata. Serie Técnica Didáctica N8. Probiota, FCNYM-UNLP. 41 pp.

DARRIGRAN, G.A. \& M. MAROÑAS. 1989. Crecimiento de las poblaciones naturales de Corbicula fluminea (Müller, 1774) y C. largillierti (Philippi, 1814) (Bivalvia, Sphaericea) en el litoral de Punta Blanca, estuario del Río de la Plata, República Argentina. Comunicaciones de la Sociedad Malacológica del Uruguay, 7 (56/57): 139-157.

DARRIGRAN, G.A., MARTIN, S.M., GULLO, B. \& L. ARMENDÁRIZ. 1998. Macroinvertebrates associated with Limnoperna fortunei (Dunker, 1857) (Bivalvia, Mytilidae) in the Río de la Plata, Argentina. Hydrobiologia, 367: 223230.

DAY, J.W., HALL, C.A.S., KEMP, W.M. \& A. YÁÑEZ-ARANCIBIA. 1989. Estuarine Ecology. John Wiley \& Sons, New York.

DIAZ VILLANUEVA, V. \& R.J. ALBARIÑO. 1999. Feeding habit of Notoperla archiplatae (Pleoptera) larvae in a North Patagonia Andean stream, Argentina. Hidrobiologia, 412: 43-52.

DOMíngUEZ, E., HUBBARD, M.D. \& M.L. PESCADOR. 1994. Los Ephemeroptera en Argentina. En: "Fauna de Agua Dulce de la República Argentina", Castellanos, Z.A. (ed), FECIC, Buenos Aires, 33: 1-141 pp.

DYER, S.D., WHITE-HULL, C.E., WANG, X., JOHNSON, T.D. \& G.J. CARR. 2002. Determining the influence of habitat and chemical factors on instream biotic integrity for a Southern Ohio watershed. Journal of Aquatic Ecosystem Stress and Recovery, 6: 91-110.

FAIRBRIDGE, R.W. 1980. The estuary: its definition and geodynamic cycle ( $p: 1-$ 35). In: "Chemistry and Biogeochemistry of Estuaries", Olausson, E. \& I. Cato (eds.), Wiley, New York. 
FENOGLIO, S., BO, T. \& M. CUCCO. 2004. Small-scale macroinvertebrate distribution in a riffle of a neotropical rainforest stream (Río Bartola, Nicaragua). Caribbean Journal of Science, 40: 253-257.

FERNÁNDEZ, H.R. \& E. DOMínGUEZ. 2001. Guía para la Determinación de los Artrópodos Bentónicos Sudamericanos. Secretaría de Ciencia y Técnica de la Universidad de Tucumán.

FERNÁNDEZ, L. \& J.A. SCHNACK. 1977. Studio preliminar de la meiofauna bentónica en tramos poluídos de los arroyos Rodríguez y Carnaval (Provincia de Buenos Aires). Ecosur, 8: 103-115.

FINLAY, J.C. \& C. KENDALL. 2007. Stable isotope tracing of temporal and spatial variability in organic matter sources to freshwater ecosystems. In: "Stable Isotopes in Ecology and Environmental Science", Michener R. \& K. Lajtha (eds), Second edition. $566 \mathrm{pp}$.

FOLK, R.L. 1974. Petrology of sedimentary rocks. Austin, Texas, Hemphill Publishing Co. 182 pp.

FRADY, C.H. 2005. Headwater Stream Macroinvertebrates of the H.J. Andrews Experimental Forest, Oregon. Master of Science in Fisheries Science, USA. 112 pp.

FREPLATA. 2005. Análisis Diagnóstico Transfronterizo del Río de la Plata y su Frente Marítimo. Proyecto "Protección Ambiental del Río de la Plata y su Frente Marítimo: Prevención y Control de la Contaminación y Restauración de Hábitats". Documento Técnico. Proyecto PNUD/GEF RLA/99/G31, Montevideo, Uruguay.

FROST, P.C., STELZER, R.S., LAMBERTI, G.A. \& J.J. ELSER. 2002. Ecological stoichiometry of trophic interactions in the bentos: Understanding the role of $\mathrm{C}: \mathrm{N}: \mathrm{P}$ ratios in lentic and lotic hábitats. Journal of the North American Benthological Society, 21: 515-528.

FROST, P.C., TANK, S.E., TURNER, M.A. \& J.J. ELSER. 2003. Ecological composition of littoral from oligotrophic and eutrophic Canadian lakes. Journal of the North American Benthological Society, 22: 51-62. 
GIBERTO, D.A., BREMEC, C.S., ACHA, E.M. \& H. MIANZAN. 2004. Large-scale spatial patterns of benthic assemblages in the SW Atlantic: the Río de la Plata estuary and adjacent shelf waters. Estuarine, Coastal and Shelf Science, 61: 1-13.

GIBERTO, D.A., BREMEC, C.S., CORTELEZZI, A., RODRIGUES CAPÍTULO, A. \& A. BRAZEIRO. 2007. Ecological boundaries in estuaries: macrobenthic $\beta$-diversity in the Río de la Plata system (34-36 $\mathrm{S})$. Journal of the Marine Biological Association of the United Kingdom, 87: 377-381.

GÓMEZ, N. \& A. RODRIGUES CAPÍTULO. 2000. La Franja Costera Sur del Río de la Plata. Biología Acuática, 19: 1-6.

GÓMEZ, N. \& A. RODRIGUES CAPÍTULO. 2001. Los bioindicadores y la salud de los ríos. Actas del V Seminario Internacional Ingeniería y Ambiente. Serie Gestión Ambiental Na 3, La Plata, Argentina, 109-118pp.

GÓMEZ, N. \& D.E. BAUER. 1997. Fitoplancton (p: 101-108). En: "Calidad de las Aguas de la Franja CosteraSur del Río de la Plata. San Fernando-Magdalena".

GÓMEZ, N. \& D.E. BAUER. 1998. Coast phytoplankton of the Río de la Plata river and its relation with the pollution. Verhandlungen des Internationalen Verein Limnologie, 3(3): 1032-1037.

GÓMEZ, N. \& D.E. BAUER. 2000. Diversidad fitoplanctónica en la Franja Costera Sur del Río de la Plata. Biología Acuática, 19: 7-26.

GÓMEZ, N., HUALDE, P.R., LICURSI, M. \& D. BAUER. 2004. Spring phytoplankton of Río de la Plata: A temperate estuary of South America. Estuarine, Coastal and Shelf Science, 61: 301-309.

GÓMEZ, N. \& J. COCHERO. 2013. Development of a habitat index for the coastal freshwater zone of the Río de la Plata (Franja Costera Sur). Ecología Austral, 23: 18-26.

GÓMEZ, N., LICURSI, M. \& J. COCHERO. 2009. Seasonal and spatial distribution of the microbenthic communities of the Rio de la Plata estuary (Argentina) and possible environmental controls. Marine Pollution Bulletin, 58: 878-887. 
GÓMEZ, N., LICURSI, M., BAUER, D.E., AMBROSIO, E.S. \& A. RODRIGUES CAPÍTULO. 2012. Assessment of Biotic Integrity of the Coastal Freshwater Tidal Zone of a Temperate Estuary of South America through Multiple Indicators. Estuaries and Coasts, 35: 1328-1339.

GÓMEZ, N. \& M. LICURSI. 2001. The Pampean Diatom Index (IDP) for assessment of rivers and streams in Argentina. Aquatic Ecology, 35: 173-181.

GRAHAM J., BARRET, N.S., GRADDON, D.J. \& P.R. LAST. 2000. The conservation significance of estuaries: a classification of Tasmanian estuaries using ecological, physical and demographic attributes as a case study. Biological Conservation, 92: $383-397$.

GRASSHOFF, K., EHRHARDT, M. \& K. KREMLING. 1983. Methods of seawater analysis. Grasshoff, K., Ehrhardt, M. \& K. Kremoling (eds.), Second edition, Verlang Chemie.

GREGG, W.W. \& F.L. ROSE. 1985. Influences of aquatic macrophytes on invertebrate community structure, guild structure, and microdistribution in streams. Hydrobiologia, 128: 45-56.

GUERRERO, M.A., ACHA, M.E., FRAMINAN, M.B. \& C. LASTA. 1997. Physical oceanography of the Río de la Plata Estuary. Continental Shelf Research, 17: 727742.

GULLO, B. \& G.A. DARRIGRAN. 1991. Distribución de la fauna de Hirudíneos litorales del Estuario del Río de la Plata, República Argentina. Notas Científicas de la Segunda Reunión Argentina de Limnología. Biología Acuática, 15: 216-221.

HARPER, D.M. \& M. EVERARD. 1998. Why should the habitat-level approach underpin holistic river survey and management?. Aquatic Conservation: Marine and Freshwater Ecosystem, 8: 395-413.

HARPER, D.M., SMITH, C.D., BARHAM, P.J. \& R. HOWEL. 1995. The ecological basis for the management of the natural river environment (p: 219-238). In: "The Ecological Basis for River Management", Harper, D.M. \& A.J.D. Ferguson (eds). John Wiley \& Sons Ltd, Chichester. 
HARPER, D.M., SMITH, C.D., KEMP, J. \& G. CROSA. 1998. The use of "functional habitats" in the conservation, management, and rehabilitation of rivers ( $p: 315-$ 326). In: "Advances in River Ecology", Brestschko, G. \& J. Helesic (eds).

HAUER, F.R. \& V.H. RESH. 2006. Macroinvertebrates (p: 435-464). In: “Methods in stream ecology", Hauer R. \& G. Lamberti (eds), New York, Academic Press.

HEINO, J. 2005. Functional biodiversity of macroinvertebrate assemblages along major ecological gradients of boreal headwater streams. Freshwater Biology, 50: 1578-1587.

HENRÍQUEZ DE OLIVEIRA, A., NESSIMIAN, J. \& F. DORVILLÉ. 2003. Feeding habits of chironomid larvae (Insecta: Diptera) from a stream in the Floresta da Tijuca, Rio de Janeiro, Brazil. Brazilian Journal of Biology, 63: 269-281.

HILDREW, A., TOWNSEND, C. \& A. HASHAM. 1985. The predatory chironomidae of an iron-rich stream: feeding ecology and food web structure. Ecological Entomology, 10: 403-413.

HILSENHOFF, W.L. 1987. An improved biotic index of organic stream pollution. Great Lakes Entomologist, 20: 31-39.

HYNES, H.B.N. 1976. The ecology of running waters. University of Toronto Press, $555 \mathrm{p}$.

IMAGE-PRO PLUS. 2006. Versión 6.0 for Windows. Media Cybernetics, Inc.

INA. 2011. Evaluación de la calidad del agua en la franja costera sur del Río de la Plata mediante modelación numérica. Proyecto "INA 1.207". Informe LHA 021.207-11. Ezeiza, Argentina.

ITUARTE, C.F. 1981. Primera noticia acerca de la introducción de pelecípodos asiáticos en el área rioplatense (Mollusca, Corbiculidae). Neotropica, 27: 79-83.

ITUARTE, C.F. 1985. Growth dynamics in a natural population of Corbicula fluminea (Bivalvia Sphaeriacea) at Punta Atalaya, Río de la Plata, Argentina. Studies on Neotropical Fauna and Environment, 20: 217-225. 
JAARSMA, N.G., DE BOER, S.M., TOWNSEND, C.R., THOMPSON, R.M. \& E.D. EDWARDS. 1998. Characterizing food-webs in two New Zealand streams. New Zealand Journal of Marine and Freshwater Research, 32: 271-286.

JOWET, I.G. (ed). 1977. Instream flow methods: a comparison of approaches. Regulated Rivers: Research \& Management, 13: 115-127.

KARR, J.R. \& D.R. DUDLEY. 1981. Ecological perspective on water quality goals. Environmental Management, 5: 55-68.

KEMP, J.L., HARPER, D.M \& G.A. CROSA. 1999. Use of "functional habitats" to link ecology with morphology and hydrology in river rehabilitation. Aquatic Conservation: Marine and Freshwater Ecosystem, 9: 159-178.

KEMP, J.L., HARPER, D.M. \& G.A. CROSA. 2000. The habitat-scale ecohydraulics of rivers. Ecological Engineering, 16: 17-29.

KUTSCHKER, A., RAND, C.B. \& M.L. MISERENDINO. 2009. Evaluación de la calidad de los bosques de ribera en ríos del NO del Chubut sometidos a distintos usos de la tierra. Ecología Austral, 19(1): 19-34.

LAHITTE, H.B., HURRELL, J.A., BELGRANO, M.J., JANKOWSKI, L.S. \& K. MEHLTRETER. 2004. Plantas de la Costa. Buenos Aires, Literature of Latin America (L.O.L.A.), 200 p.

LAMMEL, E., BONFATI, E. \& M. NAVARRO. 1997. Metales pesados (p: 63-66). En: "Calidad de las aguas. Franja Costera Sur del Río de la Plata (San FernandoMagdalena)", Consejo Permanente para el Monitoreo de la Calidad de las Aguas de la Franja Costera Sur del Río de la Plata, Buenos Aires, Argentina.

LAMOUROUX, N., DOLÉDEC, S. \& S. GAYRAUD. 2004. Biological traits of stream macroinvertebrate communities: effects of microhabitat, reach and basin filters. Journal of the North American Benthological Society, 23: 449-466.

LAMPMAN, G., CARACO, N.F. \& J.J. COLE. 1999. Spatial and temporal patterns of nutrient concentration and export in the tidal Hudson River. Estuaries, 22: 285296. 
LANFREDI, N.W., SCHMIDT, S.A. \& J. SPERONI. 1979. Cartas de Corrientes de Marea, Río de la Plata, Servicio de Hidrografía Naval, División Oceanografía Física, IC-it-79/03.

LICURSI, M., GÓMEZ, N. \& J. DONADELLI. 2010. Ecological optima and tolerances of coastal benthic diatoms in the freshwater-mixohaline zone of the Río de la Plata estuary. Marine Ecology Progress Series, 418: 105-117.

LIONARD, M., MUYLAERT, K., HANOUTTI, A., MARIS, T., TACKX, M. \& W. VYVERMAN. 2008. Inter-annual variability in phytoplankton summer blooms in the freshwater tidal reaches of the Schelde estuary (Belgium). Estuarine, Coastal and Shelf Science, 79: 694-700.

LIU, C.W., LIN, K.H. \& Y.M. KUO. 2003. Application of factor analysis in the assessment of groundwater quality in a blackfoot disease area in Taiwan. Science of the Total Environment, 313: 77-89.

LOPEZ VAN OOSTEROM, M.V., OCON, C.S., BRACOLINI, F., MAROÑAS, M., SENDRA, E. \& A. RODRIGUES CAPITULO. 2013. Trophic relationships between macroinvertebrates and fish in a pampean lowland stream (Argentina). Iheringia. Serie Zoologia. Porto Alegre: Fundacao Zoobotanica Rio Grande Sul. 03(1):57-65.

LOPRETTO, E.C. \& G. TELL. 1995. Ecosistemas de aguas continentales: Metodologías para su estudio. Tomos I, II y III. Ediciones Sur, 1401 pp.

MACKERETH, F.J., HERON, F.J.H. \& J.F. TALLING. 1978. Water analysis: Some revised methods for limnologists. Scientific publication $N^{\circ} 36$, Freshwater Biological Association.

MANDAVILLE, S.M. 2002. Benthic Macroinvertebrates in Freshwaters Taxa Tolerance Values, Metrics, and Protocols. Project H-1. Soil \& Water Conservation Society of Metro Halifax, 128 pp.

MARGALEF, R. 1955. Los organismos como indicadores en la Limnología. Inst. Forestal Inv. Exp. Madrid. 300 pp. 
MCMAHON, R.F. 2000. Invasive Characteristics of the freshwater bivalve Corbicula fluminea ( $p$ : 315-343). In: "Nonindigenous freshwater organisms: vectors, biology and impacts", Caludi, R. \& J. Leach (eds), Lewis Publishers, Boca Raton.

MERRITT, R.W. \& K.W. CUMMINS. 1996. An Introduction to the aquatic insects of North America. Kendall/Hunt Publishing Co., Dubuque, 882 pp.

MERRITT, R.W., CUMMINS, K.W. \& M.B. BERG (eds). 2008. An introduction to the aquatic insects of North America. $4^{\text {rd }}$ edition. Kendall/Hunt, Dubuque, lowa.

MIANZAN, H., LASTA, C., ACHA, E., GUERRERO, R., MACCHI, G. \& C. BREMEC. 2001. The Río de la Plata Estuary, Argentina-Uruguay. In: "Coastal marine ecosystems of Latin America. Ecological studies", Seeliger, U. \& B. Kjerfve (eds), Berlin, Springer.

MISERENDINO, M.L. 2001. Macroinvertebrados de ríos andino-patagónicos. Trabajo de Tesis Doctoral. Universidad Nacional del Comahue - Centro Regional Universitario Bariloche.

MISERENDINO, M.L. 2009. Effects of flow regulation, basin characteristics and land-use on macroinvertebrates communities in a large arid Patagonian river. Biodiversity and Conservation, 8(7): 1921-1943.

MISERENDINO, M.L. \& C.I. MASI. 2010. The effects of land use on environmental features and functional organization of macroinvertebrate communities in Patagonian low order streams. Ecological Indicators, 10: 311-319.

MISERENDINO, M.L. \& L.A. PIZZOLON. 2004. Interactive effects of basin features and land-use change on macroinvertebrate communities of headwater stream in the Patagonian Andes. River Research and Applications, 20: 1-17.

MODENUTTI, B., ALBARIÑO, R., BASTIDAS NAVARRO, M., DÍAZ VILLANUEVA, V., SOUZA, M.S., TROCHINE, C., LASPOUMADERES, C., CUASSOLO, F., MARILUÁN, G., BURIA, L. \& E. BALSEIRO. 2010. Structure and dynamic of food webs in Andean North Patagonian freshwater systems: organic matter, light and nutrient relationships. Ecología Austral, 20: 95-114. 
MOLINA, C.I., GIBON, F.M., OBERDORFF, T., DOMÍNGUEZ, E., PINTO, J., MARÍN, R. \& M. ROULET. 2011. Macroinvertebrate food web structure in a floodplain lake of the Bolivian Amazon. Hydrobiologia, 663: 135-153.

MOTTA, R. \& V. UIEDA. 2004. Diet and trophic groups of an aquatic insect community in a tropical stream. Brazilian Journal of Biology, 64: 809-817.

MUÑOZ, I, ROMANÍ, A.M., RODRIGUES CAPITULO, A., GONZÁLEZ ESTEBAN, J. \& E. GARCÍA-BERTHOU. 2009. Relaciones tróficas en el ecosistema fluvial ( $p$ : 347366). En: "Conceptos y técnicas en ecología fluvial", Elosegui, A. \& S. Sabater (eds), Fundación BBVA.

NEDWELL, D.B. \& D.G. RAFFAELLI. 1999. Estuaries: Advances in Ecological Research. Volume 29. Academic Press, London, United Kingdom.

NEWSOME, S.D., MARTINEZ DEL RIO, C., BEARHOP, S. \& D.L. PHILLIPS. 2007. A niche for isotopic ecology. Frontiers in Ecology and the Environment, 429-436.

NEWSON, M.D. \& C.L. NEWSON. 2000. Geomorphology, ecology and river channel habitat: mesoscale approaches to basin scale challenges. Progress in Physical Geography, 24: 195-217.

OCON, C.S. \& A. RODRIGUES CAPÍTULO. 2004. Presence and abundance of Ephemeroptera and other sensitive macroinvertebrates in relation with habitat conditions in pampean streams (Buenos Aires, Argentina). Archiv für Hydrobiologie, 159(4):473-487.

OCON, C., LOPEZ VAN OOSTEROM, M.V., MUÑOZ, M.I. \& A. RODRIGUES CAPÍTULO. 2013. Macroinvertebrate trophic responses to nutrient addition in a temperate stream in South America. Fundamental and Applied Limnology, 182 (1): 17-30.

OCON C.S., RODRIGUES CAPITULO, A. \& A.C. PAGGI. 2008. Evaluation of zoobenthic assemblages and recovery following petroleum spill in a coastal area of Río de la Plata estuarine system, South America. Environmental Pollution, 156: 82-89. 
PAGGI, A.C., OCON, C., TANGORRA, M. \& A. RODRIGUES CAPÍTULO. 2006. Response of the zoobenthos community along the dispersion plume of a highly polluted stream in the receiving waters of a large river (Rio de la Plata, Argentina). Hydrobiologia, 568: 1-14.

PAlMeR, C., O’KeEFFe, J., PALMeR, A., DUNNe, T. \& S. RADLOFF. 1993. Macroinvertebrate functional feeding groups in the middle and lower reaches of the Buffalo River, Eastern Cape, South Africa. I. Dietary variability. Freshwater Biology, 29: 441-453.

PASTORINO, G., DARRIGRAN, G.A., MARTíN, S.M. \& L. LUNASCHI. 1993. Limnoperna fortunei (Dunker, 1857) (Mytilidae), nuevo bivalvo invasor en aguas del Río de la Plata. Neotropica, 39: 34.

PETTS, G.E. \& P. CALOW. 1996. The Nature of Rivers (p: 1-6). In: "River Restoration", Petts, G. \& P. Calow (eds).

PIELOU, E.C. 1975. Ecological Diversity. John Wiley \& Sons. New York.

PIZARRO, M.J. \& A.M. ORLANDO. 1984. Distribución de fósforo, nitrógeno y silicio disueltos en el Río de la Plata. Servicio de Hidrografía Naval, Publ. H., 625: 1-57.

PLA, L.E. 1986. Análisis Multivariado: Método de Componentes Principales. The General Secretariat of the Organization of American States.

POI DE NEIFF, A. 1990. Dry weight loss and colonization by invertebrates of Eichornia crassipes under aerobic conditions. Journal of Tropical Ecology, 30: 175182.

POI DE NEIFF, A., GALASSI, M.E. \& M.C FRANCESCHINI. 2009. Invertebrate assemblages associated with leaf litter in three floodplain wetlands of the Paraná River. Wetlands, 29(3): 896-906.

PRAT, N., RIREADEVAlL, M., MUNNE, A. \& G. CHACON. 1996. Estudis de la qualitat ecològica dels Rius. Vol. I: La qualitat ecològica del Besòs i el Llobregat. Informe 1994-1995. Diputació de Barcelona. 102 pp. 
PRÍNCIPE, E.R., BOCCOLINI, M.F. \& M.C. CORIGLIANO. 2008. Structure and spatial-temporal dynamics of Chironomidae fauna (Diptera) in upland and lowland fluvial habitats of the Chocancharava River basin (Argentina). International Review of Hydrobiology, 93: 342-357.

PRÍNCIPE, E.R., GUALDONI, C.M, OBERTO, A.M, RAFFAINI, G.B. \& M.C. CORIGLIANO. 2010. Spatial-temporal patterns of functional feeding groups inmountain streams of Córdoba, Argentina. Ecología Austral, 20: 257-268.

PRITCHARD, D.W. 1967. What is an estuary: physical viewpoint (p: 3-5). In:

"Estuaries", Lauf, G.H., A.A.A.S. Publ. 83, Washington, DC.

RABENI, C.F., DOISY, K.E. \& D.L. GALAT. 2002. Testing the biological basis of a stream habitat classification using benthic macroinvertebrates. Ecological Application, 12: 782-796.

RESH, V., NORRIS, R. \& M. BARBOUR. 1995. Design and implementation of rapid assessment approaches for water resource monitoring using benthic macroinvertebrates. Australian Journal of Ecology, 20: 108-121.

RINGUELET, R.A. 1962. Ecología Acuática Continental. EUDEBA, Buenos Aires, 137 pp.

RINGUELET, R.A. 1985. Hirudinea. Fauna de Agua Dulce de la República Argentina. FECIC, 17(1): 11-321.

RODRIGUES CAPÍTULO, A. 1999. Los macroinvertebrados como indicadores de calidad de ambientes lóticos en el área pampeana. Revista de la Sociedad Entomológica Argentina, 58: 208-217.

RODRIGUES CAPÍTULO, A., AMBROSIO, E.S. \& N. GÓMEZ. 2006. "Los invertebrados y la calidad del hábitat como indicadores de la condición biológica de la costa del Río de la Plata (Argentina)". XIII Congreso de la Asociación Española de Limnología. Barcelona.

RODRIGUES CAPÍTULO, A., CÉSAR, I., TASSARA, M., PAGGI, A.C. \& M. REMES LENICOV. 1997. Zoobentos (p: 131-141). En: "Calidad de las Aguas de la Franja Costera Sur del Río de la Plata. San Fernando-Magdalena". 
RODRIGUES CAPÍTULO, A., CÉSAR, I., TASSARA, M., PAGGI, A.C. \& M. REMES LENICOV. 1998. Distribution of the macrobenthic fauna of the South Coastal Fringe of the "Río de la Plata" River (Argentine). Impact of the urban contamination. Verhandlungen des Internationalen Verein Limnologie, 26: 12601265.

RODRIGUES CAPÍTULO, A., OCON, C.S., TANGORRA, M., PAGGI, A.C., CORTELEZZI, A. \& F. SPACCESI. 2003. Estudios zoobentónicos recientes en el Río de la Plata. En: "Diatomeas y Macroinvertebrados bentónicos en el monitoreo de sistemas lóticos bonaerenses". Biología Acuática, 21: 19-30.

RODRIGUES CAPÍtUlo, A., MUÑOZ, I., BONADA, N., GAUDES, A. \& S. TOMANOVA. 2009. La biota de los ríos: los invertebrados (p: 253-270). In: "Conceptos y técnicas en ecología fluvial", Elosegui, A. \& S. Sabater (eds), Fundación BBVA.

RODRIGUES CAPÍTULO, A., TANGORRA, M. \& C.S. OCON. 2001. Use of benthic macroinvertebrate to assess the ecological status of Pampean rivers (Argentine). Aquatic Ecology, 35: 109-119.

ROSENBERG, D.M. \& V.H RESH. 1996. Use of aquatic insects in biomonitoring ( $p$ : 87-97). In: "An Introduction to the aquatic insects of North America", Merritt, R.W. \& K.W. Cummins (eds), Kendall/Hunt, Dubuque, I.A.

SARDIÑA, P., CATALDO, D.H. \& D. BOLTOVSKOY. 2008. The effects of the invasive mussel, Limnoperna fortunei, on associated fauna in South American freshwaters: importance of physical structure and food supply. Fundamental and Applied Limnology, 173: 135-144.

SCARABINO, F. 1999. Inventario de los moluscos bentónicos del Río de la Plata y su frente Marítimo; estado actual de conocimiento, necesidades y perspectivas de estudio. Comunicaciones de la Sociedad Malacológica del Uruguay, 11(39).

SCHUCHARDT, B. \& M. SCHIRMER. 1991. Phytoplankton maxima in the tidal freshwater reaches of two coastal plain estuaries. Estuarine, Coastal and Shelf Science, 32: 187-206. 
SEGNINI, S. 2003. El uso de los macroinvertebrados bentónicos como indicadores de la condición ecológica de los cuerpos de agua corriente. Ecotropicos, 16: 4563.

SHANNON, C.E. \& W. WEAVER. 1949. The Mathematical Theory of Communication. The University of Illinois Press, Urbana. 117pp.

SHIEH, S., WARD, J. \& B. KONDRATIEFF. 2002. Energy flow through macroinvertebrates in a polluted plains stream. Journal of the North American Benthological Society, 21: 660-675.

SIGMASTAT. 2007. Advisory Statistics for Scientists. Version 3.5 (integrated with SigmaPlot 10). Systat Software, Inc.

SINGH, K.P., MALIK, A., MOHAN, D. \& S. SINHA. 2004. Multivariate statistical techniques for the evaluation of spatial and temporal variations in water quality of Gomti River (India)-a case study. Water Research, 38: 3980-3992.

SPACCESI, F.G. \& A. RODRIGUES CAPÍTULO. 2012. Benthic communities on hard substrates covered by Limnoperna fortunei Dunker (Bivalvia, Mytilidae) at an estuarine beach (Río de la Plata, Argentina). Journal of Limnology, 71(1): 144-153.

STATSOFT INC. 2001. Statistica for Windows version 6.0. Data analysis software system, Tulsa, Oklahoma, USA.

STATZNER, B., BADY, P., DOLÉDEC, S. \& F. SCHÖLL. 2005. Invertebrate traits for the biomonitoring of large European rivers: An initial assessment of traits patterns in least impacted river reaches. Freshwater Biology, 50: 2136-2161.

STATZNER, B., HILDREW, A.G. \& V.H. RESH. 2001. Species traits and environmental constrains: Entomological research and the history of ecological theory. Annual Review of Entomology, 46: 291-316.

STERNER, R.W. \& J.J. ELSER. 2002. Ecological stoichiometry. Nueva Jersey, Princeton University Press.

STOREY, A.W. \& J. LYNAS. 2007. Application of the functional habitat concept to the regulated Lower Ord River, Western Australia, Part I: macroinvertebrate assemblages. Hydrobiologia, 592: 499-512. 
SUBRAMANIAN, K.A. \& K.G. SIVARAMAKRISHNAN. 2005. Habitat and microhabitat distribution of stream insect communities of the Western Ghats. Current Science, 89: 976-986.

TANGORRA, M. 2004. Colonización y descomposición de especies vegetales por invertebrados es sistemas lóticos pampásicos. Trabajo de Tesis Doctoral. Facultad de Ciencias Naturales y Museo. Universidad Nacional de La Plata. 118 pp.

TER BRAAK, C.J.F. 1998. CANOCO. A Fortran Program for Canonical Community Ordination. (Versión 4). Centro de Biometría Wageningen, The Netherlands.

TER BRAAK, C.J.F. \& P. SMILAUER. 1999. CANOCO Reference Manual and User's Guide to Canoco for Windows: Software for Canonical Community Ordination (Versión 4).

TICKNER, B., ARMITAGE, P.D., BICKERTON, M.A. \& K.A. HALL. 2000. Assessing stream quality using information on mesohabitat distribution and character. Aquatic Conservation: Marine and Freshwater Ecosystem, 10: 179-196.

TOMANOVA, S., GOITIA, E. \& J. HELESIC. 2006. Trophic levels and functional feeding groups of macroinvertebrates in neotropical streams. Hydrobiologia, 556: 251-264.

TOWNSEND, C.R. \& A.G. HILDREW. 1994. Species traits in relation to a habitat templet for river systems. Freshwater Biology, 31: 265-275.

TRANSPURGER, W. 2000. The biology and ecology of lotic nematodes. Freshwater Biology, 44: 29-45.

TROITIÑIO, E., COSTA, M.C, FERRARI, L. \& A. GIORGI. 2010. La conservación de las zonas ribereñas de un arroyo pampeano. I Congreso Internacional de Hidrología de Llanuras Azul, Buenos Aires, Argentina. Tomo II: 777-784.

UNDERWOOD, A.J. 2007. Experiments in ecology. Their logical design and interpretation using analysis of variance. Cambridge University Press.

URIEN, C.M. 1972. Río de la Plata estuary environments (p: 213-234). In: "Environmental Framework of Coastal Plain Estuaries", Memoir 133, Nelson, B.W. (ed), Boulder: The Geological Society of America. 
USEPA. 2006. Voluntary estuary monitoring manual. EPA-842-B-06-003.

VANNOTE, R.L., MINSHALL, G.W., CUMMINS, K.W., SEDELL, J.R. \& C.E. CUSHING. 1980. The river continuum concept. Canadian Journal of Fisheries and Aquatic Sciences, 37: 130-137.

VAN DER GEEST, H.G., KRAAK, M.H.S. \& G.D. GREVE. 2002. Insects in polluted rivers: an experimental analysis. Proceedings of the Section Experimental and Applied Entomology of the Netherlands Entomological Society, 13: 9-19.

VELÁSQUEZ, S.M. \& M.L. MISERENDINO. 2003a. Análisis de la materia orgánica alóctona y organización funcional de macroinvertebrados en relación con el tipo de hábitat en ríos de montaña de Patagonia. Ecología Austral, 13: 67-82.

VELÁSQUEZ, S.M. \& M.L. MISERENDINO. 2003b. Habitat type and macroinvertebrate assemblages in low order Patagonian streams. Archiv für Hydrobiologie, 158: 461-483.

WADESON, R.A. 1994. A geomorphological approach to the identification and classification of instream flow environment. South African Journal Aquatic Science, 20: 38-61.

WALLACE, J.B. \& J.R. WEBSTER. 1996. The role of macroinvertebrates in stream ecosystem function. Annual Review of Entomology, 41: 115-139.

WANTZEN, K.M. \& R. WAGNER. 2006. Detritus processing by invertebrate shredders. A neotropical temperate comparison. Journal of the North American Benthological Society, 25: 216-232.

WAY, C.M., HORNBACH, D.J., MILLER-WAY, C.A., PAYNE, B.S. \& A.C. MILLER. 1990. Dynamics of filter feeding in Corbicula fluminea (Bivalvia: Corbiculidae). Canadian Journal of Zoology, 68: 115-120.

WINTERBOURN, M., COWIE, B. \& J. ROUNICK. 1984. Food resources and ingestion patterns of insects along a West Coast, South Island, river system. New Zealand Journal of Marine and Freshwater Research, 18(1): 43-51. 
WITTMANN, M., REUTER, J., SCHLADOW, G., HACKLEY, S., ALLEN, B., CHANDRA, S. \& A. CAIRES. 2008. Asian clam (Corbicula fluminea) of Lake Tahoe: Preliminary scientific findings in support of a management plan. UC Davis Tahoe Environmental Research Center, $47 \mathrm{pp}$.

WRIGHT, J.F., CHESSMAN, B., FAIRWEATHER, P. \& L. BENSON. 1995. Measuring the impact of sewage effluent on the macroinvertebrate community of an upland stream: the effect of different levels of taxonomic resolution and quantification. Australian Journal of Ecology, 20: 142-149.

ZILLI, F.L., MONTALTO, L. \& M.R. MARCHESE. 2008. Benthic invertebrate assemblages and functional feeding groups in the Paraná River floodplain (Argentina). Limnologica, 38: 159-171. 

Tabla A. Grupos funcionales alimentarios (GFA) y modos de vida de los taxa registrados en los sitios de muestreo estudiados.

\begin{tabular}{|c|c|c|}
\hline Taxones & GFA & Modos de vida \\
\hline Nematoda & Colector-Recolector & Apoyados \\
\hline Dactylobiotus dispar & Colector-Recolector & Apoyados \\
\hline Girardia anceps & Depredador & Apoyados \\
\hline Temnocephala spp. & Parásito & Aferrados \\
\hline Cordylophora caspia & Colector-Filtrador & Aferrados \\
\hline Hydra sp. & Depredador & Trepadores \\
\hline Urnatella gracilis & Colector-Filtrador & Aferrados \\
\hline Limnodrilus hoffmeisteri & Colector-Recolector & Minadores \\
\hline Limnodrilus udekemianus & Colector-Recolector & Minadores \\
\hline Limnodrilus claparedianus & Colector-Recolector & Minadores \\
\hline Aulodrilus pigueti & Colector-Recolector & Minadores \\
\hline Nais variabilis & Colector-Recolector & Apoyados \\
\hline Nais communis & Colector-Recolector & Apoyados \\
\hline Nais bretscheri & Colector-Recolector & Apoyados \\
\hline Nais pardalis & Colector-Recolector & Apoyados \\
\hline Stephensoniana trivandrana & Colector-Recolector & Apoyados \\
\hline Stylaria lacustris & Colector-Recolector & Apoyados \\
\hline Dero (Dero) sawayai & Colector-Recolector & Apoyados \\
\hline Dero (Dero) pectinata & Colector-Recolector & Apoyados \\
\hline Dero (Dero) digitata & Colector-Recolector & Apoyados \\
\hline Paranais frici & Colector-Recolector & Apoyados \\
\hline Chaetogaster diastrophus & Depredador & Apoyados \\
\hline Chaetogaster diaphanus & Depredador & Apoyados \\
\hline Slavina isochaeta & Colector-Recolector & Apoyados \\
\hline Slavina appendiculata & Colector-Recolector & Apoyados \\
\hline Amphichaeta leydigi & Colector-Recolector & Apoyados \\
\hline Allonais paraguayensis & Colector-Recolector & Apoyados \\
\hline Pristina aequiseta & Colector-Recolector & Apoyados \\
\hline Pristina longidentata & Colector-Recolector & Apoyados \\
\hline Pristina osborni & Colector-Recolector & Apoyados \\
\hline Pristina jenkinae & Colector-Recolector & Apoyados \\
\hline Pristina acuminata & Colector-Recolector & Apoyados \\
\hline Pristina americana & Colector-Recolector & Apoyados \\
\hline Pristina leidyi & Colector-Recolector & Apoyados \\
\hline Pristina breviseta & Colector-Recolector & Apoyados \\
\hline
\end{tabular}


Continuación Tabla A.

\begin{tabular}{|c|c|c|}
\hline Taxones & GFA & Modos de vida \\
\hline Bothrioneurum americanum & Colector-Recolector & Minadores \\
\hline Narapa bonettoi & Colector-Recolector & Apoyados \\
\hline Enchytraeidae & Colector-Recolector & Minadores \\
\hline Megadrili & Colector-Recolector & Minadores \\
\hline Aeolosoma sp. & Colector-Recolector & Apoyados \\
\hline Helobdella spp. & Depredador & Aferrados \\
\hline Semiscolex spp. & Depredador & Aferrados \\
\hline Heleobia piscium & Raspador & Apoyados \\
\hline Heleobia australis & Raspador & Apoyados \\
\hline Pomacea canaliculata & Raspador & Trepadores \\
\hline Stenophysa marmorata & Raspador & Trepadores \\
\hline Physella (Costatella) cubensis & Raspador & Trepadores \\
\hline Chilina sp. & Raspador & Trepadores \\
\hline Biomphalaria sp. & Raspador & Apoyados \\
\hline Drepanotrema sp. & Raspador & Apoyados \\
\hline Hebetancylus moricandi & Raspador & Aferrados \\
\hline Uncancylus concentricus & Raspador & Aferrados \\
\hline Corbicula fluminea & Colector-Recolector & Apoyados \\
\hline Pisidium sp. & Colector-Filtrador & Apoyados \\
\hline Limnoperna fortunei & Colector-Filtrador & Aferrados \\
\hline Anodontites sp. & Colector-Filtrador & Apoyados \\
\hline Isotomidae & Colector-Recolector & Apoyados \\
\hline Poduridae & Colector-Recolector & Apoyados \\
\hline Sminthuridae & Colector-Recolector & Patinador \\
\hline Dytiscidae & Depredador & Nadadores \\
\hline Elmidae (larva) & Colector-Recolector & Trepadores \\
\hline Noteridae & Depredador & Nadadores \\
\hline Aeshna bonariensis & Depredador & Trepadores \\
\hline Coenagrionidae & Depredador & Trepadores \\
\hline Baetis sp. & Colector-Recolector & Aferrados \\
\hline Caenis sp. & Colector-Recolector & Apoyados \\
\hline Chironomidae & Colector-Recolector & Minadores \\
\hline Ceratopogonidae & Depredador & Apoyados \\
\hline Psychodidae & Colector-Recolector & Minadores \\
\hline Stratiomyidae & Colector-Recolector & Apoyados \\
\hline
\end{tabular}


Continuación Tabla A.

\begin{tabular}{|l|c|c|}
\hline \multicolumn{1}{|c|}{ Taxones } & GFA & Modos de vida \\
\hline Tipulidae & Depredador & Minadores \\
Ephydridae & Colector-Recolector & Minadores \\
Leptoceridae & Fragmentador & Minadores \\
Hydroptilidae & Colector-Recolector & Minadores \\
Cyprididae & Colector-Recolector & Nadadores \\
Daphnidae & Colector-Filtrador & Nadadores \\
Chidoridae & Colector-Filtrador & Nadadores \\
Bosminidae & Colector-Filtrador & Nadadores \\
Macrothricidae & Colector-Filtrador & Nadadores \\
Harpacticoida sp. & Colector-Recolector & Nadadores \\
Acanthocyclops spp. & Depredador & Nadadores \\
Hyalella curvispina & Colector-Recolector & Nadadores \\
Corophium rioplatense & Colector-Recolector & Nadadores \\
Sinelobus stanfordi & Colector-Recolector & Nadadores \\
Claudicuma platensis & Colector-Recolector & Nadadores \\
Pseudosphaeroma platense & Depredador & Nadadores \\
Heterias (Fritzianira) exul & Colector-Recolector & Nadadores \\
Basphaeroma rhombobrontale & Depredador & Nadadores \\
Trichodactylus panoplus & Fragmentador & Nadadores \\
Palaemonetes argentinus & Colector-Recolector & Nadadores \\
Hydrachnidia & Depredador & Apoyados \\
Belostoma sp. & Depredador & Nadadores \\
& & \\
\hline
\end{tabular}


Tabla B. Sensibilidad de los macroinvertebrados registrados en el área de estudio. MT: "muy tolerantes"; T: "tolerantes"; S: "sensibles".

\begin{tabular}{|c|c|c|c|}
\hline Taxa & MT & $\mathbf{T}$ & $\mathbf{S}$ \\
\hline Nematoda & $x$ & & \\
\hline Dactylobiotus dispar & $x$ & & \\
\hline Girardia anceps & & $x$ & \\
\hline Temnocephala spp. & & $x$ & \\
\hline Cordilophora caspia & & & $x$ \\
\hline Hydra sp. & & & $x$ \\
\hline Urnatella gracilis & & & $x$ \\
\hline Tubificinae & $x$ & & \\
\hline Naidinae (restantes) & $x$ & & \\
\hline Nais sp. & & $x$ & \\
\hline Paranais sp. & & & $x$ \\
\hline Chaetogaster sp. & & & $x$ \\
\hline Dero sp. & & $x$ & \\
\hline Pristininae & $x$ & & \\
\hline Rhyacodrilinae & & $x$ & \\
\hline Narapidae & & & $x$ \\
\hline Enchytraeidae & $x$ & & \\
\hline Megadrili & $x$ & & \\
\hline Aeolosomatidae & $x$ & & \\
\hline Hirudinea & & $x$ & \\
\hline Heleobia piscium & & $x$ & \\
\hline Heleobia australis & & $x$ & \\
\hline Pomacea canaliculata & & $x$ & \\
\hline Physella cubensis & & $x$ & \\
\hline Biomphalaria sp. & & $x$ & \\
\hline Drepanotrema sp. & & $x$ & \\
\hline Hebetancylus moricandi & & & $x$ \\
\hline Uncancylus concentricus & & & $x$ \\
\hline Corbicula fluminea & & $x$ & \\
\hline Pisidium sp. & & $x$ & \\
\hline Limnoperna fortunei & & $x$ & \\
\hline Anodontites sp. & & $x$ & \\
\hline Isotomidae & $x$ & & \\
\hline Poduridae & $x$ & & \\
\hline
\end{tabular}

\begin{tabular}{|c|c|c|c|}
\hline Таха & $\mathrm{MT}$ & $\mathbf{T}$ & $\mathbf{S}$ \\
\hline Sminthuridae & $\mathrm{x}$ & & \\
\hline Dytiscidae & & $x$ & \\
\hline Elmidae & & $x$ & \\
\hline Noteridae & & $x$ & \\
\hline Aeshna bonariensis & & & $x$ \\
\hline Coenagrionidae & & $x$ & \\
\hline Baetis sp. & & $x$ & \\
\hline Caenis sp. & & $x$ & \\
\hline Chironomidae & $\mathrm{x}$ & & \\
\hline Ceratopogonidae & & $x$ & \\
\hline Psychodidae & $\mathrm{x}$ & & \\
\hline Stratiomyidae & & $x$ & \\
\hline Tipulidae & $\mathrm{x}$ & & \\
\hline Ephydridae & $\mathrm{x}$ & & \\
\hline Leptoceridae & & & $x$ \\
\hline Hydroptilidae & & & $x$ \\
\hline Cyprididae & & $x$ & \\
\hline Daphnidae & & $x$ & \\
\hline Chidoridae & & $x$ & \\
\hline Bosminidae & & $x$ & \\
\hline Macrothricidae & & $x$ & \\
\hline Harpacticoida sp. & & $x$ & \\
\hline Acanthocyclops spp. & & $x$ & \\
\hline Hyalella curvispina & & & $\mathrm{x}$ \\
\hline Corophium rioplatense & & & $x$ \\
\hline Sinelobus stanfordi & & & $x$ \\
\hline Claudicuma platensis & & & $\mathrm{x}$ \\
\hline Pseudosphaeroma platense & & & $\mathrm{x}$ \\
\hline Heterias (Fritzianira) exul & & & $x$ \\
\hline Basphaeroma rhombobrontale & & & $x$ \\
\hline Trichodactylus panoplus & & & $x$ \\
\hline Palaemonetes argentinus & & & $x$ \\
\hline Acari & & $x$ & \\
\hline Belostoma sp. & & $x$ & \\
\hline
\end{tabular}


Tabla C. Acrónimos y valores de sensibilidad ecológica $(\mathrm{Vx})$ asignados a los taxa registrados en los sitios estudiados.

\begin{tabular}{|c|c|c|c|c|c|}
\hline Taxa & Acrónimos & Vx* & Taxa & Acrónimos & $\mathbf{V x} *$ \\
\hline Nematoda & Nem & 0,1 & Elmidae & Elm & 0,4 \\
\hline Dactylobiotus dispar & Ddi & 0,25 & Noteridae & No & 0,35 \\
\hline Girardia anceps & Gan & 0,5 & Anisoptera & Ani & 1,2 \\
\hline Temnocephala spp. & Tem & 0,5 & Zygoptera & Zy & 1,2 \\
\hline Cordilophora caspia & Cca & 1 & Baetis sp. & Bae & 1 \\
\hline Hydra sp. & Hyd & 1 & Caenis sp. & Cae & 1 \\
\hline Urnatella gracilis & Ugr & 1 & Chironomidae & Chi & 0,3 \\
\hline Tubificinae & Tub & 0,15 & Ceratopogonidae & Cer & 0,4 \\
\hline Naidinae & Nai & 0,2 & Psychodidae & Psy & 0,1 \\
\hline Pristininae & Pri & 0,2 & Stratiomyidae & Str & 0,2 \\
\hline Rhyacodrilinae & Rhy & 0,35 & Tipulidae & Tip & 0,3 \\
\hline Narapidae & Nar & 0,2 & Ephydridae & Eph & 0,2 \\
\hline Enchytraeidae & Enc & 0,15 & Leptoceridae & Lep & 2,0 \\
\hline Megadrili & Me & 0,2 & Hydroptilidae & Hydro & 2,0 \\
\hline Aeolosomatidae & $\mathrm{Ae}$ & 0,2 & Cyprididae & Сyp & 0,4 \\
\hline Hirudinea & Hir & 0,5 & Daphnidae & Dap & 0,6 \\
\hline Heleobia piscium & Hpi & 0,6 & Chidoridae & Chid & 0,6 \\
\hline Heleobia australis & Hau & 0,6 & Bosminidae & Bos & 0,6 \\
\hline Pomacea canaliculata & Pca & 0,6 & Macrothricidae & Mac & 0,6 \\
\hline Physella cubensis & Pcu & 0,6 & Harpacticoida sp. & Har & 0,4 \\
\hline Biomphalaria sp. & Bio & 0,6 & Acanthocyclops spp. & Acan & 0,4 \\
\hline Drepanotrema sp. & Dre & 0,6 & Hyalella curvispina & $\mathrm{Hy}$ & 0,9 \\
\hline Hebetancylus moricandi & Hmo & 0,6 & Corophium rioplatense & Cri & 0,9 \\
\hline Uncancylus concentricus & Uco & 0,6 & Sinelobus stanfordi & Sst & 0,9 \\
\hline Corbicula fluminea & CfI & 0,6 & Claudicuma platensis & Cpl & 1,3 \\
\hline Pisidium sp. & $\mathbf{P i}$ & 0,6 & Pseudosphaeroma platense & Ppl & 0,7 \\
\hline Limnoperna fortunei & Lfo & 0,6 & Heterias (Fritzianira) exul & Hex & 0,7 \\
\hline Anodontites sp. & An & 0,6 & Basphaeroma rhombobrontale & Brh & 0,7 \\
\hline Isotomidae & Iso & 0,2 & Trichodactylus panoplus & Tri & 1,5 \\
\hline Poduridae & Po & 0,2 & Palaemonetes argentinus & Par & 1,5 \\
\hline Sminthuridae & Smin & 0,2 & Acari & Aca & 0,3 \\
\hline Dytiscidae & Dyt & 0,35 & Belostoma sp. & $\mathrm{Be}$ & 0,8 \\
\hline
\end{tabular}

*Vx: tomado de Rodrigues Capítulo (1999), Gómez \& Rodrigues Capítulo (2001). 
Tabla D. Composición estequiométrica (a) e isótopos estables (b) de aquellos taxa registrados en el área de estudio que no fueron incluidos en el análisis por no presentar datos para todos los sitios y/o fechas de muestreo. (En negrita se indican los casos en que sólo se cuenta con un único valor).

a)

\begin{tabular}{|c|c|c|c|c|c|c|}
\hline & \multicolumn{2}{|c|}{$N\left(\mathrm{mg} \mathrm{g}^{-1}\right)$} & \multicolumn{2}{|c|}{$C\left(\mathrm{mg} \mathrm{g}^{-1}\right)$} & \multicolumn{2}{|c|}{$P\left(\mathrm{mg} \mathrm{g}^{-1}\right)$} \\
\hline & Promedio & DS & Promedio & DS & Promedio & DS \\
\hline Trichodactylus panoplus & 86,7 & 3,87 & 367,7 & 28,76 & 30,40 & 4,93 \\
\hline Palaemonetes argentinus & 168,5 & 2,99 & 510,9 & 10,47 & 37,52 & 3,43 \\
\hline Pseudosphaeroma platense & 87,2 & & 375,3 & & & \\
\hline Heleobia piscium & 17,4 & 3,47 & 196,4 & 10,70 & 4,37 & 1,33 \\
\hline Hebetancylus moricandi & 37,4 & 12,60 & 238,5 & 23,97 & & \\
\hline Limnoperna fortunei & 129,5 & 0,89 & 618,3 & 14,06 & 23,34 & \\
\hline Oligoquetos & 131,7 & & 454,4 & & & \\
\hline Physella cubensis & 42,0 & & 253,6 & & & \\
\hline Biomphalaria sp. & 35,9 & & 240,0 & & 2,63 & \\
\hline Anodontites sp. & 94,4 & & 436,3 & & 82,27 & \\
\hline
\end{tabular}

b)

\begin{tabular}{lcccccc}
\hline & \multicolumn{2}{c}{$\boldsymbol{\delta}^{\mathbf{1 3}} \mathbf{C}$} & & \multicolumn{2}{c}{$\boldsymbol{\delta}^{\mathbf{1 5}} \mathbf{N}$} \\
\cline { 2 - 3 } \cline { 6 - 7 } & Promedio & DS & & Promedio & DS \\
\hline Trichodactylus panoplus & $-23,8$ & 0,94 & & 14,7 & 2,24 \\
Palaemonetes argentinus & $-23,2$ & 0,89 & & 15,7 & 2,63 \\
Pseudosphaeroma platense & $\mathbf{- 2 2 , 3}$ & & & $\mathbf{1 5 , 4}$ & \\
Heleobia piscium & $-14,4$ & 0,16 & & 13,2 & 2,72 \\
Hebetancylus moricandi & $-17,6$ & 0,46 & & 13,5 & 0,18 \\
Limnoperna fortunei & $-27,9$ & 0,78 & & 13,3 & 1,81 \\
Oligoquetos & $-23,0$ & & & 11,4 & \\
Physella cubensis & $-20,0$ & & & 7,4 & \\
Biomphalaria sp. & $-17,3$ & & & 13,0 & \\
Anodontites sp. & $-25,0$ & & & 16,8 & \\
\hline
\end{tabular}

